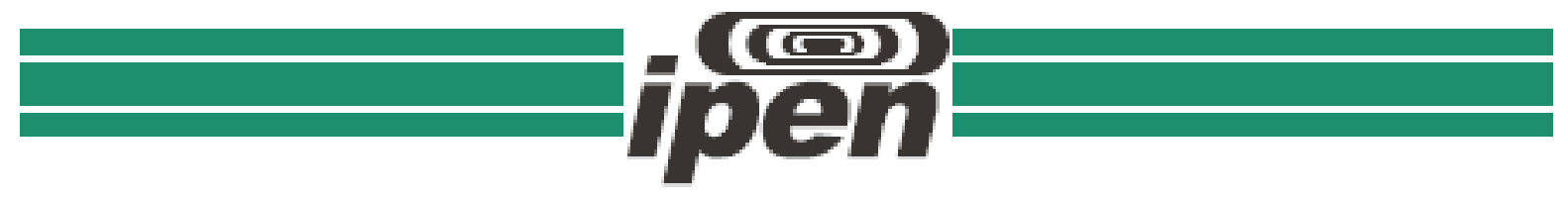

AUTARQUIA ASSOCIADA À UNIVERSIDADE DE SĂO PAULO

DETERMINAÇÃO DOS CONSTITUINTES INORGÂNICOS

EM PLANTAS MEDICINAIS E SEUS EXTRATOS

LUCILAINE SILVA FRANICISCONI

Dissertação apresentada como parte dos requisitos para obtenção do Grau de Mestre em Ciências na Área de Tecnologia Nuclear - Aplicações

Orientador:

Prof. Dr. Paulo Sergio Cardoso da Silva 
A minha amada família, obrigada por ser meu alicerce em cada sonho realizado Amo vocês! 


\section{AGRADECIMENTOS}

A Deus, por me fazer encontrar motivo em cada momento triste em prosseguir na realização dos meus objetivos. O seu amor e a sua força esteve presente comigo mesmo quando eu estava ausente de ti.

Ao meu pai João dos Santos Francisconi (in memorian), por acreditar em mim desde o primeiro momento da minha existência, obrigada pai pelo seu amor incondicional e pela presença constante em minha vida.

À minha linda mãe Aurea Oracina S S Francisconi, por me ensinar a ser forte, a não desistir a acreditar que o ser humano pode ser melhor, obrigada mãe pelo seu carinho, por estar sempre ao meu lado, por me ensinar a ser melhor sempre.

As minhas lindas irmãs Angela, Rosangela e Kelly Cristina não imaginam o quanto me orgutho de vocês, a nossa união cada dia se fortalece mais não importando os momentos distantes, amo-as incondicionalmente. Aos meus sobrinhos Junior, Bruno, Thor, Gabrielly e Thomas por ser a minha alegria de viver. A vocês Kamila e Jessica minhas lindas filhas vocês são um presente de Deus dado a mim. Aos pequenos Guilherme e Miguel que amo muito. Aos meus cunhados pelo carinho e companheirismo em família.

Ao meu esposo Paulo Andrade da Silva, obrigado pelo apoio e companheirismo.

Ao meu filho Leonardo Francisconi da Silva, o melhor pedaço de mim, sem o seu sorriso nada disso teria sentido desculpas por estar ausente na maioria do tempo, mas seu amor sempre me guia.

Ao meu querido orientador Doutor Paulo Sergio Cardoso da Silva, por conduzir meus caminhos na realização deste ideal. Com você aprendi a despertar a vontade pelo saber e, principalmente, descobri que a cada novo amanhecer, existe sempre um novo horizonte há ser desvendado, hoje sei que nem sempre vai ser fácil alcançar as estrelas, porém, sei que terei 
sempre um amigo presente a cada tentativa. Obrigado mestre pela paciência, dedicação, confiança, amizade. Sou grata por ter a oportunidade de conviver com você.

À minha amiga Flávia Valverde Lapa, amiga estar com você sempre foi motivo de alegria, obrigado por todos os momentos que juntos vivemos, pelos erros e acertos cometidos, por cada aprendizado, pelo carinho, por todas as risadas, você é muito importante nesta conquista.

Ao Rodolfo Daniel Moreno Reis Gonçalves por me auxiliar ao longo deste trabalho. Obrigado pela convivência e aprendizado em laboratório.

Aos meus colegas de sala Regina Bec e, Edson Alves, e aos meus queridos professores e amigos Guilherme Soares Zahn e Vera Akiko Maihara por todos os 6ons momentos que passamos juntos como forma de expressar minha gratidão e carinho por toda contribuição e amizade que recebi na forma de incentivos.

Aos integrantes da Banca Examinadora, Dr. Marcos Roberto Furlan e Dra. Mitiko Saiki, pelos comentários e sugestões apresentadas com o objetivo de valorizar o trabalho.

Ao Instituto de Pesquisas Energéticas e $\mathcal{N}$ ucleares (IPEN), pela infraestrutura acadêmica, laboratórios e equipamentos disponíveis, pela condução do programa de pós-graduação em nível de mestrado, possibilitando o acontecimento desta pesquisa.

À Capes pela bolsa concedida.

Às pessoas não citadas, porém não menos importantes, que de alguma maneira passaram pela minha vida e contribuíram para o meu crescimento pessoal e/ou profissional. 
"Crê e trabalha. Esforça-te no bem e espere com paciência. Tudo passa e tudo se renova na terra, mas o que vem do céu permanecerá. Luta e serve. Aprende e adianta-te. Brilha a alvorada além da noite. Hoje, é possível que a tempestade te amarfanhe o coração e te atormente o ideal, aguilhoando-te com a aflição ou ameaçando-te. Não te esqueças, porém, de que amanhã será outro dia...

É exatamente disso que a vida é feita, de momentos. Momentos que temos que passar, sendo bons ou ruins, para o nosso próprio aprendizado. $\mathcal{N}$ unca se esquecendo do mais importante: $\mathcal{N} a d a$ nessa vida é por acaso. Absolutamente nada. Por isso, temos que nos preocupar em fazer a nossa parte, da melhor forma possivel. $A$ vida nem sempre segue a nossa vontade, mas ela é perfeita naquilo que tem que ser...

Agradeço todas as dificuldades que enfrentei; não fosse por elas, eu não teria saído do lugar. As facilidades nos impedem de caminhar. Mesmo as críticas nos auxiliam muito!" 


\title{
DETERMINAÇÃO DOS CONSTITUINTES INORGÂNICOS EM PLANTAS MEDICINAIS E SEUS EXTRATOS
}

\author{
LUCILAINE SILVA FRANCISCONI
}

\section{RESUMO}

Diferentes tipos de terapias vêm sendo introduzidas como tratamento alternativo ao combate a diversos tipos de distúrbios humanos e entre eles, a utilização de chás com plantas medicinais vem se destacando pelo custo/benefício, facilidade de aquisição e administração. $O$ objetivo deste estudo foi determinar os constituintes inorgânicos, avaliar a concentração dos elementos $\mathrm{As}, \mathrm{Ba}, \mathrm{Br}, \mathrm{Ca}, \mathrm{Co}$, $\mathrm{Cr}, \mathrm{Cs}, \mathrm{Fe}, \mathrm{Hf}, \mathrm{K}, \mathrm{Mg}, \mathrm{Mn}, \mathrm{Na}, \mathrm{Rb}, \mathrm{Sb}, \mathrm{Sc}, \mathrm{Se}, \mathrm{Ta}, \mathrm{Th}, \mathrm{Ti}, \mathrm{U}, \mathrm{V}, \mathrm{Zn}$ e Zr por análise por ativação neutrônica; o $\mathrm{Cd}, \mathrm{Cu}, \mathrm{Ni}$ e $\mathrm{Pb}$ pela espectrometria de emissão com plasma indutivamente acoplado e o $\mathrm{Hg}$ por espectrometria de absorção atômica com geração de vapor frio nas plantas medicinais e seus extratos cuja comercialização é regulamentada pela Agência Nacional de Vigilância Sanitária (ANVISA). A relevância dessas análises é justificada pela necessidade de contribuir para a recomendação destas plantas como fontes desses minerais na dieta. As técnicas utilizadas apresentaram sensibilidade adequada na obtenção da concentração de todos os elementos analisados, foram encontrados elementos considerados tóxicos em concentrações não prejudiciais ao organismo humano. Este estudo também possibilitou relacionar a concentração elementar nas espécies analisadas por meio das análises de coeficiente de correlação e da análise de agrupamento. Pode-se com isso, verificar a confirmação da similaridade no comportamento de grupos de elementos em relação à variação de suas concentrações observadas nas plantas e em seus extratos. Os elementos que exercem papel importante no metabolismo foram determinados em concentrações que podem auxiliar tanto no tratamento como na carência destes elementos no organismo, quando introduzido na dieta alimentar. 


\title{
INORGANIC CONSTITUINTS DETERMINATION \\ IN MEDICINAL PLANTS AND THEIR EXTRACTS
}

\section{LUCILAINE SILVA FRANCISCONI}

\begin{abstract}
Different types of therapies have been introduced as an alternative treatment to combat different types of human disorders. Among them, the use of herbal teas has been highlighted by the cost/benefit, easiness of acquisition and administration. The aim of this study was to determine the inorganic constituents, and evaluate the element concentrations of As, $\mathrm{Ba}, \mathrm{Br}, \mathrm{Ca}, \mathrm{Co}, \mathrm{Cr}, \mathrm{Cs}, \mathrm{Fe}, \mathrm{Hf}, \mathrm{K}, \mathrm{Mg}$. Mn, $\mathrm{Na}, \mathrm{Rb}, \mathrm{Sb}$, Sc, Se, Ta, Th, Ti, U, V, Zn and $\mathrm{Zr}$ by neutron activation analysis; and $\mathrm{Cd}, \mathrm{Cu}, \mathrm{Ni}$ and $\mathrm{Pb}$, by atomic emission spectrometry, with inductively coupled plasma source and $\mathrm{Hg}$, by atomic absorption spectrometry, with cold vapor generation in medicinal plants and their extracts, whose marketing was recently regulated by National Health Surveillance Agency (ANVISA). The relevance of these analyses is justified by the need of contributing to the recommendation of such plants as sources of minerals in the diet and, also, to verify if their concentrations cam pose some harm to the organism. The techniques showed adequate sensitivity in determining the concentration for most of the elements. Toxic elements were found in concentration not harmful to the human body. The results, also, allowed possible to correlate the elemental concentration in the analyzed species, by the determination the correlation coefficients and applications of cluster analysis. From these results it was confirmers in the groups of elements, regarding the variation of the concentrations observed in some plants and their extracts. The elements that play important roles in the human metabolism were determined in concentrations that can help both, to avoid the lack of these elements in the organisms, from the diet, and in treatment of disease.
\end{abstract}




\section{SUMÁRIO}

Páginas

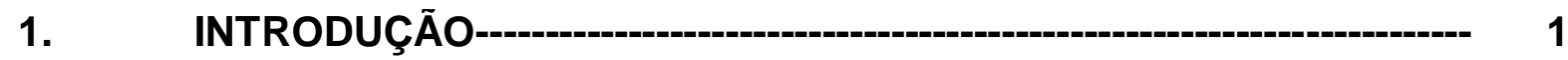

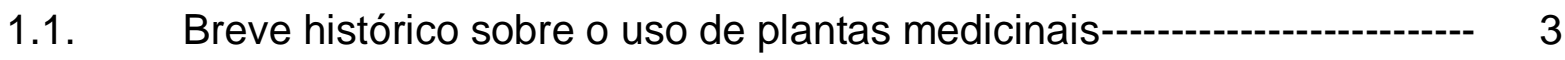

1.2. Medicamentos fitoterápicos e plantas medicinais-

1.3. Utilização de plantas medicinais no Brasil--a-an

1.4. Controle de qualidade de plantas medicinais no Brasil-a-

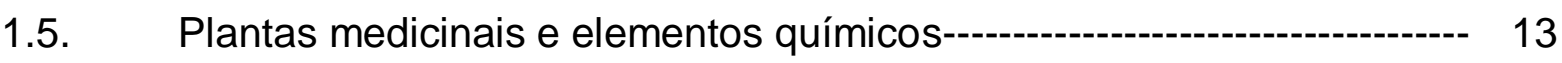

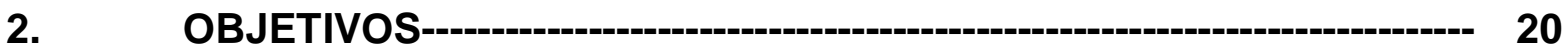

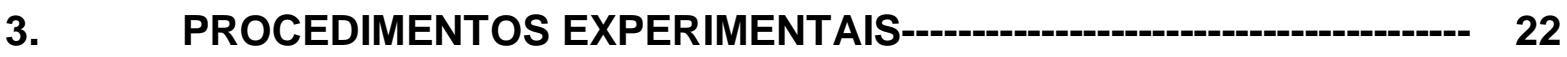

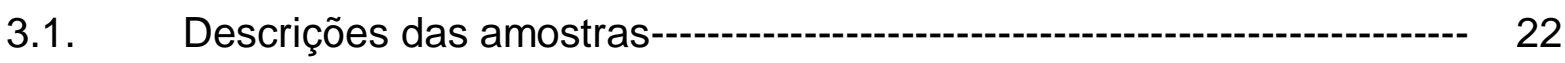

3.2. Pesquisa de materiais estranhos---on

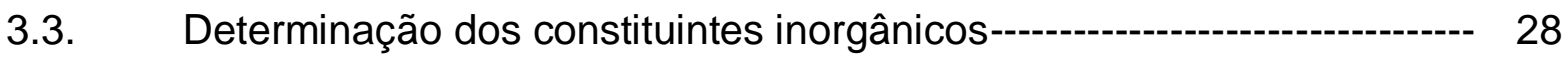

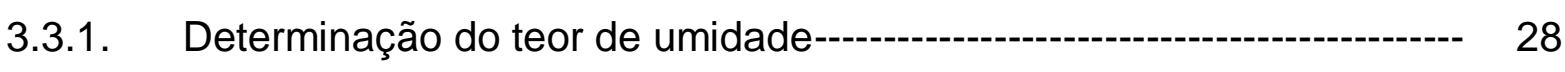

3.3.2. Determinação do teor de cinzas totais--

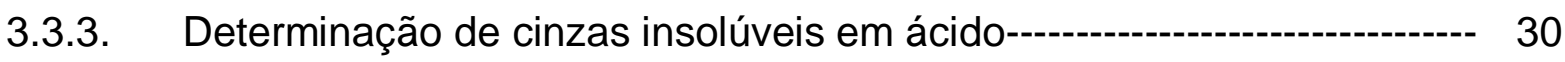

3.3.4. Análise por Ativação Neutrônica Instrumental (INAA)---------------- 31

3.3.4.1. Preparação das amostras de plantas secas para irradiação------------ 37

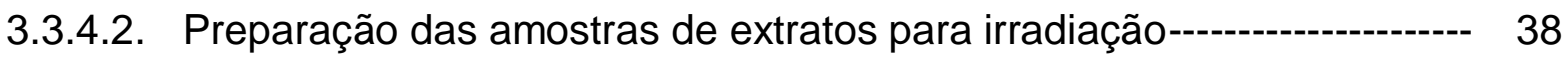

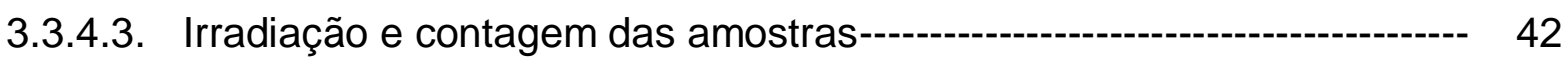


3.3.5. Espectrometria de Absorção Atômica (AAS)

3.3.5.1. Espectrometria de Absorção Atômica com Geração de Vapor Frio (CV AAS)

3.3.5.2. Procedimento experimental para as analise de $\mathrm{Hg}$ por espectrometria de absorção atômica com geração de vapor frio (CV AAS)

3.3.5.3. Determinação da curva de calibração e verificação da metodologia para CV AAS

3.3.6. Espectrometria de Emissão Óptica com Fonte de Plasma Indutivamente Acoplado (ICP-OES)

3.3.6.1. Calibração e verificação do equipamento de ICP OES

4. RESULTADOS

4.1. Pesquisa de material estranho

4.2. Determinação dos constituintes inorgânicos

4.2.1. Teor de Umidade

4.2.2. Determinação do teor de cinzas totais-

4.2.3. Determinação de cinzas insolúveis em ácido

4.3. Resultados Obtidos pelas Técnicas Analíticas INAA, CV AAS e ICPOES-

4.3.1. Limite de Detecção (LD)

4.3.2. Verificação da precisão e exatidão das técnicas analíticas INAA, CV AAS e ICP-OES-

4.3.3. Resultados das concentrações para os elementos determinados pelas técnicas analíticas INAA, CV AAS e ICP OES- 
4.3.3. Resultados das concentrações para os elementos determinados pelas técnicas analíticas INAA, CV AAS e ICP OES-

5. DISCUSSĀO

5.1. Constituintes inorgânicos

5.2. Comparação dos resultados obtidos com dados de literatura76

5.3. Composições multielementares das plantas e seus extratos 80

5.3.1. Considerações sobre os elementos $\mathrm{Ca}, \mathrm{Cl}, \mathrm{K}, \mathrm{Mg}$ e Na84

5.3.2. Consideração sobre os elementos Co, Cr, Cu, Fe, Mn, Se, V e Zn-----

5.3.3. Considerações sobre os elementos $\mathrm{As}, \mathrm{Ba}, \mathrm{Cd}, \mathrm{Cs}, \mathrm{Hg}, \mathrm{Ni}, \mathrm{Pb}, \mathrm{Sb}$, Th e U

5.3.4. Considerações sobre os elementos $\mathrm{Br}, \mathrm{Hf}, \mathrm{Rb}, \mathrm{Sc}, \mathrm{Ta}$, Ti e $\mathrm{Zr}$--------- 91

5.4. Fator de transferência dos elementos das plantas para os extratos---93

5.5. Coeficiente de correlação e Análise de agrupamento 103

6. CONCLUSÄO 
LISTA DE TABELAS

Páginas

TABELA 1.1: Procedimento e recomendações para preparação de chás de plantas medicinais-

TABELA 3.1: Relação de plantas analisadas neste estudo, presentes na lista publicada pela ANVISA em sua Resolução - RDC № 10, de 9 de março de 2010, para comercialização com finalidade terapêutica

TABELA 3.2: Elementos determinados por ativação neutrônica, radioisótopos formados na ativação, energias dos raios gama utilizadas na espectrometria gama e suas respectivas meias-vidas--------------------------------

TABELA 3.3: Elementos presentes e suas concentrações (valor \pm incerteza) ou valor informativo, em $\mu \mathrm{g} \mathrm{g}^{-1}$, nos materiais de referência Rhyolite, Glass Mountain (RGM-2) e Syenite, Table Mountain (STM-2) e dos padrões pipetados (P.P), utilizados para INAA

TABELA 3.4: Elementos presentes e suas concentrações (valor \pm incerteza combinada), em $\mu \mathrm{g} \mathrm{g}^{-1}$, nos materiais de referência SRM 1515 (Apple Leaves), SRM 1542 (Peach Leaves) e dos padrões pipetados (P.P), utilizados para INAA

TABELA 3.5: Elementos determinados pela técnica ICP-OES, linhas de emissão e faixa de concentração utilizada para construção da curva de calibração

TABELA 4.1: Teores máximos permitidos, em porcentagem (\%), de matéria estranha (ME), umidade (U), cinzas totais (CT) e cinzas insolúveis em ácido (CIA) em plantas de uso medicinal de acordo com a Farmacopeia Brasileira-----------

TABELA 4.2: Resultados obtidos para as plantas analisadas em porcentagem (\%) de matéria estranha $(\mathrm{ME})$, umidade $(\mathrm{U})$, cinzas totais (CT) e cinzas insolúveis em ácido (CIA)-------- 
TABELA 4.3: Valores de limite de detecção (LD) da técnica de INAA (mg $\mathrm{kg}^{-1}$ ) obtidos para os elementos nas amostras Apple Leaves, Peach Leaves e Tomato Leaves para os material de referência STM-2 e RGM-2----

TABELA 4.4: Intervalos obtidos exceto para $\mathrm{Hg}$, para os valores de limite de detecção (LD) para as técnicas analíticas ICPOES e CV AAS $\left(\mathrm{mg} \mathrm{kg}^{-1}\right)$, para os materiais de referência Apple Leaves e Peach Leaves-

TABELA 4.5: Resultados obtidos para o material de referência SRM 1515, Apple Leaves, utilizado para a verificação da qualidade dos resultados para a técnica de INAA, em $\mu \mathrm{g} \mathrm{g}$ 1 , exceto onde indicado \% $(n=5)$--------

TABELA 4.6: Resultados obtidos para o material de referência SRM 1547, Peach Leaves, utilizado para a verificação da qualidade dos resultados para a técnica de INAA, em $\mu \mathrm{g} \mathrm{g}$ 1 , exceto onde indicado $\%(n=5)$

TABELA 4.7: Resultados obtidos para o material de referência, SRM 1573a, Tomato Leaves, utilizado para a verificação da qualidade dos resultados para a técnica de INAA, em $\mu \mathrm{g} \mathrm{g}$ 1 , exceto onde indicado \% $(n=5)$

TABELA 4.8: $\quad$ Resultados obtidos em $\mu \mathrm{g} \mathrm{g}^{-1}$, exceto para o $\mathrm{Hg}$, em $\mathrm{ng} \mathrm{g}^{-1}$, para os materiais de referência Apple Leaves e Peach Leaves por ICP-OES e CVAAS. Resultados: Média de três determinações \pm 0 desvio padrão

TABELA 4.9: Resultados obtidos para as plantas medicinais analisadas. Os valores apresentados correspondem à técnicas analíticas AANI, ICP OES e CV AAS e à concentração em $\mu \mathrm{g} \mathrm{g}^{-1}$, ng $\mathrm{g}^{-1}$ e \%. As incertezas apresentada correspondem à propagação de erro para INAA e desvio padrão para ICP-OES e CV AAS-----

TABELA 4.10: Resultados obtidos para os extratos das plantas medicinais analisadas. Os valores apresentados correspondem à técnica analítica INAA, ICP OES e CV AAS e à concentração em $\mu \mathrm{g} \mathrm{g}^{-1} \mathrm{e} \pm \mathrm{a}$ incerteza da medida obtida por propagação de erro, exceto onde indicado por $\%$ 
TABELA 5.1: Dados estatísticos mostrando o número de amostras em que cada elemento foi determinado, a média aritmética, média geométrica, mediana, concentração mínima e máxima, desvio padrão da média aritmética e coeficiente de variação das concentrações para as plantas

TABELA 5.2: Dados estatísticos mostrando o número de amostras em que cada elemento foi determinado, a média aritmética, média geométrica, mediana, concentração mínima e máxima, desvio padrão da média aritmética e coeficiente de variação das concentrações para os extratos das plantas medicinais-

TABELA 5.3: Coeficiente de correlação de Pearson obtido para as concentrações dos elementos determinados nas amostras de plantas

TABELA 5.4: Coeficiente de correlação de Pearson obtido para as concentrações dos elementos determinados nas amostras 


\section{LISTA DE FIGURAS}

Páginas

FIGURA 3.1: Ilustração do processo utilizada para determinação de materiais estranhos

FIGURA 3.2: $\quad$ Ilustração do processo utilizado para determinação do teor de umidade: pesagem (etapa I), secagem (etapa II) e resfriamento da amostra (etapa III)

FIGURA 3.3: Ilustração da amostra na mufla para calcinação

FIGURA 3.4: Ilustração das etapas utilizadas para determinação do teor de cinzas insolúveis em ácido: adição de $\mathrm{HNO}_{3}$ (etapa I), filtração (etapa II) e pesagem (etapa III)

FIGURA 3.5: Processo esquemático da formação de um radionuclídeo artificial empregado na técnica de INAA--------------------

FIGURA 3.6: Illustração do processo de preparação das amostras de plantas para irradiação: processo de trituração (etapa I), peneiramento e homogeneização da amostra (etapa II) e acondicionamento da amostra em sacos de polietileno para irradiação (Etapa III)

FIGURA 3.7: Ilustração do processo para obtenção dos extratos por INFUSÃO: (etapa I) pesagem da amostra, (etapa II) aquecimento da água, (etapa III) introdução da amostra em água fervente, (etapa IV) resfriamento e (etapa V) filtração do extrato final

FIGURA 3.8: Ilustração do processo para obtenção dos extratos por DECOCÇÂO: (etapa I) acréscimo da amostra em água fria, (etapa II) aquecimento da água com a amostra, (etapa III) resfriamento e (etapa IV) filtração do extrato final---------

FIGURA 3.9: $\quad$ llustração do processo de preparação dos extratos para irradiação: (etapa I) secagem da amostra em chapa aquecedora, (etapa II) evaporação até quase secura da amostra, (etapa III) transferência da solução final para papel de filtro e (etapa IV) acondicionamento da amostra em sacos de polietileno 
FIGURA 3.10: Ilustração do sistema com Detector de Germânio Hiperpuro do Laboratório de Analise por Ativação Neutrônica

FIGURA 3.11: Ilustração do processo de digestão da amostra seca para analise no CV AAS e ICP OES: (etapa I) amostra triturada e homogeneizada, (etapa II) pesagem e tratamento com ácidos em frasco de teflon, (etapa III) digestão em microondas e (etapa IV) acondicionamento e armazenamento em tubos plásticos

FIGURA 3.12: Equipamento de CV AAS do Laboratório de Absorção Atômica do LAN/IPEN-SP marca Perkin Elmer, modelo FIMS 100 (Flow Injection Mercury System) para determinação de $\mathrm{Hg}$

FIGURA 3.13: Curva de calibração para Hg obtida por CV AAS

FIGURA 3.14: Curva analítica do Cd para ICP- OES

FIGURA 3.15: Curva analítica do Cu para ICP- OES-

FIGURA 3.16: Curva analítica do Ni para ICP- OES

FIGURA 3.17: $\quad$ Curva analítica do $\mathbf{P b}$ para ICP- OES

FIGURA 5.1: $\quad$ Fator de transferência para os elementos Ca e Fe

FIGURA 5.2: $\quad$ Fator de transferência para os elementos Cu e Zn-----------

FIGURA 5.3: $\quad$ Fator de transferência para os elementos Co, Cr e Se-------

FIGURA 5.4: $\quad$ Fator de transferência para os elementos As, Cd e Pb------

FIGURA 5.5: $\quad$ Fator de transferência para os elementos $\mathrm{Ba}$, Ni e Th-------

FIGURA 5.6: $\quad$ Fator de transferência para os elementos $\mathrm{Br}$, Rb e Sc-------

FIGURA 5.7: $\quad$ Fator de transferência para os elementos Cs, Hf, Sb e Zr--- 
FIGURA 5.8: $\quad$ Fator de transferência para os elementos $\mathrm{K}$ e $\mathrm{Na}$

FIGURA 5.9: Dendrograma para os elementos determinados nas plantas medicinais --.---.--

FIGURA 5.10: Dendrograma para as plantas medicinais 108

FIGURA 5.11: Dendrograma para os elementos determinados nos

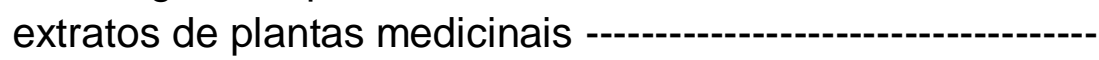

FIGURA 5.12: Dendrograma contendo os 23 extratos de plantas medicinais 


\section{LISTA DE ABREVIATURAS E/OU SIGLAS}

AANI - Analise por Ativação Neutrônica Instrumental

AAS - Atomic Absorption Spectrometry

ABIA - Associação Brasileira das Indústrias da Alimentação

ANVISA - Agência Nacional de Vigilância Sanitária

C - Cinzas Totais

CIA - Cinzas Insolúveis em Ácido

CV AAS - Cold Vapor Atomic Absorption Spectroscopy

DINAL — Divisão Nacional de Alimentos

DPR - Desvio Padrão Relativo

FT - Fator de Transferência

HPGe - Hing Purity Germanium

ICP- OES - Emission Spectrometry with Inductively Coupled Plasma Source

IDT — Limite de Ingestão Diária Tolerável

IPEN - Instituto de Pesquisas Energéticas e Nucleares

LAN — Laboratório de Ativação Neutrônica

LD — Limite de Detecção

ME - Materiais Estranhos

MRCs - Materiais de Referência Certificados

PNPIC - Politica Nacional de Práticas Integrativas e Complementares

RENAME - Relação Nacional de Medicamentos Essenciais

SUS - Sistema Único de Saúde

U - Umidade

WHO - World Health Organization 


\section{INTRODUÇÃO}

A humanidade faz uso das plantas medicinais desde o início de sua existência, utilizando-a como um dos primeiros recursos alternativos de tratamento não convencional para o cuidado da saúde dos indivíduos e de suas famílias (Oliveira e Menini, 2012). Acreditava-se que elas continham em sua essência princípios ativos, os quais, após o seu uso externo ou interno, poderiam abrandar certos tipos de distúrbios tais como dores musculares, cólicas intestinais e outros tipos de doenças (Gonçalvez et al., 2011), evidenciando assim o seu poder curativo.

Conforme nos informa Badke (2008), toda informação acumulada sobre uso de plantas medicinais, foi inicialmente transmitida oralmente de geração a geração para só depois, com advento da escrita, ser compilada em livros.

Ainda hoje o uso de plantas medicinais é o único recurso terapêutico de diversas comunidades em pequenas e grandes regiões brasileiras, sendo elas cultivadas em quintais, comercializadas em feiras livres e mercados populares (Cunha, 2008; Camargo Jr., 2006).

Nos dias atuais, com o crescimento da busca pelo cuidado autônomo à saúde e a menor dependência medicamentosa, além de avaliar a eficiência terapêutica, é de grande importância também, possuir o prévio conhecimento das finalidades, forma correta de uso, benefícios e, quando consumidas em excesso, os possíveis malefícios que as plantas medicinais podem provocar (Machado et al., 2003). Ressalta-se que, a primeira lei brasileira criada visando o controle de qualidade no comércio de plantas medicinais foi à lei de № 5.991 de 1973. Até então, plantas medicinais eram consideradas como produtos naturais, podendo ser cultivadas e comercializadas livremente, sendo este um ponto negativo, uma vez que favorece a automedicação, principalmente nos casos mais simples e corriqueiros de enfermidades (Divienne et al., 2004), e mesmo nos dias atuais, com a melhoria nas leis visando a garantia da qualidade para a produção e comercialização de plantas medicinais, em muitas localidades brasileira ainda encontra-se a venda deste produto de forma ilegal. 
Além da influência econômica, política e social, os principais fatores que levaram a busca por novos modelos de terapias menos danosas à vida humana, inclusive as que envolvem plantas medicinais, são os possíveis efeitos colaterais indesejáveis à saúde dos pacientes que muitos medicamentos sintéticos podem acarretar (Alvim et al., 2006).

Com os avanços ocorridos na área cientifica, o desenvolvimento de fitoterápicos reconhecidamente seguros e eficazes, a comprovação cientifica dos benefícios e da ação terapêutica de certas plantas e o desejo da população por um estilo de vida mais saudável, tem aumentado significativamente a procura por terapias alternativas com uso de plantas medicinais (Queiroz, 2000). De maneira geral, as plantas medicinais são usadas de forma preventiva, tendo em vista que não possuem ação terapêutica imediata e, pela mesma razão, também não são recomendados nas emergências médicas (Yunes et al., 2001).

Trabalhos de difusão e resgate do conhecimento de plantas vêm se difundindo. Em todo o Brasil se multiplicam os programas de fitoterapia, apoiados pelo serviço público de saúde. Têm-se formado equipes multidisciplinares responsáveis pelo atendimento fitoterápico, com profissionais encarregados do cultivo de plantas medicinais, da produção de fitoterápicos, do diagnóstico médico e da recomendação destes produtos. Pode-se dizer que temos hoje uma fitoterapia muito presente, que se não é predominante em termos comerciais, passa a ser em termos culturais e de aceitação. Em paralelo, no entanto, muito pouco tem ocorrido no sentido de dar-lhe o embasamento e consistência técnico-científica que permita a sua sedimentação enquanto terapêutica. Tirando raros casos de espécies bem estudadas como Ginkgo biloba, Hypericum perforatum, o restante da nossa fitoterapia continua baseada em informações populares, o que não lhe dá nem credibilidade nem consistência (Alexandre et al., 2008).

Nas pesquisas para o desenvolvimento de fitoterápicos o foco principal é a caracterização do princípio ativo da planta, para comprovação cientifica das propriedades terapêuticas (Ferreira et al., 2003; Calixto, 2000), existindo assim poucos registros com descrições das concentrações de macro e micronutrientes presentes tanto nas plantas quanto nos extratos vegetais. $O$ conhecimento das 
concentrações elementares faz-se necessário para verificar possíveis interferências na ação terapêutica, ou saber se o teor desses elementos é tóxico ao ser humano. Além disso, é também de conhecimento geral que muitos elementos traço desempenham um importante papel tanto no bem estar quanto na cura de várias doenças (Singh e Garg, 1997).

Seletivamente, espécies herbáceas têm capacidade de acumular certos elementos. Assim, o conteúdo de elementos essências em plantas medicinais pode ser afetado pelas características geoquímicas do solo no local de seu cultivo.

O interesse na composição química, levantamento bioquímico e prospecção mineral de produtos à base de plantas vêm crescendo, principalmente devido ao contínuo desenvolvimento dos setores de medicina, nutrição e farmacêutico (Karak, Bhagat, 2010). Baseado em argumentos científicos, a suplementação da dieta com plantas medicinais deve ser recomendada tanto para a cura de males do corpo, devido às suas propriedades terapêuticas, quanto pelo seu valor nutritivo (Ernst et al., 1998). Desta forma, é de grande importância conhecer o potencial de influência de certos metais sobre os efeitos farmacológicos das drogas naturais obtidas a partir destas plantas (Diaconu et al., 2012).

\subsection{Breve histórico sobre o uso de plantas medicinais}

Os primeiros registros históricos do uso de plantas medicinais datam de mais de 5.000 anos e mencionam a utilização de espécies como o louro e o tomilho pelos Sumérios (Biazzi, 2004).

De acordo com Almeida (1993), as plantas medicinais foram os primeiros recursos terapêuticos utilizados no cuidado à saúde, sendo, portanto, um conhecimento milenar que faz parte da evolução humana. Mesmo antes do aparecimento da escrita, já se fazia o uso das plantas, ora como remédio ora como alimento.

Lameira e Pinto (2008) mencionam a importância da contribuição de grandes médicos como Hipócrates, considerado o pai da medicina, Galeno, precursor de 
fórmulas farmacêuticas até hoje utilizadas e Dioscórides que escreveu o "Dissertadio medica" (tratado de matéria médica), dividido em cinco livros, nos quais são descritos cerca de 600 plantas e indicações sobre o seu uso médico. Estas obras representam um verdadeiro marco histórico sobre o conhecimento de fármacos (Menezes, 2005). Há referências ainda, no Antigo e no Novo testamento, do uso de plantas curativas como a mirra, o aloés, dentre outros (Martins et al., 2000).

No decorrer da idade média, adventos históricos tais como a queda do Império Romano e o fortalecimento da Igreja Católica fizeram com que as informações sobre o uso de plantas medicinais se mantivessem estagnadas, ficando restritas apenas aos mosteiros. Naquela época, o uso de qualquer tipo de planta para fins curativos poderia ser considerado como prática de bruxaria ou alquimia (Martins et al., 2000).

Após a idade média, conforme Silveira (2005) ocorrem a retomada dos estudos que abordam o emprego de plantas medicinais como forma paliativa ou curativa de tratar doenças. No período do Renascimento ocorreu a introdução de novos fármacos provenientes de diversas culturas na terapêutica humana. Apesar de ser um tratamento secular para as doenças em diversas culturas, na modernidade, está arte sofre muitas alterações a partir da segunda metade do século $\mathrm{XX}$, quando o uso de medicamentos sintéticos e industrializados começou a se intensificar, permitindo a entrada maciça de componentes ativos derivados de plantas empregadas desde a antiguidade, utilizadas para tratamentos patológicos leves e moderados. Desta forma, a maior parte das plantas medicinais empregadas desde a antiguidade, entrou na categoria de remédio caseiro, na maioria dos casos como componente complementar à medicina tradicional.

A utilização de plantas medicinais foi negligenciada pela supremacia dos medicamentos alopáticos que, a partir de então, passaram a predominar nas terapias modernas. Essa situação permaneceu até os anos 60, em que diversos fatores, entre eles a necessidade de encontrar novas moléculas com atividades farmacológicas e menores efeitos secundários, daí o surgimento de alguns fármacos sintéticos, desenvolvidos a partir da investigação da natureza, em particular o reino vegetal. A partir de então, o embasamento cientifico para emprego terapêutico 
passou a ser exigido, não só das plantas empregadas desde a antiguidade, como também de outras espécies consideradas, até o momento, como possíveis fontes de novas moléculas com interesse farmacológico (Silva e Ritter, 2000).

$\mathrm{Na}$ década de 80 ocorreu a retomada do interesse pela terapia a base de plantas medicinais devido às reações adversas provocadas por medicamentos alopáticos e também pelos elevados custos desses medicamentos (Adeodado et al.,1996).

\subsection{Medicamentos fitoterápicos e plantas medicinais}

O uso de fitoterápicos com finalidades profiláticas, curativas, paliativas ou com fins de diagnóstico passou a ser oficial e reconhecido pela WHO (Organização Mundial de Saúde) na declaração Alma-Ata, em 1978, que expressa sua posição a respeito da necessidade de valorizar a utilização de plantas medicinais no âmbito sanitário, tendo-se em conta que $80 \%$ da população mundial utilizam estas plantas ou preparações destas plantas no que se refere à atenção primária à saúde.

Considerando-se que plantas medicinais são aquelas capazes de aliviar ou curar enfermidades e têm tradição de uso como remédio em uma população ou comunidade, para usá-las é preciso conhecê-las, saber onde colhê-las e como prepará-las. Quando a planta medicinal é industrializada para se obter um medicamento, tem-se como resultado o fitoterápico. O processo de cultivo tende a evitar contaminações por microorganismos, agrotóxicos e substâncias estranhas. O processo de industrialização além de padronizar a quantidade e a forma que deve ser usada, resultando em uma maior segurança para o usuário (Batalha et al., 2010). Os fitoterápicos industrializados devem ser registrados na ANVISA/Ministério da Saúde antes de serem comercializados.

Nas décadas de 1980 e 1990, foram estabelecidas diversas políticas nacionais para a incorporação da fitoterapia no uso de tratamentos realizados pelo Sistema Único de Saúde - SUS. Entre elas destacam-se a implantação do "Programa de Pesquisa de Plantas Medicinais da Central de Medicamentos" em 1982; a inclusão de fitoterápicos na "Relação Nacional de Medicamentos Essenciais 
(Rename)", a introdução das "práticas alternativas de assistência à saúde" no âmbito dos serviços de saúde, possibilitando ao usuário o processo democrático de escolha de sua terapêutica preferida em 1986 e a continuidade e expansão do apoio às pesquisas para o aproveitamento do potencial terapêutico da flora nacional (Brasil, 1988), enfatizando a certificação das propriedades medicamentosas dos fitoterápicos em 1998.

Entre os avanços recentes ligados às terapias com plantas medicinais foram estimulados por eventos, como, por exemplo, a integração do uso de plantas medicinal e fitoterápica pelo Sistema Único de Saúde (SUS) em 2003; a resolução 338/04 do Conselho Nacional de Saúde (2004), que por meio da "Política Nacional de Assistência Farmacêutica" que apoiou ações intersetoriais que visem à utilização de plantas medicinais e de medicamentos fitoterápicos no processo de atenção à saúde (Brasil, 2004), com respeito aos conhecimentos tradicionais incorporados e com embasamento científico; o decreto presidencial, em 2005, que criou o Grupo de Trabalho que elaborou a "Política Nacional de Plantas Medicinal e Fitoterápico" em 2006. Neste mesmo ano foi instituída a "Política Nacional de Práticas Integrativas e Complementares no SUS" (PNPIC, 2006), aprovada pelo Conselho Nacional de Saúde no ano de 2005 e publicada por meio de Portaria GM no 971, de 03 de maio de 2006 (Ministério da Saúde, 2006), que propõe a inclusão das plantas medicinais e fitoterapia, além de outras práticas integrativas, como opções terapêuticas no sistema público de saúde. Esta política traz dentre suas diretrizes para plantas medicinais e fitoterapia a elaboração da Relação Nacional de Plantas Medicinais e de Fitoterápicos e o provimento do acesso a plantas medicinais e fitoterápicas aos usuários do SUS.

Segundo a Resolução da Diretoria Colegiada №. 48/2004 da Agência Nacional de Vigilância Sanitária - ANVISA, drogas vegetais são definidas como plantas medicinais ou suas partes, após processo de coleta, estabilização e secagem, podendo ser integra, rasurada, triturada ou pulverizada. Os medicamentos fitoterápicos são preparados exclusivamente com plantas medicinais ou partes destas (raízes, cascas, folhas, flores, frutos ou sementes), que possuem propriedades reconhecidas de cura, prevenção, diagnóstico ou tratamento 
sintomático de doenças, validadas em estudos etnofarmacológicos, documentações tecnocientíficas ou ensaios clínicos (Shu, 1998; Strobl, 2000). Os fitomedicamentos, como medicamentos farmacêuticos obtidos por processos tecnologicamente adequados, empregando exclusivamente matérias primas vegetais, com finalidade profilática, curativa, paliativas ou para fins de diagnóstico. É caracterizado pelo conhecimento da eficácia e dos riscos de seus usos, assim como pela reprodutividade e constância de sua qualidade. Não se considera medicamento fitoterápico aquele que, na sua composição, inclua substâncias ativas, de qualquer origem, nem as associações destas com extratos vegetais.

O principal objetivo da resolução $n^{0} 48 / 2004$ (ANVISA, 2004) é a garantia da qualidade dos fitoterápicos, exigindo a reprodutibilidade dos mesmos, através de quantidade de marcador, componentes ou classes de compostos químicos (ex. alcaloides, flavonoides, ácidos graxos, etc.), assegurando a mesma quantidade de substância ativa qualquer que seja o fabricante.

Já a expansão da terapia com plantas medicinais entre a população ocorreu devido a fatores tais como efeitos adversos causados pelos medicamentos sintéticos, preferência dos consumidores por tratamentos "naturais", validação científica das propriedades farmacológicas das espécies vegetais, desenvolvimento de novos métodos analíticos colocados à disposição do controle de qualidade, desenvolvimento de novas formas de preparações e administrações de produtos fitoterápicos, melhor conhecimento químico, farmacológico e clínico das drogas vegetais e seus derivados, além também do menor custo se comparado com os fármacos sintéticos (Cañigueral et al., 2003; Vieira, 2001).

Como consequência da grande difusão e da utilização das plantas medicinais, as indústrias vêm produzindo produtos à base de espécies vegetais, de diversas formas farmacêuticas que têm sido comercializados em farmácias, supermercados e casas de produtos naturais.

As plantas medicinais são introduzidas na terapia de diversos distúrbios humanos por possuírem ação antiemética, sedativa, ansiolítica, diurética, hipotensora, antialérgica, antipirética, anti-inflamatória, analgésica, broncodilatadora, 
entre outras. Hoje já existem 66 espécies reconhecidas pela ANVISA para uso como alternativa medicamentosa e 71 espécies de plantas medicinais de interesse de uso no SUS (RENISUS, 2009), das quais 38 espécies fazem parte das duas listas. E ainda, vários estudos científicos para reconhecimento e introdução de novas espécies estão em andamento.

Entre as possíveis formas de apresentação para administração dos medicamentos fitoterápicos ou terapias à base de plantas medicinais, a forma oral é a mais utilizada (consiste na administração, pela boca, de uma forma farmacêutica que após a deglutição, o principio ativo chega até o TGI "estômago, intestino delgado e intestino grosso"). A absorção, neste tipo de fórmula, é mais lenta, porém, é considerado o meio mais simples, conveniente e seguro (Ansel et al., 2000). Plantas medicinais podem ser consumidas de diferentes maneiras na administração por via oral, tais como chás, sucos, tinturas e extratos. Das possíveis formas de administração, os chás fornecem substâncias terapêuticas que hidratam, desintoxicam, estimulam, auxiliam na digestão e controlam a temperatura, sendo ainda os mais utilizados e indicados para uso de pacientes infantis e idosos (Kobers, Santos, 2007). Para o tipo de via de administração farmacêutica oral a ANVISA dispõe de três formas de preparação: decocção, infusão e maceração que estão descritas na Tabela 1.1. No contexto do crescimento da utilização de drogas vegetais com finalidade terapêutica, a Rede Brasileira de Metrologia Legal e Qualidade - (INMETRO) considerou necessária à avaliação da qualidade dos chás disponíveis para comercialização, a fim de verificar o cumprimento dos critérios estabelecidos na legislação e as questões de saúde do consumidor (Azevedo; Maduro; Goulart, 2009). Os critérios e a metodologia aplicados para garantia da qualidade dos chás foram combinados em conjunto entre a ANVISA, que é o órgão regulador do produto, e a Associação Brasileira das Indústrias da Alimentação $(\mathrm{ABI})$. 


\subsection{Utilização de plantas medicinais no Brasil}

No Brasil, o uso da terapêutica com plantas medicinais já é conhecido desde a colonização, quando os índios faziam uso delas para cura de seus males. Conforme Carreira (2002) "não há historiografia brasileira sobre a importância da colaboração do índio em práticas de saúde para adaptação do europeu ao novo mundo". Sabe-se apenas que a utilização de ervas medicinal está ligada às culturas do europeu, dos negros e dos índios, como principal forma de cura a ser utilizada pela população (Coelho, 1989).

O privilégio deste tipo de terapia ser vastamente utilizada deve-se, em parte, à magnitude da biodiversidade brasileira que ainda não é totalmente conhecida, porém, é sabido que o país detém a maior diversidade biológica do mundo, favorecendo a descoberta de substâncias curativas. Referindo-se exclusivamente à variabilidade de organismos vegetais, o Brasil apresenta cerca de 55 mil espécies de plantas catalogadas, das quais há relatos de investigação de apenas 0,4\% (GuribFakim, 2006).

Cerca de $20 \%$ da população brasileira consome $63 \%$ dos medicamentos alopáticos (são medicamentos que produzem, no organismo do doente, reações opostas aos sintomas a fim de controlar ou combater as doenças), o restante encontra nos produtos de origem natural, especialmente nas plantas, a principal fonte alternativa para obtenção de medicação (Foglio et al., 2006).

Segundo a Associação Brasileira de Empresas do Setor Fitoterápico, não existem dados oficiais sobre o tamanho deste mercado no país e as estimativas variam entre US\$ 350 milhões e US\$ 550 milhões (Ministério da Saúde, 2012). O crescimento do mercado de fitoterápicos é de cerca de $15 \%$ ao ano, enquanto que o dos medicamentos sintéticos cresce em torno de 4\% (Febrafarma, 2007). 
TABELA 1.1: Procedimento e recomendações para preparação de chás de plantas medicinais.

\begin{tabular}{|c|c|c|}
\hline Tipos de preparo & Procedimentos & Observação \\
\hline $\begin{array}{c}\text { Decocção } \\
\text { (1); (2) }\end{array}$ & $\begin{array}{l}\text { Colocam-se as plantas em uma } \\
\text { vasilha e verte-se água fria em } \\
\text { cima. O tempo de cozimento } \\
\text { pode variar de } 5 \text { a } 30 \text { minutos } \\
\text { dependendo da parte da planta } \\
\text { utilizada. Tira-se a vasilha do } \\
\text { fogo, conservando-a tapada } \\
\text { durante alguns minutos, em } \\
\text { seguida o chá é coado. }\end{array}$ & $\begin{array}{l}\text { Recomendada para } \\
\text { cascas, raízes e talos. } \\
\text { Pode-se ingerir ainda } \\
\text { quente, morno ou frio. }\end{array}$ \\
\hline $\begin{array}{c}\text { Maceração } \\
\text { (1) }\end{array}$ & $\begin{array}{l}\text { Põe-se de molho as plantas em } \\
\text { água fria por um período de } 10 \\
\text { a } 24 \text { horas. Está água pode ser } \\
\text { fervida ou filtrada. Tapar bem o } \\
\text { recipiente, deixar por horas, } \\
\text { dias ou semanas, coar e tomar. }\end{array}$ & $\begin{array}{l}\text { Maneira pela qual foram } \\
\text { preparados os extratos } \\
\text { de alho e laranja amarga. } \\
\text { A vantagem deste } \\
\text { método é que os sais } \\
\text { minerais e as vitaminas } \\
\text { das ervas são melhor } \\
\text { aproveitadas. }\end{array}$ \\
\hline $\begin{array}{l}\text { Infusão } \\
\text { (1); (2) }\end{array}$ & $\begin{array}{l}\text { Fracionar a parte indicada da } \\
\text { planta, colocar num recipiente, } \\
\text { e verter nele água fervente. } \\
\text { Tapar para abafar, deixar em } \\
\text { repouso por } 5 \text { a } 15 \text { minutos e } \\
\text { coar em seguida. }\end{array}$ & $\begin{array}{l}\text { Método mais apropriado } \\
\text { para as folhas e flores. } \\
\text { Pode-se ingerir ainda } \\
\text { quente, frio ou morno. }\end{array}$ \\
\hline
\end{tabular}

Fontes: (1) Balbach; 1992 e (2) Korbes et al.; 2007 


\subsection{Controle de qualidade de plantas medicinais no Brasil}

O aumento da popularidade de drogas vegetais despertou também o crescimento da procura, tornando insuficiente a oferta das mesmas, o que pode resultar em uma queda na sua qualidade. Este fato pode ocorrer devido ao desconhecimento por parte de muitos produtores dos cuidados necessários nas diversas etapas para obtenção da matéria prima. Segundo Yamamoto et al. (2004), a segurança e a eficácia do uso de plantas medicinais dependem de diversos fatores como coleta, cultivo e armazenamento; sendo que tais fatores podem influenciar na qualidade do produto, podendo ainda, ocasionar problemas de saúde aos usuários.

Apesar de toda a importância terapêutica e comercial, o Brasil tem investido pouco em estudos de pesquisa e desenvolvimento das terapias com plantas medicinais, o que prejudica a aceitação deste tipo de tratamento. A grande maioria das plantas utilizadas com fins terapêuticos não possui dados científicos que comprovem sua eficácia, sendo que muitas delas também não são descritas na Farmacopeia Brasileira, o que impossibilita os médicos de receitarem oficialmente medicação a base de plantas (Stefanello, 2005).

O mais preocupante em relação ao uso de plantas medicinais é que este tipo de produto é produzido basicamente por produtores de pequeno porte, que na maioria das vezes processam seus produtos de forma precária não garantindo sua qualidade final. Associado a isto, não há fiscalização efetiva para os produtos naturais e ainda, a legislação vigente sobre ervas medicinais encontrar-se em estado inicial (no que refere à produção, uso, comercialização e fiscalização de produtos derivados exclusivamente de espécies vegetais) quando comparada à dos medicamentos sintéticos (Brandão et al., 1998; Zuin et al., 2004). Estes fatos podem levar a presença de diversas irregularidades que comprometam a eficácia da terapia (Zuccolotto et al., 1999).

Veiga-Junior et al., 2005 enfatizaram que as pesquisas para avaliação do uso seguro de plantas medicinais e fitoterápicos no Brasil ainda são incipientes, como também a fiscalização do comércio por parte dos órgãos competentes. 
Em maio de 1978, a Organização Mundial de Saúde (OMS) através de uma resolução de sua XXXI Assembleia Geral, determinou o início de um programa mundial com a finalidade de avaliar e utilizar os métodos da chamada "medicina tradicional" (Mors, 1982). Anos depois, estabeleceu padrões para o controle de qualidade de plantas medicinais incluindo a classificação, identificação botânica, determinação dos princípios ativos e identificação de contaminantes (WHO, 1999). Estabeleceu também em suas resoluções WHA 31.33, 1978; WHA 40.33, 1987 e WHA 42.43, 1989 a necessidade de se assegurar o controle de qualidade de produtos medicinais de origem vegetal pelo uso de técnicas modernas de análise e controle e utilização de padrões adequados (WHO, 1990; WHO, 1998).

A necessidade de assegurar o controle de qualidade nos produtos à base de plantas medicinais ocorreu devido ao crescimento da poluição ambiental que afeta diretamente as plantas, que podem acumular certos tipos de elementos tóxicos ou não, tornando de grande importância pesquisas que determinem a concentração de elementos maiores, menores e traços devido a sua presença em processos metabólicos humanos (Naidu et al., 1999).

Mesmo com os padrões estabelecidos pela legislação brasileira vigente para assegurar a qualidades dos produtos feitos com plantas medicinais e, provavelmente, devido a uma farmacovigilância ausente (Brandão et al., 2002), os produtos a base de espécies vegetais ainda são comercializados fora dos padrões estabelecidos, ocorrendo ainda a venda de produtos sem nenhuma comprovação pré-clínica, nem clínica quanto a sua eficácia e que assegure a saúde do consumidor (Yunes et al., 2001).

Sabendo-se que $80 \%$ da população mundial dependem das práticas tradicionais no que se refere à atenção primária à saúde e $85 \%$ dessa parcela utiliza plantas ou preparações a base de vegetais (Martins e Santos, 1995), vários comunicados e resoluções da WHO expressam a posição desta organização a respeito da necessidade de valorizar o uso desses medicamentos no âmbito sanitário. 
Considerando a importância das plantas na terapia medicinal, em 9 de março de 2010 a Diretoria Colegiada da Agência Nacional de Vigilância Sanitária (ANVISA) publicou uma Resolução que dispõe sobre a notificação de drogas vegetais, a partir da experiência da sociedade civil em suas diferentes formas de organização de modo a garantir e promover a segurança, eficácia e a qualidade desses produtos visando a necessidade de contribuição na construção do marco regulatório para a produção de plantas medicinais, particularmente sob a forma de drogas vegetais. Nesta resolução (RDC № 10, de 9 de março de 2010) a ANVISA publicou uma lista contendo 66 espécies de plantas medicinais aptas a serem comercializadas bem como empregadas pelo SUS nos atendimento complementar à saúde (DOU, 2010).

\subsection{Plantas medicinais e elementos químicos}

As plantas dispõem de três fontes fornecedoras de elementos químicos, o carbono, hidrogênio e oxigênio presente no gás carbônico $\left(\mathrm{CO}_{2}\right)$ vindo do ar e da água. Podem também absorver, pelas raízes, determinados elementos químicos que auxiliam em diversas funções biológicas envolvidas nos processos metabólicos. Estes elementos podem ser classificados em macroelementos, como por exemplo, $\mathrm{Ca}, \mathrm{K}, \mathrm{Mg}, \mathrm{N}$, Na P e S, e microelementos, como por exemplo Fe, Mn, Zn e Cu. Quanto à sua função biológica, os elementos podem ser classificados em essenciais, quando fazem parte de algum constituinte, ou metabólico essencial para a planta, não podendo ser substituído por outro elemento; benéficos, aqueles que não são essenciais, mas aumentam o crescimento e a produção em situações particulares como $\mathrm{Co}, \mathrm{Cr}$ e Se; e os elementos tóxicos, que são aqueles que podem provocar danos ao metabolismo mesmo em baixas concentrações como o As, $\mathrm{Hg}$, $\mathrm{Cd}$ e $\mathrm{Pb}$ (Faquin, 2005).

Segundo Vaz (1995), diversos íons podem estar presentes inicialmente no solo e podem ser disponibilizados imediatamente para as plantas sendo deslocados através do córtex e cilindro central até as partes aéreas. $O$ deslocamento depende das constantes de equilíbrio, que variam a partir de fatores como: tipo de nutriente, forma do composto, temperatura e $\mathrm{pH}$. As partes aéreas das plantas, apesar de 
adaptadas para realização de fotossíntese, também possuem a capacidade de absorver água e nutrientes do meio externo.

Desta forma, as plantas medicinais podem conter elementos químicos que podem ser disponibilizados para o corpo humano em qualquer tipo de consumo dessas ervas e seus extratos. Nem todos os elementos possuem funções biológicas totalmente descritas, todavia a maioria deles é responsável por importantes atividades no metabolismo humano e, portanto, estão diretamente relacionados com a manutenção da saúde e o funcionamento adequado do organismo. Muitas enzimas vitais são ativadas quando na presença de certos elementos, que influenciam de forma primordial os processos bioquímicos de células.

A ANVISA, em sua resolução RDC n 48, de 16 de março de 2004 que dispõe sobre registro de medicamentos fitoterápicos, em seu item 8.3, estabelece que entre os requisitos necessários para a obtenção de registro está a ausência de risco tóxico ao usuário e ausência de grupos ou substâncias químicas tóxicas, ou presença dentro de limites comprovadamente seguros. Esta regulamentação admite que para a comprovação destes itens sejam apresentados dados de literatura com prospecção fitoquímica do extrato mostrando que o mesmo não possui substâncias químicas reconhecidamente tóxicas.

A importância de estudos que possibilitem conhecer a concentração destes elementos em plantas medicinais é poder auxiliar na verificação de possíveis interferências na sua ação terapêutica e também contribuir para a recomendação destas plantas como fontes minerais na dieta alimentar (Chen e Pan, 2001) e, auxiliar no controle de qualidade para plantas medicinais no que se refere á proteção dos consumidores para os riscos de contaminação.

Adiante são apresentadas as implicações de alguns elementos sobre a saúde humana, e o limite de ingestão recomendado ou tolerável quando existente.

Antimônio: a toxicidade do antimônio depende do seu estado químico, podendo causar danos respiratórios, cardiovasculares e gastrointestinais. O limite de 
ingestão diária tolerável (IDT) de antimônio é de $6 \mu \mathrm{g} / \mathrm{kg}$ de peso corporal (Committee On Toxicity Of Chemicals In Food, 2006).

Arsênio: este elemento não faz parte do metabolismo humano. Uma vez ingerido é bem distribuído para praticamente todos os órgão e tecidos do corpo. Pode ser acumulado em tecidos com queratina, como por exemplo, pele, cabelo e unha. Possui pouca deposição e acúmulo em vísceras e ainda pode passar a barreira placentária atingindo o feto. Os riscos à saúde associados a este elemento podem ser dermatológico, hematológico, renal, respiratório, cardiovascular, hepático, gastrointestinal, carcinogênico e teratogênico. O consumo médio de arsênio por homens e mulheres adultos é cerca de 2,0 a 2,9 $\mu \mathrm{g} / \mathrm{dia}$ e 1,7 a 2,1 $\mathrm{mg} / \mathrm{dia}$, respectivamente (Dietary Reference Intakes for Arsenic, 2001).

Bário: o íon bário é um estimulante muscular e é muito tóxico para o coração, podendo causar fibrilação ventricular. Os sintomas de envenenamento com bário são: salivação excessiva, tremores e convulsões, ritmo cardíaco acelerado, hipertensão, paralisia dos braços e das pernas, hemorragias internas e eventualmente, a morte. Para este elemento o IDT (Ingestão diária tolerável) é de $0,21 \mathrm{mg} / \mathrm{kg}$ do peso corpóreo/dia (Committee On Toxicity Of Chemicals In Food, 2006)

Bromo: muitos compostos de bromo têm uma ação fisiológica importante como sedativos, anestésicos ou anti-sépticos. Para este elemento, o IDT é de 1 $\mathrm{mg} / \mathrm{kg}$ do peso corpóreo/dia (Committee on toxicity of chemicals in food, 1997).

Cálcio: contribui para a rigidez de ossos e dentes, também é necessário para muitos processos corporais como a coagulação sanguínea e contração muscular. $O$ limite de ingestão diária tolerável para o cálcio é de $2.500 \mathrm{mg} / \mathrm{dia}$ (Dietary Reference Intakes for Calcium, 2001).

Cádmio: esse elemento pode gerar efeitos tóxicos ao organismo humano, mesmo em quantidades moderadas, atingindo órgãos vitais como rins, fígado e pulmões. A intoxicação por cádmio pode provocar danos no sistema ósseo, 
cânceres, dentre outros distúrbios. O limite de ingestão semanal tolerável provisório para este elemento é de $25 \mu \mathrm{g} / \mathrm{kg}$ peso corpóreo (Azevedo e Chasin, 2003).

Césio: pode ter uma forte ação biológica se administrado na dieta dos animais em quantidades equivalentes às do potássio. A sua ingestão pode causar hiper-irritabilidade, espasmos ou mesmo a morte.

Cloro: ativador de enzimas, regula o equilíbrio eletrolítico e ácido-base. Neutraliza as cargas positivas dos fluidos, os quais sempre devem ser neutros. É o ânion mais abundante (partícula negativamente carregada, $\mathrm{Cl}^{-}$) fora das células.

Cobalto: componente da vitamina B 12, uma das formadoras dos glóbulos vermelhos, também importante no desenvolvimento normal e funcional das células humanas (Golden, 2009).

Cobre: presente nos músculos, auxilia na regularização e na liberação de energia produzida pelo organismo, participa da produção de melanina e na formação de glóbulos vermelhos do sangue (Favier, 1991) A dose diária de ingestão de cobre recomendada para adultos é de 700 a $1300 \mu \mathrm{g} / \mathrm{dia}$ (Dietary Reference Intakes for Copper, 2001).

Cromo: tem como função auxiliar a insulina, hormônio produzido pelo pâncreas, a metabolizar o açúcar no corpo atuando na regularização da glicemia. $A$ dose diária de ingestão de cromo recomendada para adultos é de 1,00 a $35 \mathrm{mg} / \mathrm{dia}$ (Dietary Reference Intakes for Chromium, 2001).

Chumbo: é um dos mais perigosos entre os metais pesados, acometendo principalmente os sistemas nervosos central e periférico, medula óssea e rins. $O$ chumbo inibe a atividade de enzimas envolvidas na biossíntese da heme e diminui concentrações de eritropoietina sérica levando a anemia. O limite de ingestão semanal tolerável provisório para este elemento é de $25 \mu \mathrm{g} / \mathrm{kg}$ peso corpóreo (Azevedo e Chasin, 2003).

Ferro: presente na hemoglobina, auxilia o transporte de oxigênio sanguíneo. Uma deficiência de ferro pode acarretar anemia grave e anormalidades 
imunológicas, predispondo o organismo a infecções. $O$ excesso de ferro parece contribuir para carcinogênese. O limite máximo de ingestão diária deste nutriente que provavelmente não representa um risco a saúde é de 40 a $45 \mathrm{mg} / \mathrm{dia}$ (Dietary Reference Intakes for Iron, 2001).

Magnésio: auxilia o nucleotídeo ATP no armazenamento de energia necessária para muitas enzimas funcionarem apropriadamente nas células, este elemento também atua na formação de anticorpos e alívio do estresse. O limite máximo de ingestão diária de magnésio que provavelmente não representa risco a saúde de um adulto é de $350 \mathrm{mg} / \mathrm{dia}$ (Dietary Reference Intakes for Magnesium, 2001).

Manganês: serve como ativador essencial em uma série de reações metabólicas catalisadas por enzimas sendo muito importante para a reprodução e o crescimento, é também associado à formação de tecido conjuntivo e ósseo além de ajudar a expulsar os radicais livres que promovem o envelhecimento. A dose diária de ingestão de manganês recomendada para adultos é de 1,6 a 2,3 mg/dia (Dietary Reference Intakes for Manganese, 2001).

Mercúrio: considerado não essencial, não participa de nenhuma atividade indispensável ao funcionamento do organismo. Sua ausência não causa nenhuma anormalidade. Sua presença, por outro lado, age de forma devastadora. Uma vez absorvido, deposita-se em várias regiões do corpo, tais como cérebro, rins, aparelhos digestivo e reprodutivo, pulmões, rins, fígado, pâncreas e outros, causando graves distúrbios por vezes irreversíveis. A ingestão tolerável de mercúrio total é de $2 \mu \mathrm{g} / \mathrm{kg}$ de peso corporal peso por dia (WHO, 2011).

Niquel: com o auxílio de outros minerais, está envolvido em processos metabólicos que regulam a produção de energia e o bom funcionamento do corpo humano. No entanto as necessidades de ingestão de níquel nos seres humanos são muito pequenas: $5 \mu \mathrm{g} / \mathrm{dia}$ - ainda que o consumo estimado numa dieta normal seja de $150 \mu \mathrm{g} / \mathrm{dia}$ (Gjorgieva et al., 2012). 
Potássio: é um elemento essencial para os seres humanos, na forma do cátion $\left(\mathrm{K}^{+}\right)$. Associado ao sódio é importante na condução de impulsos nervosos e na contração e relaxamento muscular, para a secreção de insulina através do pâncreas e para a conservação do equilíbrio ácido/base. Em casos de carência, a falta de potássio pode causar problemas de ritmo cardíaco e debilidade muscular (Franco, 1998). O limite de ingestão adequado para adultos de potássio é de $4 \mathrm{~g} / \mathrm{dia}$ (Dietary Reference Intakes for Potassium, 2005).

Rubídio: existem evidências de certo grau de toxicidade do rubídio para os seres humanos. De acordo com experiências realizadas em animais, a inclusão do elemento na dieta, pode provocar sintomas de hiperirritabilidade neuromuscular e deficiências reprodutivas. Em casos extremos provoca espasmos musculares violentos ou mesmo a morte.

Selênio: possui grande capacidade antioxidante, ou seja, neutraliza a ação dos radicais livres no organismo, retardando o processo de envelhecimento e evitando o desencadeamento de algumas formas de câncer, auxilia na manutenção do corpo e no sistema de defesa contra infecção. A dose diária de ingestão recomendada para selênio em adultos é de 40 a $70 \mu \mathrm{g} /$ dia (Dietary Reference Intakes for Selenium, 2001).

Sódio: a importância desse mineral na nossa alimentação está associada às funções vitais no organismo humano, como a regulação do volume plasmático, regula a osmolaridade, $\mathrm{pH}$ e a condução dos impulsos nervosos e a contração muscular. A dose de ingestão diária tolerável de sódio é de 2,3 g/dia (Dietary Reference Intakes for Sodium, 2005).

Tório: os riscos do tório para a saúde humana podem ser classificados em radiológicos e químicos. Os perigos radiológicos do tório estão relacionados com a radioatividade dos seus isótopos, particularmente na cadeia de decaimento de tório 232 para chumbo 208. No corpo humano, os isótopos de tório tendem a concentrarse no fígado, nos rins, no baço e na medula óssea. 
Urânio: após a ingestão a maior parte deste elemento é excretada em poucos dias sem atingir a corrente sanguínea, uma pequena fração, no entanto, pode atingir a corrente sanguínea e depositar-se nos ossos ou nos rins. Além dos efeitos radiológicos, a ingestão de urânio também representa um risco devido à alta toxicidade de seus sais solúveis. O IDT estabelecido para o urânio e de 0,6 $\mu \mathrm{g} / \mathrm{kg}$ do peso corpóreo/dia (Committee On Toxicity Of Chemicals In Food, 2006).

Vanádio: é um dos principais combustíveis para o cérebro. Dentre outras funções já conhecidas pela ciência médica, o vanádio tem importante ação inibidora da síntese de colesterol, evitando a deposição de gorduras nas paredes das artérias, o que previne ataques cardíacos e isquemia cerebral (AVC). Dentro do nosso corpo, o vanádio é um componente mineral que tem a capacidade de "imitar" os fortes efeitos da insulina, um hormônio anabólico potente que atua no armazenamento dos nutrientes no músculo pós-exercícios, como a glicose, creatina e aminoácidos. O vanádio simula os efeitos da insulina provocando a condução da glicose e de vários aminoácidos para dentro da célula em um grau maior do que normalmente ocorreria sem a utilização deste oligoelemento. O limite de ingestão tolerável para homens e mulheres entre 19 e 70 anos é de $1,8 \mathrm{mg} / \mathrm{dia}$ (Dietary Reference Intakes for Vanadium, 2001).

Zinco: é um componente essencial de um grande número de enzimas e desempenha um papel central no crescimento celular e diferenciação de tecidos. Este elemento atua na reparação dos tecidos e na cicatrização de ferimentos, também participa na síntese e degradação de carboidratos, lipídeos, proteínas e ácidos nucleicos, além de estar presente na defesa imunológica (Hambidge, 2000). O limite máximo de ingestão diária, que provavelmente não representara risco a saúde em um adulto, para o zinco é de 8 a $13 \mathrm{mg} /$ dia e o limite diário tolerável e de $40 \mathrm{mg} / \mathrm{dia}$ (Dietary Reference Intakes for Zinc, 2001).

Diante do exposto, verifica-se necessidade de se estudar a composição elementar inorgânica das plantas medicinais tradicionalmente empregadas pela população. 


\section{OBJETIVOS}

Este estudo teve como objetivo geral, a determinação dos constituintes inorgânicos em plantas medicinais e seus extratos indicado para uso terapêutico regulamentado pela ANVISA na Resolução-RDC № 10, de 9 de março de 2010. Avaliando assim:

$\checkmark$ Características organolépticas;

$\checkmark$ Pesquisa de matéria estranha;

$\checkmark$ O teor de umidade;

$\checkmark$ Cinzas Totais;

$\checkmark$ Cinzas insolúveis em ácido.

Determinar nas plantas e seus extratos:

$\checkmark$ A concentração dos elementos As, Ba, Br, Ca, Cl, Cs, Co, Cr, Fe, Hf, K, $\mathrm{Mg}, \mathrm{Mn}, \mathrm{Na}, \mathrm{Rb}, \mathrm{Sb}, \mathrm{Sc}, \mathrm{Se}, \mathrm{Ta}, \mathrm{Th}, \mathrm{Ti}, \mathrm{U}, \mathrm{V}, \mathrm{Zn}$ e Zr pela técnica analítica Analise por Ativação Neutrônica Instrumental (INAA).

$\checkmark$ A concentração dos elementos $\mathrm{Cu}, \mathrm{Ni}, \mathrm{Pb}$ e $\mathrm{Cd}$ pela técnica de Espectrometria de Emissão Atômica com Fonte de Plasma Indutivamente Acoplado ICP-OES.

$\checkmark \quad$ A concentração do elemento $\mathrm{Hg}$ por Espectrometria de Absorção Atômica com Geração de Vapor Frio (CV AAS).

Os objetivos específicos foram:

$\checkmark$ Avaliar as técnicas analíticas empregadas para a determinação da concentração dos elementos traços nas amostras analisadas. 
$\checkmark$ Ampliar o conhecimento sobre as concentrações de elementos essências, benéficos e tóxicos em plantas medicinais, por serem amplamente utilizadas como medicina complementar, pela população.

$\checkmark$ Contribuir para a formação de um banco de dados sobre a composição inorgânica das espécies estudadas.

$\checkmark$ Contribuir para a recomendação destas plantas na introdução terapêutica e também como fonte mineral na dieta alimentar.

Ressalta-se que este estudo é inédito para a maioria das plantas analisadas bem como os elementos nele determinados. 


\section{PROCEDIMENTOS EXPERIMENTAIS}

\subsection{Descrições das amostras}

Para este estudo a princípio foram selecionadas 25 espécies de plantas medicinais escolhidas entre as mais utilizadas popularmente como instrumento de Assistência Farmacêutica, entre as 66 catalogadas para comercialização pela ANVISA.

As amostras das plantas foram adquiridas em farmácias especializadas, casas de produtos naturais e a amostra Cymbopogon citratus (capim santo) foi adquirida no mercado informal, ou seja, banca localizada em via pública. Na Tabela 3.1 são apresentadas as 24 espécies de plantas selecionadas, bem como, nome científico, nome popular e família, principais constituintes, forma de uso, partes utilizadas, posologia e indicação. Todas as amostras adquiridas estavam dentro do prazo de validade para consumo.

Das 25 amostras inicialmente selecionadas, a Lippia alba (falsa melissa), foi posteriormente excluída devido ao fato desta espécie não encontrar-se disponível no mercado varejista.

TABELA 3.1: Relação de plantas analisadas neste estudo, presentes na lista publicada pela ANVISA em sua Resolução - RDC № 10, de 9 de março de 2010, para comercialização com finalidade terapêutica.

\begin{tabular}{|c|c|c|}
\hline $\begin{array}{c}\text { Nome científico, Nome } \\
\text { popular, "Família" }\end{array}$ & $\begin{array}{l}\text { Constituintes e partes } \\
\text { utilizadas, forma de } \\
\text { preparo do extrato aquoso }\end{array}$ & Posologia e Indicação \\
\hline $\begin{array}{l}\text { Achyrocline satureioides } \\
\text { Macela } \\
\text { "Asteraceae" } \\
(1) ;(5)\end{array}$ & $\begin{array}{l}\text { Flavonoides, polifenóis, } \\
\text { cumarinas, oligoelementos, } \\
\text { lactonas. } \\
\text { Sumidades floridas. } \\
\text { Infusão: } 1,5 \mathrm{~g}(1 / 2 \mathrm{col} . \text { de } \\
\text { sopa }) \text { em } 150 \mathrm{ml} \text {. }\end{array}$ & $\begin{array}{l}\text { Utilizar } 1 \text { xíc. chá, } 4 \text { x } \\
\text { ao dia. } \\
\text { Má digestão, cólica } \\
\text { intestinal, como sedativo } \\
\text { leve, anti-inflamatório, } \\
\text { imunoestimulante e } \\
\text { antioxidante. }\end{array}$ \\
\hline
\end{tabular}


Continuação: Tabela 3.1

\begin{tabular}{|c|c|c|}
\hline $\begin{array}{l}\text { Bidens pilosa } \\
\text { Picão } \\
\text { "Asteraceae" } \\
\text { (3); (4); (8) }\end{array}$ & $\begin{array}{l}\text { Flavonoides e poliacetilenos. } \\
\text { Folhas. } \\
\text { Infusão: } 2 \mathrm{~g}(1 \mathrm{col} \text {. } \\
\text { sobremesa) em } 150 \mathrm{ml} \text {. }\end{array}$ & $\begin{array}{c}\text { Utilizar } 1 \text { xíc. chá, } 4 \text { x } \\
\text { ao dia. } \\
\text { Icterícia (coloração } \\
\text { amarelada de pele e } \\
\text { mucosas), hepatoprotetor, } \\
\text { estimula a produção } \\
\text { de insulina. }\end{array}$ \\
\hline $\begin{array}{l}\text { Calendula officinalis } \\
\text { Calêndula } \\
\text { "Asteraceae" } \\
\text { (1); (3); (6) }\end{array}$ & $\begin{array}{l}\text { Glicosídeos amargos e } \\
\text { flavonóides. } \\
\text { Flores. } \\
\text { Infusão: } 1-2 \text { g (1 a } 2 \text { col. } \\
\text { chá) em } 150 \mathrm{ml} .\end{array}$ & $\begin{array}{c}\text { Aplicar compressa na } \\
\text { região afetada } 3 \text { x ao dia. } \\
\text { Inflamações e lesões, } \\
\text { contusões e } \\
\text { queimaduras e em uso } \\
\text { interno, sudorífico, } \\
\text { diurético, depurativo do } \\
\text { sangue e } \\
\text { imunoestimulante. }\end{array}$ \\
\hline $\begin{array}{l}\text { Cymbopogon citratus } \\
\text { Capim santo } \\
\text { "Poaceae" } \\
(7) ;(8)\end{array}$ & $\begin{array}{l}\text { Triterpenos e flavonoides. } \\
\text { Folhas. } \\
\text { Infusão: } 1-3 \mathrm{~g} \text { (1 a } 3 \text { col. } \\
\text { chá) em } 150 \mathrm{ml} \text {. }\end{array}$ & $\begin{array}{c}\text { Utilizar } 1 \text { xíc. chá, de } 2 \text { a } 3 \\
\text { x ao dia. } \\
\text { Cólicas intestinais e } \\
\text { uterinas, quadros } \\
\text { leves de ansiedade e } \\
\text { insônia, como calmante. }\end{array}$ \\
\hline $\begin{array}{l}\text { Cynara scolymus } \\
\text { Alcachofra } \\
\text { "Asteraceae" } \\
\text { (3); (5); (8) }\end{array}$ & $\begin{array}{l}\text { Cinarina e flavonoides. } \\
\text { Folhas. } \\
\text { Infusão: } 2 \mathrm{~g}(1 \mathrm{col} . \\
\text { sobremesa) em } 150 \mathrm{ml} \text {. }\end{array}$ & $\begin{array}{c}\text { Utilizar } 1 \text { xíc. chá, } 3 \text { x } \\
\text { ao dia. } \\
\text { Dispepsia (distúrbios da } \\
\text { digestão), inchaços, } \\
\text { náuseas, hepatoprotetora, } \\
\text { dor de barriga e colesterol. }\end{array}$ \\
\hline $\begin{array}{c}\text { Eucalyptus globulus } \\
\text { Eucalipto } \\
\text { "Myrtaceae" } \\
\text { (1); (5); (8) }\end{array}$ & $\begin{array}{l}\text { Eucaliptina e quercetina } \\
\text { Folhas. } \\
\text { Infusão: } 2 \mathrm{~g}(1 \mathrm{col} \text {. } \\
\text { sobremesa) em } 150 \mathrm{ml} \text {. }\end{array}$ & $\begin{array}{c}\text { Fazer inalação de } 2 \text { a } \\
3 \times \text { ao dia. } \\
\text { Gripes e resfriados, } \\
\text { para desobstrução } \\
\text { das vias respiratórias, } \\
\text { como adjuvante no } \\
\text { tratamento de bronquite e } \\
\text { asma, tosse e resfriado. }\end{array}$ \\
\hline $\begin{array}{l}\text { Illicium verum } \\
\text { Anis estrelado } \\
\text { "Illiaceae" } \\
\text { (3); (7); (8) }\end{array}$ & $\begin{array}{l}\text { Anetol e ácido chiquímico. } \\
\text { Fruto. } \\
\text { Infusão: } 1,5 \mathrm{~g}\left(1 \frac{1}{2} \mathrm{col} \text {. de }\right. \\
\text { chá) em } 150 \mathrm{ml} .\end{array}$ & $\begin{array}{c}\text { Utilizar } 1 \text { xíc. de chá, 3-4 } \\
\text { x ao dia. } \\
\text { Bronquite, expectorante, } \\
\text { Digestivo, anti- } \\
\text { espasmódico e } \\
\text { espasmolítico. }\end{array}$ \\
\hline
\end{tabular}


Continuação: Tabela 3.1

\begin{tabular}{|c|c|c|}
\hline $\begin{array}{l}\text { Malva sylvestris } \\
\text { Malva } \\
\text { "Malvaceae" } \\
(4) ;(5)\end{array}$ & $\begin{array}{l}\text { Mucilagens vegetais, } \\
\text { taninos, flavonoides. } \\
\text { Folhas e flores. } \\
\text { Infusão: } 2 \text { g (1 col. } \\
\text { sobremesa) em } 150 \mathrm{ml} \text {. }\end{array}$ & $\begin{array}{c}\text { Utilizar } 1 \text { xíc. chá, } 4 \text { x ao } \\
\text { dia. } \\
\text { Afecções respiratórias } \\
\text { como expectorante, } \\
\text { tosse, dor de garganta, } \\
\text { afta, bronquite, } \\
\text { rouquidão, laringite. }\end{array}$ \\
\hline $\begin{array}{l}\text { Matricaria recutita } \\
\text { Camomila } \\
\text { "Asteraceae" } \\
(2) ;(5) ;(8)\end{array}$ & $\begin{array}{l}\text { Flavonoides, cumarinas e } \\
\text { taninos. } \\
\text { Flores. } \\
\text { Infusão: } 3 \mathrm{~g}(1 \mathrm{col} \text {. sopa) } \\
\text { em } 150 \mathrm{ml} .\end{array}$ & $\begin{array}{l}\text { Utilizar } 1 \text { xíc. chá, de } 3 \text { a } \\
4 \times \text { ao dia. Cólicas } \\
\text { intestinais, como calmante } \\
\text { em quadros leves de } \\
\text { ansiedade, espasmolítico, } \\
\text { antialérgico, } \\
\text { antibacteriano, antifúngico. }\end{array}$ \\
\hline $\begin{array}{c}\text { Melissa officinalis } \\
\text { Melissa } \\
\text { "Lamiaceae" } \\
\text { (1); (3); (8) }\end{array}$ & $\begin{array}{l}\text { Flavonoides. } \\
\text { Sumidades floridas. } \\
\text { Infusão: } 2 \text { a } 4 \mathrm{~g}(1-2 \mathrm{col} \text {. } \\
\text { sobremesa) em } 150 \mathrm{ml} \text {. }\end{array}$ & $\begin{array}{l}\text { Utilizar } 1 \text { xíc. chá, } 2 \text { a } 3 \text { x } \\
\text { ao dia. Em quadros leves } \\
\text { de ansiedade e insônia, } \\
\text { cólicas abdominais, } \\
\text { problemas digestivos, } \\
\text { azia e queimação } \\
\text { do estômago. }\end{array}$ \\
\hline $\begin{array}{c}\text { Mentha pulegium } \\
\text { Poejo } \\
\text { “Lamiaceae" } \\
(2) ;(3) ;(5)\end{array}$ & $\begin{array}{l}\text { Taninos e mentol. } \\
\text { Partes aéreas. } \\
\text { Infusão: } 1 \mathrm{~g}(1 \mathrm{col} \text {. } \\
\text { sobremesa) em } 150 \mathrm{ml} \text {. }\end{array}$ & $\begin{array}{c}\text { Utilizar } 1 \text { xíc. chá, } 2 \text { a } \\
3 \text { x ao dia durante ou após } \\
\text { as refeições. } \\
\text { Afecções respiratórias, } \\
\text { como expectorante, } \\
\text { estimulante do apetite, em } \\
\text { perturbações digestivas e } \\
\text { espasmos } \\
\text { gastrointestinais. }\end{array}$ \\
\hline $\begin{array}{c}\text { Mikania glomerata } \\
\text { Guaco } \\
\text { "Asteraceae" } \\
\text { (8) }\end{array}$ & $\begin{array}{c}\text { Taninos, saponinas, } \\
\text { cumarinas e guacosídeos. } \\
\text { Folhas. } \\
\text { Infusão: } 3 \mathrm{~g}(1 \mathrm{col} \text {. sopa) } \\
\text { em } 150 \mathrm{ml} .\end{array}$ & $\begin{array}{c}\text { Utilizar } 1 \text { xíc. chá, } 3 \text { x ao } \\
\text { dia. } \\
\text { Gripes e resfriados, } \\
\text { bronquites alérgicas e } \\
\text { infecciosas, como } \\
\text { expectorante } \\
\text { (broncodilatador) }\end{array}$ \\
\hline $\begin{array}{l}\text { Passiflora alata } \\
\text { Maracujá } \\
\text { "Passifloraceae" } \\
\text { (5) }\end{array}$ & $\begin{array}{c}\text { Flavonoides, alcaloides e } \\
\text { cumarinas. } \\
\text { Folhas. } \\
\text { Infusão: } 3 \mathrm{~g}(1 \mathrm{col} \text {. sopa) } \\
\text { em } 150 \mathrm{ml} \text {. }\end{array}$ & $\begin{array}{l}\text { Utilizar } 1 \text { xíc. chá, } 1 \text { a } \\
2 \text { x ao dia. Em quadros } \\
\text { leves de ansiedade e } \\
\text { insônia, como calmante } \\
\text { suave, irritabilidade e } \\
\text { estresse e para } \\
\text { hiperatividade infantil. }\end{array}$ \\
\hline
\end{tabular}


Continuação: Tabela 3.1

\begin{tabular}{|c|c|c|}
\hline $\begin{array}{l}\text { Peumus boldus } \\
\text { Boldo-do-chile } \\
\text { "Monimiaceae" } \\
\quad(7) ;(8)\end{array}$ & $\begin{array}{l}\text { Cineol, boldinas, taninos e } \\
\text { cumarinas. } \\
\text { Folhas. } \\
\text { Infusão: } 1 \text { a } 2 \text { g (1 a } 2 \text { col. } \\
\text { chá) em } 150 \text { ml. }\end{array}$ & $\begin{array}{c}\text { Utilizar } 1 \text { xíc. chá, } 2 \text { x ao } \\
\text { dia. } \\
\text { Dispepsia (distúrbios da } \\
\text { digestão), como colagogo } \\
\text { e colerético }\end{array}$ \\
\hline $\begin{array}{l}\text { Phyllanthus niruri } \\
\text { Quebra-pedra } \\
\text { "Eurforbiáceas" } \\
\text { (7) }\end{array}$ & $\begin{array}{l}\text { Flavonoides, taninos, } \\
\text { alcalóides e vitamina C. } \\
\text { Partes aéreas. } \\
\text { Infusão: } 3 \mathrm{~g}(1 \mathrm{col} \text {. sopa) } \\
\text { em } 150 \mathrm{ml} .\end{array}$ & $\begin{array}{l}\text { Utilizar } 1 \text { xíc. chá, de } 2 \text { a } \\
3 \times \text { ao dia. } \\
\text { auxiliar na eliminação } \\
\text { de cálculos renais, } \\
\text { analgésico, relaxante } \\
\text { muscular, diurético. }\end{array}$ \\
\hline $\begin{array}{l}\text { Psidium guajava } \\
\text { Goiabeira } \\
\text { "Myrtaceae" } \\
(3) ;(6)\end{array}$ & $\begin{array}{c}\text { Taninos, saponinas, resinas } \\
\text { e pectinas. } \\
\text { Folhas jovens. } \\
\text { Infusão: } 2 \mathrm{~g}(\mathrm{col} . \\
\text { sobremesa) em } 150 \mathrm{ml} \text {. }\end{array}$ & $\begin{array}{c}\text { Utilizar } 1 \text { cálice }(30 \mathrm{ml}) \\
\text { após a evacuação em no } \\
\text { máximo } 10 \text { x ao dia. } \\
\text { Diarréias não infecciosas, } \\
\text { constipação, afecção da } \\
\text { garganta, afta, estomatite } \\
\text { e gengivite. }\end{array}$ \\
\hline $\begin{array}{l}\text { Rosmarinus officinalis } \\
\text { Alecrim } \\
\text { "Lamiaceae" } \\
\text { (8) }\end{array}$ & $\begin{array}{c}\text { Ácido carnósico e taninos. } \\
\text { Folhas. } \\
\text { Infusão: } 3-6 \mathrm{~g}(1-2 \mathrm{col} \text {. } \\
\text { sopa) em } 150 \mathrm{ml} \text {. }\end{array}$ & $\begin{array}{c}\text { Utilizar de } 1 \text { a } 2 \text { xícaras } \\
\text { de chá aodia. } \\
\text { Dispepsia, distúrbios } \\
\text { digestivo, enxaqueca e dor } \\
\text { de cabeça. }\end{array}$ \\
\hline $\begin{array}{l}\text { Sambucus nigra } \\
\text { Sabugueiro } \\
\text { "Adoxaceae" } \\
\text { (1); (8) }\end{array}$ & $\begin{array}{l}\text { Flavonoides, glicosídeos e } \\
\text { taninos. } \\
\text { Flor. } \\
\text { Infusão: } 3 \mathrm{~g}(1 \mathrm{col} \text {. sopa }) \\
\text { em } 150 \mathrm{ml} \text {. }\end{array}$ & $\begin{array}{c}\text { Utilizar } 1 \text { xíc. de chá, } 2 \text { a } 3 \\
\text { x dia. } \\
\text { febre, tosse, gripe e } \\
\text { resfriado, dor de } \\
\text { garganta, algumas } \\
\text { infecções virais e rinite. }\end{array}$ \\
\hline $\begin{array}{l}\text { Solanum paniculatum } \\
\text { Jurubeba } \\
\text { "Solanaceae" } \\
(6) ;(8)\end{array}$ & $\begin{array}{l}\text { Alcaloides, saponinas, } \\
\text { ácidos orgânicos, } \\
\text { glicosídeos, mucilagens } \\
\text { vegetais } \\
\text { Planta inteira. } \\
\text { Infusão: } 1 \mathrm{~g} \text { (1 col. chá) } \\
\text { em } 150 \text { ml. }\end{array}$ & $\begin{array}{c}\text { Utilizar } 1 \text { xíc. chá, } 3 \text { a } \\
4 \text { x ao dia. } \\
\text { Dispepsia (distúrbios da } \\
\text { digestão), febre, doenças } \\
\text { do fígado, diabetes, } \\
\text { tumores do útero e } \\
\text { abdômen, anemias, } \\
\text { problemas de bexiga. }\end{array}$ \\
\hline
\end{tabular}


Continuação: Tabela 3.1

\begin{tabular}{|c|c|c|}
\hline $\begin{array}{c}\text { Aesculus } \\
\text { hippocastanum } \\
\text { Castanha-da-índia } \\
\text { "Hyppocastaniaceae" } \\
\text { (5); (7) }\end{array}$ & $\begin{array}{l}\text { Saponinas e flavonoides. } \\
\text { Sementes com casca. } \\
\text { Decocção: } 1,5 \mathrm{~g} \mathrm{(1/2} \mathrm{col.} \\
\text { sopa) em } 150 \mathrm{ml} .\end{array}$ & $\begin{array}{l}\text { Utilizar } 1 \text { xíc. chá, } 2 \text { x dia, } \\
\text { logo após as refeições. } \\
\text { Fragilidade capilar, } \\
\text { insuficiência venosa } \\
\text { (hemorróidas e varizes), } \\
\text { edemas e equimoses. }\end{array}$ \\
\hline $\begin{array}{l}\text { Cinnamomum verum } \\
\text { Canela } \\
\text { "Lauraceae" } \\
\text { (5) }\end{array}$ & $\begin{array}{l}\text { Derivados cinâmicos, } \\
\text { aldeído de zinco e } \\
\text { cumarinas. } \\
\text { Casca. } \\
\text { Decocção: } 0,5-2 \mathrm{~g} \mathrm{(1} \mathrm{a} 4 \\
\text { col. café) em } 150 \text { ml. }\end{array}$ & $\begin{array}{c}\text { Utilizar } 1 \text { xic. Chá, } 2 \text { a } \\
6 \text { x ao dia. } \\
\text { Falta de apetite, cólicas } \\
\text { leves, flatulência (gases) e } \\
\text { sensação de plenitude } \\
\text { gástrica e tonificante. }\end{array}$ \\
\hline $\begin{array}{c}\text { Stryphnodendrom } \\
\text { adstrigens } \\
\text { Barbatimão } \\
\text { "Fabaceae" } \\
(8)\end{array}$ & $\begin{array}{c}\text { Taninos, sacarose e } \\
\text { dextrose. } \\
\text { Casca } \\
\text { Decocção: } 3 \mathrm{~g} \text { (col. sopa) } \\
\text { em } 1 \text { L de água. }\end{array}$ & $\begin{array}{c}\text { Aplicar compressas no } \\
\text { local afetado } 2 \text { a } 3 \text { x ao } \\
\text { dia. Como cicatrizante e } \\
\text { anti-séptico tópico na pele } \\
\text { e mucosas bucal e genital, } \\
\text { gastrite, úlcera e dor de } \\
\text { garganta. }\end{array}$ \\
\hline $\begin{array}{l}\text { Zingiber officinale } \\
\text { Gengibre } \\
\text { "Zingiberaceae" } \\
(4) ;(8)\end{array}$ & $\begin{array}{c}\text { Gingeróis. } \\
\text { Rizoma. } \\
\text { Decocção: } 0,5 \text { - } 1 \mathrm{~g} \mathrm{(1} \mathrm{a} 2 \\
\text { col. de café) em } 150 \mathrm{ml} \text {. }\end{array}$ & $\begin{array}{c}\text { Utilizar } 1 \text { xíc. chá, } 2 \text { a } \\
4 \text { x ao dia. } \\
\text { Enjôo, náusea e vômito } \\
\text { da gravidez, movimento e } \\
\text { pós-operatório, dispepsias } \\
\text { em geral, tônico, } \\
\text { antiemético. }\end{array}$ \\
\hline $\begin{array}{l}\text { Paullinia cupana } \\
\text { Guaraná } \\
\text { "Sapindaceae" } \\
\text { (3); (7) }\end{array}$ & $\begin{array}{c}\text { Alcaloides purínicos: } \\
\text { cafeína, teobrominas, } \\
\text { teofilinas, taninos. } \\
\text { Sementes. } \\
0,5-2 \text { g do pó ( } 1 \text { a } 4 \text { col. } \\
\text { café). }\end{array}$ & $\begin{array}{l}\text { Utilizar puro ou diluído } \\
\text { em água. } \\
\text { Estimulante do sistema } \\
\text { nervoso central, para } \\
\text { fadiga, afrodisíaco, } \\
\text { antioxidante e perda } \\
\text { de peso. }\end{array}$ \\
\hline
\end{tabular}

Fontes: (1) Ernest; Thompson, 2001; (2) Langmea; Rampton, 2001; (3) Prasad et al., 2002; (4) Matos, 2000; (5) Simões et al., 1999;(6) Secretaria Municipal da Saúde, Fortaleza, 2002; (7) Czelusniak et al; 2012 e (8) Simionato et al., 2011 acesso em: 12/2013. 


\subsection{Pesquisa de materiais estranhos}

Segundo a Farmacopeia Brasileira IV (1988), matéria estranha pode ser caracterizada em três grupos: partes do organismo ou organismos dos quais a droga deriva, excetuados aqueles incluídos na definição e descrição da droga, acima do limite de tolerância especificado na monografia; quaisquer organismos, porções ou produtos de organismos além daqueles especificados na definição e descrição da droga, em sua respectiva monografia; e impurezas de natureza, minerais ou orgânicas, não inerentes à droga.

Devido ao aumento da demanda por produtos a base de plantas medicinais, em consequência do aumento do interesse do público por "terapias naturais", tornase necessário investigar como estes produtos estão sendo oferecidos aos consumidores, bem como verificar se os produtos comercializados atendem aos requisitos estabelecidos pela Farmacopeia Brasileira quanto ao teor de material estranho permitido.

As amostras obtidas foram analisadas com relação a sua pureza nos seguintes requisitos: avaliação de suas propriedades organolépticas (cor, odor, textura), avaliação de seu estado de conservação (presença de fungos e sinais de deterioração) e determinação de matéria estranha. Para realização destas análises as amostras foram integralmente retiradas das embalagens, pesadas e em seguida, espalhadas sobre uma superfície plana, branca e limpa. Para que está determinação pudesse ser realizada, os materiais estranhos à planta foram separados manualmente, com o auxílio de uma pinça revestida com filme de PVC (Figura 3.1). Posteriormente, todo material separado foi pesado. A avaliação do estado de conservação e coloração foi feita a olho nu.

O teor de Material estranho (ME), em porcentagem em relação à massa (\%, $\mathrm{m} / \mathrm{m}$ ), para cada espécie analisada foi calculado de acordo com as equações 3.1.

ME $=100 \times$ (massa total da amostra - massa da amostra após triagem)/ massa total da amostra 
Todas as análises posteriores foram feitas utilizando-se somente a parte da planta indicada para uso após a separação do material estranho quando existente.

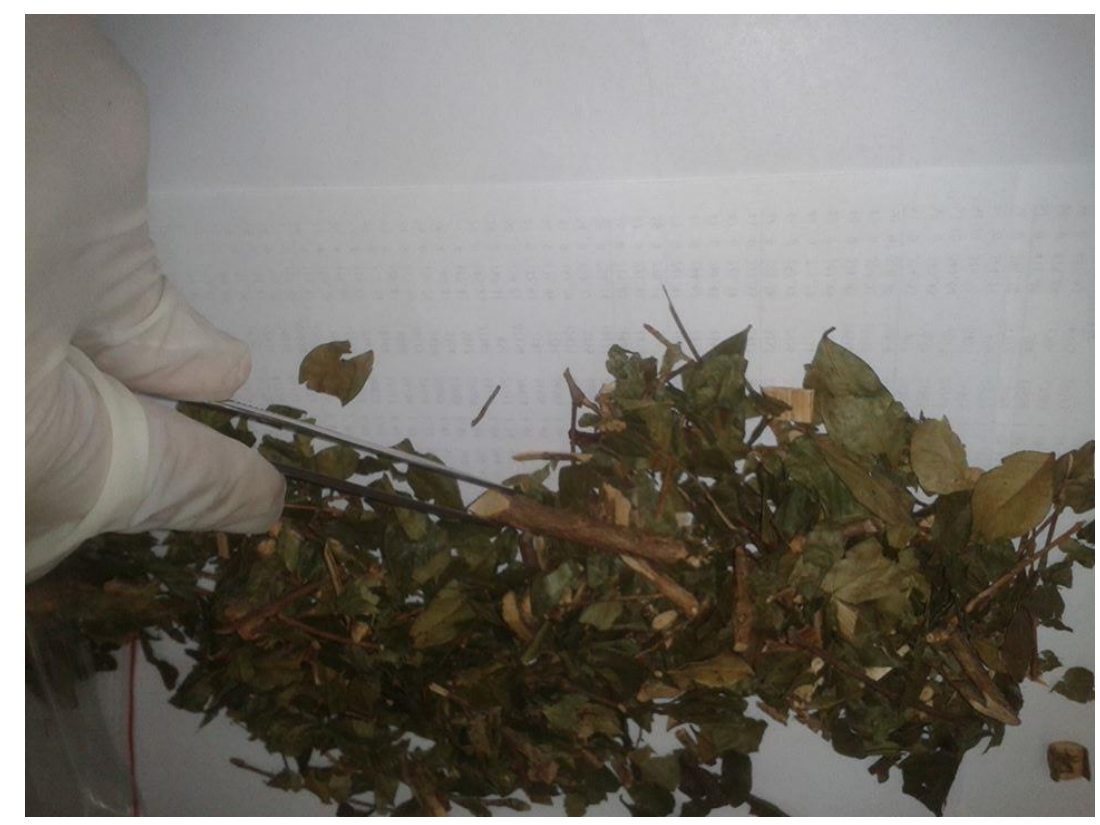

FIGURA 3.1: llustração do processo utilizada para determinação de materiais estranhos.

\subsection{Determinação dos constituintes inorgânicos}

\subsubsection{Determinação do teor de umidade}

Aproximadamente $5 \mathrm{~g}$ das partes indicadas para uso, de cada espécie de planta, foram colocados em estufa de secagem e esterilização, modelo 320-SE com "circulação de ar mecânica"- FANEN, a $40^{\circ} \mathrm{C}$ por um período de 24 horas para a eliminação da umidade. Em seguida as amostras foram resfriadas em temperatura ambiente em dessecador e pesadas, processo demonstrado na Figura 3.2. Esta operação foi repetida até a obtenção da massa constante em duas pesagens consecutivas.

O teor de umidade $(\mathbf{U})$ é expresso como porcentagem em relação às massas $(\%, \mathrm{~m} / \mathrm{m})$ da massa da planta seca em relação à massa inicial, e foi calculado utilizando-se a equação 3.2. 

$\mathbf{U} \%=$ (massa inicial - massa da amostra seca) /massa inicial da amostra $\times 100$

(Equação 3.2)

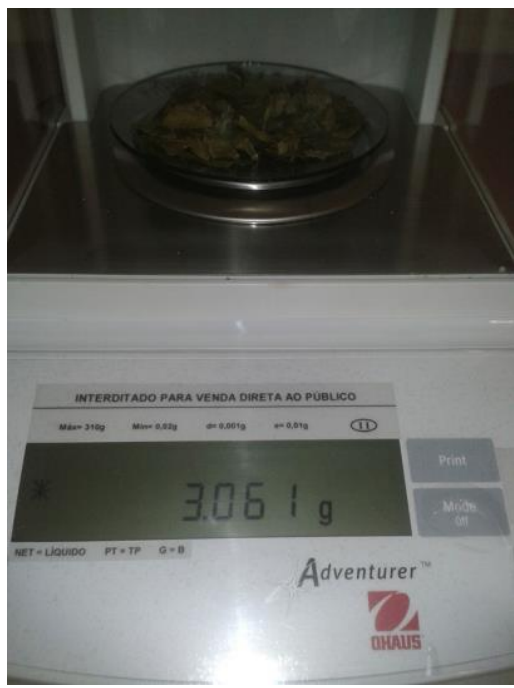

Etapa I

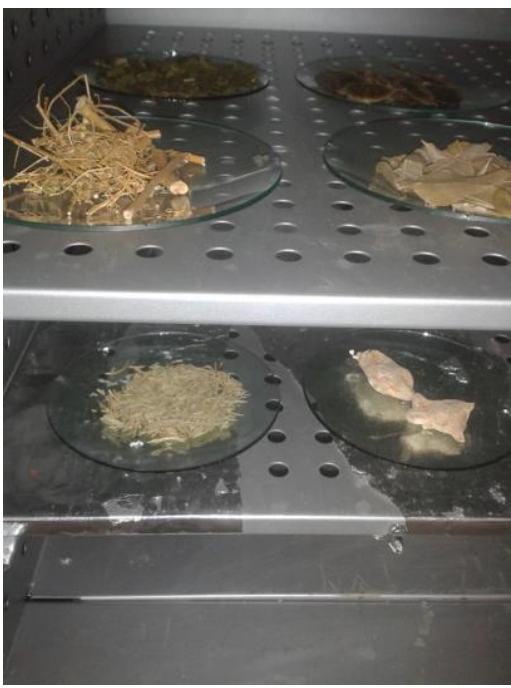

Etapa II

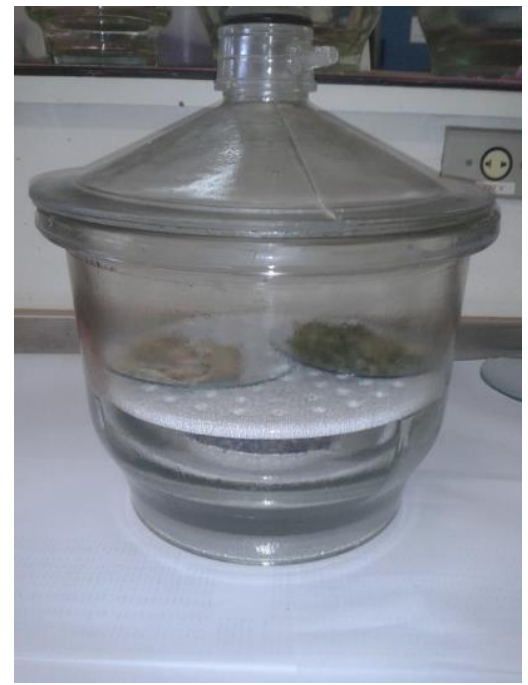

Etapa III

FIGURA 3.2: Ilustração do processo utilizado para determinação do teor de umidade: pesagem (etapa I), secagem (etapa II) e resfriamento da amostra (etapa III).

\subsubsection{Determinação do teor de cinzas totais}

A determinação do teor de cinzas auxilia na quantificação de impurezas inorgânicas não voláteis que podem estar presentes como contaminantes na amostra. A determinação da quantidade de cinzas totais é realizada por incineração e a metodologia baseia-se na determinação da massa dos resíduos não voláteis existentes na matéria-prima, que podem ser, além das cinzas das plantas, areia ou terra que estão ligados à droga vegetal.

As amostras de plantas secas na etapa anterior (teor de umidade) foram transferidapara cadinhos de porcelana previamente calcinados e foram precisamente pesadas. Em seguida, o material foi calcinado em mufla, modelo "Cobel", em temperatura de aproximadamente $1000^{\circ} \mathrm{C}$ por um período de $12 \mathrm{~h}$, 
como demonstrado na Figura 3.3. Após o resfriamento em temperatura ambiente com o auxilio do dessecador, os cadinhos foram pesados. O teor de cinzas totais (C) foi calculado expressando-se o resultado em porcentagem da massa da amostra calcinada em relação à massa inicial da amostra anterior a etapa de determinação do teor de umidade $(\%, \mathrm{~m} / \mathrm{m})$, através da equação.

C $\%=($ massa da amostra calcinada $\times 100) /$ massa inicial da amostra

(Equação 3.3)

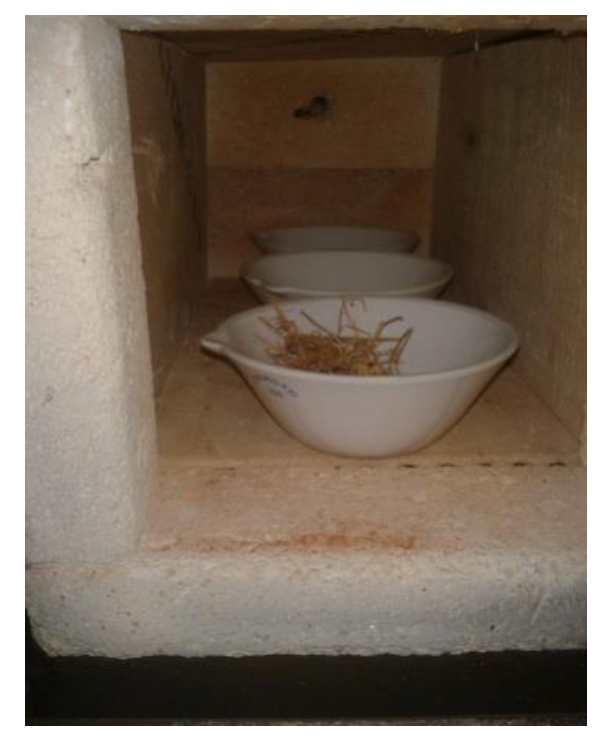

FIGURA 3.3: Ilustração da amostra na mufla para calcinação.

\subsubsection{Determinação do teor de cinzas insolúveis em ácido}

As cinzas insolúveis em ácido são os resíduos obtidos depois do processo de obtenção do teor de cinzas totais. A determinação de seu teor permite a verificação de contaminantes como resíduo de terra ou areia, geralmente observada em raízes (WHO, 1998). 
Para determinação do teor de cinzas insolúveis em ácido, o material obtido na etapa de determinação de cinzas totais foi tratado com ácido nítrico, filtrado e a fração não solúvel foi seca em temperatura ambiente e novamente pesada (Figura 3.4). O cálculo para determinação de cinzas insolúveis em ácidos (CIA) é expresso em porcentagem $(\% \mathrm{~m} / \mathrm{m})$ da massa do resíduo insolúvel em relação à massa inicial da amostra, anterior à etapa da determinação do teor de umidade, e foi feito através da equação 3.4 .

CIA \% = (massa do resíduo insolúvel em ácido x 100) /massa inicial da amostra

(Equação 3.4)

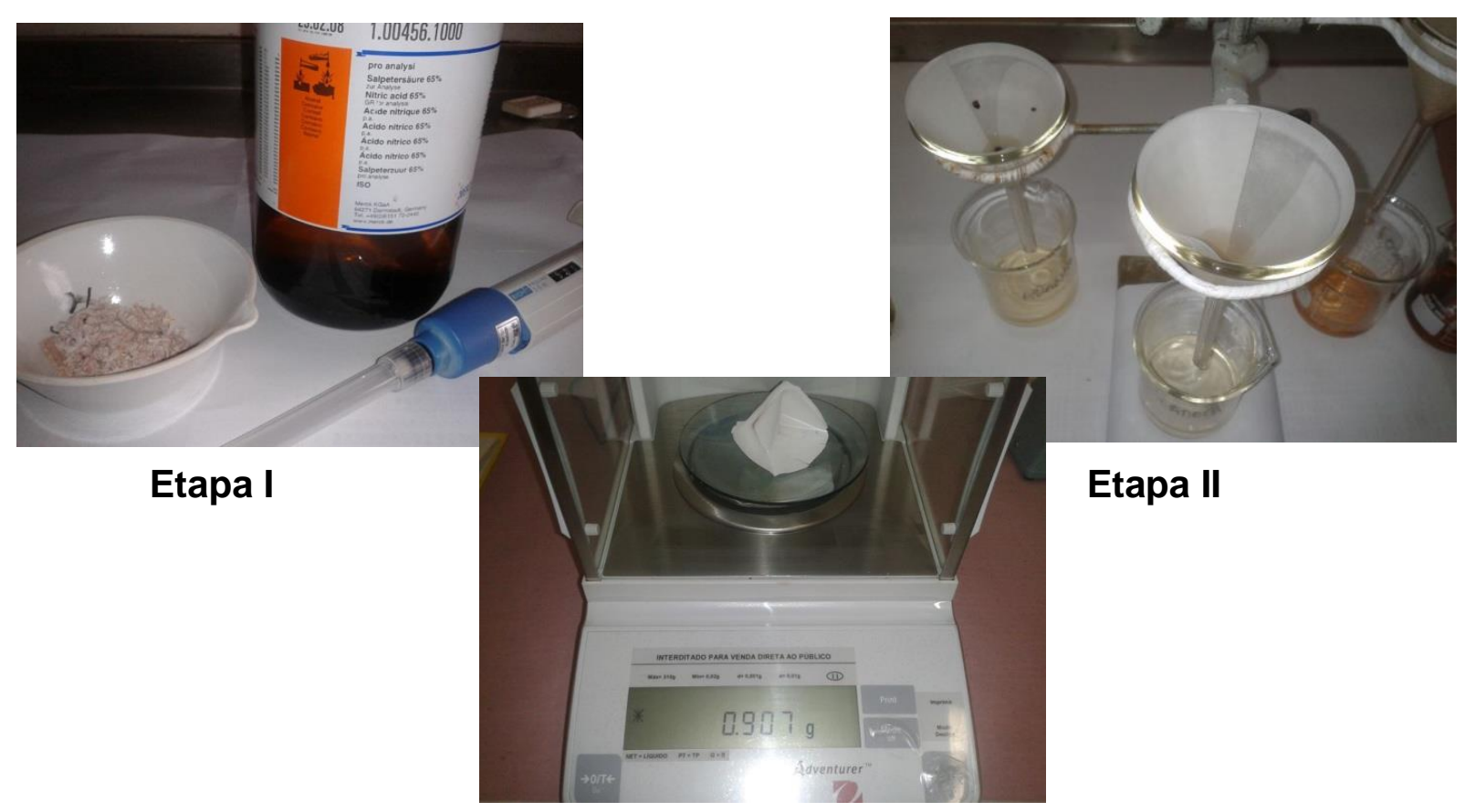

Etapa III

FIGURA 3.4: Ilustração das etapas utilizadas para determinação do teor de cinzas insolúveis em ácido: adição de $\mathrm{HNO}_{3}$ (etapa I), filtração (etapa II) e pesagem (etapa III).

\subsubsection{Análise por Ativação Neutrônica Instrumental (INAA)}

Esta técnica é baseada na medida de radiação característica de cada radionuclídeo formado, direta ou indiretamente, pela irradiação da amostra de interesse com nêutrons (Figura 3.5). Quando um nêutron interage com um núcleo- 
alvo por meio de colisões não-elásticas, um núcleo composto é formado em um estado excitado e a energia de excitação do núcleo composto é devida a energia de ligação do nêutron com o núcleo. O núcleo composto decairá quase que instantaneamente para uma configuração mais estável através da emissão de um ou mais raios gama característicos. Em muitos casos, essa nova configuração gera um núcleo radioativo, que também decai pela emissão de uma partícula carregada ( $\alpha, \beta$ ou $\beta^{+}$), seguido ou não por um ou mais raios gama atrasados característicos, mas a um ritmo mais lento, de acordo com a meia-vida única deste núcleo. Dependendo da espécie radioativa em particular, a meia-vida pode variar de frações de segundos até vários anos (Bostelmann, 2006; Glascock, 2010).

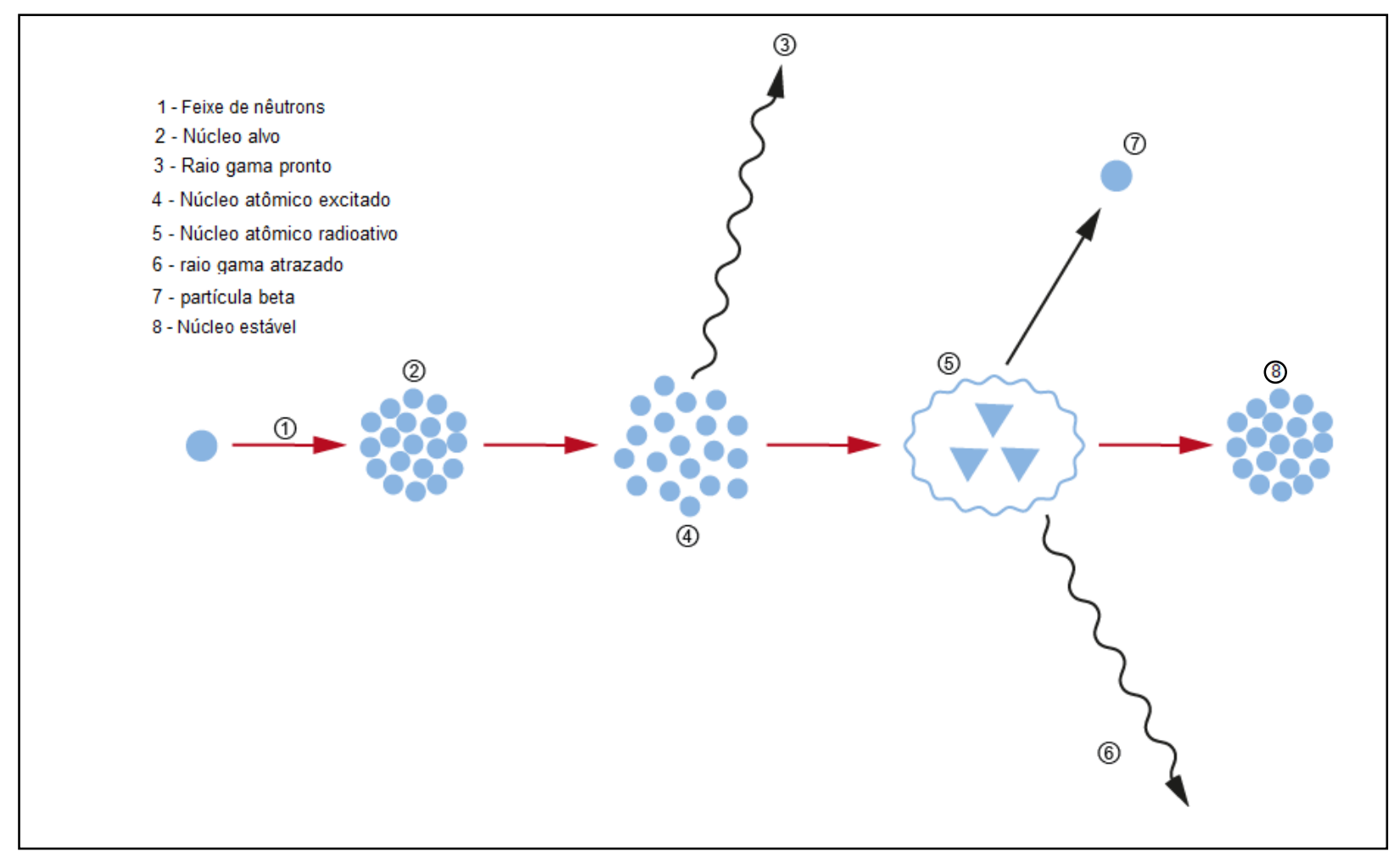

FIGURA 3.5: Processo esquemático da formação de um radionuclídeo artificial empregado na técnica de INAA.

Embora existam varias fontes de nêutrons (reatores, aceleradores e os radioisotópicos emissores de nêutrons), a mais adequada para análise por ativação são os reatores nucleares de pesquisa. Dentre os diferentes tipos de reatores 
nucleares existentes, e dependendo da posição no interior do reator e dos materiais utilizados para moderador de nêutrons de fissão primária, a distribuição de energia e o fluxo de nêutrons podem variar consideravelmente sendo bastante ampla e geralmente dividida em três componentes principais: nêutrons térmicos, epitérmicos e rápidos. A reação nuclear $(n, \gamma)$ é a mais comumente empregada devido à sua maior probabilidade de ocorrência, tanto com nêutrons térmicos como com nêutrons epitérmicos. Na Tabela 3.2 são apresentados os dados nucleares dos elementos determinados por INAA neste trabalho.

TABELA 3.2: Elementos determinados por ativação neutrônica, radioisótopos formados na ativação, energias dos raios gama utilizadas na espectrometria gama e suas respectivas meias-vidas.

\begin{tabular}{cccc}
\hline Elementos & Radioisótopo & $\mathrm{E}(\mathrm{keV})$ & Meia-Vida \\
\hline $\mathrm{As}$ & ${ }^{6} \mathrm{As}$ & 559 & 26,32 horas \\
$\mathrm{Ba}$ & ${ }^{131} \mathrm{Ba}$ & 496 & 11,8 dias \\
$\mathrm{Br}$ & ${ }^{82} \mathrm{Br}$ & $554 \mathrm{e} 776$ & 35,3 horas \\
$\mathrm{Ca}$ & ${ }^{47} \mathrm{Sc}$ & 158 & 3,35 dias \\
$\mathrm{Cl}$ & ${ }^{38} \mathrm{Cl}$ & 1642,7 & 37,24 minutos \\
$\mathrm{Co}$ & ${ }^{60} \mathrm{Co}$ & $1173 \mathrm{e} 1332$ & 5,27 anos \\
$\mathrm{Cr}$ & ${ }^{51} \mathrm{Cr}$ & 320 & 27,7 dias \\
$\mathrm{Cs}$ & ${ }^{134} \mathrm{Cs}$ & 795,8 & 2,06 anos \\
$\mathrm{Fe}$ & ${ }^{59} \mathrm{Fe}$ & $1099 \mathrm{e} 1291$ & 44,5 dias \\
$\mathrm{Hf}$ & ${ }^{181} \mathrm{Hf}$ & 482,1 & 42,39 dias \\
$\mathrm{K}$ & ${ }^{42} \mathrm{~K}$ & 1524,5 & 12,36 horas \\
$\mathrm{Mg}$ & ${ }^{27} \mathrm{Mg}$ & $844 \mathrm{e} 1014$ & 9,45 minutos \\
$\mathrm{Mn}$ & ${ }^{56} \mathrm{Mn}$ & $847 \mathrm{e} 1811$ & 2,58 horas \\
$\mathrm{Na}$ & ${ }^{24} \mathrm{Na}$ & 1368,6 & 14,96 horas \\
$\mathrm{Rb}$ & ${ }^{86} \mathrm{Rb}$ & 1076,6 & 18,66 dias \\
$\mathrm{Sb}$ & ${ }^{122} \mathrm{Sb}$ & 564 & 2,7 dias \\
$\mathrm{Sc}$ & ${ }^{47} \mathrm{Sc}$ & 889,2 & 83,81 dias \\
$\mathrm{Se}$ & ${ }^{75} \mathrm{Se}$ & 264,7 & 119,77 dias \\
$\mathrm{Ta}$ & ${ }^{182} \mathrm{Ta}$ & 1221 & 114,5 dias \\
$\mathrm{Ti}$ & ${ }^{50} \mathrm{Ti}$ & 320 & 5,76 minutos \\
$\mathrm{Th}$ & ${ }^{233} \mathrm{~Pa}$ & 312,01 & 27 dias \\
$\mathrm{U}$ & ${ }^{239} \mathrm{~Np}$ & $228,1 \mathrm{e} 277,6$ & 2,36 dias \\
$\mathrm{V}$ & ${ }^{51} \mathrm{~V}$ & 1434 & 3,74 minutos \\
$\mathrm{Zn}$ & ${ }^{65} \mathrm{Zn}$ & 1115,6 & 243,9 dias \\
$\mathrm{Zr}$ & ${ }^{95} \mathrm{Zr}$ & $724,2 \mathrm{e} 756,7$ & 64,02 dias \\
\hline
\end{tabular}

Nas últimas décadas, a análise por ativação neutrônica tem sido amplamente utilizada na determinação de elementos em níveis menores e traço em vários tipos de matrizes. Dentre suas aplicações, estão análises ambientais, estudos 
nutricionais, estudos relacionados à saúde, materiais geológicos e ciência dos materiais (IAEA, 2001).

Entre as principais características da técnica de INAA, podemos destacar:

$\checkmark$ Capacidade de determinação multielementar simultânea;

$\checkmark$ Alta sensibilidade, determinação em níveis de $\mu \mathrm{g} \mathrm{kg}^{-1}$ até concentrações elevadas (\%);

$\checkmark$ Boa exatidão e precisão;

$\checkmark$ Baixo limite de detecção para 30 a 40 elementos;

$\checkmark$ Técnica não destrutiva;

$\checkmark$ Pequena quantidade de amostra utilizada para a análise.

Entre as desvantagens da utilização desta técnica, podemos destacar:

$\checkmark$ Tempo longo de análise, comparado com as demais técnicas;

$\checkmark$ Manipulação de amostras irradiadas;

$\checkmark$ Geração de lixo radioativo;

$\checkmark$ Necessidade de um reator nuclear.

Para este estudo a quantificação das concentrações dos elementos $\mathrm{Ba}, \mathrm{Br}$, $\mathrm{Ca}, \mathrm{Co}, \mathrm{Cl}, \mathrm{Cr}, \mathrm{Hf}, \mathrm{Fe}, \mathrm{Mg}, \mathrm{Mn}, \mathrm{Na}, \mathrm{Rb}$, Sb, Sc, Se, Ta, Ti, Th, V, Zn e Zr presentes em extratos e plantas medicinais foi realizada por Análise por Ativação Neutrônica Instrumental sendo esta uma técnica comumente utilizada em estudos relacionados a plantas medicinais como, por exemplo, em Yamashita et al., (2005); Dim et al., (2004); Saiki et al., (2012) e Sussa et al., (2009).

Para que as concentrações dos elementos de interesse pudessem ser obtidas, utilizou-se o método INAA comparativo. Este método permite que as concentrações desconhecidas dos elementos de interesse na amostra sejam diretamente calculadas a partir das taxas de contagens da amostra e de um padrão 
de composição similar, conhecendo-se as massas dos mesmos (Bostelmann, 2006; Moreira, 2010).

A equação utilizada para calcular a concentração dos elementos presentes na amostra desconhecida em relação ao padrão de comparação, é apresentada na equação 3.5 .

$$
\mathbf{C}_{a i}=\frac{\left(A_{a i} m_{p} C_{p i}\right) e^{-\lambda(t a-t p)}}{A_{p i} m_{a}}
$$

(Equação 3.5)

onde:

$\mathbf{C}_{\mathrm{ai}}=$ concentração do elemento i na amostra $\left(\mu \mathrm{g} \mathrm{g}^{-1}\right.$ ou \%)

$\mathbf{C}_{\mathrm{pi}}=$ Concentração do elemento i no padrão ( $\mu \mathrm{g} \mathrm{g} \mathrm{g}^{-1}$ ou \%)

$\mathbf{A}_{\mathrm{ai}}=$ Atividade do elemento i na amostra (cps)

$A_{p i}=$ Atividade do elemento i no padrão (cps)

$\mathbf{m}_{\mathrm{a}} \mathbf{e} \mathbf{m}_{\mathrm{p}}=$ massas da amostra e do padrão, respectivamente $(\mathrm{g})$

$\lambda=$ Constante de decaimento do radioisótopo $\mathrm{i}\left(\mathrm{min}^{-1}\right)$

ta e tp = tempo de resfriamento da amostra e padrão, respectivamente (min)

Como padrões, foram utilizados neste trabalho, os materiais de referência certificados (MRCs) Rhyolite, Glass Mountain (RGM-2) e Syenite, Table Mountain (STM-2) do United States Geological Survey e também padrões sintéticos provenientes de soluções-padrão (SPEX CERTIPREP) com concentrações conhecidas dos elementos As, $\mathrm{Ba}, \mathrm{Br}, \mathrm{Ca}, \mathrm{Cs}, \mathrm{Co}, \mathrm{Cr}, \mathrm{Fe}, \mathrm{Hf}, \mathrm{K}, \mathrm{Na}, \mathrm{Rb}, \mathrm{Sb}$, Se, U e Zn pipetados em papel de filtro. Na Tabela 3.3 são apresentadas as concentrações 
(valor \pm incerteza) referentes aos materiais referência certificados (STM-2 e RGM- 2) e o do padrão pipetado utilizado neste trabalho.

Para os elementos $\mathrm{Cl}, \mathrm{Mn}$, Ti e $\mathrm{V}$ foram utilizados como padrões, neste trabalho, os materiais de referência certificados NIST SRM 1515 (Apple Leaves) e NIST SRM 1542 (Peach Leaves) e também padrões sintéticos provenientes de soluções-padrão (SPEX CERTIPREP) com concentrações conhecidas dos elementos mesmo elementos pipetados em papel de filtro. Na Tabela 3.4 são apresentadas as concentrações (valor \pm incerteza combinada) referentes aos materiais referência certificados (Apple Leaves e Peach Leaves) e o do padrão pipetado utilizado neste trabalho. A incerteza para as concentrações dos padrões pipetados foi obtida através do desvio padrão de 20 pesagens do volume a ser utilizado na preparação do padrão.

TABELA 3.3: Elementos presentes e suas concentrações (valor \pm incerteza) ou valor informativo, em $\mu \mathrm{g} \mathrm{g}^{-1}$, nos materiais de referência Rhyolite, Glass Mountain (RGM-2) e Syenite, Table Mountain (STM-2) e dos padrões pipetados (P.P), utilizados para INAA.

\begin{tabular}{|c|c|c|c|}
\hline Elementos & $\begin{array}{c}\text { Conc. } \mathbf{I} \text { Incert. } \\
\text { STM }\end{array}$ & $\begin{array}{c}\text { Conc. } \pm \text { Incert. } \\
\mathbf{R G M}\end{array}$ & $\begin{array}{c}\text { Conc. } \mathbf{\text { Incert}} \\
\mathbf{P . P}\end{array}$ \\
\hline $\mathbf{A s}$ & --- & $3,3 \pm 0,3$ & $19,90 \pm 0,28$ \\
$\mathbf{B a}$ & $639 \pm 61$ & $842 \pm 35$ & $500,8 \pm 0,2$ \\
$\mathbf{B r}$ & --- & --- & $49,83 \pm 0,21$ \\
$\mathbf{C a}$ & $7800 \pm 300$ & $8800 \pm 200$ & $995,9 \pm 1,4$ \\
$\mathbf{C o}$ & --- & $2 \pm 0,3$ & $19,1 \pm 1,4$ \\
$\mathbf{C r}$ & --- & 4 & $19,1 \pm 1,4$ \\
$\mathbf{C s}$ & $1,52 \pm 0,06$ & --- & $19,1 \pm 1,4$ \\
$\mathbf{F e}$ & $37700 \pm 900$ & $13000 \pm 300$ & $995,9 \pm 1,4$ \\
$\mathbf{H f}$ & $27 \pm 0,8$ & $6,0 \pm 0,6$ & $19,1 \pm 1,4$ \\
$\mathbf{N a}$ & $66100 \pm 3800$ & $30700 \pm 900$ & $512,6 \pm 2,1$ \\
$\mathbf{N d}$ & $81 \pm 4,8$ & $20 \pm 1$ & $4,094 \pm 0,006$ \\
$\mathbf{R b}$ & $114 \pm 11$ & $147 \pm 5$ & $50,8 \pm 0,2$ \\
$\mathbf{S b}$ & --- & 0,8 & $56,5 \pm 0,2$ \\
$\mathbf{S e}$ & --- & --- & $53,1 \pm 0,2$ \\
$\mathbf{T a}$ & $16 \pm 11$ & 1 & --- \\
$\mathbf{T h}$ & $27 \pm 5$ & $15 \pm 1$ & $4,094 \pm 0,006$ \\
$\mathbf{U}$ & 7,6 & $5,9 \pm 0,9$ & $9,973 \pm 0,044$ \\
$\mathbf{Z n}$ & $223 \pm 19$ & $33 \pm 2$ & --- \\
$\mathbf{Z r}$ & $1280 \pm 62$ & $222 \pm 17$ & --- \\
\hline
\end{tabular}

--- valor não informado. 
TABELA 3.4: Elementos presentes e suas concentrações (valor \pm incerteza combinada), em $\mu \mathrm{g} \mathrm{g}{ }^{-1}$, nos materiais de referência SRM 1515 (Apple Leaves), SRM 1542 (Peach Leaves) e dos padrões pipetados (P.P), utilizados para INAA.

\begin{tabular}{|c|c|c|c|}
\hline Elementos & $\begin{array}{c}\text { Conc. } \pm \text { Incert. } \\
\text { Apple Leaves }\end{array}$ & $\begin{array}{c}\text { Conc. } \pm \text { Incert. } \\
\text { Peach Leaves }\end{array}$ & $\begin{array}{c}\text { Conc. } \pm \text { Incert. } \\
\text { P.P }\end{array}$ \\
\hline $\mathbf{C l}$ & $579 \pm 23$ & $360 \pm 19$ & $708 \pm 2$ \\
$\mathbf{M g}$ & $2710 \pm 8$ & $4320 \pm 8$ & $500 \pm 2$ \\
$\mathbf{M n}$ & $54 \pm 3$ & $89 \pm 3$ & $5,00 \pm 0,02$ \\
$\mathbf{T i}$ & --- & --- & $250 \pm 2$ \\
$\mathbf{V}$ & $0,26 \pm 0,03$ & $0,37 \pm 0,03$ & $5,00 \pm 0,02$ \\
\hline
\end{tabular}

--- valor não informado.

\subsubsection{Preparação das amostras de plantas secas para irradiação}

A determinação das concentrações dos elementos nas plantas medicinais deste estudo foi realizada em amostras da planta seca bem como em seus extratos aquosos. O procedimento utilizado para a preparação das amostras de planta secas está descrito a seguir e ilustrado na Figura 3.6.

Depois de retiradas as impurezas, as amostras foram colocadas sobre uma folha de papel branca e limpa e retirou-se, por quarteamento, uma alíquota se aproximadamente $10 \mathrm{~g}$. Cada alíquota foi posta para secar em estufa FANEN, modelo $320-\mathrm{SE}$, a $40^{\circ} \mathrm{C}$ por períodos variando de 12 a 24 horas, dependendo de cada espécie. As amostras foram trituradas com auxílio de grau e pistilo de porcelana, para obtenção de um material fino e homogêneo, a uma granulometria de 100 mesh, utilizando-se peneiras de aço inoxidável com malha de nylon. Após a trituração, as amostras foram acondicionadas em pequenos invólucros de polietileno, previamente desmineralizados. Para cada espécie de planta medicinal, foram pesados cerca de $150 \mathrm{mg}$ com auxílio de balança analítica Shmadzu modelo AUW 220 D, e os involucros selados foram embalados em folhas de alumínio. 


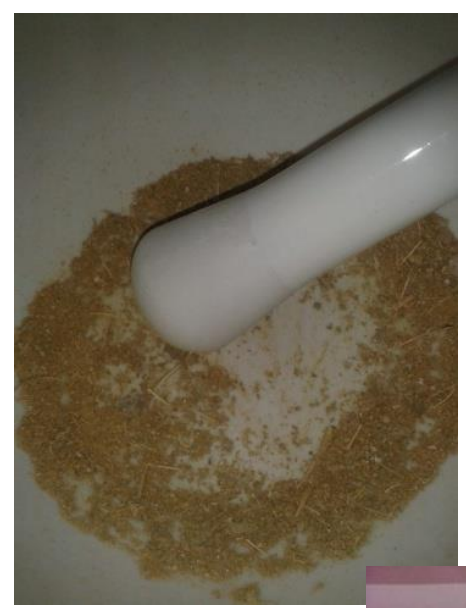

ETAPA I

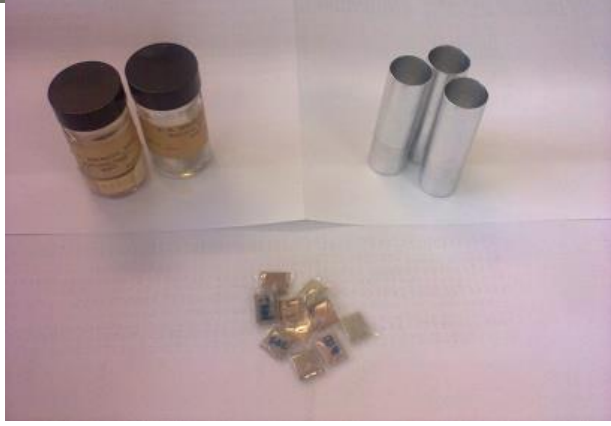

ETAPA III

FIGURA 3.6: Ilustração do processo de preparação das amostras de plantas para irradiação: processo de trituração (etapa I), peneiramento e homogeneização da amostra (etapa II) e acondicionamento da amostra em sacos de polietileno para irradiação (Etapa III).

Para irradiação dos materiais de referência foram pesados aproximadamente $100 \mathrm{mg}$. Tanto os MRCs quanto os padrões sintéticos pipetados foram acondicionados em invólucros de polietileno nas mesmas condições das amostras.

\subsubsection{Preparação das amostras de extratos para irradiação}

A preparação dos extratos foi realizada após a obtenção do chá que foram feitos em seguida ao processo de retirada de material estranho (antes da secagem em estufa), sendo adotados os procedimentos estabelecidos na Resolução-RDC № 10, de 9 de março de 2010 da ANVISA, quanto à massa de cada erva a ser usada, 0 volume de água e o processo de extração (decocção ou infusão).

$\mathrm{Na}$ preparação dos extratos das plantas macela, picão, calêndula, capim santo, alcachofra, eucalipto, malva, camomila, melissa, poejo, guaco, maracujá, 
boldo-do-chile, quebra-pedra, goiabeira, alecrim, sabugueiro e jurubeba o processo empregado para produção do extrato foi o de infusão (Figura 3.7), de acordo com o seguinte procedimento: aqueceu-se $150 \mathrm{~mL}$ de água ultrapura, sistema Milli- $\mathrm{Q}^{\circledR}$, em chapa aquecedora, da marca Marconi modelo 239 , a temperatura de $100^{\circ} \mathrm{C}$, por aproximadamente 10 minutos. Após este período, a amostra da planta, previamente pesada conforme determinação da ANVISA foi colocada na água fervente por três minutos. Em seguida retirou-se o béquer da chapa, abafou-se com vidro de relógio e aguardou-se o resfriamento por um período de 30 minutos.

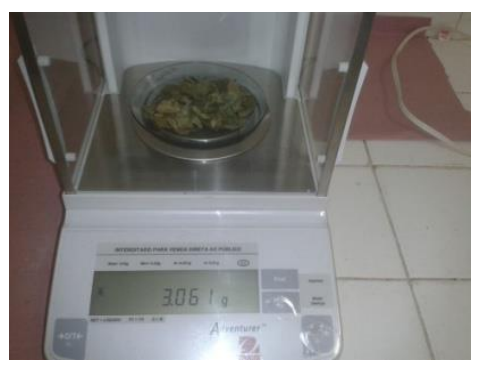

ETAPA I

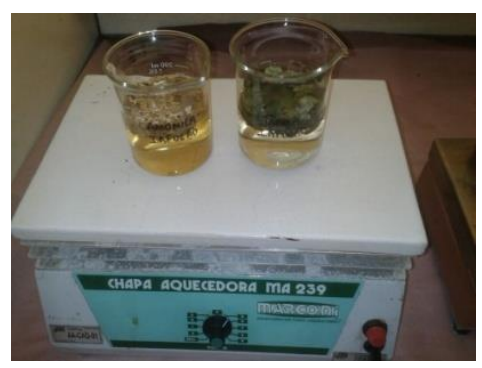

ETAPA IV

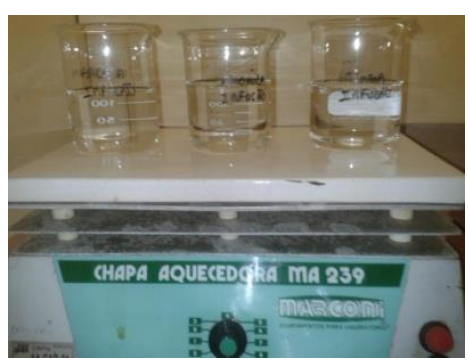

ETAPA II

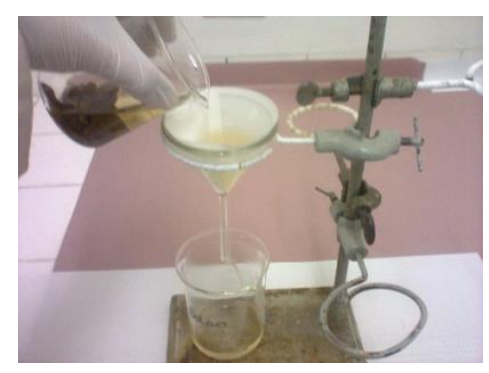

ETAPA V

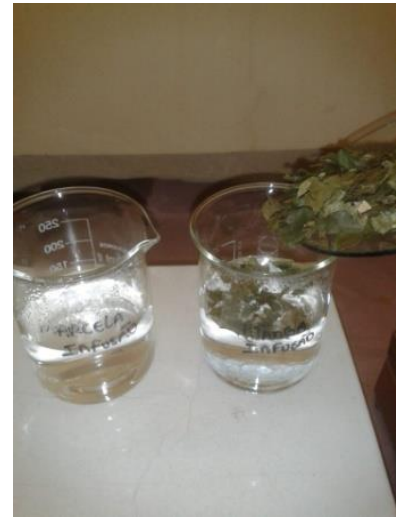

ETAPA III

FIGURA 3.7: Ilustração do processo para obtenção dos extratos por INFUSÃO: (etapa I) pesagem da amostra, (etapa II) aquecimento da água, (etapa III) introdução da amostra em água fervente, (etapa IV) resfriamento e (etapa V) filtração do extrato final.

Para as plantas canela, gengibre e barbatimão, os extratos foram preparados utilizando-se o processo de decocção de acordo com o seguinte procedimento: as amostras das plantas previamente pesadas foram colocadas em um béquer contendo $150 \mathrm{~mL}$ de água ultrapura (exceto para amostra barbatimão cuja decocção foi feita utilizando-se 1 litro de água), sistema Milli- $Q^{\circledR}$, ainda fria (Figura 3.8). A mistura foi levada à ebulição, em chapa aquecedora. Três minutos após início da 
ebulição, retirou-se o béquer da chapa aquecedora, abafou-se por 30 minutos e em seguida a mistura foi deixada para resfriar.

As soluções dos extratos obtidas por infusão e decocção foram filtradas com auxílio de funil de vidro e papel de filtro Millipore. Tanto o béquer quanto o papel de filtro foram lavados sucessivamente com água Milli- $Q^{\circledR}$ para garantir que toda a solução fosse transferida para o novo recipiente. A solução resultante desta filtração foi levada à chapa aquecedora e deixada para evaporar até a quase secura em temperatura de $40^{\circ} \mathrm{C}$. O material precipitado durante o processo de evaporação dos extratos foi tratado com $5 \mathrm{~mL}$ de ácido nítrico $\left(\mathrm{HNO}_{3}\right)$ e $2 \mathrm{~mL}$ de água oxigenada $\left(\mathrm{H}_{2} \mathrm{O}_{2}\right)$ repetidas vezes até a sua completa dissolução.

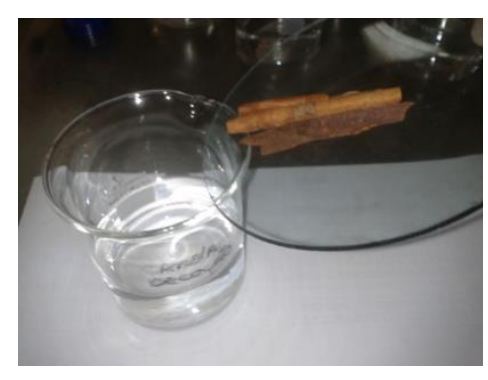

ETAPA I

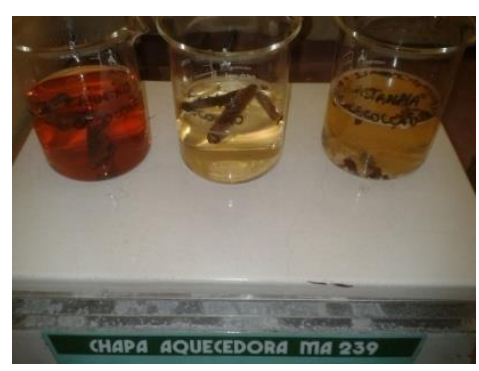

ETAPA III

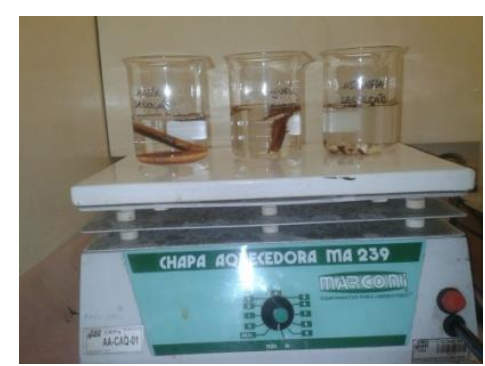

ETAPAII

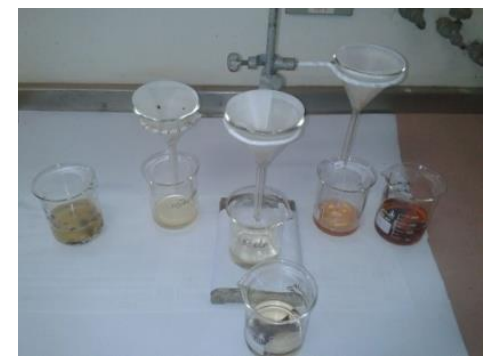

ETAPA IV

FIGURA 3.8: Ilustração do processo para obtenção dos extratos por DECOCÇÂO: (etapa I) acréscimo da amostra em água fria, (etapa II) aquecimento da água com a amostra, (etapa III) resfriamento e (etapa IV) filtração do extrato final.

A solução final contendo aproximadamente $1 \mathrm{~mL}$ foi transferida para papel de filtro com auxílio de micropipeta e deixada para secar em temperatura ambiente 
(Figura 3.9). Após a secagem do papel, este foi cuidadosamente dobrado e embalado em sacos plásticos de polietileno e papel alumínio.

Os materiais de referência certificados e os padrões sintéticos para irradiação foram preparados conforme descrito no item 3.3.4.1.

Para verificar a possível interferência do papel de filtro e dos reagentes na determinação da concentração dos elementos presentes em amostra, estes foram analisados em duplicatas. O branco desta medida constituio do papel Millipore, água e reagentes utilizados na produção dos extratos. Verificou-se que as concentrações do branco foram insignificantes em relação às obtidas nas amostras de plantas medicinais.

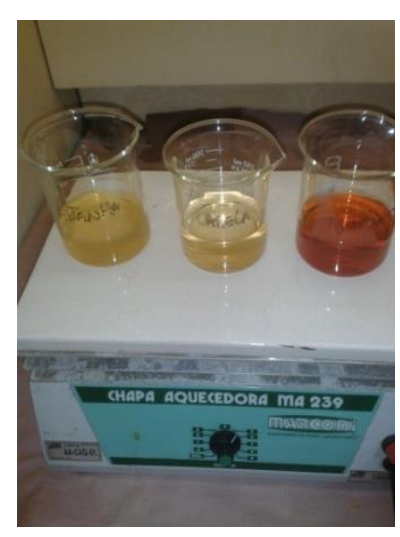

ETAPA I

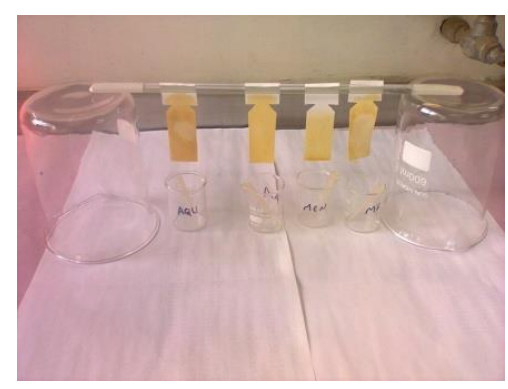

ETAPA III

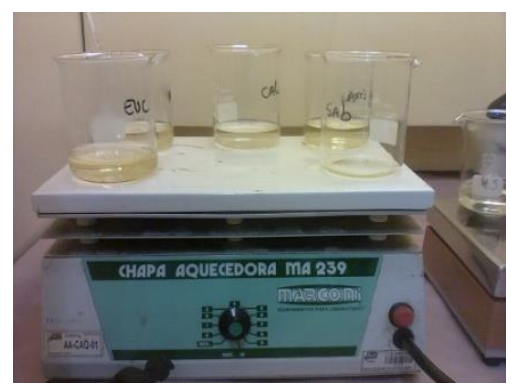

ETAPA II

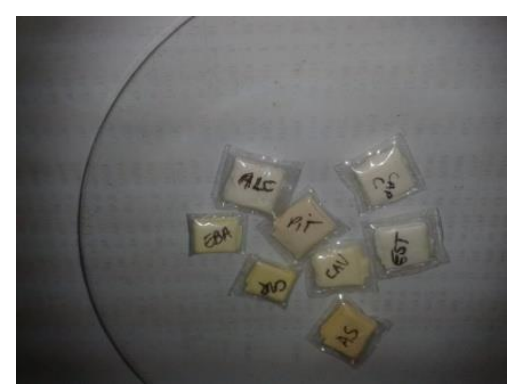

ETAPA IV

FIGURA 3.9: Ilustração do processo de preparação dos extratos para irradiação: (etapa I) secagem da amostra em chapa aquecedora, (etapa II) evaporação até quase secura da amostra, (etapa III) transferência da solução final para papel de filtro e (etapa IV) acondicionamento da amostra em sacos de polietileno. 


\subsubsection{Irradiação e contagem das amostras}

Amostras secas e seus extratos, materiais de referência e os padrões sintéticos, foram irradiados no reator nuclear IEA-R1 do IPEN/CNEN-SP a um fluxo de nêutrons térmicos de 1 a $5 \times 10^{12} \mathrm{n} \mathrm{cm}^{-2} \mathrm{~s}^{-1}$. Foram realizadas duas séries de irradiação de acordo com o tempo de decaimento de cada radionuclídeo de interesse formado na amostra, chamadas de irradiação longa e irradiação curta.

A irradiação longa é empregada para determinação das concentrações dos radionuclídeos de meia-vida longa e intermediária. Para esta irradiação, as amostras, os materiais de referência e os padrões sintéticos, foram acondicionados em recipientes de alumínio, denominado "coelhos", completamente vedados que são posicionados próximos ao núcleo de reator e expostos ao fluxo de nêutrons especificado por um período de oito horas.

Nesta irradiação são realizadas, normalmente, duas séries de contagem. A primeira foi feita após sete dias de decaimento, para determinação dos elementos As, $\mathrm{Br}, \mathrm{K}, \mathrm{Na}, \mathrm{Sb}$ e U. A segunda, foi feita após 15 dias de decaimento para determinação dos elementos $\mathrm{Ba}, \mathrm{Ca}$, $\mathrm{Co}, \mathrm{Cr}$, Cs, Fe, Hf, Rb, Sb, Sc, Se, Th, Zn e Zr. A contagem da atividade gama induzida nas amostras, dos materiais de referência e dos padrões sintéticos foram feitas utilizando um detector de GeHiperpuro, EG\&G Ortec e equipamentos eletrônicos associados, com resolução de 0,88 keV e 2,09 keV para os picos de $122 \mathrm{keV}$ e $1332 \mathrm{keV}$ do ${ }^{57} \mathrm{Co}$ e ${ }^{60} \mathrm{Co}$, respectivamente. A análise dos espectros foi feita utilizando-se o programa VISPECT2 e os cálculos foram feitos em planilha eletrônica. O tempo de contagem para as amostras foi de 1 hora, para os materiais de referência 30 minutos, e de 15 minutos para os padrões pipetados sintéticos.

A irradiação curta foi empregada para determinar os radionuclídeos de meiasvidas curtas (da ordem de alguns segundos a poucas horas) e neste trabalho foi utilizado na determinação dos elementos $\mathrm{Cl}, \mathrm{Mn}, \mathrm{Mg}$, Ti e V. Para sua realização, as amostras, os materiais de referência e os padrões sintéticos pipetados, foram acondicionados em tubos de polietileno (coelhos) completamente vedados e irradiados por 20 segundos sob fluxo da ordem de $10^{12} \mathrm{n} \mathrm{cm}^{2} \mathrm{~s}^{-1}$. O tempo de 
resfriamento na irradiação curta variou de 2 a 20 minutos. As contagens foram feitas durante 3 minutos para as amostras e 2 minutos para os materiais de referência e para os padrões sintéticos utilizando um detector de Ge-hiperpuro EG\&G Ortec e equipamentos eletrônicos associados, com uma resolução de 1,23 keV e 2,15 keV para os picos de $122 \mathrm{keV}$ e $1332 \mathrm{keV}$ do ${ }^{57} \mathrm{Co}$ e do ${ }^{60} \mathrm{Co}$, respectivamente (Figura 3.10). A análise dos espectros foi feita utilizando-se o programa VISPECT2 e os cálculos feitos em planilha eletrônica.

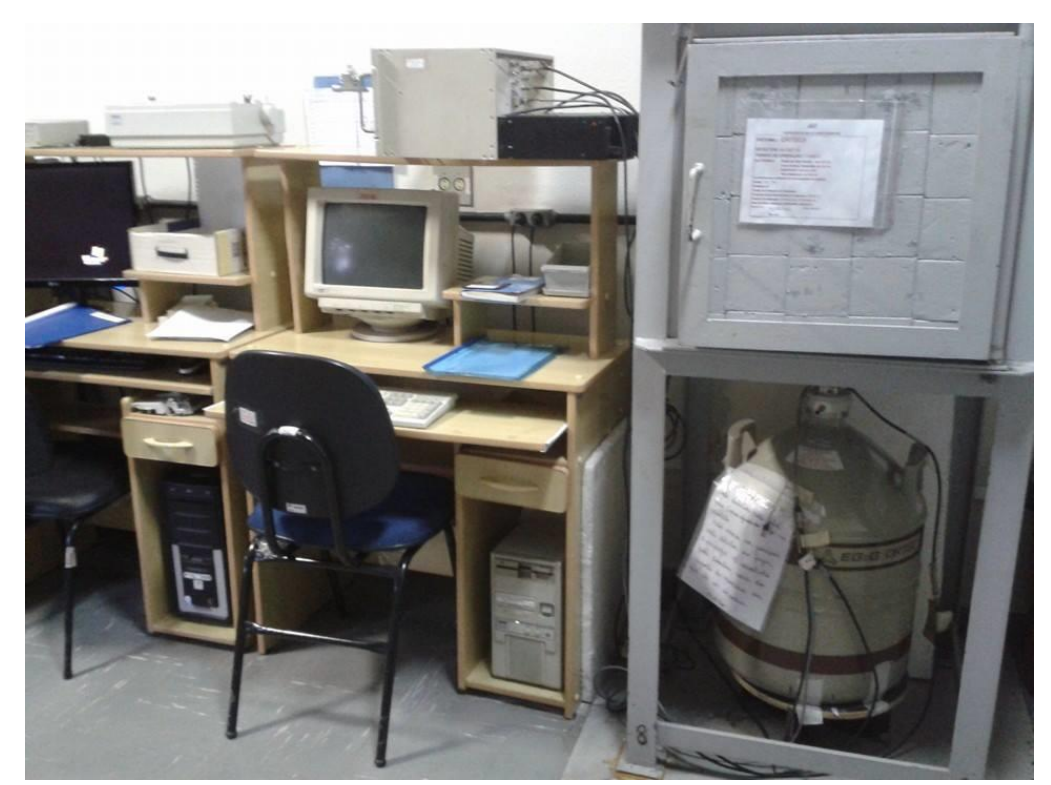

FIGURA 3.10: Ilustração do sistema com Detector de Germânio Hiperpuro do Laboratório de Analise por Ativação Neutrônica.

\subsubsection{Espectrometria de Absorção Atômica (AAS)}

Espectrometria por absorção atômica (AAS) consiste na interação da radiação ultravioleta e/ou radiação visível com a matéria. Nestas interações as espécies absorvedoras são átomos livres ou os seus íons e as únicas transições que ocorrem são aquelas entre os níveis atômicos de energia (Skoog et al., 1998; Guimarães, 2011).

Quando um átomo se encontra em seu estado fundamental, ou seja, seus elétrons estão nos orbitais mais próximos ao núcleo, onde o nível de energia envolvido é menor, e a este átomo for adicionada energia, como resultado de 
absorção de radiação eletromagnética ou de uma colisão com outro tipo de partícula (elétron, átomo, íon ou molécula), um dos prováveis eventos que pode ocorrer é esta energia ser utilizada para aumentar a energia do átomo, deixando-o em seu estado excitado e promover um elétron a um orbital com maior nível energético. Ao ocorrer a saída do elétron de um nível de maior energia para um nível menos energético, o átomo libera um fóton com comprimento de onda específico, cuja energia é exatamente a mesma que pode ser absorvida pelo átomo em estado livre (Correia et al., 2003).

Atualmente, a Espectrometria de Absorção Atômica é amplamente utilizada em laboratórios de pesquisas, sendo empregada na determinação de diversos elementos em diferentes áreas como analises clinicas e ambientais. Na área farmacêutica, além do auxílio no processo de determinação de contaminação por elementos metálicos, esta técnica também é muito empregada na determinação de diversos nutrientes presentes em plantas medicinais como citados nos estudos feitos por Almeida et al., (2002); Lopes et al., (1998); Schwanz et al., (2007).

Um espectrofotômetro típico é constituído pelos seguintes componentes: uma fonte de radiação que emite as linhas espectrais características do elemento de interesse; um atomizador onde ocorre a separação dos átomos da amostra a ser analisada por dissociação molecular térmica; um monocromador e/ou grade de difração onde ocorre a dispersão da radiação em vários comprimentos de onda até o isolamento do comprimento de onda de interesse; uma célula fotomultiplicadora que tem a função de converter os fótons em sinais elétricos e um detector (Correia et al., 2003).

A grande vantagem desta técnica está na sensibilidade. Em geral, os níveis de detecção atingem concentrações inferiores a $0,1 \mu \mathrm{g} \mathrm{L}^{-1}$.

A Espectrometria por Absorção Atômica pode ser dividida em: Absorção Atômica com Chama (FAAS), Absorção Atômica com Forno de Grafite (GF AAS) e Absorção Atômica com Geração de Vapor Frio (CV AAS). 


\subsubsection{Espectrometria de Absorção Atômica com Geração de Vapor Frio (CV} AAS)

A determinação do mercúrio total $(\mathrm{Hg})$ nas amostras de plantas medicinais e seus extratos obtidos a partir dos processos de decocção e de infusão, neste estudo, foi realizada através da Espectrometria de Absorção Atômica com Geração de Vapor Frio, CV AAS (Cold Vapor Atomic Absorption Spectrometry), por se tratar de um elemento metálico com alta pressão de vapor a temperaturas relativamente baixas (Skoog et al., 1998).

Este método promove a vaporização fria do mercúrio presente na amostra, seguida pela medida de absorção atômica. Para liberar o mercúrio de uma solução aquosa, $\mathrm{O} \mathrm{Hg}^{+2}$ é convertido, por tratamento da amostra com misturas oxidantes como, por exemplo, acido nítrico $\left(\mathrm{HNO}_{3}\right)$ e acido sulfúrico $\left(\mathrm{H}_{2} \mathrm{SO}_{4}\right)$, seguida pela sua redução a $\mathrm{Hg}^{0}$ pela reação química com o $\mathrm{SnCl}_{2}$, conforme mostrado na equação 3.6.

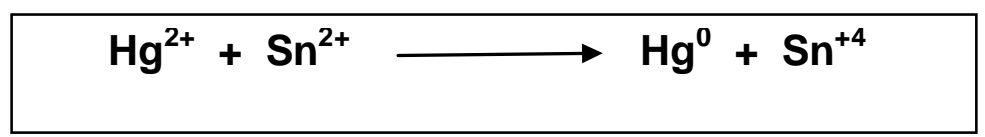

(Equação 3.6)

A redução é feita em sistema fechado, usando argônio ou nitrogênio, como gás de arraste, borbulhado na solução. Os átomos de mercúrio metálico são transportados pelo gás de arraste para um tubo (ou cela) de absorção, que é colocado no percurso óptico do espectrômetro de absorção atômica, onde é realizada a medida de absorção a $253,7 \mathrm{~nm}$. A quantidade de energia absorvida é proporcional à quantidade do elemento de interesse na amostra. A quantificação do metal se dá com a comparação do sinal obtido na leitura da amostra, com a curva analítica. (Skool et al., 1998; Beaty e Kerber, 1993; Vasconcelos et al., 2000). 


\subsubsection{Procedimento experimental para as analise de $\mathrm{Hg}$ por espectrometria de absorção atômica com geração de vapor frio (CV AAS)}

Para a determinação da concentração de $\mathrm{Hg}$ pela técnica de absorção atômica por geração de vapor frio (CV AAS) as amostras necessitam de digestão prévia. Optou-se pela digestão assistida por microondas, por sua eficiência, rapidez e baixa contaminação (Figura. 3.11).

Para esta analises, as amostras de plantas secas e homogeneizadas foram transferidas para frascos de $\operatorname{Teflon}^{\circledR}$ e aproximadamente $300 \mathrm{mg}$, para cada espécie de planta, foram pesados com o auxilio de balança semianalítica, OHAUS modelo Adventurer I. Adicionou-se, em seguida, $10 \mathrm{~mL}$ de $\mathrm{HNO}_{3}, 1 \mathrm{~mL}$ de $\mathrm{HCl}, 2 \mathrm{~mL}$ de $\mathrm{H}_{2} \mathrm{O}_{2}$ e $0,5 \mathrm{~mL}$ de $\mathrm{HClO}_{4}$ para digestão total da amostra, que foi feita em sistema fechado, com monitoramento de temperatura nos frascos, em forno de micro-ondas modelo MARS 5 da CEM. O programa de digestão utilizado foi feito em duas fases: na primeira empregou-se uma potência de $300 \mathrm{~W}$ a $100 \%$, durante 5 minutos, para elevar a temperatura da amostra à $80^{\circ} \mathrm{C}$ e em seguida, permanecer neste valor por 55 minutos. Na segunda fase empregou-se uma potência de $300 \mathrm{~W}$ a $100 \%$, durante 5 minutos para elevar a temperatura à $100^{\circ} \mathrm{C}$ e em seguida permanecer neste valor por mais 55 minutos. Após a digestão e resfriamento dos tubos, as amostras e os materiais de referencia foram filtrados em papel de filtro Vetec (filtração media), com auxilio de funil de vidro, diretamente em balão volumétrico de $50 \mathrm{~mL}$ e o volume dos balões foi completado com água ultrapura Milli- $Q^{\circledR}$. 


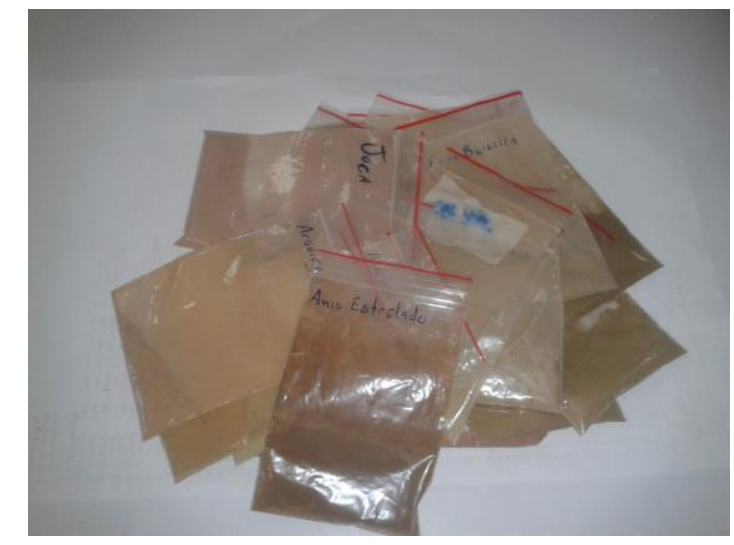

ETAPA I

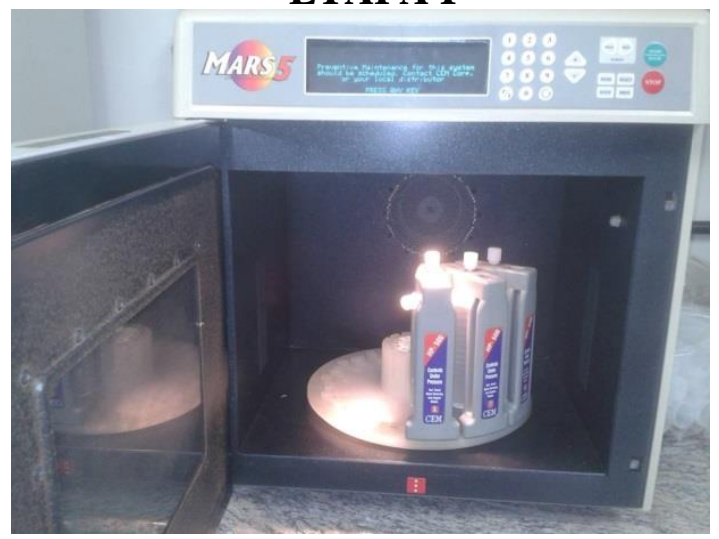

ETAPA III

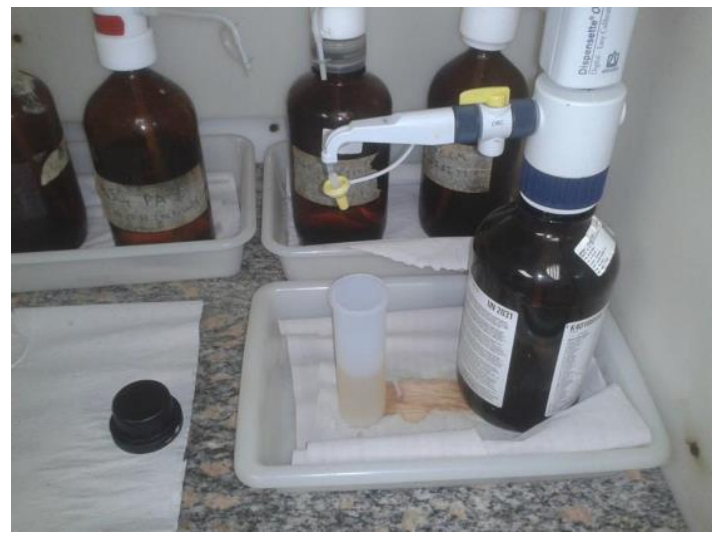

ETAPA II

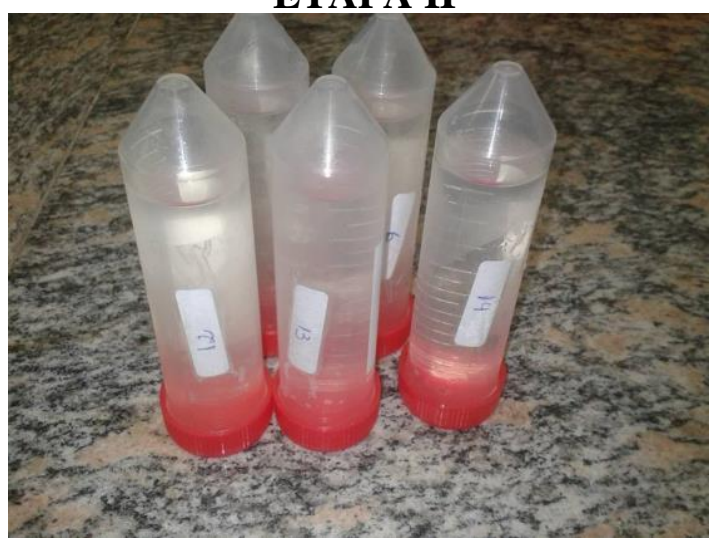

ETAPA IV

FIGURA 3.11: Ilustração do processo de digestão da amostra seca para analise no CV AAS e ICP OES: (etapa I) amostra triturada e homogeneizada, (etapa II) pesagem e tratamento com ácidos em frasco de teflon, (etapa III) digestão em micro-ondas e (etapa IV) acondicionamento e armazenamento em tubos plásticos.

Os extratos das plantas medicinais foram obtidos como descrito no item 3.3.4.2, evaporados e avolumados em balão volumétrico de $50 \mathrm{~mL}$.

As amostras e os materiais de referência foram analisados no equipamento de CV AAS, marca Perkin Elmer, modelo FIMS 100 (Flow Injection Mercury System) no laboratório de Absorção Atomica do LAN/IPEN-SP (Figura 3.12). 


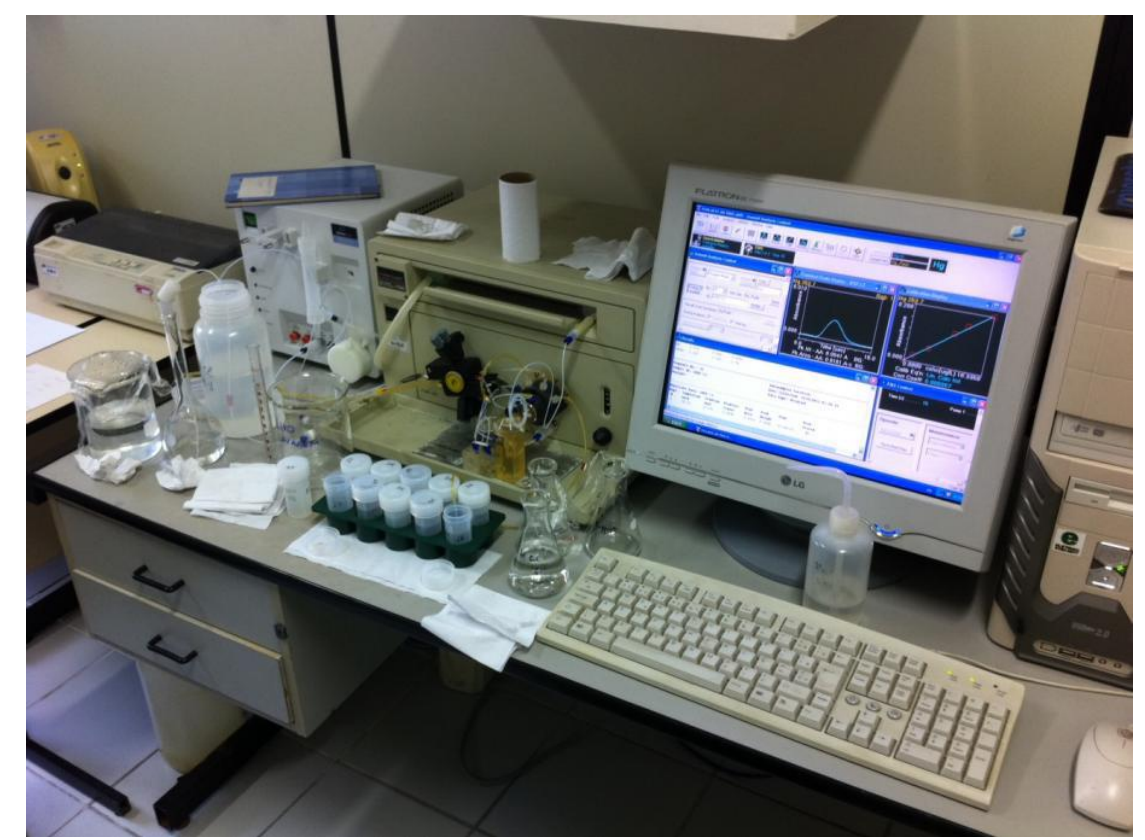

FIGURA 3.12: Equipamento de CV AAS do Laboratório de Absorção Atômica do LAN/IPEN-SP marca Perkin Elmer, modelo FIMS 100 (Flow Injection Mercury System) para determinação de Hg.

\subsubsection{Determinação da curva de calibração e verificação da metodologia para CV AAS}

Antes de dar início aos procedimentos para determinação de $\mathrm{Hg}$ nas amostras, procedeu-se a verificação dos parâmetros de ajuste do equipamento: ajuste da vazão de $\mathrm{SnCl}_{2} 1,1 \%(\mathrm{~m} / \mathrm{v})$ para 4 a $6 \mathrm{~mL} \mathrm{~min}^{-1}$; ajuste da vazão de $\mathrm{HCl}$ $3 \%$ (v/v) para 9 a $11 \mathrm{~mL} \mathrm{~min}^{-1}$; leitura da solução teste de $\mathrm{Hg}\left(10,07 \mathrm{ng} \mathrm{mL}{ }^{-1}\right)$ e calibração do equipamento com solução padrão de mercúrio para construção da curva de calibração de modo a obter os valores de interceptação da curva, inclinação e coeficiente de correlação.

As soluções para a construção da curva analítica - digeridas juntamente com as amostras - e a solução teste $\left(10,07 \mathrm{ng} \mathrm{mL}^{-1}\right)$ foram preparadas a partir de uma solução padrão de mercúrio $\left(1157,93 \pm 0,01 \mathrm{ng} \mathrm{mL}^{-1}\right)$ que foram pipetadas com pipetador automático e diluídas, em balões volumétricos calibrados, com água do Milli-Q ${ }^{\circledR}$. 
A solução de $\mathrm{SnCl}_{2} 1,1 \%(\mathrm{~m} / \mathrm{v})$ foi utilizada para promover a redução do mercúrio iônico a mercúrio metálico, conforme mostrado na Equação 1 e a solução $\mathrm{HCl} 3 \%(\mathrm{v} / \mathrm{v})$ foi utilizada como carregador no sistema de injeção em fluxo. Em seguida, procedeu-se à leitura das soluções padrão e do branco para construção da curva analítica, utilizando-se o programa Winlab 32 for AAS versão 6.2.0.0079 (Perkim Elmer). Após a construção da curva de calibração iniciou-se a leitura das amostras das plantas, dos extratos e dos materiais de referência. $O$ sinal analítico foi determinado a partir da área do pico de absorção e utilizou-se o modo de regressão linear para o ajuste da curva.

Na Figura 3.13 é apresentada a curva de calibração obtida a partir das soluções padrão, a equação da reta e o coeficiente de correlação.

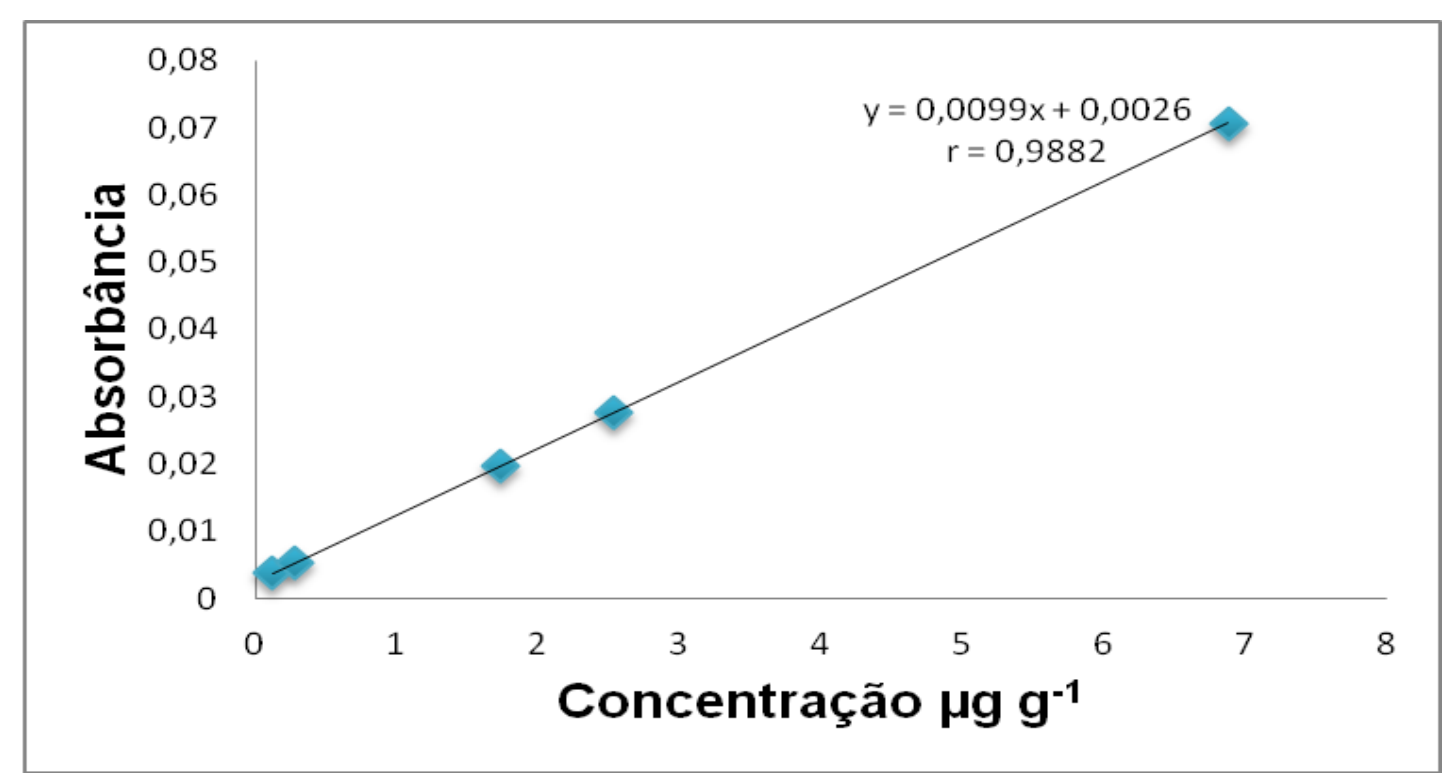

FIGURA 3.13: Curva de calibração para Hg obtida por CV AAS.

Obteve-se um valor do coeficiente de correlação linear $r=0,9882$. A reta foi considerada como sendo de um modelo matemático adequado para esse estudo, na qual o sinal do equipamento é diretamente proporcional à concentração do analito quantificado. 


\subsubsection{Espectrometria de Emissão Óptica com Fonte de Plasma Indutivamente Acoplado (ICP-OES)}

Esta técnica possui a capacidade para ser empregada a uma grande variedade de aplicações, não somente devido ao grande número de elementos que podem ser determinados rapidamente em níveis traço, mas também devido à grande diversidade de matrizes que podem ser analisadas.

A técnica de Espectrometria Emissão Óptica com Plasma Indutivamente Acoplado (ICP-OES) utiliza um plasma como fonte de atomização e excitação. $O$ plasma é um gás altamente ionizado, porém eletricamente neutro, que consiste de íons, elétrons e átomos. A energia que mantém um plasma analítico é derivada de um campo elétrico ou magnético, e não uma "chama". Vários plasmas operam com argônio puro ou hélio, nos quais uma combustão é impossível. Os plasmas são caracterizados por suas temperaturas, bem como suas densidades eletrônicas e iônicas. A temperatura usualmente encontrada em plasmas de instrumentos analíticos varia de 600 a $8.000 \mathrm{~K}$, podendo chegar a até $10.000 \mathrm{~K}$ (Manning e Grow, 1997).

Na técnica de espectrometria de emissão ótica, a amostra é submetida a uma temperatura suficiente para causar não só a dissociação dos átomos, mas também para causar significativa quantidade de excitação por colisão (e ionização) dos átomos da amostra. Uma vez que os átomos ou íons estão em seus estados excitados, eles podem decair para estados energéticos mais baixos, através da radiação ou transições de energia. A intensidade da luz emitida em comprimentos de onda específicos é utilizada para determinar as concentrações dos elementos de interesse (Boss e Fredeen, 1997).

As etapas básicas da análise por ICP-OES consistem, resumidamente, em:

$\checkmark$ preparação das amostras - algumas amostras requerem etapas especiais de preparação, incluindo tratamento com ácidos, aquecimento e digestão por micro-ondas;

$\checkmark$ nebulização - nesta etapa a solução contendo a amostra é convertida em aerossol. A maioria das amostras são nebulizadas na forma de aerossol que 
consiste em uma névoa fina de gotículas que são então levadas ao centro do plasma, pelo fluxo de argônio;

$\checkmark$ dessolvatação/volatilização - nesta etapa o solvente é evaporado e as porções remanescentes de líquidos e sólidos são convertidas em gases;

$\checkmark$ atomização - a fase gasosa é quebrada e ficam disponíveis apenas os átomos. A temperatura do plasma e o ambiente quimicamente inerte são fundamentais neste estágio;

$\checkmark$ excitação/emissão: os átomos ganham energia devido à colisões e emitem luz com comprimentos de onda característicos para cada elemento químico.

$\checkmark$ separação/detecção: a luz separada pela grade de difração é quantitativamente mensurada (Manning et al., 1997).

No ICP-OES, a luz emitida pelos átomos e íons excitados no plasma, é medida para obter informações sobre as amostras. Devido às espécies excitadas no plasma emitirem luz em diversos comprimentos de onda, a emissão do plasma é dita como policromática. Esta radiação policromática pode ser separada em comprimentos de onda individuais, para que a emissão de cada espécie excitada seja identificada e a intensidade seja medida sem interferências de emissões de outros comprimentos de onda. A separação da luz de acordo com cada comprimento de onda geralmente é feita utilizando um monocromador, que é utilizado para medir a radiação de cada elemento individualmente, um a um. No caso de realizar a medida de vários comprimentos de onda de elementos diferentes em uma única vez, é utilizado um policromador (Boss e Fredeen, 1997).

Além de ser capaz de determinar um grande número de elementos em uma ampla faixa de concentrações, uma grande vantagem da técnica de ICP-OES é que muitos elementos podem ser determinados facilmente em uma mesma corrida analítica. Esta capacidade multielementar decorre do fato de que todos os sinais de emissão necessários para obter informações qualitativas e quantitativas são emitidos a partir do plasma, ao mesmo tempo. 
A precisão e exatidão das análises ICP-OES são consideradas suficientes para análises elementares em níveis traço. Mesmo na presença de interferências, modernas técnicas de compensação de sinal são utilizadas para realizar análises com notável precisão (geralmente menor de 1\%) (Boss e Fredeen, 1997).

\subsubsection{Calibração e verificação do equipamento de ICP-OES}

O equipamento utilizado neste estudo foi um Espectrômetro de Emissão Óptica com Plasma Indutivamente Acoplado (ICP-OES) da marca Varian, modelo MPX 710ES com tocha geradora de plasma de argônio e configuração radial; células fotomultiplicadoras, amostrador automático equipado com bomba peristáltica para inserção da amostra no equipamento e câmara de nebulização para condução da amostra até a tocha.

Foi feita a calibração antes de cada conjunto de medidas, separada por séries de leitura de modo a minimizar qualquer interferência química ou espectral. $\mathrm{Na}$ Tabela 3.5 são apresentadas as linhas de emissão para os elementos determinados e faixas de concentração utilizadas para a obtenção das condições de operação do equipamento.

TABELA 3.5: Elementos determinados pela técnica ICP-OES, linhas de emissão e faixa de concentração utilizada para construção da curva de calibração.

\begin{tabular}{|c|c|c|}
\hline Elemento & Linha de Emissão $(\mathbf{n m})$ & Faixa de Trabalho $\left(\mathbf{m g ~}_{\mathbf{~ g g}} \mathbf{- 1}\right)$ \\
\hline $\mathbf{C d}$ & 226,502 & $0,0025-5$ \\
$\mathbf{P b}$ & 220,531 & $0,05-10$ \\
$\mathrm{Cu}$ & 324,754 & $0,00125-2,5$ \\
$\mathrm{Ni}$ & 231,604 & $0,025-5$ \\
\hline
\end{tabular}

Para a calibração do equipamento, foram construídas curvas analíticas usando soluções padrão por diluição de soluções certificadas. As curvas de calibração obtidas são apresentadas nas Figuras 3.14, 3.15, 3.16 e 3.17. 


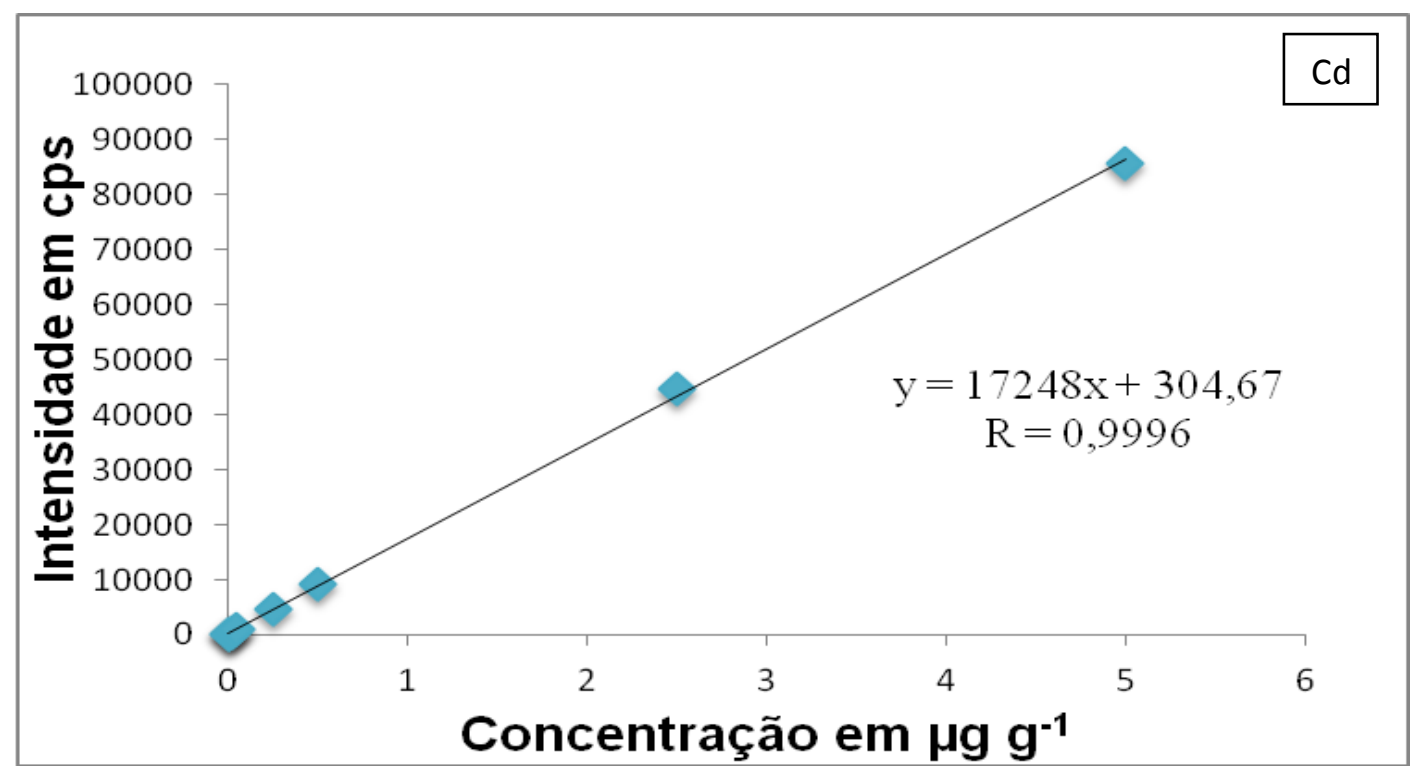

FIGURA 3.14: Curva analítica do Cd para ICP- OES.

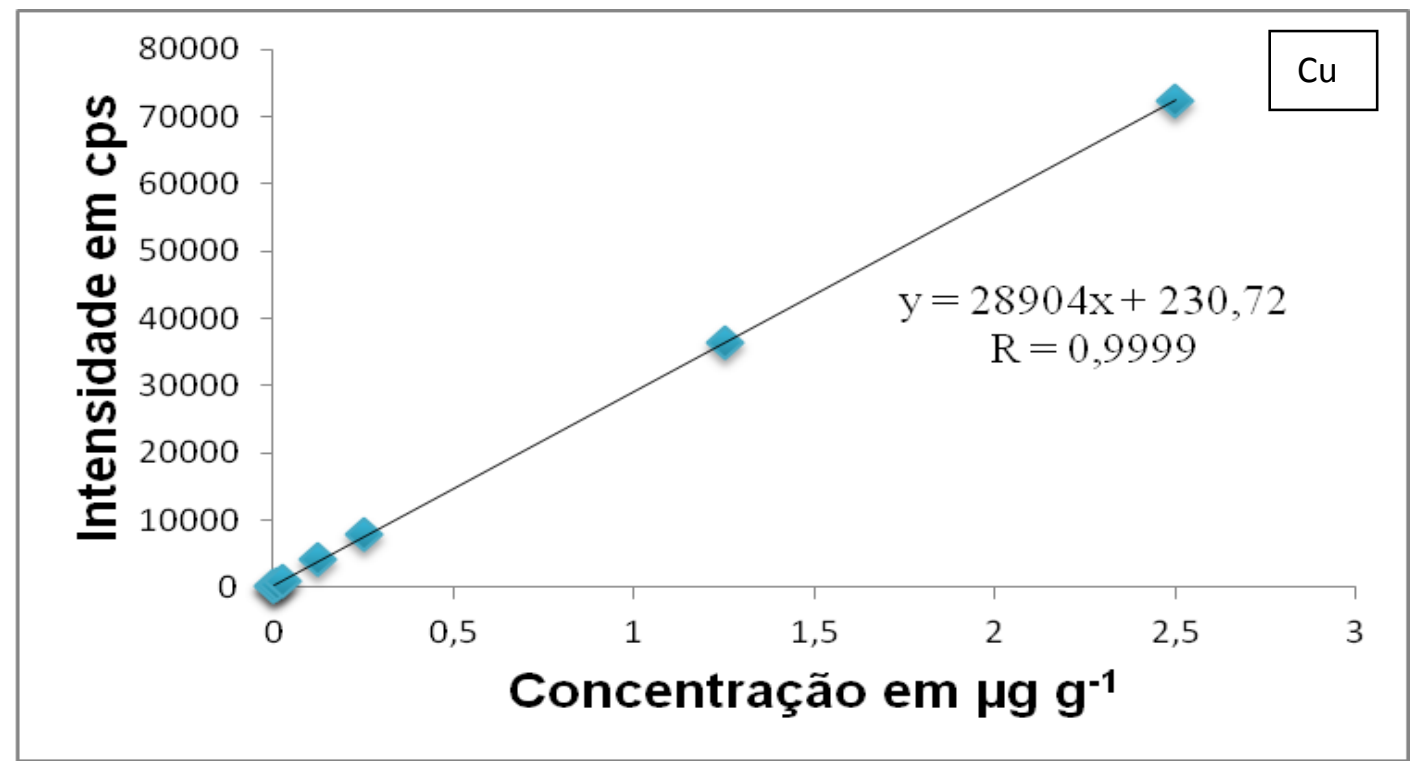

FIGURA 3.15: Curva analítica do Cu para ICP- OES. 


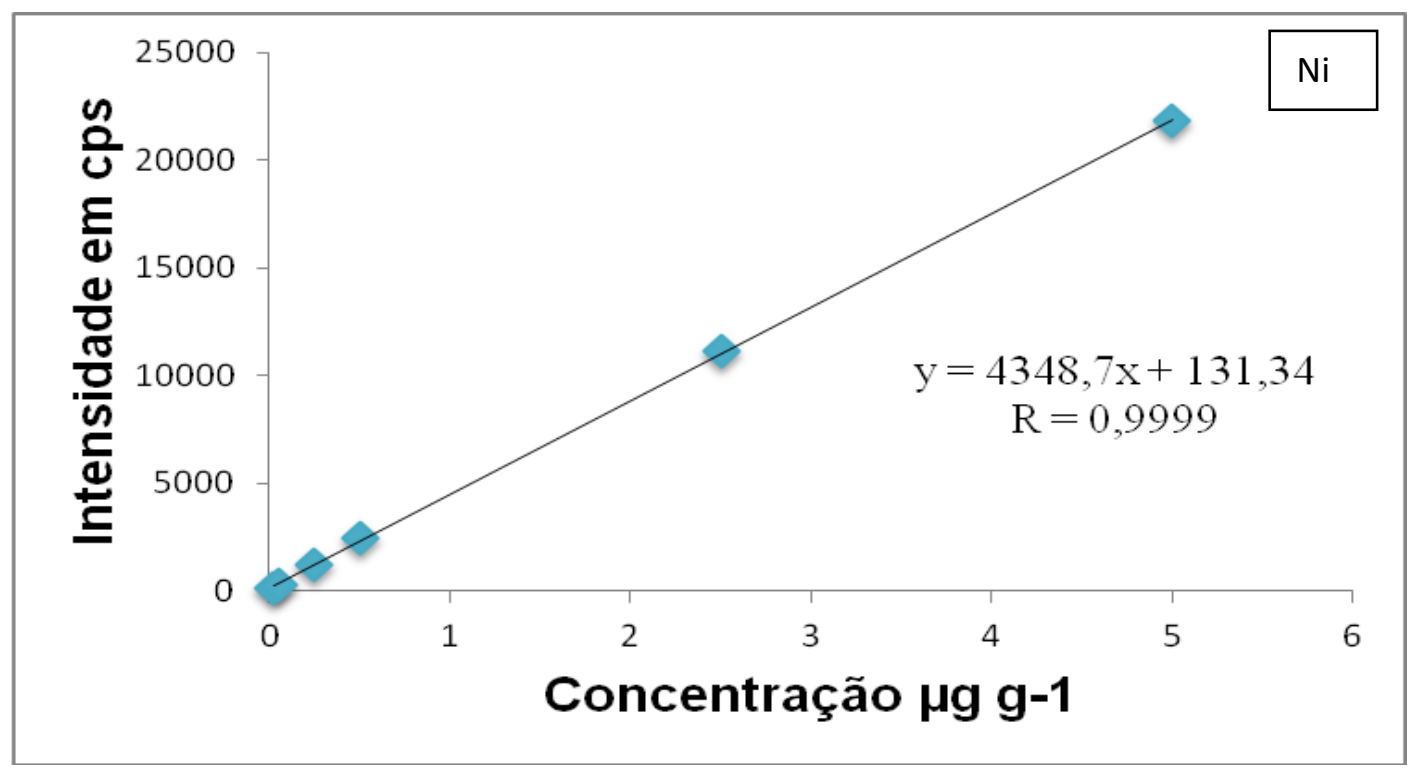

FIGURA 3.16: Curva analítica do Ni para ICP- OES.

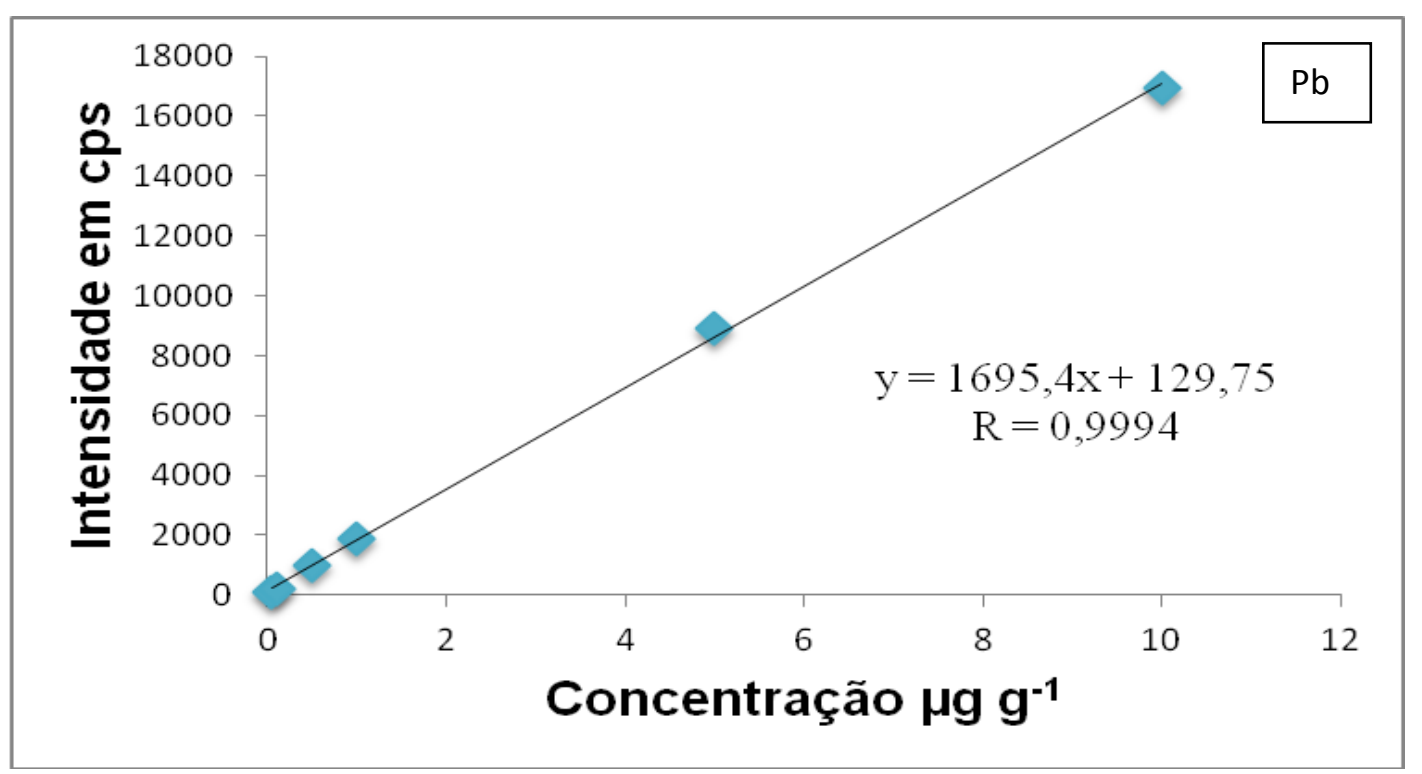

FIGURA 3.17: Curva analítica do Pb para ICP- OES. 


\section{RESULTADOS}

\subsection{Pesquisa de material estranho}

A definição de critérios de qualidade para insumos farmacêuticos de origem vegetal é de suma importância para garantir a manutenção da eficácia do produto final, especialmente devido à complexidade de composição das matérias-primas e às variações ligadas às condições de cultivo e de coleta do vegetal, assim como de tratamentos empregados para promover sua estabilidade (Sonaglio et al., 2003). $\mathrm{Na}$ Tabela 4.1 são apresentados os teores máximos de matéria estranha (ME), umidade (U), cinzas totais $(C T)$ e cinzas insolúveis em ácido (CIA) permitidos em plantas de uso medicinal de acordo com a Farmacopeia Brasileira de 1959; Farmacopeia Brasileira, parte I e II, 1988; Farmacopeia 5a edição, 2010 e a ANVISA, 2009.

Segundo a Farmacopeia Brasileira, 5a edição (2010), salvo indicação em contrário, a porcentagem de elementos estranhos não deve ser superior a $2 \%$ (massa/massa).

Na Tabela 4.2 são apresentados os resultados obtidos para as análises de porcentagem de matéria estranha (ME), umidade $(\mathrm{U})$, cinzas totais $(\mathrm{CT})$ e cinzas insolúveis em ácido $(\mathrm{CIA})$ nas amostras deste estudo. Neste trabalho considerou-se como elementos estranhos tudo aquilo que não era preconizado como parte constituinte da droga vegetal, de acordo com as monografias específicas (Melo et al., 2004).

Foi verificado que as amostras apresentaram boas condições quanto às suas propriedades organolépticas e seu estado de conservação, e não foram observados sinais de deterioração ou mau cheiro em nenhuma delas.

Em relação à análise de impurezas das 24 amostras analisadas $54 \%$ das espécies apresentaram teores de impurezas acima do limite estabelecido pela Farmacopeia Brasileira, sendo que o principal tipo de material estranho encontrado foram partes da planta não indicadas para o uso. 
TABELA 4.1: Teores máximos permitidos, em porcentagem (\%), de matéria estranha (ME), umidade (U), cinzas totais (CT) e cinzas insolúveis em ácido (CIA) em plantas de uso medicinal de acordo com a Farmacopeia Brasileira.

\begin{tabular}{|c|c|c|c|c|}
\hline Planta & $\begin{array}{c}\text { Matéria } \\
\text { Estranha } \\
(\%)\end{array}$ & $\begin{array}{c}\text { Teor de } \\
\text { Umidade } \\
(\%)\end{array}$ & $\begin{array}{c}\text { Cinzas } \\
\text { Totais } \\
(\%)\end{array}$ & $\begin{array}{c}\text { Cinzas } \\
\text { Insolúveis } \\
\text { em Ácido } \\
\text { (\%) }\end{array}$ \\
\hline Achyrocline satureioides (Macela) & 2 & 10 & 8 & --- \\
\hline Aesculus hippocastanum (C. India) & 2 & 10 & 14 & --- \\
\hline Bidens pilosa (Picão Preto) & 2 & 8 a 14 & --- & --- \\
\hline Calendula officinalis (Calêndula) & 3 & 12 & 10 & --- \\
\hline Cinnamomum verum (Canela) & 2 & 8 a 14 & 5 & --- \\
\hline Cymbopogon citratus (C. Santo) & 1 & 11 & 9 & --- \\
\hline Cynara scolymus (Alcachofra) & 2 & 12 & 20 & --- \\
\hline Eucalyptus globulus (Eucalipto) & 3 & 8 a 14 & 5 & --- \\
\hline Illicium verum (A. Estrelado) & 2 & 7 & 6 & --- \\
\hline Malva sylvestris (Malva) & 2 & 8 a 14 & 16 & --- \\
\hline Matricaria recutita (Camomila) & 5 & 8 a 14 & 14 & --- \\
\hline Melissa officinalis (Melissa) & 10 & 12 & 10 & --- \\
\hline Mentha pulegium (Poejo) & 2 & 8 a 14 & --- & --- \\
\hline Mikania glomerata (Guaco) & 2 & 8 a 14 & --- & --- \\
\hline Passiflora alata (Maracujá) & 2 & 11 & 10 & 0,4 \\
\hline Paullinia cupana (Guaraná) & 0,8 & 9,5 & 3 & --- \\
\hline Peumus boldus (Boldo) & 3 & 10 & 10 & 6 \\
\hline Phyllanthus niruri (Q. Pedra) & 2 & 10 & 6 & --- \\
\hline Psidium guajava (Goiabeira) & 2 & 12 & 9 & --- \\
\hline Rosmarinus officinalis (Alecrim) & 2 & 8 a 14 & --- & --- \\
\hline Sambucus nigra (Sabugueiro) & 8 & 11 & 9 & --- \\
\hline Solanum paniculatum (Jurubeba) & 2 & 8 a 14 & 14 & --- \\
\hline $\begin{array}{c}\text { Stryphnodendrom adstrigens } \\
\text { (Barbatimão) }\end{array}$ & 2 & 14 & 2 & --- \\
\hline Zingiber officinale (Gengibre) & 2 & 10 & 6 & --- \\
\hline
\end{tabular}

----Valor máximo não estabelecido. Fontes: Farmacopeia, 1959; Farmacopeia Brasileira, parte I e II, 1988; Farmacopeia Brasileira 5ª Edição; ANVISA, 2009. 


\subsection{Determinação dos constituintes inorgânicos}

\subsubsection{Teor de umidade}

Os teores de umidade encontrados nas amostras analisadas variaram de 4 a 11,6\% como demonstrado na Tabela 4.2 e para a maioria das amostras, está dentro dos limites estabelecidos para drogas vegetais, segundo a Farmacopeia Brasileira (2010), que variam entre 8 a 14\%. Apenas a amostra de Illicium verum (anis estrelado) ficou acima do valor máximo estipulado para está espécie que é de 7\%.

\subsubsection{Determinação do teor de cinzas totais}

Comparando-se os valores obtidos (Tabela 4.2) com os estabelecidos pela Farmacopeia Brasileira apenas as amostras de Cinnamomum verum (canela) e a amostra Illicium verum (anis estrelado) apresentaram valores de cinzas totais superiores aos permitidos, que são, respectivamente, de 5\% e de 6\% (Tabela 4.1).

\subsubsection{Determinação de cinzas insolúveis em ácido}

Para cinzas insolúveis em ácido, comparando-se os valores determinados (Tabela 4.2) com aqueles encontrados na Farmacopeia Brasileira (1988), pode-se notar que as amostras de Passiflora alata (maracujá) e Peumus boldus (boldo-dochile) apresentaram este teor acima dos limites estabelecidos, que são no máximo de $0,4 \%$ e $6 \%$ respectivamente.

\subsection{Resultados obtidos pelas técnicas analíticas INAA, CV AAS e ICP-OES}

\subsubsection{Limite de detecção (LD)}


Quando são realizadas medidas em amostras com baixos níveis do analito, como por exemplo, análise de traços, é importante saber qual o menor valor de concentração do analito que pode ser detectado pelo método. Para a validação de um método analítico, é normalmente suficiente fornecer uma indicação do nível em que a detecção do analito pode ser distinguida do sinal do branco/ruído.

TABELA 4.2: Resultados obtidos para as plantas analisadas em porcentagem (\%) de matéria estranha (ME), umidade (U), cinzas totais (CT) e cinzas insolúveis em ácido (CIA).

\begin{tabular}{|c|c|c|c|c|}
\hline Planta & $\begin{array}{c}\text { Material } \\
\text { Estranho }\end{array}$ & $\begin{array}{c}\text { Teor de } \\
\text { Umidade }\end{array}$ & $\begin{array}{c}\text { Cinzas } \\
\text { Totais }\end{array}$ & $\begin{array}{c}\text { Cinzas } \\
\text { Insolúveis } \\
\text { em Ácido }\end{array}$ \\
\hline Achyrocline satureioides & 7,3 & 5,7 & 3,5 & 0,5 \\
Aesculus hippocastanum & 0,1 & 8,6 & 2,2 & 0,4 \\
Bidens pilosa & 5,4 & 9,9 & 6,6 & 0,4 \\
Calendula officinalis & 0,4 & 8,0 & 6,4 & 0,7 \\
Cinnamomum verum & 0,03 & 6,1 & 24,9 & 1,7 \\
Cymbopogon citratus & 6,4 & 8,2 & 6,3 & 1,0 \\
Cynara scolymus & 6,6 & 8,5 & 7,4 & 2,3 \\
Eucalyptus globulus & 30,4 & 4,0 & 3,1 & 0,1 \\
Illicium verum & 1,4 & 11,6 & 36,1 & 0,2 \\
Malva sylvestris & 5,3 & 6,7 & 6,8 & 0,6 \\
Matricaria recutita & 1,9 & 7,9 & 5,9 & 0,1 \\
Melissa officinalis & 0,3 & 6,8 & 5,6 & 1,7 \\
Mentha pulegium & 15,2 & 7,5 & 9,0 & 3,6 \\
Mikania glomerata & 52,8 & 6,2 & 8,5 & 3,7 \\
Passiflora alata & 5,1 & 7,3 & 5,8 & 4,8 \\
Paullinia cupana & 0,81 & 7,8 & 2,1 & 1,4 \\
Peumus boldus & 5,7 & 10,3 & 8,7 & 6,5 \\
Phyllanthus niruri & 0,6 & 5,6 & 3,9 & 0,7 \\
Psidium guajava & 45,2 & 7,4 & 4,0 & 0,9 \\
Rosmarinus officinalis & 15,6 & 4,9 & 3,9 & 0,5 \\
Sambucus nigra & 26,5 & 7,0 & 6,8 & 1,6 \\
Solanum paniculatum & 1,1 & 7,6 & 6,8 & 2,0 \\
Stryphnodendrom adstrigens & 0,1 & 6,8 & 0,4 & 0,2 \\
Zingiber officinale & 0,001 & 7,5 & 2,9 & 2,3 \\
\hline
\end{tabular}


O limite de deteç̧ão também é considerado como a menor concentração do analito que um procedimento analítico específico pode detectar com segurança. Sendo também definido como a concentração mínima na qual uma substância pode ser medida e declarada, a um determinado grau de confiança, de que a concentração do analito é maior que zero. O Limite de detecção para a técnica analítica INAA foi estabelecido através da raiz quadrada da média da radiação de seis fundos de análises de cada um dos materiais de referência em plantas medicinais SRM 1515, SRM 1547 e SRM 1573a. O desvio padrão relativo (DPR) é uma medida de dispersão, e o valor reflete a variabilidade das observações em relação à média. E o erro relativo (ER) determina o valor aproximado de um número, sendo a razão entre o erro absoluto e o seu valor exato (INMETRO, 2003; US EPA, 2007).

O limite de deteç̧ão para a técnica de INAA foi determinado por meio de medidas, em replicata, dos materias de referência Apple Leaves, Peach Leaves e Tomato Leaves, tendo-se como padrões comparativos os MRC Rhyolite, Glass Mountain (RGM-2) e Syenite, Table Mountain (STM-2) do United States Geological Survey além de soluções padrão sintéticas pipetadas, provenientes de soluçõespadrão (SPEX CERTIPREP) com concentrações conhecidas dos elementos As, Ba, $\mathrm{Br}, \mathrm{Ca}, \mathrm{Cs}, \mathrm{Co}, \mathrm{Cr}, \mathrm{Fe}, \mathrm{Hf}, \mathrm{K}, \mathrm{Na}, \mathrm{Rb}, \mathrm{Sb}, \mathrm{Se}, \mathrm{U}$ e Zn em papel de filtro. Na Tabela 4.3 são apresentados os valores obtidos para o de Limite de Detecção dos elementos determinados. As amostras dos extratos foram preparadas a partir de massas variando de 0,5 a $9 \mathrm{~g}$ e volumes variando de 150 a $1000 \mathrm{~mL}$. Os seus respectivos limites de deteç̧ão devem, portanto, levar em consideração tanto estas massas quanto o fator de concentração, visto que, as soluções obtidas na preparação do chá foram concentradas a aproximadamente $1 \mathrm{~mL}$.

$\mathrm{Na}$ Tabela 4.4 são apresentados os valores obtidos para o limite de detecção em função das massas e volumes das amostras analisadas, nas determinações feitas por ICP-OES e CV AAS obtidos através de medidas em replicata do branco analítico de cada método. 


\subsubsection{Verificação da precisão e exatidão das técnicas analíticas INAA, CV AAS e ICP-OES}

Para verificação dos resultados obtidos por INAA, as concentrações elementares dos materiais de referência Apple Leaves, Peach Leaves e Tomato Leaves foram determinadas e as concentrações obtidas estão apresentadas nas Tabelas 4.5, 4.6 e 4.7. Na mesma tabela também são mostrados os valores de desvio padrão relativo (DPR) e erro relativo (ER) para avaliação da precisão e da exatidão das determinações. Não poderam ser calculado o limite de detecção, desvio padrão relativo e erro relativo para os elementos $\mathrm{As}, \mathrm{Br}, \mathrm{Cl}, \mathrm{Cs}, \mathrm{Mn}, \mathrm{Se}, \mathrm{Ta}$, $\mathrm{Ti}, \mathrm{U}$ e $\mathrm{Zr}$, para a INAA pois os mesmos não foram determinados em um número suficiente de amostras ou não possuem valor certificado ou informativo para os materiais de referência certificado utilizados neste estudo. Elementos cujos cetificados apresentam apenas valor informativo também foram considerados no cálculo do erro relavito para que este parâmetro pudesse ser avaliado, pelo menos em relação a sua ordem de grandeza.

TABELA 4.3: Valores de limite de detecção (LD) da técnica de INAA ( $\left.\mathrm{mg} \mathrm{kg}^{-1}\right)$ obtidos para os elementos nas amostras Apple Leaves, Peach Leaves e Tomato Leaves para os material de referência STM-2 e RGM-2.

\begin{tabular}{|c|c|c|}
\hline ELEMENTOS & \multicolumn{2}{|c|}{ LD } \\
\cline { 2 - 3 } & STM-2 & RGM-2 \\
\hline As & 0,057 & 0,43 \\
$\mathbf{B a}$ & 20 & 28 \\
$\mathbf{B r}$ & 0,11 & 0,11 \\
$\mathbf{C a}$ & 1033 & 1313 \\
$\mathbf{C o}$ & 0,15 & 0,15 \\
$\mathbf{C r}$ & 0,19 & 1,037 \\
$\mathbf{C s}$ & 0,046 & 0,047 \\
$\mathbf{F e}$ & 46 & 46 \\
$\mathbf{H f}$ & 0,32 & 0,32 \\
$\mathbf{K}$ & 2970 & 2970 \\
$\mathbf{N a}$ & 16 & 18 \\
$\mathbf{S b}$ & 0,066 & 0,021 \\
$\mathbf{S c}$ & 0,054 & 0,0085 \\
$\mathbf{S e}$ & 0,16 & 0,16 \\
$\mathbf{T a}$ & 0,11 & 0,17 \\
$\mathbf{T h}$ & 0,049 & 0,08 \\
$\mathbf{U}$ & 0,11 & 0,14 \\
$\mathbf{Z n}$ & 2,08 & 1,95 \\
$\mathbf{Z r}$ & 15 & 14 \\
\hline
\end{tabular}


TABELA 4.4: Intervalos obtidos exceto para $\mathrm{Hg}$, para os valores de limite de detecção (LD) para as técnicas analíticas ICP-OES e CV AAS $\left(\mathrm{mg} \mathrm{kg}^{-1}\right)$, para os materiais de referência Apple Leaves e Peach Leaves.

\begin{tabular}{|c|c|c|}
\hline ELEMENTOS & TÉCNICA & LD \\
\hline $\mathbf{C d}$ & ICP OES & $0,063-0,37$ \\
$\mathbf{C u}$ & ICP OES & $0,035-0,21$ \\
$\mathbf{H g}$ & CV AAS & $3,23 \mathrm{ng} \mathrm{g}^{-1}$ \\
$\mathbf{N i}$ & ICP OES & $0,026-0,15$ \\
$\mathbf{P b}$ & ICP OES & $0,067-0,40$ \\
\hline
\end{tabular}

TABELA 4.5: Resultados obtidos para o material de referência SRM 1515, Apple Leaves, utilizado para a verificação da qualidade dos resultados para a técnica de INAA, em $\mu g^{-1}$, exceto onde indicado \% $(\mathrm{n}=5)$.

\begin{tabular}{|c|c|c|c|c|}
\hline \multicolumn{5}{|c|}{ APPLE LEAVES } \\
\hline ELEMENTO & Valor Medido & Valor Certificado & Erro Relativo & D.P.R. \\
\hline $\mathbf{B a}$ & $51 \pm 11$ & $49 \pm 2$ & 4,08 & 21,6 \\
$\mathbf{C a}(\%)$ & $1,2 \pm 0,4$ & $1,526 \pm 0,015$ & 21,3 & 33,3 \\
$\mathbf{C l}$ & $654 \pm 56$ & $579 \pm 23$ & 12,9 & 8,56 \\
$\mathbf{F e}$ & $86 \pm 28$ & $83 \pm 5$ & 3,6 & 32,5 \\
$\mathbf{K}$ (\%) & $1,3 \pm 0,3$ & $1,61 \pm 0,02$ & 19,2 & 23,07 \\
Mg & $2674 \pm 112$ & $2710 \pm 80$ & 1,3 & 4,18 \\
Mn & $50 \pm 2$ & $54 \pm 32$ & 7,4 & 4 \\
$\mathbf{N a}$ & $29 \pm 7$ & $24,4 \pm 1,2$ & 18,8 & 24,13 \\
$\mathbf{R b}$ & $10 \pm 3$ & $10,2 \pm 1,5$ & 1,9 & 30 \\
$\mathbf{S c}$ & $0,03 \pm 0,01$ & 0,03 & 0 & 33,3 \\
Th & $0,03 \pm 0,01$ & 0,03 & 0 & 33,3 \\
$\mathbf{V}$ & $0,23 \pm 0,06$ & $0,26 \pm 0,03$ & 11,5 & 26,08 \\
Zn & $15 \pm 2$ & $12,5 \pm 0,3$ & 20 & 13,3 \\
\hline
\end{tabular}

D.P.R. Desvio Padrão Relativo. 
TABELA 4.6: Resultados obtidos para o material de referência SRM 1547, Peach Leaves, utilizado para a verificação da qualidade dos resultados para a técnica de INAA, em $\mu \mathrm{g} \mathrm{g}^{-1}$, exceto onde indicado \% $(\mathrm{n}=5)$.

\begin{tabular}{|c|c|c|c|c|}
\hline \multicolumn{5}{|c|}{ PEACH LEAVES } \\
\hline ELEMENTO & Valor Medido & Valor Certificado & Erro Relativo & D.P.R. \\
\hline Ba & $118 \pm 26$ & $124 \pm 4$ & 4,8 & 22,03 \\
Ca (\%) & $1,2 \pm 0,2$ & $1,56 \pm 0,02$ & 23 & 16,6 \\
Fe & $236 \pm 54$ & $218 \pm 14$ & 8,2 & 22,88 \\
K (\%) & $1,5 \pm 0,3$ & $2,43 \pm 0,03$ & 38,3 & 20 \\
Mg & $2674 \pm 112$ & $2710 \pm 80$ & 1,3 & 4,18 \\
Na & $26 \pm 1$ & $24 \pm 2$ & 8,3 & 3,84 \\
Rb & $19 \pm 7$ & $19,7 \pm 1,2$ & 3,5 & 36,84 \\
Sb & $0,024 \pm 0,002$ & 0,02 & 20 & 8,3 \\
Sc & $0,05 \pm 0,01$ & 0,04 & 25 & 20 \\
Th & $0,06 \pm 0,01$ & 0,05 & 20 & 16,6 \\
Zn & $21 \pm 4$ & $17,9 \pm 0,4$ & 17,3 & 19,04 \\
\hline
\end{tabular}

D.P.R. Desvio Padrão Relativo.

TABELA 4.7: Resultados obtidos para o material de referência, SRM 1573a, Tomato Leaves, utilizado para a verificação da qualidade dos resultados para a técnica de INAA, em $\mu \mathrm{g} \mathrm{g}^{-1}$, exceto onde indicado \% $(n=5)$.

\begin{tabular}{|c|c|c|c|c|}
\hline \multicolumn{5}{|c|}{ TOMATO LEAVES } \\
\hline ELEMENTO & Valor Medido & Valor Certificado & Erro Relativo & D.P.R. \\
\hline $\mathbf{B a}$ & $49 \pm 10$ & 63 & 22,2 & 20,4 \\
$\mathbf{B r}$ & $1489 \pm 193$ & 1300 & 14,6 & 12,96 \\
$\mathbf{C a}$ & $4,31 \pm 1,79$ & $5,05 \pm 0,09$ & 14,6 & 41,5 \\
$\mathbf{C o}$ & $0,8 \pm 0,1$ & $0,57 \pm 0,02$ & 40,3 & 12,5 \\
$\mathbf{C r}$ & $1,9 \pm 0,3$ & $1,99 \pm 0,06$ & 4,5 & 15,78 \\
$\mathbf{F e}$ & $316 \pm 35$ & $368 \pm 7$ & 14,1 & 11,07 \\
$\mathbf{H f}$ & $0,16 \pm 0,04$ & 0,14 & 14,2 & 25 \\
$\mathbf{K}(\%)$ & $2,5 \pm 0,2$ & $2,70 \pm 0,05$ & 7,4 & 8 \\
$\mathbf{N a}$ & $112 \pm 21$ & $136 \pm 4$ & 17,6 & 18,75 \\
$\mathbf{R b}$ & $12 \pm 2$ & $14,89 \pm 0,27$ & 19,4 & 16,6 \\
$\mathbf{S c}$ & $0,09 \pm 0,01$ & 0,1 & 10 & 11,1 \\
$\mathbf{T h}$ & $0,11 \pm 0,04$ & 0,12 & 8,3 & 36,36 \\
$\mathbf{Z n}$ & $28 \pm 3$ & $30,9 \pm 0,7$ & 9,3 & 10,71 \\
\hline
\end{tabular}

D.P.R. Desvio Padrão Relativo. 
Todos os valores para os elementos determinados nos materiais de referência apresentaram resultados aceitáveis em relação ao valor certificado, considerando-se os níveis de concentração a que estão relacionados pode-se verificar que foram obtidas boas precisão e exatidão para a maioria dos elementos. Para verificação dos resultados obtidos pelas técnicas analíticas ICP-OES e CV AAS, as concentrações elementares dos materiais de referência Apple Leaves e Peach Leaves foram determinadas e as concentrações obtidas, desvio padrão relativo (D.P.R) e o erro relativo estão apresentados na Tabela 4.8 .

TABELA 4.8: Resultados obtidos em $\mu \mathrm{g} \mathrm{g}^{-1}$, exceto para $\circ \mathrm{Hg}$, em $\mathrm{ng} \mathrm{g}{ }^{-1}$, para os materiais de referência Apple Leaves e Peach Leaves por ICP-OES e CVAAS. Resultados: Média de três determinações \pm o desvio padrão.

\begin{tabular}{|l|c|c|c|c|c|}
\hline \multicolumn{5}{|c|}{ APPLE } & \multicolumn{5}{c|}{ LEAVES } \\
\hline \multirow{3}{*}{$\begin{array}{l}\text { Valor Certificado } \\
\text { Valor Medido } \\
\text { Erro relativo } \\
\text { D.P.R }\end{array}$} & $\mathbf{C d}$ & $\mathbf{C u}$ & $\mathbf{N i}$ & $\mathbf{P b}$ & $\mathbf{H g}$ \\
\cline { 2 - 7 } & $0,013 \pm 0,002$ & $5,64 \pm 0,24$ & $0,91 \pm 0,12$ & $0,470 \pm 0,024$ & $44 \pm 4$ \\
\cline { 2 - 7 } & --- & $5 \pm 1$ & $0,9 \pm 0,2$ & $0,55 \pm 0,08$ & $39 \pm 4$ \\
\cline { 2 - 7 } & --- & 11,34 & 1,09 & 17,02 & 11,36 \\
\hline & -- & 20 & 22,2 & 14,54 & 10,25 \\
\hline \multirow{3}{*}{$\begin{array}{l}\text { Valor Certificado } \\
\text { Valor Medido } \\
\text { Erro relativo } \\
\text { D.P.R }\end{array}$} & $0,026 \pm 0,003$ & $3,7 \pm 0,4$ & $0,69 \pm 0,09$ & $0,87 \pm 0,03$ & $31 \pm 7$ \\
\cline { 2 - 7 } & --- & $3,77 \pm 0,07$ & $0,56 \pm 0,02$ & $0,7 \pm 0,3$ & $36 \pm 9$ \\
\cline { 2 - 7 } & --- & 1,89 & 18,84 & 19,54 & 16,12 \\
\cline { 2 - 7 } & --- & 1,85 & 3,57 & 42,85 & 25 \\
\hline
\end{tabular}

--- abaixo do limite de detecção 


\subsubsection{Resultados das concentrações para os elementos determinados pelas técnicas analíticas INAA, CV AAS e ICP OES}

Plantas medicinais contêm elementos químicos que podem ser disponibilizados para o corpo humano em qualquer tipo de consumo das ervas e seus extratos. Nem todos os elementos possuem funções biológicas totalmente descritas, todavia a maioria deles é responsável por importantes atividades no metabolismo humano e, portanto, estão diretamente relacionados com a manutenção da saúde e o funcionamento adequado do organismo.

$\mathrm{Na}$ Tabela 4.9 estão apresentados os resultados para os elementos As, Ba, $\mathrm{Br}, \mathrm{Ca}, \mathrm{Cd}, \mathrm{Cl}, \mathrm{Co}, \mathrm{Cr}, \mathrm{Cs}, \mathrm{Cu}, \mathrm{Fe}, \mathrm{Hf}, \mathrm{Hg}, \mathrm{K}, \mathrm{Mg}, \mathrm{Mn}, \mathrm{Na}, \mathrm{Pb}, \mathrm{Rb}, \mathrm{Sb}$, Se, Ta, Th, Ti, $\mathrm{U}, \mathrm{V}, \mathrm{Zn}$ e $\mathrm{Zr}$ para as amostras de plantas medicinais, obtidos pelas técnicas analíticas INAA, ICP OES e CV AAS. Todos os resultados em discussões apresentados neste trabalho referem-se à base seca.

$\mathrm{Na}$ Tabela 4.10 estão apresentados os resultados, para os elementos As, $\mathrm{Ba}$, $\mathrm{Br}, \mathrm{Ca}, \mathrm{Cd}, \mathrm{Co}, \mathrm{Cr}, \mathrm{Cs}, \mathrm{Cu}, \mathrm{Fe}, \mathrm{Hf}, \mathrm{Hg}, \mathrm{K}, \mathrm{Na}, \mathrm{Pb}, \mathrm{Rb}, \mathrm{Sb}, \mathrm{Se}, \mathrm{Ta}, \mathrm{Th}, \mathrm{U}, \mathrm{Zn}$ e Zr para as amostras de extratos, obtidos através das plantas medicinais determinados pelas técnicas analíticas INAA, ICP OES e CV AAS. Paullinia cupana (guaraná) não foi analisada em relação ao seu extrato, pois não a modo de preparo para o chá desta espécie na Resolução - RDC № 10, de 9 de março de 2010. 
Tabela 4.9: Resultados obtidos para as plantas medicinais analisadas. Os valores apresentados correspondem à técnicas analíticas AANI, ICP OES e CV AAS e à concentração em $\mathrm{g} \mathrm{g} \mathrm{g}^{-1}, \mathrm{ng} \mathrm{g}^{-1} \mathrm{e} \%$. As incertezas apresentada correspondem à propagação de erro para INAA e desvio padrão para ICP-OES e CV AAS.

\begin{tabular}{|c|c|c|c|c|c|c|c|c|c|c|c|c|}
\hline Plantas & \multicolumn{12}{|c|}{ Elementos } \\
\hline Nome científico & As & $\pm 1 \sigma$ & $\mathrm{Ba}$ & $\pm 1 \sigma$ & $\mathrm{Br}$ & $\pm 1 \sigma$ & $\mathrm{Ca} \%$ & $\pm 1 \sigma$ & Co & $\pm 1 \sigma$ & $\mathrm{Cl} \%$ & $\pm 1 \sigma$ \\
\hline 1-Achyrocline satureioides & ---- & ---- & 68 & 3 & 11,1 & 0,1 & 0,33 & 0,04 & 0,40 & 0,02 & 0,52 & 0,02 \\
\hline 2- Aesculus hippocastanum & ---- & ---- & --- & --- & 115,3 & 0,6 & 0,22 & 0,04 & 1,76 & 0,08 & 0,56 & 0,03 \\
\hline 3- Bidens pilosa & ---- & ---- & 141 & 6 & 41,6 & 0,2 & 0,9 & 0,1 & 0,38 & 0,02 & 0,24 & 0,02 \\
\hline 4- Calendula officinalis & ---- & ---- & 20 & 2 & 21,1 & 0,1 & 0,47 & 0,06 & 0,25 & 0,01 & 0,59 & 0,02 \\
\hline 5- Cinnamomum verum & ---- & ---- & 2 & 1 & 40,5 & 0,2 & 1,4 & 0,1 & 0,14 & 0,01 & 0,59 & 0,02 \\
\hline 6- Cymbopogon citratus & ---- & ---- & 18 & 1 & 74,0 & 0,4 & 0,52 & 0,08 & 0,35 & 0,02 & 0,25 & 0,02 \\
\hline 7- Cynara scolymus & ---- & --- & 47 & 3 & 32,6 & 1,2 & 1,5 & 0,1 & 0,58 & 0,02 & 0,063 & 0,004 \\
\hline 8- Eucalyptus globulus & --- & --- & 99 & 6 & 15,2 & 0,2 & 1,2 & 0,2 & 0,38 & 0,02 & 0,17 & 0,01 \\
\hline 9- Illicium verum & ---- & ---- & 6 & 3 & 0,72 & 0,01 & 0,20 & 0,03 & 0,27 & 0,03 & 0,91 & 0,08 \\
\hline 10- Malva sylvestris & --- & --- & 187 & 6 & 67,2 & 0,2 & 1,30 & 0,09 & 0,91 & 0,04 & 0,24 & 0,01 \\
\hline 11- Matricaria recutita & --- & --- & 4 & 2 & 34,1 & 0,2 & 0,49 & 0,05 & 0,79 & 0,04 & 0,017 & 0,002 \\
\hline 12- Melissa officinalis & --- & ---- & 56 & 3 & 7,69 & 0,05 & 2,0 & 0,1 & 0,30 & 0,02 & 1,60 & 0,06 \\
\hline 13- Mentha pulegium & ---- & --- & 116 & 5 & 43,2 & 0,2 & 1,1 & 0,4 & 9,1 & 0,5 & --- & ---- \\
\hline 14- Mikania glomerata & ---- & ---- & 13 & 1 & 9,70 & 0,09 & 1,51 & 0,09 & 0,21 & 0,01 & 0,072 & 0,004 \\
\hline 15- Passiflora alata & ---- & ---- & 156 & 6 & 6,59 & 0,05 & 1,7 & 0,1 & 0,069 & 0,004 & 0,73 & 0,05 \\
\hline 16- Paullinia cupana & 125 & 13 & ---- & ---- & 6,01 & 0,05 & 0,10 & 0,01 & 0,38 & 0,02 & --- & ---- \\
\hline 17- Peumus boldus & --- & ---- & 25 & 2 & 18,6 & 0,1 & 1,15 & 0,07 & 0,29 & 0,01 & 0,029 & 0,003 \\
\hline 18- Phyllanthus niruri & 297 & 52 & 54 & 3 & 10,4 & 0,3 & 0,78 & 0,05 & 0,65 & 0,02 & 1,06 & 0,05 \\
\hline 19- Psidium guajava & 51 & 20 & 83 & 4 & 4,78 & 0,07 & 2,0 & 0,3 & 0,25 & 0,01 & 0,172 & 0,007 \\
\hline 20- Rosmarinus officinalis & 248 & 44 & 15 & 2 & 13,6 & 0,1 & 0,8 & 0,1 & 0,31 & 0,01 & 0,24 & 0,04 \\
\hline 21- Sambucus nigra & ---- & ---- & 26 & 2 & 7,11 & 0,08 & 0,49 & 0,04 & 0,25 & 0,01 & 0,18 & 0,01 \\
\hline 22- Solanum paniculatum & ---- & ---- & 116 & 4 & 80 & 3 & 0,53 & 0,06 & 0,76 & 0,02 & 0,019 & 0,002 \\
\hline 23- Stryphnodendron adstringens & --- & --- & 33 & 2 & 7,7 & 0,1 & 0,14 & 0,02 & 0,19 & 0,02 & 1,38 & 0,06 \\
\hline 24-Zingirber officinale & 530 & 47 & 6 & 1 & 2,82 & 0,04 & 0,18 & 0,02 & 0,60 & 0,03 & 0,12 & 0,01 \\
\hline
\end{tabular}

---- Abaixo do limite de detecção 
Continuação: Tabela 4.9

\begin{tabular}{|c|c|c|c|c|c|c|c|c|c|c|c|c|}
\hline Plantas & \multicolumn{12}{|c|}{ Elementos } \\
\hline Nome científico & $\mathbf{C r}$ & \pm 10 & Cs & $\pm 1 \sigma$ & Fe & $\pm 1 \sigma$ & Hf & $\pm 1 \sigma$ & $\mathrm{K} \%$ & $\pm 1 \sigma$ & Mg \% & $\pm 1 \sigma$ \\
\hline 1- Achyrocline satureioides & 30 & 2 & 242 & 14 & 429 & 5 & 632 & 14 & 0,9 & 0,2 & 0,25 & 0,01 \\
\hline 2- Aesculus hippocastanum & 1,8 & 0,1 & 59 & 14 & 1215 & 13 & 718 & 17 & 0,032 & 0,002 & 0,07 & 0,01 \\
\hline 3- Bidens pilosa & 6,3 & 0,5 & 82 & 10 & 317 & 4 & 141 & 5 & 4,0 & 0,3 & 0,28 & 0,02 \\
\hline 4- Calendula officinalis & 4,6 & 0,2 & 110 & 14 & 175 & 4 & ---- & ---- & 3,2 & 0,3 & 0,36 & 0,01 \\
\hline 5- Cinnamomum verum & 6,7 & 0,4 & ---- & ---- & 55 & 3 & 14 & 3 & 0,7 & 0,1 & 0,024 & 0,005 \\
\hline 6- Cymbopogon citratus & 14,4 & 0,9 & 183 & 9 & 161 & 2 & 42 & 3 & 3,3 & 0,7 & 0,14 & 0,01 \\
\hline 7- Cynara scolymus & 31 & 1 & ---- & ---- & 720 & 9 & 119 & 8 & 8 & 2 & 0,29 & 0,01 \\
\hline 8- Eucalyptus globulus & 2,9 & 0,1 & ---- & ---- & 490 & 8 & 107 & 8 & 0,29 & 0,08 & ---- & ---- \\
\hline 9- Illicium verum & 12,4 & 0,9 & 1146 & 84 & 187 & 7 & 50 & 8 & 1,6 & 0,3 & 0,06 & 0,01 \\
\hline 10- Malva sylvestris & 52 & 3 & 170 & 18 & 1370 & 11 & 1691 & 37 & 3,3 & 0,5 & 0,51 & 0,03 \\
\hline 11- Matricaria recutita & 68 & 5 & --- & --- & 482 & 7 & 93 & 6 & 3,8 & 0,6 & 0,20 & 0,01 \\
\hline 12-Melissa officinalis & 8,1 & 0,4 & 124 & 11 & 174 & 4 & 67 & 6 & 0,1 & 0,3 & 0,37 & 0,01 \\
\hline 13- Mentha pulegium & 69 & 3 & 350 & 40 & 1,23 & 84 & 2340 & 53 & 1,99 & 0,04 & 0,22 & 0,02 \\
\hline 14- Mikania glomerata & 10,7 & 0,5 & 456 & 20 & 189 & 2 & 55 & 2 & 0,4 & 0,2 & 0,11 & 0,02 \\
\hline 15- Passiflora alata & 2,6 & 0,1 & --- & --- & 202 & 2 & 65 & 3 & 3,6 & 0,9 & 0,32 & 0,01 \\
\hline 16- Paullinia cupana & 0,5 & 0,0 & 128 & 9 & 111 & 1 & 24 & 2 & 0,62 & 0,08 & 0,113 & 0,005 \\
\hline 17- Peumus boldus & 18,1 & 0,8 & 125 & 12 & 308 & 3 & 58 & 3 & 1,00 & 0,02 & 0,18 & 0,01 \\
\hline 18- Phyllanthus niruri & 6,1 & 0,2 & ---- & --- & 1882 & 16 & 227 & 7 & $-\cdots$ & --- & 0,29 & 0,03 \\
\hline 19- Psidium guajava & 1,7 & 0,1 & 47 & 7 & 154 & 5 & 51 & 5 & 0,011 & 0,001 & 0,21 & 0,02 \\
\hline 20- Rosmarinus officinalis & 4,6 & 0,2 & 82 & 12 & 313 & 6 & 63 & 6 & 2,1 & 0,5 & 0,24 & 0,01 \\
\hline 21-Sambucus nigra & 11,2 & 0,5 & 27 & 8 & 381 & 4 & 42 & 5 & 3,0 & 0,2 & 0,32 & 0,01 \\
\hline 22- Solanum paniculatum & 36 & 1 & 220 & 27 & 618 & 7 & 1447 & 45 & 1,8 & 0,1 & 0,22 & 0,02 \\
\hline 23- Stryphnodendron & 6,5 & 0,3 & 22 & 9 & 59 & 3 & 92 & 4 & 0,8 & 0,1 & 0,03 & 0,01 \\
\hline 24- Zingirber officinale & 16,0 & 0,8 & 14 & 7 & 109 & 2 & 27 & 3 & 2 & 1 & 0,14 & 0,01 \\
\hline
\end{tabular}

---- Abaixo do limite de detecção 
Continuação: Tabela 4.9

\begin{tabular}{|c|c|c|c|c|c|c|c|c|c|c|c|c|}
\hline Plantas & \multicolumn{12}{|c|}{ Elementos } \\
\hline Nome científico & $\overline{M n}$ & $\pm 1 \sigma$ & $\mathrm{Na}$ & $\pm 1 \sigma$ & $\mathbf{R b}$ & $\pm 1 \sigma$ & $\mathbf{S b}$ & $\pm 1 \sigma$ & Sc & $\pm 1 \sigma$ & $\mathrm{Se}$ & $\pm 1 \sigma$ \\
\hline 1- Achyrocline satureioides & 73 & 2 & 270 & 7 & 25,3 & 0,7 & 27 & 5 & 132 & 3 & 0,17 & 0,09 \\
\hline 2- Aesculus hippocastanum & 126 & 3 & 113 & 5 & 2,9 & 0,3 & --- & ---- & 23 & 1 & $-\ldots$ & --- \\
\hline 3- Bidens pilosa & 102 & 2 & 76 & 3 & 72 & 2 & --- & ---- & 74 & 2 & 0,37 & 0,08 \\
\hline 4- Calendula officinalis & 150 & 4 & 793 & 19 & 83 & 3 & 5 & 2 & 24,0 & 0,8 & ---- & -.-- \\
\hline 5- Cinnamomum verum & 565 & 213 & 9 & 1 & 7,1 & 0,2 & --- & ---- & 3,1 & 0,3 & 0,13 & 0,05 \\
\hline 6- Cymbopogon citratus & 163 & 4 & 28 & 3 & 46 & 1 & --- & ---- & 14,5 & 0,4 & ---- & ---- \\
\hline 7- Cynara scolymus & 47 & 2 & 2255 & 75 & 28,9 & 0,7 & ---- & ---- & 126 & 2 & 0,20 & 0,09 \\
\hline 8- Eucalyptus globulus & 809 & 16 & ---- & ---- & 28 & 1 & 40 & 7 & 160 & 3 & 0,18 & 0,07 \\
\hline 9- Illicium verum & 336 & 8 & 100 & 3 & 69 & 4 & --- & ---- & 45 & 2 & & -.- \\
\hline 10- Malva sylvestris & 309 & 9 & 144 & 3 & 29,0 & 0,8 & 21 & 11 & 343 & 8 & 0,20 & 0,08 \\
\hline 11- Matricaria recutita & 73 & 2 & 140 & 5 & 79 & 2 & ---- & --- & 47 & 1 & 0,8 & 0,3 \\
\hline 12- Melissa officinalis & 123 & 3 & 54 & 1 & 19,2 & 0,7 & 25 & 5 & 41 & 1 & $-\cdots$ & --- \\
\hline 13- Mentha pulegium & 297 & 7 & 459 & 8 & 23,7 & 0,7 & 52 & 6 & 3663 & 86 & ---- & ---- \\
\hline 14- Mikania glomerata & 1046 & 68 & 1591 & 29 & 176 & 5 & 23 & 4 & 28,8 & 0,7 & ---- & ---- \\
\hline 15- Passiflora alata & 27 & 1 & 22 & 1 & 73 & 2 & 10 & 2 & 38,6 & 0,9 & 0,17 & 0,05 \\
\hline 16- Paullinia cupana & 16,6 & 0,5 & 48 & 1 & 23,0 & 0,6 & 9 & 2 & 13,9 & 0,4 & 0,15 & 0,03 \\
\hline 17- Peumus boldus & 103 & 3 & 239 & 4 & 14,7 & 0,4 & ---- & ---- & 80 & 2 & 0,23 & 0,09 \\
\hline 18- Phyllanthus niruri & 204 & 5 & 103 & 4 & 8,8 & 0,4 & 22 & 4 & 585 & 11 & ---- & --- \\
\hline 19- Psidium guajava & 183 & 5 & 85 & 3 & 13,2 & 0,6 & 24 & 4 & 30 & 1 & ---- & ---- \\
\hline 20- Rosmarinus officinalis & 19,7 & 0,8 & 84 & 2 & 2,6 & 0,2 & ---- & ---- & 97 & 2 & 0,15 & 0,03 \\
\hline 21-Sambucus nigra & 52 & 2 & 144 & 4 & 11,0 & 0,4 & 40 & 6 & 59 & 1 & 0,5 & 0,1 \\
\hline 22- Solanum paniculatum & 129 & 4 & 43 & 2 & 28 & 1 & 23 & 4 & 105 & 2 & -- & --- \\
\hline 23- Stryphnodendron & 6,6 & 0,3 & 12 & 2 & 7,9 & 0,3 & 30 & 5 & 3,0 & 0,3 & 0,17 & 0,06 \\
\hline 24- Zingirber officinale & 484 & 12 & 64 & 2 & 3,9 & 0,2 & 10 & 2 & 15,7 & 0,5 & 0,60 & 0,06 \\
\hline
\end{tabular}

---- Abaixo do limite de detecção 
Continuação: Tabela 4.9

\begin{tabular}{|c|c|c|c|c|c|c|c|c|c|c|c|c|}
\hline Plantas & \multicolumn{12}{|c|}{ Elementos } \\
\hline $\begin{array}{c}\text { 2- Aesculus hippocastanum } \\
\text { 3- Bidens pilosa }\end{array}$ & $\begin{array}{l}--- \\
---\end{array}$ & $\begin{array}{l}---- \\
----\end{array}$ & $\begin{array}{l}25 \\
58\end{array}$ & $\begin{array}{l}8 \\
5\end{array}$ & $\begin{array}{l}45 \\
0,7\end{array}$ & $\begin{array}{l}14 \\
0,3\end{array}$ & ---- & $\begin{array}{l}--- \\
---\end{array}$ & $\begin{array}{c}1,0 \\
0,15\end{array}$ & $\begin{array}{c}0,1 \\
0.08\end{array}$ & $\begin{array}{c}17,5 \\
----\end{array}$ & $\begin{array}{l}0,8 \\
---\end{array}$ \\
\hline 5- Cinnamomum verum & --- & ---- & ---- & --- & ---- & ---- & 871 & 400 & ---- & ---- & 10,6 & 0,5 \\
\hline 6- Cymbopogon citratus & ---- & ---- & 20 & 3 & ---- & ---- & ---- & ---- & 0,14 & 0,05 & 21,9 & 0,8 \\
\hline 7- Cynara scolymus & 14 & 5 & 148 & 9 & 86 & 28 & 661 & 504 & ---- & ---- & 23,1 & 0,8 \\
\hline 10- Malva sylvestris & 91 & 7 & 1252 & 52 & 186 & 35 & 317 & 26 & 2,7 & 0,2 & 67 & 2 \\
\hline 11- Matricaria recutita & ---- & ---- & 26 & 5 & ---- & ---- & ---- & ---- & 0,5 & 0,2 & 29 & 1 \\
\hline 12- Melissa officinalis & ---- & ---- & 37 & 5 & ---- & ---- & --- & ---- & 0,31 & 0,06 & 33 & 2 \\
\hline 13- Mentha pulegium & 77 & 13 & 1986 & 82 & 644 & 59 & 280 & 24 & 5,5 & 0,4 & 48 & 1 \\
\hline 14- Mikania glomerata & --- & --- & 33 & 2 & --- & --- & ---- & --- & ---- & ---- & 30,5 & 0,9 \\
\hline 15- Passiflora alata & 3 & 1 & 39 & 2 & 22 & 19 & ---- & ---- & 0,12 & 0,06 & 40 & 1 \\
\hline 16- Paullinia cupana & --- & ---- & 24 & 2 & ---- & ---- & ---- & ---- & 0,19 & 0,03 & 20,9 & 0,6 \\
\hline 21- Sambucus nigra & --- & --- & 89 & 7 & 193 & 66 & --- & --- & --- & --- & 42 & 2 \\
\hline 22- Solanum paniculatum & ---- & ---- & 327 & 14 & ---- & --- & --- & ---- & ---- & ---- & 23,3 & 0,7 \\
\hline 23- Stryphnodendron & ---- & ---- & 59 & 5 & ---- & ---- & ---- & ---- & ---- & ---- & 18 & 1 \\
\hline 24- Zingirber officinale & ---- & ---- & 19 & 4 & ---- & ---- & 13 & 2 & ---- & --- & 23,1 & 0,9 \\
\hline
\end{tabular}

---- Abaixo do limite de deteç̧ão 
Continuação: Tabela 4.9

\begin{tabular}{|c|c|c|c|c|c|c|c|c|c|c|c|c|}
\hline Plantas & \multicolumn{12}{|c|}{ Elementos } \\
\hline 2- Aesculus hippocastanum & 23 & 3 & 2,5 & 0,5 & --- & --- & 9,2 & 0,3 & 27,0 & 0,4 & 38,2 & 0,8 \\
\hline 3- Bidens pilosa & 6 & 2 & 32 & 6 & 0,24 & 0,03 & 13,4 & 0,2 & 2,4 & 0,2 & 8,5 & 0,6 \\
\hline 5- Cinnamomum verum & ---- & ---- & 104 & 6 & 0,22 & 0,01 & 3,11 & 0,09 & 2,4 & 0,3 & 5,6 & 0,7 \\
\hline 6- Cymbopogon citratus & --- & ---- & 116 & 7 & 0,07 & 0,05 & 6,4 & 0,2 & 6,2 & 0,3 & 14,7 & 0,7 \\
\hline 7- Cynara scolymus & ---- & ---- & 32 & 3 & --- & ---- & 5,52 & 0,01 & 1,9 & 0,3 & 1,0 & 0,8 \\
\hline 10- Malva sylvestris & 51 & 3 & 81 & 2 & 0,05 & 0,04 & 8,16 & 0,08 & 4,3 & 0,2 & 2,3 & 0,3 \\
\hline 11- Matricaria recutita & ---- & ---- & ---- & ---- & 0,04 & 0,02 & 9,1 & 0,2 & 0,9 & 0,2 & ---- & ---- \\
\hline 12- Melissa officinalis & --- & ---- & 47 & 3 & 0,06 & 0,05 & 14,7 & 0,3 & 2,7 & 0,2 & ---- & --- \\
\hline 13- Mentha pulegium & 109 & 6 & 34 & 2 & 0,07 & 0,01 & 10,5 & 0,1 & 8,2 & 0,1 & 4,6 & 0,6 \\
\hline 14- Mikania glomerata & 2,4 & 0,4 & 75 & 5 & 0,20 & 0,08 & 10,9 & 0,2 & 2,7 & 0,1 & 0,7 & 0,5 \\
\hline 15- Passiflora alata & --- & --- & 54,8 & 0,1 & ---- & --- & 7,3 & 0,2 & 12,8 & 0,2 & 1,2 & 0,7 \\
\hline 16- Paullinia cupana & --- & ---- & 69 & 2 & ---- & ---- & 16,5 & 0,2 & 2,7 & 0,2 & 1,2 & 0,5 \\
\hline 21- Sambucus nigra & --- & --- & 56 & 2 & 0,06 & 0,03 & 11,2 & 0,1 & 1,2 & 0,2 & 2,9 & 0,3 \\
\hline 22- Solanum paniculatum & --- & --- & 203,5 & 0,5 & ---- & --- & 14,68 & 0,07 & 0,4 & 0,3 & 2,1 & 0,3 \\
\hline 23- Stryphnodendron & --- & --- & 194 & 2 & ---- & ---- & 5,9 & 0,2 & 0,7 & 0,1 & 0,9 & 0,3 \\
\hline 24- Zingirber officinale & --- & ---- & 59 & 11 & 0,26 & 0,01 & 3,93 & 0,02 & 1,2 & 0,2 & 1,7 & 0,9 \\
\hline
\end{tabular}

---- Abaixo do limite de detecção 
TABELA 4.10: Resultados obtidos para os extratos das plantas medicinais analisadas. Os valores apresentados correspondem à técnica analítica INAA, ICP OES e CV AAS e à concentração em $\mu \mathrm{g} \mathrm{g}{ }^{-1} \mathrm{e} \pm \mathrm{a}$ incerteza da medida obtida por propagação de erro, exceto onde indicado por \%.

\begin{tabular}{|c|c|c|c|c|c|c|c|c|c|c|c|c|}
\hline Extrato da Planta & \multicolumn{12}{|c|}{ Elementos } \\
\hline Nome científico & As & $\pm 1 \sigma$ & $\mathrm{Ba}$ & $\pm 1 \sigma$ & $\mathrm{Br}$ & $\pm 1 \sigma$ & $\mathrm{Ca} \%$ & $\pm 1 \sigma$ & Co & $\pm 1 \sigma$ & $\mathrm{Cr}$ & $\pm 1 \sigma$ \\
\hline 1- Achyrocline satureioides & 6 & 2 & 6,5 & 0,7 & 0,80 & 0,01 & 0,037 & 0,004 & 26 & 2 & 0,68 & 0,08 \\
\hline 2- Aesculus hippocastanum & ---- & ---- & ---- & ---- & ---- & ---- & 0,029 & 0,003 & 23 & 2 & 0,59 & 0,05 \\
\hline 3- Bidens pilosa & ---- & ---- & 8,1 & 0,5 & 2,33 & 0,01 & 0,14 & 0,03 & 99 & 6 & 0,28 & 0,02 \\
\hline 4- Calendula officinalis & ---- & ---- & 2,2 & 0,2 & 0,170 & 0,004 & 0,13 & 0,02 & 78 & 4 & 1,01 & 0,06 \\
\hline 5- Cinnamomum verum & ---- & ---- & ---- & ---- & 0,186 & 0,004 & 0,031 & 0,004 & 74 & 6 & 0,53 & 0,03 \\
\hline 6- Cymbopogon citratus & ---- & ---- & 6,9 & 0,5 & 0,34 & 0,01 & 0,23 & 0,02 & 34 & 2 & 1,8 & 0,1 \\
\hline 7- Cynara scolymus & ---- & ---- & 10,3 & 0,7 & 0,13 & 0,01 & 0,40 & 0,03 & 68 & 4 & 2,7 & 0,2 \\
\hline 8- Eucalyptus globulus & ---- & ---- & 8,2 & 0,6 & 0,47 & 0,01 & 0,020 & 0,003 & 62 & 5 & 0,48 & 0,05 \\
\hline 9- Illicium verum & 44 & 18 & 2,1 & 0,4 & 0,45 & 0,01 & 0,039 & 0,009 & 33 & 2 & 0,19 & 0,04 \\
\hline 10- Malva sylvestris & 44 & 15 & 6,0 & 0,5 & 4,88 & 0,04 & 0,07 & 0,02 & 157 & 10 & 1,17 & 0,20 \\
\hline 11- Matricaria recutita & ---- & ---- & 1,7 & 0,4 & 1,28 & 0,02 & 0,16 & 0,04 & 136 & 12 & 1,1 & 0,2 \\
\hline 12- Melissa officinalis & ---- & ---- & 8,7 & 0,6 & 0,337 & 0,003 & 0,29 & 0,04 & 81 & 7 & 0,69 & 0,07 \\
\hline 13- Mentha pulegium & ---- & ---- & 3,4 & 0,7 & ---- & ---- & 0,031 & 0,004 & 827 & 94 & 1,4 & 0,3 \\
\hline 14- Mikania glomerata & ---- & ---- & 1,8 & 0,2 & ---- & ---- & 0,13 & 0,01 & 36 & 4 & 0,8 & 0,2 \\
\hline 15- Passiflora alata & ---- & ---- & 24,7 & 1,5 & ---- & ---- & 0,15 & 0,01 & 31 & 4 & 1,8 & 0,4 \\
\hline 16- Peumus boldus & 23 & 12 & 1,2 & 0,2 & ---- & ---- & 0,020 & 0,002 & 34 & 4 & 0,8 & 0,2 \\
\hline 17- Phyllanthus niruri & 24 & 4 & 6,4 & 0,5 & 0,60 & 0,01 & 0,17 & 0,04 & 117 & 7 & 0,29 & 0,02 \\
\hline 18- Psidium guajava & 15 & 6 & 1,1 & 0,2 & --- & ---- & 0,012 & 0,002 & 31 & 4 & 0,55 & 0,08 \\
\hline 19- Rosmarinus officinalis & 63 & 13 & 3,8 & 0,3 & ---- & ---- & 0,28 & 0,02 & 91 & 10 & 1,1 & 0,1 \\
\hline 20- Sambucus nigra & ---- & ---- & 0,5 & 0,2 & ---- & ---- & 0,013 & 0,002 & 28 & 5 & 0,3 & 0,1 \\
\hline 21- Solanum paniculatum & ---- & ---- & 3,6 & 0,3 & ---- & ---- & 0,028 & 0,002 & 96 & 11 & 2,65 & 0,36 \\
\hline 22- Stryphnodendron adstringens & 11 & 2 & 3,0 & 0,2 & 0,289 & 0,004 & 0,021 & 0,002 & 10,8 & 0,9 & 0,45 & 0,02 \\
\hline 23- Zingirber officinale & 200 & 10 & 2,3 & 0,3 & 0,536 & 0,004 & 0,012 & 0,002 & 102 & 9 & 0,52 & 0,03 \\
\hline
\end{tabular}

---- Abaixo do limite de detecção 
Continuação: Tabela 4.10

\begin{tabular}{|c|c|c|c|c|c|c|c|c|c|c|c|c|}
\hline Extrato da Planta & \multicolumn{12}{|c|}{ Elementos } \\
\hline Nome científico & $\begin{array}{c}\mathrm{Cs} \\
\mathrm{ng} \mathrm{g}^{-1}\end{array}$ & $\pm 1 \sigma$ & $\mathrm{Fe}$ & $\pm 1 \sigma$ & $\begin{array}{c}\mathrm{Hf} \\
\mathrm{ng} \mathrm{g}^{-1}\end{array}$ & $\pm 1 \sigma$ & $\mathrm{K} \%$ & $\pm 1 \sigma$ & $\mathrm{Na}$ & $\pm 1 \sigma$ & $\mathrm{Rb}$ & \pm 10 \\
\hline 1- Achyrocline satureioides & --- & +--- & 15,7 & 0,7 & --- & $-\cdots$ & $\begin{array}{ll}--- \\
--\end{array}$ & ---- & 273 & 7 & 16,3 & 0,5 \\
\hline 2- Aesculus hippocastanum & 3 & 1 & 38,6 & 0,7 & 1,3 & 0,4 & ---- & ---- & 14,9 & 0,4 & 2,0 & 0,1 \\
\hline 3- Bidens pilosa & 25 & 1 & 14,8 & 0,2 & ---- & ---- & 1,7 & 0,2 & 129 & 3 & 44 & 2 \\
\hline 4- Calendula officinalis & 53 & 5 & 17,1 & 0,3 & --- & ---- & 5 & 2 & 864 & 20 & 50 & 2 \\
\hline 5- Cinnamomum verum & 69 & 4 & 19,6 & 0,3 & ---- & ---- & 0,25 & 0,05 & 181 & 4 & 6,6 & 0,3 \\
\hline 6- Cymbopogon citratus & 118 & 7 & 11,9 & 0,3 & ---- & ---- & --- & --- & 119 & 3 & 41 & 2 \\
\hline 7- Cynara scolymus & 24 & 4 & 24,3 & 0,5 & 1,5 & 0,5 & 8 & 3 & 1952 & 44 & 22,6 & 0,5 \\
\hline 8- Eucalyptus globulus & 11 & 2 & 8,5 & 0,4 & ---- & ---- & 0,5 & 0,1 & 286 & 7 & 14,6 & 0,6 \\
\hline 9- Illicium verum & 241 & 18 & 20,5 & 0,6 & ---- & ---- & 1,2 & 0,6 & 71 & 2 & 26 & 1 \\
\hline 10- Malva sylvestris & 48 & 5 & 23,2 & 0,6 & ---- & ---- & 2 & 1 & 169 & 4 & 20,7 & 0,9 \\
\hline 11- Matricaria recutita & 74 & 7 & 12,5 & 0,4 & ---- & ---- & 4 & 2 & 275 & 7 & 60 & 3 \\
\hline 12- Melissa officinalis & 67 & 6 & 7,6 & 0,3 & 1,1 & 0,4 & 1,2 & 0,3 & 112 & 3 & 15,4 & 0,6 \\
\hline 13- Mentha pulegium & 19 & 5 & 75,9 & 1,8 & --- & --- & --- & --- & 655 & 21 & 20 & 1 \\
\hline 14- Mikania glomerata & 169 & 20 & 11,4 & 0,2 & ---- & --- & ---- & ---- & 933 & 30 & 135 & 8 \\
\hline 15- Passiflora alata & 21 & 3 & 19,4 & 0,5 & 1,8 & 0,7 & ---- & ---- & 146 & 5 & 54 & 3 \\
\hline 16- Peumus boldus & 17 & 3 & 13,4 & 0,5 & ---- & --- & ---- & ---- & 264 & 9 & 9,0 & 0,5 \\
\hline 17- Phyllanthus niruri & 11 & 1 & 18,0 & 0,4 & ---- & ---- & 1,0 & 0,1 & 100 & 2 & 5,8 & 0,2 \\
\hline 18- Psidium guajava & 8 & 2 & 8,3 & 0,3 & ---- & --- & --- & -- & --- & -- & 6,3 & 0,4 \\
\hline 19- Rosmarinus officinalis & ---- & --- & 26,4 & 0,7 & 3,0 & 0,7 & ---- & ---- & 260 & 9 & 3,2 & 0,2 \\
\hline 20- Sambucus nigra & 6 & 2 & 9,3 & 0,4 & --- & ---- & ---- & ---- & 109 & 4 & 5,6 & 0,3 \\
\hline 21-Solanum paniculatum & 113 & 13 & 28,5 & 0,5 & ---- & & ---- & ---- & 233 & 8 & 22 & 1 \\
\hline 22- Stryphnodendron adstringens & 16 & 1 & 39,4 & 0,4 & 2,8 & 0,2 & ---- & ---- & 455 & 11 & 9,3 & 0,3 \\
\hline 23- Zingirber officinale & ---- & ---- & 34,3 & 0,5 & ---- & ---- & ---- & ---- & --- & ---- & 8,4 & 0,3 \\
\hline
\end{tabular}

---- Abaixo do limite de detecção 
Continuação: Tabela 4.10

\begin{tabular}{|c|c|c|c|c|c|c|c|c|c|c|c|c|}
\hline Extrato da Planta & \multicolumn{12}{|c|}{ Elementos } \\
\hline Nome científico & $\begin{array}{c}\mathrm{Sb} \\
\mathrm{ng} \mathrm{g}^{-1}\end{array}$ & $\pm 1 \sigma$ & $\begin{array}{c}\mathrm{Sc} \\
\mathrm{ng} \mathrm{g}^{-1}\end{array}$ & $\pm 1 \sigma$ & $\mathrm{Se}$ & $\pm 1 \sigma$ & $\begin{array}{c}\mathrm{Ta} \\
\mathbf{n g ~ g}^{-1}\end{array}$ & $\pm 1 \sigma$ & $\begin{array}{c}\text { Th } \\
\mathbf{n g ~ g}^{-1}\end{array}$ & $\pm 1 \sigma$ & $\begin{array}{c}U \\
\mathrm{Ug} \mathrm{g} \mathbf{g}^{-1}\end{array}$ & $\pm 1 \sigma$ \\
\hline 1- Achyrocline satureioides & 8,0 & 0,9 & 3,6 & 0,2 & ---- & $\begin{array}{ll}--- \\
-\cdots\end{array}$ & ---- & $\begin{array}{c}--- \\
\end{array}$ & ---- & ---- & --- & $\begin{array}{c}--- \\
-\end{array}$ \\
\hline 2- Aesculus hippocastanum & 11,7 & 0,9 & 0,6 & 0,0 & ---- & ---- & ---- & ---- & 2,68 & 1,06 & ---- & --- \\
\hline 3- Bidens pilosa & 11 & 1 & 2,7 & 0,1 & ---- & ---- & ---- & ---- & 4,1 & 0,5 & ---- & --- \\
\hline 4- Calendula officinalis & 19 & 1 & 4,1 & 0,2 & 0,05 & 0,01 & ---- & ---- & 9,5 & 0,9 & ---- & ---- \\
\hline 5- Cinnamomum verum & 4,7 & 0,4 & 1,4 & 0,0 & ---- & ---- & ---- & ---- & 2,4 & 0,3 & ---- & --- \\
\hline 6- Cymbopogon citratus & 277 & 38 & 2,5 & 0,1 & ---- & ---- & ---- & ---- & ---- & ---- & ---- & --- \\
\hline 7- Cynara scolymus & 24 & 3 & 5,9 & 0,2 & ---- & ---- & ---- & ---- & 9 & 1 & ---- & ---- \\
\hline 8- Eucalyptus globulus & 8,5 & 0,7 & 8,0 & 0,3 & ---- & ---- & ---- & --- & 7,8 & 1,0 & ---- & ---- \\
\hline 9- Illicium verum & 18 & 2 & 1,9 & 0,1 & ---- & ---- & ---- & ---- & 2,3 & 0,7 & ---- & --- \\
\hline 10- Malva sylvestris & ---- & --- & 11,8 & 0,4 & ---- & ---- & ---- & ---- & 34 & 2 & 16 & 2 \\
\hline 11- Matricaria recutita & 9 & 2 & 1,9 & 0,1 & ---- & ---- & ---- & ---- & ---- & ---- & ---- & --- \\
\hline 12- Melissa officinalis & 26 & 2 & 4,6 & 0,2 & ---- & ---- & ---- & ---- & 5,8 & 0,8 & ---- & ---- \\
\hline 13- Mentha pulegium & 28 & 2 & 34 & 1 & --- & ---- & ---- & --- & 26 & 3 & --- & --- \\
\hline 14- Mikania glomerata & 15 & 1 & 3,2 & 0,1 & ---- & ---- & ---- & ---- & 2,7 & 0,4 & ---- & --- \\
\hline 15- Passiflora alata & 14,8 & 0,6 & 4,9 & 0,2 & ---- & ---- & ---- & ---- & 5,8 & 0,8 & ---- & ---- \\
\hline 16- Peumus boldus & 8,6 & 1,0 & 7,3 & 0,3 & ---- & ---- & ---- & ---- & 5,8 & 0,9 & ---- & ---- \\
\hline 17- Phyllanthus niruri & 1,3 & 0,2 & 20,3 & 0,7 & ---- & ---- & ---- & ---- & 9 & 1 & ---- & ---- \\
\hline 18- Psidium guajava & 2,3 & 0,7 & 2,1 & 0,1 & ---- & ---- & ---- & ---- & 3,8 & 0,7 & 23 & 7 \\
\hline 19- Rosmarinus officinalis & 4,2 & 1,0 & 11,5 & 0,4 & ---- & ---- & ---- & ---- & 9,1 & 1,0 & ---- & --- \\
\hline 20- Sambucus nigra & 5,6 & 0,7 & 1,5 & 0,1 & ---- & ---- & ---- & ---- & ---- & ---- & ---- & ---- \\
\hline 21- Solanum paniculatum & 36 & 3 & 6,7 & 0,2 & ---- & ---- & 1,4 & 0,4 & 22 & 2 & ---- & ---- \\
\hline 22- Stryphnodendron adstringens & ---- & --- & 4,0 & 0,1 & 0,018 & 0,003 & 0,7 & 0,1 & 17 & 1 & 5,7 & 0,6 \\
\hline 23- Zingirber officinale & 10,8 & 0,4 & 4,2 & 0,2 & 0,09 & 0,02 & ---- & ---- & 5,4 & 0,9 & ---- & ---- \\
\hline
\end{tabular}

---- Abaixo do limite de detecção 
Continuação: Tabela 4.10

\begin{tabular}{|c|c|c|c|c|c|c|c|c|c|c|c|c|}
\hline Extrato da Planta & \multicolumn{12}{|c|}{ Elementos } \\
\hline Nome científico & $\mathrm{Zn}$ & $\pm 1 \sigma$ & $\mathrm{Zr}$ & $\pm 1 \sigma$ & $\begin{array}{c}\text { Cd } \\
\text { ng g }^{-1}\end{array}$ & $\pm 1 \sigma$ & $\mathrm{Cu}$ & $\pm 1 \sigma$ & $\mathbf{N i}$ & $\pm 1 \sigma$ & $\mathbf{P b}$ & $\pm 1 \sigma$ \\
\hline 1- Achyrocline satureioides & 8,4 & 0,6 & $\begin{array}{ll}--- \\
-1\end{array}$ & $\begin{array}{ll}--- \\
\end{array}$ & 18 & 2 & 1,29 & 0,02 & 0,15 & 0,01 & 0,27 & 0,02 \\
\hline 2- Aesculus hippocastanum & 5,5 & 0,2 & 19 & 1 & 19 & 1 & 1,30 & 0,02 & 0,13 & 0,01 & 0,32 & 0,04 \\
\hline 3- Bidens pilosa & ---- & ---- & ---- & ---- & 19 & 3 & 1,15 & 0,01 & 0,151 & 0,006 & 0,15 & 0,02 \\
\hline 4- Calendula officinalis & --- & $\mid---$ & ---- & ---- & 33 & 3 & 0,946 & 0,009 & 0,04 & 0,01 & 0,25 & 0,06 \\
\hline 5- Cinnamomum verum & 3,6 & 0,1 & --- & ---- & --- & --- & 0,137 & 0,006 & 0,024 & 0,007 & 0,10 & 0,02 \\
\hline 6- Cymbopogon citratus & 5,2 & 0,2 & ---- & --- & 8 & 2 & 0,209 & 0,005 & --- & --- & 0,12 & 0,04 \\
\hline 7- Cynara scolymus & 9,1 & 0,4 & ---- & ---- & 16 & 4 & 2,34 & 0,04 & 0,020 & 0,007 & 0,197 & 0,006 \\
\hline 8- Eucalyptus globulus & 4,0 & 0,2 & 1,0 & 0,3 & 7,1 & 0,7 & 1,54 & 0,01 & 0,25 & 0,02 & 0,13 & 0,05 \\
\hline 9- Illicium verum & 3,7 & 0,2 & --- & ---- & 9 & 5 & 2,105 & 0,004 & 0,11 & 0,01 & 0,32 & 0,04 \\
\hline 10- Malva sylvestris & 18,2 & 0,8 & 3,2 & 0,7 & 17 & 4 & 1,19 & 0,02 & 0,50 & 0,02 & 0,18 & 0,03 \\
\hline 11- Matricaria recutita & 13,4 & 0,6 & --- & --- & 21 & 1 & 0,882 & 0,009 & 0,11 & 0,01 & 0,09 & 0,04 \\
\hline 12- Melissa officinalis & 8,9 & 0,4 & 1,2 & 0,3 & 6 & 1 & 0,913 & 0,008 & 0,174 & 0,002 & 0,13 & 0,03 \\
\hline 13- Mentha pulegium & 28 & 2 & 4,8 & 1,0 & 35 & 3 & 0,75 & 0,02 & 0,249 & 0,001 & 0,20 & 0,01 \\
\hline 14- Mikania glomerata & 6,8 & 0,4 & 1,1 & 0,2 & 14 & 2 & 1,30 & 0,02 & 0,157 & 0,006 & 0,33 & 0,03 \\
\hline 15- Passiflora alata & 13,8 & 0,9 & --- & ---- & 18 & 2 & 0,422 & 0,009 & 0,05 & 0,01 & 0,151 & 0,008 \\
\hline 16- Peumus boldus & 5,9 & 0,4 & ---- & --- & 23 & 2 & 0,12 & 0,01 & 0,05 & 0,01 & 0,15 & 0,03 \\
\hline 17- Phyllanthus niruri & ---- & $\mid---$ & 0,5 & 0,2 & 18 & 2 & 0,415 & 0,007 & 0,051 & 0,006 & 0,11 & 0,02 \\
\hline 18- Psidium guajava & 8,7 & 0,6 & --- & ---- & 12 & 3 & 1,388 & 0,004 & 0,15 & 0,01 & 0,39 & 0,04 \\
\hline 19- Rosmarinus officinalis & 18 & 1 & ---- & ---- & 14,8 & 0,6 & 0,252 & 0,005 & 0,04 & 0,01 & 0,33 & 0,02 \\
\hline 20- Sambucus nigra & 13,7 & 0,9 & 0,7 & 0,3 & 18 & 2 & 1,93 & 0,02 & 0,143 & 0,006 & 0,58 & 0,03 \\
\hline 21- Solanum paniculatum & 11,0 & 0,7 & 3,5 & 0,4 & 40 & 3 & 2,17 & 0,01 & 0,10 & 0,03 & 0,49 & 0,04 \\
\hline 22- Stryphnodendron adstringens & 6,3 & 0,2 & 4,7 & 0,4 & 5,6 & 0,6 & 0,148 & 0,005 & 0,066 & 0,006 & 0,63 & 0,01 \\
\hline 23-Zingirber officinale & 16,6 & 0,6 & --- & ---- & 9 & 1 & 0,45 & 0,01 & 0,06 & 0,03 & 0,21 & 0,05 \\
\hline
\end{tabular}

---- Abaixo do limite de detecção 


\section{DISCUSSÃO}

\subsection{Constituintes inorgânicos}

A segurança e a eficácia dos produtos dependem de diversos fatores, dentre estes se destaca a qualidade do produto comercializado. Segundo Farias (2001), a eficácia é dada pela comprovação, por meio de ensaios farmacológicos pré-clínicos e clínicos e dos efeitos biológicos preconizados para esses recursos terapêuticos e a segurança é determinada pelos ensaios que comprovam a ausência de efeitos tóxicos. A má qualidade de um produto fitoterápico ou droga vegetal pode não só vir a anular a sua eficácia como também trazer riscos à saúde do consumidor.

$\mathrm{Na}$ triagem feita com as 24 espécies escolhidas neste estudo para a separação e constatação de substâncias estranhas, observou-se que as maiores quantidades de material estranho foram encontrados nas amostras cuja parte indicada para consumo eram as folhas, como exemplo, as amostras de Sambucus nigra (sabugueiro) com $26,5 \%$ de material estranho, Eucalyptus globulus (eucalipto) com $30,4 \%$, Psidium guajava (goiabeira) com $45,2 \%$, chegando a $52,8 \%$ na amostra de Mikania glomerata (guaco). Observou-se que, nestas amostras, os principais tipos de matéria estranha encontrados foram caules, raízes e areia.

Ressalta-se que matérias estranhas são consideradas impurezas desde que não caracterizem falsificação ou adulteração da amostra (Farias, 2003). Se observada alteração do produto, esta pode ser de forma não intencional pelo acréscimo da mistura de outras plantas, devido às condições de fabricação não adequadas, o que diminui a qualidade final da droga vegetal ou ainda, feito de forma intencional como para a alteração do peso real indicado na embalagem tornando-se, fraude de origem econômica contra o consumidor.

Melo et al. (2004) enfatizam ainda que a fraude e a má qualidade em fitoterápicos são motivos de preocupação por parte dos profissionais da área de saúde e da comunidade científica, pois interferem na eficácia e segurança do produto a ser consumido. 
Por outro lado quando a parte indicada para uso da planta são as cascas, semente, fruto, flor, raiz, rizoma ou a planta inteira, os teores de material estranho são geralmente inferiores a $1 \%$ ou inexistentes como nas amostras de Paullinia cupana (guaraná) e Aesculus hippocastanum (castanha-da-índia) cuja indicação de uso são as sementes; Calendula officinalis (calêndula) cuja indicação de uso são as flores, Melissa officinalis (melissa) cuja indicação de uso são as sumidades floridas, Stryphnodendrom adstrigens (barbatimão) e Cinnamomum verum (canela) cuja indicação de uso são as cascas e Zingiber officinale (gengibre) que apresentou o menor valor para matéria estranha e sua indicação de uso são seus rizomas.

A principal forma de comercialização de plantas medicinais é a desidratada, ou seja, na forma de planta seca. A secagem de plantas medicinais tem por objetivo retirar a maior parte da água disponível nas células e nos tecidos, impedindo o processo de degradação enzimática e proporcionando a conservação do produto pelo período de tempo necessário para que se obtenha uma nova safra. Visa também contribui para a manutenção da qualidade do produto em relação à composição química, impedindo que a umidade provoque a ativação de enzimas que criem condições favoráveis para a proliferação de micro-organismos, uma vez que o ambiente úmido é favorável a este tipo de contaminação vegetal (Farias, 2003). Neste quesito os resultados obtidos foram satisfatórios, pois apenas a amostra de Illicium verum (anis estrelado) apresentou teor de umidade em quantidade maior do que o estabelecido pela Farmacopeia Brasileira que é de $7 \%$ e, neste estudo, esta amostra apresentou um teor de 11,6\%.

Segundo a Farmacopéia Brasileira IV (1988), as cinzas totais incluem cinzas fisiológicas, as quais são derivadas do tecido vegetal e as cinzas não fisiológicas, que são derivadas de materiais estranhos, especialmente areia e terra. Comparando-se os valores de cinzas totais obtidos com os estabelecidos pela Farmacopeia Brasileira, que variam de 2 a 16\%, os resultados demonstraram que a maioria das plantas medicinais estudadas apresenta-se abaixo dos limites permitidos. Apenas duas amostras, Cinnamomum verum (canela) com $24,9 \%$ e 
Illicim verum (anis estrelado) com 36,1\%, apresentaram teores de cinzas totais superiores aos permitidos, que são de $5 \%$ e $6 \%$, respectivamente.

A determinação das cinzas insolúveis em ácido contidas em amostras de plantas medicinais permite a verificação da adição de matéria inorgânica ou contaminante como resíduo de terra ou areia e são, geralmente, observados em raízes. Neste estudo, quando comparado com dados da Farmacopeia, apenas a amostra de Passiflora alata (maracujá) apresentou um teor de cinzas insolúveis em ácido (4,8\%) bem acima do máximo permitido que é de 0,4\% para esta espécie.

\subsection{Comparações dos resultados obtidos com dados de literatura}

Comparando-se os resultados obtidos nas plantas medicinais analisadas neste estudo com os de Cantarelli et al., (2010) para a amostra de Achyrocline satureioides (macela), pode-se observar que as concentrações de Ba $\left(66 \mu \mathrm{g} \mathrm{g}^{-1}\right)$ e Co $\left(0,36 \mu \mathrm{g} \mathrm{g}^{-1}\right)$ estão em concordância com os resultados obtidos neste trabalho para Ba $\left(68 \mu \mathrm{g} \mathrm{g}^{-1}\right)$ e Co $\left(0,40 \mu \mathrm{g} \mathrm{g}^{-1}\right)$. Para as concentrações dos elementos $\mathrm{Cu}$ (12 $\left.\mu \mathrm{g} \mathrm{g}^{-1}\right)$, Fe $\left(639 \mu \mathrm{g} \mathrm{g}^{-1}\right), \mathrm{K}\left(11737 \mu \mathrm{g} \mathrm{g}^{-1}\right)$, Mn $\left(152 \mu \mathrm{g} \mathrm{g}^{-1}\right)$ e $\mathrm{V}\left(1,43 \mu \mathrm{g} \mathrm{g}^{-1}\right)$ verifica-se que as concentrações obtidas neste trabalho se mostraram inferiores $\mathrm{Cu}(9,67 \mu \mathrm{g} \mathrm{g}$ $\left.{ }^{1}\right)$, Fe $\left(429 \mu \mathrm{g} \mathrm{g}^{-1}\right), \mathrm{K}\left(9199 \mu \mathrm{g} \mathrm{g}^{-1}\right), \mathrm{Mn}\left(73 \mu \mathrm{g} \mathrm{g}^{-1}\right)$ e $\mathrm{V}\left(0,08 \mu \mathrm{g} \mathrm{g}^{-1}\right)$, em relação aos elementos $\mathrm{Ni}\left(2,12 \mu \mathrm{g} \mathrm{g}^{-1}\right)$ e $\mathrm{Ti}\left(25 \mu \mathrm{g} \mathrm{g}^{-1}\right)$ as concentrações obtidas neste trabalho $\mathrm{Ni}\left(6,7 \mu \mathrm{g} \mathrm{g}^{-1}\right)$ e $\mathrm{Ti}\left(92 \mu \mathrm{g} \mathrm{g}{ }^{-1}\right)$ foram superiores às relatadas na referência citada.

A concentração de Zn determinada por Karada e Kara (2012) e Anicic et al., (2011) em amostras de Aesculus hippocastanum (castanha-da-índia) são concordantes com os valores encontrados no presente estudo.

Lou et al. (2011) e Wu et al. (2010) determinaram concentrações de Ca (17 $\left.20 \mu \mathrm{g} \mathrm{g}{ }^{-1}\right)$, Cr $\left(0,8-2,4 \mu g g^{-1}\right)$, Fe $\left(210-440 \mu g g^{-1}\right)$ e $Z n\left(150-183 \mu g^{-1}\right)$ em amostras de Bidens pilosa (picão). Comparando-se com os resultados obtidos com os do presente estudo o $\mathrm{Zn}$ apresenta um valor inferior enquanto que o $\mathrm{Ca}$ apresenta um valor significativamente superior ao relatado pelos referidos autores. 
Sun et al. (2009), obtiveram uma concentração de $147,3 \mu \mathrm{g} \mathrm{g}^{-1}$ de $\mathrm{Cd}$ nas folhas de Bidens pilosa (picão), valor muito superior quando comparado com o encontrado neste trabalho $0,24 \mu \mathrm{g} \mathrm{g} \mathrm{g}^{-1}$. Para os elementos $\mathrm{Cu}$ e $\mathrm{Pb}$, as concentrações obtidas neste trabalho foram bastante inferiores àquelas encontradas no estudo realizado por Lou et al., (2011) para esta espécie, que foi, respectivamente, de $71,4 \mu \mathrm{g} \mathrm{g}^{-1}$ e $43,7 \mu \mathrm{g} \mathrm{g}^{-1}$.

Ducat et al. 2011, avaliou os elementos $\mathrm{Ca}, \mathrm{K}, \mathrm{Na}$ e $\mathrm{Zn}$, em amostras de Calendula officinalis (calêndula). As concentrações encontradas por estes autores, $167 \mu \mathrm{g} \mathrm{g}^{-1}, 9579 \mu \mathrm{g} \mathrm{g}^{-1}, 154 \mu \mathrm{g} \mathrm{g}^{-1}$ e $10 \mu \mathrm{g} \mathrm{g}^{-1}$, respectivamente, são mais elevadas do que as obtidas no presente estudo.

As concentrações de Ca $\left(9070-10130 \mu \mathrm{g} \mathrm{g}{ }^{-1}\right)$, Co $\left(0,058-0,062 \mu \mathrm{g} \mathrm{g}^{-1}\right), \mathrm{Cr}$ $\left(0,48-0,56 \mu \mathrm{g} \mathrm{g}^{-1}\right)$ e $\mathrm{Zn}\left(35-42 \mu \mathrm{g} \mathrm{g}{ }^{-1}\right)$ obtidas para Cinnamomum verum (canela) por Karada e Kara (2012) apresentam a mesma ordem de grandeza para os elementos $\mathrm{Ca}$ e $\mathrm{Zn}$, enquanto que os elementos $\mathrm{Co}$ e $\mathrm{Cr}$ deste trabalho possuem concentrações relativamente mais elevadas.

A análise do Cymbopogon citratus (capim santo) indicou que o Ca e K são mais enriquecidos nas amostras deste estudo que naquelas apresentadas por Ducat et al. (2011) e Naithani e Kakkar (2006) que obtiveram valores de $99 \mathrm{\mu g} \mathrm{g}^{-1}$ para o $\mathrm{Ca}, 4,0 \mu \mathrm{g} \mathrm{g}^{-1}$ para o $\mathrm{Cr}, 2801 \mu \mathrm{g} \mathrm{g}{ }^{-1}$ para o $\mathrm{K}, 71 \mu \mathrm{g} \mathrm{g}^{-1}$ para o $\mathrm{Na}, 3,37 \mu \mathrm{g} \mathrm{g}^{-1}$ para o $\mathrm{Ni}, 9,97 \mu \mathrm{g} \mathrm{g}{ }^{-1}$ para o $\mathrm{Pb}$ e 4,4 $\mu \mathrm{g} \mathrm{g}^{-1}$ para o $\mathrm{Zn}$. Em relação ao elemento Cd cuja concentração variou de 0,07 a $0,27 \mu g^{-1}$ no estudo de Naithani e Kakkar (2006) o presente estudo demonstrou concordância entre os valores obtidos.

Assim como verificado para outras plantas, a Cynara scolymus (alcachofra) também apresentou concentração de Cr bastante superior ao determinado em outro trabalho. Razic et al. (2008), determinaram para este elemento o valor de $0,91 \mu \mathrm{g} \mathrm{g}^{-1}$ e para os elementos Ca, Fe e Zn obtiveram valores de $11772 \mu \mathrm{g} \mathrm{g}^{-1}, 123,7 \mu \mathrm{g} \mathrm{g}{ }^{-1} \mathrm{e}$ $26,5 \mu \mathrm{g} \mathrm{g}^{-1}$, respectivamente. No estudo feito por Peris et al., (2007) foram obtidas concentrações de Ni $\left(1,32 \mu \mathrm{g} \mathrm{g}^{-1}\right), \mathrm{Cu}\left(8,7 \mu \mathrm{g} \mathrm{g}^{-1}\right), \mathrm{Cr}\left(90,68 \mu \mathrm{g} \mathrm{g}{ }^{-1}\right)$, Fe $\left(65 \mu \mathrm{g} \mathrm{g}^{-1}\right)$, $\mathrm{Mn}\left(21 \mu \mathrm{g} \mathrm{g}{ }^{-1}\right), \mathrm{Pb}\left(0,28 \mu \mathrm{g} \mathrm{g}^{-1}\right)$ e $\mathrm{Zn}\left(44,3 \mu \mathrm{g} \mathrm{g}^{-1}\right)$ em amostras desta mesma 
espécie e verifica-se que os elementos $\mathrm{Fe}, \mathrm{Cr}, \mathrm{Mn}$ e $\mathrm{Pb}$ apresentaram concentrações maiores no presente trabalho, enquanto os elementos $\mathrm{Cu}$ e $\mathrm{Zn}$ apresentaram concentrações menores.

Analisando amostras de Eucalyptus globulus (eucalipto), Queralt et al. (2005) determinaram valores de $12184 \mu \mathrm{g} \mathrm{g}^{-1}, 507 \mu \mathrm{g} \mathrm{g}^{-1}, 250 \mu \mathrm{g} \mathrm{g}^{-1}, 28 \mu \mathrm{g} \mathrm{g}^{-1}$ e $20 \mu \mathrm{g} \mathrm{g}^{-1}$ para $\mathrm{Ca}, \mathrm{Fe}, \mathrm{Na}, \mathrm{Rb}$ e $\mathrm{Zn}$, respectivamente. Nota-se que estes valores são concordantes com os apresentados para a análise desta planta no presente trabalho.

Amostras de Malva sylvestris (malva) analisadas por Hiçsönmez et al. (2009) apresentaram as seguintes concentrações para os elementos $\mathrm{Ba}\left(3,4-19,1 \mu \mathrm{g} \mathrm{g}^{-1}\right)$, Ca $\left(6778-19000 \mu g^{-1}\right)$, Co $\left(0,9-1,2 \mu g^{-1}\right), \operatorname{Cr}\left(0,1-3,9 \mu g g^{-1}\right)$, Cu $(6,1-10,3$ $\left.\mu \mathrm{g} \mathrm{g}{ }^{-1}\right)$, Fe $\left(40,7-106,3 \mu \mathrm{g} \mathrm{g}^{-1}\right), \mathrm{K}\left(212,6-371,3 \mu \mathrm{g} \mathrm{g}^{-1}\right), \mathrm{Na}\left(5,2-83,1 \mu \mathrm{g} \mathrm{g}^{-1}\right), \mathrm{Pb}$ $\left(1,2-2,0 \mu \mathrm{g} \mathrm{g}^{-1}\right)$, Ti $\left(0,2-1,4 \mu \mathrm{g} \mathrm{g}^{-1}\right), \mathrm{U}\left(0,1-0,6 \mu \mathrm{g} \mathrm{g}^{-1}\right)$ e $\mathrm{Zn}\left(12,3-33,4 \mu \mathrm{g} \mathrm{g}{ }^{-1}\right)$. Entre estes valores pode-se observar que os elementos $\mathrm{Ba}, \mathrm{Cr}, \mathrm{Fe}, \mathrm{K}$ e $\mathrm{Ti}$ determinados no presente estudo possuem concentrações significativamente maiores.

Gjorgieva et al. (2010) e Queralt et al, (2005) apresentaram os seguintes resultados para análise de Matricaria recutita (camomila): Ca $\left(7114 \mu \mathrm{g} \mathrm{g}^{-1}\right), \mathrm{Cr}(3,51$ $\left.\mu \mathrm{g} \mathrm{g}^{-1}\right)$, Fe $\left(227,5 \mu \mathrm{g} \mathrm{g}^{-1}\right)$, Na $\left(277,7 \mu \mathrm{g} \mathrm{g}{ }^{-1}\right)$, Rb $\left(20 \mu \mathrm{g} \mathrm{g}^{-1}\right)$ e Zn $\left(35,5 \mu \mathrm{g} \mathrm{g}^{-1}\right)$; indicando um enriquecimento de $\mathrm{Cr}$ nas amostras desta planta, aqui analisadas. Em relação aos elementos $\mathrm{Cd}, \mathrm{Cu}, \mathrm{Mn}$ e $\mathrm{Pb}$ analisados por Gjorgieva et al., 2010, que obtiveram os respectivos resultados $7,94 \mu \mathrm{g} \mathrm{g}^{-1}, 15,88 \mu \mathrm{g} \mathrm{g}^{-1}, 90,01 \mu \mathrm{g} \mathrm{g}^{-1}$ e 1,57 $\mu \mathrm{g}$ $\mathrm{g}^{`} 1$, para esta mesma espécie verifica-se que no presente estudo as concentrações obtidas são inferiores.

Petenatti et al. (2011) determinaram as concentrações de Ca $\left(14800 \mu \mathrm{g} \mathrm{g}^{-1}\right)$, Fe $\left(900 \mu \mathrm{g} \mathrm{g}^{-1}\right), \mathrm{K}\left(16900 \mu \mathrm{g} \mathrm{g}^{-1}\right)$, Na $\left(490 \mu \mathrm{g} \mathrm{g}^{-1}\right)$ e Cu $\left(13500 \mu \mathrm{g} \mathrm{g}^{-1}\right)$ em amostras de Melissa officinalis (melissa). Os valores encontrados foram concordantes com os do presente estudo. 
Mamani et al. (2004), analisou a espécie Mikania glomerata (guaco) para a determinação da concentração de $\mathrm{Cd}\left(0,21 \mu \mathrm{g} \mathrm{g}^{-1}\right)$ e $\mathrm{Pb}\left(0,43 \mu \mathrm{g} \mathrm{g}^{-1}\right)$ e encontraram resultados que foram concordantes para o elemento $\mathrm{Cd}$ e inferiores para o $\mathrm{Pb}$.

Para espécie Peumus boldus (boldo-do-chile), Schwanz et al. (2007) quantificou 109,7 - 315,7 $\mathrm{\mu g} \mathrm{g}^{-1}$ de Fe, mostrando-se este valor próximo ao que foi determinado neste trabalho.

Gowrishankar et al. (2010) determinaram as seguintes concentrações para os elementos $\mathrm{Br}\left(44,9 \mu \mathrm{g} \mathrm{g}^{-1}\right)$, Ca $\left(17773 \mu \mathrm{g} \mathrm{g}^{-1}\right), \mathrm{Cr}\left(65,4 \mu \mathrm{g} \mathrm{g}^{-1}\right)$, Fe $\left(259,9 \mu \mathrm{g} \mathrm{g}^{-1}\right)$ e $\mathrm{Zn}$ $\left(21 \mathrm{\mu g} \mathrm{g}^{-1}\right)$ em amostras de Phyllanthus niruri (quebra-pedra), que apresentou valor consideravelmente maior para o Fe no presente estudo.

Os resultados determinados neste estudo para Rosmarinus officinalis (alecrim) são concordantes com aqueles obtidos por Cala et al. (2005) e Karada e Kara (2012) para os elementos Ba $\left(9,91-12,93 \mu \mathrm{g} \mathrm{g}^{-1}\right) \mathrm{Ca}\left(12750 \mu \mathrm{g} \mathrm{g}^{-1}\right)$, Co $(0,230$ $\left.-0,306 \mu \mathrm{g} \mathrm{g}^{-1}\right)$ e $\mathrm{Cr}\left(2,91-3,37 \mu \mathrm{g} \mathrm{g}^{-1}\right)$, superiores para Fe $\left(75,5 \mu \mathrm{g} \mathrm{g}^{-1}\right)$ e $\mathrm{Zn}(27,6$ $\left.\mu \mathrm{g} \mathrm{g}^{-1}\right)$, e inferiores para $\mathrm{Na}\left(1190 \mu \mathrm{g} \mathrm{g}^{-1}\right)$.

Nos resultados encontrados por Abdul et al. (2007) para os elementos $\mathrm{Cu}(3,8$ $\left.-8,5 \mu \mathrm{g} \mathrm{g}^{-1}\right)$, Fe $\left(312-682 \mu \mathrm{g} \mathrm{g}^{-1}\right), \mathrm{Ni}\left(3,0-4,8 \mu \mathrm{g} \mathrm{g}^{-1}\right)$, os valores obtidos foram concordantes com o presente estudo exceto para o $\mathrm{Pb}\left(12,4-86,5 \mu \mathrm{g} \mathrm{g}^{-1}\right)$.

As concentrações dos elementos As e Ca presentes em Zingiber officinale (gengibre) medidas neste trabalho foram concordantes com aquelas determinadas por Mishra et al. (2007), WHO (1998), Meena et al. (2010). Em relação ao estudo de Ajasa et al. (2004), por outro lado, se mostraram enriquecidas para Mn (484 $\left.\mathrm{g} \mathrm{g} \mathrm{g}^{-1}\right)$, $\mathrm{Pb}\left(1,7 \mu \mathrm{g} \mathrm{g}^{-1}\right)$, e inferiores para Ca $\left(1840 \mu \mathrm{g} \mathrm{g}^{-1}\right), \mathrm{Cu}\left(3,92 \mu \mathrm{g} \mathrm{g}^{-1}\right), \mathrm{Fe}\left(109 \mu \mathrm{g} \mathrm{g}^{-1}\right), \mathrm{K}$ $\left(16179 \mu \mathrm{g} \mathrm{g}^{-1}\right), \mathrm{Mg}\left(1409 \mu \mathrm{g} \mathrm{g}^{-1}\right)$, Na $\left(64 \mu \mathrm{g} \mathrm{g}{ }^{-1}\right)$ e Zn $\left(23,1 \mu \mathrm{g} \mathrm{g}^{-1}\right)$. O estudo realizado por Naithani e Kakkar (2006) para amostras da mesma espécie encontrou os seguintes resultados para os elementos $\mathrm{Cd}\left(0,18-0,29 \mu \mathrm{g} \mathrm{g}^{-1}\right)$, Ni $(1,10-3,68$ $\left.\mu \mathrm{g} \mathrm{g}^{-1}\right)$ e $\mathrm{Pb}\left(3,44-8,83 \mu \mathrm{g} \mathrm{g}^{-1}\right)$, que são concordantes com os obtidos no presente estudo. 
Há poucos estudos realizados referentes aos extratos feitos a partir das plantas medicinais. Queralt et al. (2004) analisaram Eucaliptus globulus (eucalipto) em relação aos elementos $\mathrm{Ca}\left(24 \mu \mathrm{g} \mathrm{g}^{-1}\right)$, Fe $\left(0,06 \mu \mathrm{g} \mathrm{g}{ }^{-1}\right), \mathrm{K}\left(109 \mu \mathrm{g} \mathrm{g}{ }^{-1}\right)$ e $\mathrm{Na}(41$ $\left.\mu \mathrm{g} \mathrm{g}^{-1}\right)$. Observa-se que todos os resultados obtidos neste trabalho foram superiores aos encontrados nesta referência.

Não foram encontradas referências bibliográficas para as seguintes espécies analisadas neste estudo: Illicium verum (anis estrelado), Mentha pulegium (poejo), Passiflora alata (maracujá), Paullinia cupana (guaraná), Psidium guajava (goiabeira), Sambucus nigra (sabugueiro), Stryphnodendrom adstrigens (barbatimão).

As comparações dos resultados obtidos neste estudo com aqueles encontrados em literatura, de maneira geral, demonstraram uma boa concordância entre os valores de concentração elementar das plantas aqui analisadas e aquelas encontradas nos referidos artigos, embora se possa verificar o enriquecimento de alguns elementos ou deficiência de outros.

\subsection{Composições multielementares das plantas e seus extratos}

As plantas podem acumular elementos químicos em todos os seus tecidos, podendo disponibilizá-los para o ser humano através da cadeia alimentar. Uns dos temas de interesse medicinal é o acumulo desses minerais no organismo devido aos potenciais efeitos nocivos na saúde humana e ao fato de seus limites de tolerância, de maneira em geral, serem muito baixos (Maiga et al., 2005).

No organismo esses elementos atuam como minerais ativando o funcionamento de enzimas, peças chaves nas reações químicas e metabólicas que possibilitam ao corpo a realização de suas atividades de forma precisa. Fato que torna necessário identificar e avaliar a concentração desses elementos em alimentos consumidos normalmente. Nas Tabelas 5.1 e 5.2 são apresentados o número de amostras, a média, média geométrica, mediana, concentração mínima e máxima, desvio padrão e coeficiente de variação para as plantas medicinais e seus extratos. Os elementos $\mathrm{Cl}, \mathrm{Mg}, \mathrm{Mn}, \mathrm{Ti}$ e $\mathrm{V}$ não foram determinados devido a problemas 
técnico no reator e o $\mathrm{Hg}$ ficou abaixo do limite de detecção em todos os extratos de plantas medicinais.

TABELA 5.1: Dados estatísticos mostrando o número de amostras em que cada elemento foi determinado, a média aritmética, média geométrica, mediana, concentração mínima e máxima, desvio padrão da média aritmética e coeficiente de variação das concentrações para as plantas medicinais.

\begin{tabular}{|c|c|c|c|c|c|c|c|c|}
\hline & & & PLANTA & 5 MEDIC & NAIS & & & \\
\hline Elementos & \begin{tabular}{|c|}
$\mathrm{n}=\mathrm{de}$ \\
plantas
\end{tabular} & $\begin{array}{l}\text { Média } \\
\text { Arit. }\end{array}$ & $\begin{array}{c}\text { Média } \\
\text { Geometrica }\end{array}$ & Mediana & \begin{tabular}{|c|} 
Conc. \\
Mínima
\end{tabular} & \begin{tabular}{|c|} 
Conc. \\
Máxima
\end{tabular} & \begin{tabular}{|l|} 
Desvio \\
Padrão \\
\end{tabular} & \begin{tabular}{|c|} 
Coef. \\
Variação
\end{tabular} \\
\hline As $\left(n g g^{-1}\right)$ & 5 & 250 & 190 & 248 & 51,5 & 530 & 184 & 74 \\
\hline $\mathbf{B a}\left(\mu \mathrm{g} \mathrm{g}^{-1}\right)$ & 22 & 59 & 33 & 40 & 2,2 & 187 & 55 & 93 \\
\hline $\mathbf{B r}\left(\mu \mathrm{g} \mathrm{g}^{-1}\right)$ & 24 & 28,0 & 15,76 & 14,41 & 0,72 & 115,26 & 29,6 & 105 \\
\hline Ca (\%) & 24 & 0,9 & 0,6 & 0,79 & 0,10 & 2,0 & 0,6 & 67 \\
\hline $\mathbf{C d}\left(\mu \mathrm{g} \mathrm{g}^{-1}\right)$ & 15 & 0,14 & 0,10 & 0,07 & 0,04 & 0,46 & 0,12 & 86 \\
\hline $\mathbf{C l}(\%)$ & 22 & 0,44 & 0,234 & 0,238 & 0,017 & 1,60 & 0,45 & 102 \\
\hline Co $\left(\mu g^{-1}\right)$ & 24 & 0,8 & 0,4 & 0,36 & 0,07 & 9,1 & 1,8 & 225 \\
\hline $\mathbf{C r}\left(\mu \mathrm{g} \mathrm{g}^{-1}\right)$ & 24 & 28 & 11,4 & 11,0 & 0,50 & 256,5 & 53 & 189 \\
\hline Cs $\left(n g g^{-1}\right)$ & 18 & 199 & 114 & 124 & 14 & 1146 & 263 & 132 \\
\hline Cu $\left(\mu g^{-1}\right)$ & 24 & 9 & 8 & 9 & 2 & 16 & 4 & 44 \\
\hline Fe $\left(\mu g^{-1}\right)$ & 24 & 421 & 229 & 255 & 1,23 & 1882 & 461 & 109 \\
\hline $\mathbf{H f}\left(\mathrm{ng} \mathrm{g}^{-1}\right)$ & 23 & 355 & 116 & 67 & 14 & 2340 & 625 & 176 \\
\hline$H \mathbf{H}\left(n g g^{-1}\right)$ & 23 & 96 & 59,7 & 68,8 & 2,51 & 434 & 94 & 98 \\
\hline $\mathbf{K}(\%)$ & 23 & 2,02 & 1,02 & 1,62 & 0,011 & 8,2 & 1,89 & 93 \\
\hline Mg (\%) & 23 & 0,21 & 0,17 & 0,22 & 0,024 & 0,51 & 0,12 & 57 \\
\hline $\operatorname{Mn}\left(\mu g g^{-1}\right)$ & 24 & 227 & 121 & 128 & 7 & 1046 & 262 & 115 \\
\hline $\mathrm{Na}\left(\mu \mathrm{g} \mathrm{g}^{-1}\right)$ & 23 & 299 & 109 & 100 & 8,8 & 2255 & 550 & 184 \\
\hline $\mathbf{N i}\left(\mu \mathrm{g} \mathrm{g}^{-1}\right)$ & 24 & 5 & 3 & 3 & 0,43 & 27,0 & 6 & 120 \\
\hline $\mathbf{P b}\left(\mu \mathrm{g} \mathrm{g}^{-1}\right)$ & 21 & 5 & 2 & 2 & 0,59 & 38,2 & 8 & 160 \\
\hline $\mathbf{R b}\left(\mu \mathrm{g} \mathrm{g}^{-1}\right)$ & 24 & 36 & 22 & 25 & 3 & 176 & 39 & 108 \\
\hline Sb $\left(n g g^{-1}\right)$ & 15 & 24 & 20 & 23 & 5 & 52 & 13 & 54 \\
\hline Sc $\left(n g g^{-1}\right)$ & 24 & 240 & 54 & 46 & 3 & 3663 & 740 & 308 \\
\hline Se $\left(\mu g^{-1}\right)$ & 14 & 0,28 & 0,24 & 0,19 & 0,13 & 0,80 & 0,20 & 71 \\
\hline $\mathrm{Ta}\left(\mathrm{ng} \mathrm{g}^{-1}\right)$ & 5 & 45 & 26 & 40 & 3 & 91 & 38 & 84 \\
\hline Th $\left(n g g^{-1}\right)$ & 22 & 215 & 73 & 53 & 19 & 1986 & 474 & 220 \\
\hline $\mathbf{T i}\left(\mu \mathrm{g} \mathrm{g}^{-1}\right)$ & 9 & 190 & 72 & 92 & 0,67 & 643,81 & 216 & 113 \\
\hline $\mathbf{U}\left(\mathrm{ng} \mathrm{g}^{-1}\right)$ & 8 & 400 & 262 & 340 & 13 & 871 & 276 & 69 \\
\hline $\mathbf{V}\left(\mu \mathrm{g} \mathrm{g}^{-1}\right)$ & 13 & 1,5 & 0,54 & 0,46 & 0,08 & 7,1 & 2,3 & 153 \\
\hline $\mathbf{Z n}\left(\mu \mathrm{g} \mathrm{g}^{-1}\right)$ & 21 & 31 & 27 & 23 & 11 & 67 & 15 & 48 \\
\hline $\mathbf{Z r}\left(\mu g^{-1}\right)$ & 7 & 32 & 17 & 23 & 2 & 109 & 38 & 118 \\
\hline
\end{tabular}


Tabela 5.2 Dados estatísticos mostrando o número de amostras em que cada elemento foi determinado, a média aritmética, média geométrica, mediana, concentração mínima e máxima, desvio padrão da média aritmética e coeficiente de variação das concentrações para os extratos das plantas medicinais.

\begin{tabular}{|l|c|c|c|c|c|c|c|c|}
\hline \multicolumn{7}{|c|}{ EXTRATOS DE PLANTAS MEDICINAIS } \\
\hline Elementos & $\begin{array}{c}\mathbf{n}^{\mathbf{o}} \text { de } \\
\text { plantas }\end{array}$ & Média & $\begin{array}{c}\text { Média } \\
\text { Geometrica }\end{array}$ & Mediana & $\begin{array}{c}\text { Conc. } \\
\text { Mínima }\end{array}$ & $\begin{array}{c}\text { Conc. } \\
\text { Máxima }\end{array}$ & $\begin{array}{c}\text { Desvio } \\
\text { Padrão }\end{array}$ & $\begin{array}{c}\text { Coef. } \\
\text { Variação }\end{array}$ \\
\hline $\mathbf{A s}\left(\mathrm{ng} \mathrm{g}^{-1}\right)$ & 9 & 48 & 29 & 24 & 6 & 200 & 60 & 125 \\
$\mathbf{B a}\left(\mu \mathrm{g} \mathrm{g}^{-1}\right)$ & 21 & 5,36 & 3,67 & 3,65 & 0,46 & 24,70 & 5,29 & 99 \\
$\mathbf{B r}\left(\mu \mathrm{g} \mathrm{g}^{-1}\right)$ & 14 & 0,91 & 0,52 & 0,46 & 0,13 & 4,88 & 1,28 & 140 \\
$\mathbf{C a}(\%)$ & 23 & 0,11 & 0,06 & 0,04 & 0,01 & 0,40 & 0,11 & 102 \\
$\mathbf{C d}\left(\mathrm{ng} \mathrm{g}^{-1}\right)$ & 22 & 17 & 15 & 17 & 6 & 40 & 9 & 54 \\
$\mathbf{C o}\left(\mathrm{ng} \mathrm{g}^{-1}\right)$ & 23 & 99 & 60 & 68 & 11 & 827 & 164 & 166 \\
$\mathbf{C r}\left(\mu \mathrm{g} \mathrm{g}^{-1}\right)$ & 23 & 0,95 & 0,75 & 0,69 & 0,19 & 2,71 & 0,70 & 74 \\
$\mathbf{C s}\left(\mathrm{ng} \mathrm{g}^{-1}\right)$ & 20 & 56 & 31 & 25 & 3 & 241 & 62 & 112 \\
$\mathbf{C u}\left(\mu \mathrm{g} \mathrm{g}^{-1}\right)$ & 23 & 1,02 & 0,73 & 0,95 & 0,12 & 2,34 & 0,69 & 68 \\
$\mathbf{F e}\left(\mu \mathrm{g} \mathrm{g}^{-1}\right)$ & 23 & 22 & 18 & 18 & 8 & 76 & 15 & 69 \\
$\mathbf{H f}\left(\mathrm{ng} \mathrm{g}^{-1}\right)$ & 6 & 1,93 & 1,81 & 1,68 & 1,14 & 2,96 & 0,79 & 41 \\
$\mathbf{K}(\%)$ & 10 & 2,56 & 1,62 & 1,48 & 0,25 & 8,45 & 2,54 & 99 \\
$\mathbf{N a}\left(\mu \mathrm{g} \mathrm{g}^{-1}\right)$ & 21 & 362 & 219 & 233 & 15 & 1952 & 441 & 122 \\
$\mathbf{N i}\left(\mu \mathrm{g} \mathrm{g}^{-1}\right)$ & 22 & 0,13 & 0,09 & 0,11 & 0,02 & 0,50 & 0,11 & 85 \\
$\mathbf{P b}\left(\mu \mathrm{g} \mathrm{g}^{-1}\right)$ & 23 & 0,25 & 0,22 & 0,20 & 0,09 & 0,63 & 0,15 & 60 \\
$\mathbf{R b}\left(\mu \mathrm{g} \mathrm{g}^{-1}\right)$ & 23 & 26 & 16 & 16 & 2 & 135 & 29 & 113 \\
$\mathbf{S b}\left(\mathrm{ng} \mathrm{g}^{-1}\right)$ & 21 & 26 & 12 & 11 & 1 & 277 & 58 & 225 \\
$\mathbf{S c}\left(\mathrm{ng} \mathrm{g}^{-1}\right)$ & 23 & 6,46 & 4,23 & 4,14 & 0,63 & 33,89 & 7,44 & 115 \\
$\mathbf{S e}\left(\mu \mathrm{g} \mathrm{g}^{-1}\right)$ & 3 & 0,05 & 0,04 & 0,05 & 0,02 & 0,09 & 0,04 & 71 \\
$\mathbf{T a}\left(\mathrm{ng} \mathrm{g}^{-1}\right)$ & 2 & 1,03 & 0,97 & 1,03 & 0,68 & 1,39 & 0,50 & 49 \\
$\mathbf{T h}\left(\mathrm{ng} \mathrm{g}^{-1}\right)$ & 19 & 10 & 7 & 6 & 2 & 34 & 9 & 91 \\
$\mathbf{U}\left(\mathrm{ng} \mathrm{g}^{-1}\right)$ & 3 & 15 & 13 & 16 & 6 & 23 & 9 & 58 \\
$\mathbf{Z n}\left(\mu \mathrm{g} \mathrm{g}^{-1}\right)$ & 20 & 10 & 9 & 9 & 4 & 28 & 6 & 60 \\
$\mathbf{Z r}\left(\mu \mathrm{g} \mathrm{g}^{-1}\right)$ & 10 & 4,00 & 2,18 & 2,19 & 0,52 & 19,24 & 5,60 & 140 \\
\hline
\end{tabular}

Pode-se observar que vários elementos tiveram a sua concentração determinada em apenas um pequeno número de amostras indicando que tais elementos ficaram abaixo do limite de detecção na maioria delas. 
Comparando-se os valores médios é possível observar que a média aritmética é maior que a média geométrica e a mediana para, praticamente todos os elementos. Uma vez que a média geométrica é menos influenciada por valores extremos e a mediana não sofre influência, pode-se concluir que tais valores extremos estão presentes em todas as plantas, ou seja, para cada elemento, pelo menos uma das plantas analisadas possui a capacidade de concentrar este elemento.

Em relação ao coeficiente de variação verifica-se uma ampla faixa de dispersão dos elementos determinados. Entre as possíveis explicações para esta dispersão podemos considerar que foram analisadas plantas de diferentes espécies e que, portanto podem apresentar diferentes características de absorção para os vários elementos; foram analisadas partes diferentes das plantas como raízes, casca, folhas, flores, frutos e sementes. Deve considerar também o fato de que a composição mineral das plantas está relacionada à absorção desses elementos presentes no solo e nas águas; utilização de fertilizantes orgânicos, minerais e pesticidas; o fato de que o processo de absorção de um determinado elemento pode ser afetado pela presença de outros no solo ou na água; e ainda possíveis contaminações por fontes poluidoras.

Nos extratos pode-se observar as mesmas relações para as médias, ou seja, média aritmética maior que e média geométrica e mediana, e estas bastante semelhantes entre si. A dispersão mostrada pelos coeficientes de variação deve estar relacionada a fatores tais como a solubilidade do elemento no solvente utilizado, a volatilidade do elemento na temperatura de preparo do extrato e o tipo de ligação envolvida na estrutura dos compostos vegetais. Os elementos que apresentaram maior variação nos extratos foram $\mathrm{As}, \mathrm{Br}, \mathrm{Co}, \mathrm{Na}$, Sb e $\mathrm{Zr}$. 


\subsubsection{Consideração sobre os elementos $\mathrm{Ca}, \mathrm{Cl}, \mathrm{K}, \mathrm{Mg}$ e $\mathrm{Na}$}

São considerados os principais minerais para a manutenção e o bom funcionamento do organismo. Alguns deles são também nutrientes importantes para as plantas e estão presentes em praticamente todos os seus órgãos e tecidos.

No organismo humano o cálcio (Ca) compõe ossos e dentes sendo imprescindível na habilitação das mensagens conduzidas pelos nervos. Entre outras coisas, ele permite que os músculos se contraiam para que aconteça o batimento cardíaco. Sua deficiência, particularmente em idosos, pode causar a osteoporose. A concentração média para o Ca nas plantas analisadas neste trabalho foi de $0,9 \%$. As maiores concentrações foram observadas nas espécies Psidium guajava (goiabeira) e a Melissa officinalis (melissa), $2 \%$ em ambas. Para os extratos, a concentração média obtida foi de $0,11 \%$ e a espécie que apresentou a maior concentração de $\mathrm{Ca}$ foi a Cynara scolymus (alcachofra) com valor de 0,40\%. O consumo deste chá de acordo com o recomendado pela ANVISA, três vezes ao dia, resulta em uma ingestão de cálcio de $24 \mathrm{mg} / \mathrm{dia}$, valor bem abaixo do limite adequado para este mineral que é de 1000-1200 mg/dia.

O cloro $(\mathrm{Cl})$ é encontrado no líquido extracelular e age com o sódio na manutenção e equilíbrio dos líquidos corpóreos, além de ser um dos componentes do acido clorídrico no estômago. Entre todas as plantas a Melissa officinalis (melissa) foi a que apresentou a maior concentração deste elemento, 1,6\%. A concentração nas demais amostras variou de $0,017 \%$ a $1,38 \%$. As principais funções do potássio $(\mathrm{K})$ e do sódio $(\mathrm{Na})$ são a manutenção do equilíbrio do $\mathrm{pH}$ (ácido-básico), a regulagem do equilíbrio hídrico e a contratura das fibras musculares. A deficiência desses minerais pode ocasionar dores musculares, hipertensão ou hipotensão no caso do sódio. A concentração do $\mathrm{K}$ nas plantas variou de $0,011 \%$ a $8,2 \%$, e cerca de $0,25 \%$ a $8,45 \%$ nos extratos. Nas plantas, a concentração de Na variou entre $8,8 \mu \mathrm{g} \mathrm{g}^{-1}$ e $2255 \mu \mathrm{g} \mathrm{g}{ }^{-1}$ e nos extratos, entre 14,9 $\mu g g^{-1}$ e $1952 \mu g g^{-1}$. 
Importante mineral por atuar especialmente contra doenças cardíacas o magnésio $(\mathrm{Mg})$, também promove o bom funcionamento dos músculos, auxilia em funções neurológicas e no processo digestivo. Sua deficiência pode causar fraqueza muscular, cansaço, comportamento nervoso e hiperatividade em crianças. Este elemento foi determinado para as plantas medicinais na concentração média de $0,21 \%$. A espécie Malva sylvestris (malva) foi a que apresentou a concentração mais elevada para Mg com o valor de 0,51\% e Stryphnodendron adstrigens (barbatimão), a menor concentração, $0,03 \%$.

\subsubsection{Consideração sobre os elementos $\mathrm{Co}, \mathrm{Cr}, \mathrm{Cu}, \mathrm{Fe}, \mathrm{Mn}, \mathrm{Se}$, $\mathrm{V}$ e $\mathrm{Zn}$}

São minerais importantes ao organismo em quantidades menores. São elementos que na maioria das vezes são acumulados no organismo através da alimentação.

Elemento essencial na nutrição humana, o ferro $(\mathrm{Fe})$ é responsável pela produção de hemoglobina, e oxigenação das hemácias, sendo também necessário à saúde do sistema imunológico, uma vez que potencializa a função dos leucócitos (glóbulos brancos, sistema de defesa). Entre as plantas analisadas, a maior concentração de $\mathrm{Fe}$ foi observada na espécie Phyllanthus niruri (quebra-pedra) com $1882 \mu \mathrm{g} \mathrm{g}^{-1}$ e a concentração média foi de $421 \mu \mathrm{g} \mathrm{g}^{-1}$. Para os extratos a espécie Mentha pulegium (poejo) foi a que apresentou a maior concentração de $\mathrm{Fe}$ com 75,9 $\mu \mathrm{g} \mathrm{g}^{-1}$ sendo que a concentração média foi de $22 \mu \mathrm{g} \mathrm{g}^{-1}$. A recomendação diária para este nutriente é de 8 a $18 \mathrm{mg} \mathrm{d}^{-1}$. O uso deste chá, conforme a recomendação da ANVISA, resulta em uma ingestão diária de $0,2277 \mathrm{mg} /$ dia deste elemento. Verificase que este valore é menor do limite tolerável, que é de $45 \mathrm{mg} / \mathrm{dia}$.

Principal protetor do sistema imunológico estimulando a produção de leucócitos, o zinco $(Z n)$, além de auxiliar no processo de cicatrização, de atuar no desenvolvimento do feto e da criança, também é considerado um antioxidante. Sua deficiência causa aumento da suscetibilidade ás infecções. Nas plantas indicadas para o auxílio ao combate às inflamações como Calendula officinalis (calêndula), 
Eucaliptos globulus (eucalipto), Illicium verum (anis estrelado), Malva sylvestris (malva), Mentha pulegium (poejo), Mikania glomerata (guaco), Sambucus nigra (sabugueiro) e Stryphnodendrom adstrigens (barbatimão) a concentração média de

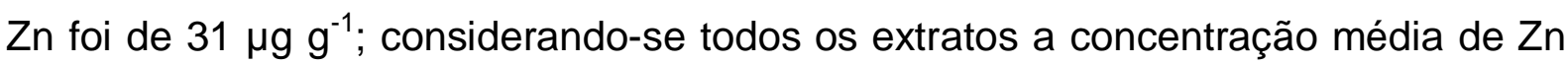
foi $10 \mu \mathrm{g} \mathrm{g}^{-1}$, estando abaixo do limite de detecção apenas para o extrato da amostra Calendula officinalis.

A espécie Malva sylvestris (malva) demonstrou ser a mais enriquecida em Zn com uma concentração de $18,2 \mu \mathrm{g} \mathrm{g}^{-1}$ no extrato, ao ingerir este chá como recomendado pela ANVISA, um individuo estaria inserindo em sua dieta alimentar a quantidade de 0,1456 mg/dia, valor que também fica abaixo limite máximo permitido diariamente deste nutriente para não apresentar risco de efeito adverso que é de 40 $\mathrm{mg} / \mathrm{dia}$ (Dietary Reference Intakes for Zinc, 2001).

Entre algumas das inúmeras funções do cobre $(\mathrm{Cu})$ está a ajuda na formação dos ossos, hemoglobina e hemácias. Funciona em equilíbrio com o zinco e a vitamina $C$ para formar colágeno e a elastina. Sua deficiência pode causar, além de outras coisas, aumento no colesterol. A concentração média de Cu encontrada para as 24 plantas analisadas foi de $9 \mu \mathrm{g} \mathrm{g}^{-1}$, e nos 23 extratos em que este elemento foi determinado a concentração média foi de $1,02 \mu \mathrm{g} \mathrm{g}{ }^{-1}$. A espécie com a maior concentração de Cu no extrato foi a Cynara scolymus (alcachofra) com valor de 2,34 $\mathrm{g} \mathrm{g}^{-1}$, sendo que este chá é normalmente indicado para redução do colesterol. O consumo deste chá introduz 14,04 $\mu \mathrm{g} / \mathrm{dia}$ de $\mathrm{Cu}$ em uma dieta alimentar normal, lembrando que a recomendação diária de ingestão para adultos de Cu é de 700 a $1300 \mu g$ ao dia (Dietary Reference Intakes for copper, 2001).

Participando do metabolismo de carboidratos, gordura e proteínas o manganês $(\mathrm{Mn})$ também é utilizado na produção de energia, crescimento e formação dos ossos, além de auxiliar no funcionamento do cérebro e de ser necessário para o metabolismo da glicose. Quando em deficiência, o Mn pode causar anomalias ósseas e estar relacionado ao diabetes. A concentração média encontrada para $\mathrm{Mn}$ foi de $227 \mu \mathrm{g} \mathrm{g}^{-1}$. Entre as espécies analisadas a Mikania glomerata (guaco) 
demonstrou ser rica em Mn com cerca de $1046 \mu \mathrm{g} \mathrm{g}^{-1}$ de concentração em suas folhas.

Possuindo função similar à vitamina $E$, o selênio $(\mathrm{Se})$ é um excelente antioxidante. Está envolvido na função normal da glândula tireoide e de seus hormônios, além de possuir efeito positivo sobre o sistema imunológico. Este elemento foi determinado apenas em aproximadamente metade das plantas medicinais aqui analisadas, 14 espécies. A concentração média encontrada foi de $0,28 \mu \mathrm{g} \mathrm{g}^{-1}$ para as plantas e $0,05 \mu \mathrm{g} \mathrm{g}^{-1}$ para os extratos. A maior concentração de Se foi determinada no extrato da espécie Zingirber officinale (gengibre) sendo igual a $0,09 \mu \mathrm{g} \mathrm{g}^{-1}$. Nas espécies Paullinia cupana (guaraná), Achyrocline satureioides (macela) e Bidens pilosa (picão), indicadas devido à sua ação antioxidante, a concentração de Se foi de $0,15-0,17-0,37 \mu \mathrm{g} \mathrm{g}^{-1}$ respectivamente, porém no extrato a concentração deste elemento ficou abaixo do limite de detecção para estes três tipos de plantas medicinais. A recomendação diária para este nutriente é de 55 $\mu \mathrm{g}$ ao dia. O uso do chá de gengibre pode fornecer ao indivíduo a metade da recomendação necessária, $0,36 \mu \mathrm{g} / \mathrm{dia}$.

O cromo ( $\mathrm{Cr}$ ) participa do metabolismo de lipídeos e da glicose, portanto, necessário para produção de energia. Auxilia a manutenção de níveis estáveis de açúcares para utilização adequada de insulina, tanto no diabético como no organismo normal. Sua falta pode ocasionar intolerância à glicose, ansiedade e fadiga. Entre as plantas analisadas Bidens pilosa (picão), Cymbopongon citratus (capim santo), Matricaria recutita (camomila), Melissa officinalis (melissa) e Passiflora alata (maracujá), são indicadas para auxiliar no tratamento de quadros de deficiência de Cr. As espécies Cymbopongon citratus (capim santo) e Passiflora alata (maracujá), são as que apresentam a maior concentração nos extratos, sendo que em ambas o valor encontrado foi de $1,8 \mu \mathrm{g} \mathrm{g} \mathrm{g}^{-1}$. O limite de ingestão recomendado para adultos varia de 25 a $35 \mathrm{mg}$ por dia. O uso do chá de jurubeba, como recomendado pela ANVISA, é capaz de fornecer ao organismo uma quantidade de $0,0105 \mathrm{mg} / \mathrm{dia}$. 
Componente da vitamina B12, o cobalto (Co) também auxilia na manutenção do sistema nervoso. Sua deficiência pode acarretar anemia, mais seu excesso pode ocasionar problemas na tireoide. A espécie Mentha pulegium (poejo) foi a que apresentou a maior concentração de Co entre as plantas e os extratos, com valores de $9,1 \mu \mathrm{g} \mathrm{g}^{-1}$ e $0,82 \mu \mathrm{g} \mathrm{g}^{-1}$, respectivamente.

Estudos nutricionais têm demonstrado que o vanádio (V) é um elemento químico essencial para o organismo, sendo que sua deficiência pode ocasionar redução do crescimento, comprometer o sistema reprodutivo, causar distúrbios no metabolismo lipídico por ser agente regulador das atividades enzimáticas e do metabolismo da glicose (WHO, 2001). O limite de ingestão tolerável máximo entre pessoas de 19 a 70 anos é de 1,8 mg/dia. Foi possível determinar o elemento $V$ em 13 das 24 espécies de plantas analisadas, sendo que o valor médio encontrado para estas plantas foi de $1,5 \mu \mathrm{g} \mathrm{g}^{-1}$. Entre todas as espécies, a maior concentração de vanádio foi observada na espécie Phyllanthus niruri (quebra-pedra) com valor de 7,1 $\mu \mathrm{g} \mathrm{g^{-1 }}$ deste elemento.

\subsubsection{Considerações sobre os elementos $\mathrm{As}, \mathrm{Ba}, \mathrm{Cd}, \mathrm{Cs}, \mathrm{Hg}, \mathrm{Ni}, \mathrm{Pb}, \mathrm{Sb}$, Th e U}

Considerados contaminantes, estes elementos, dependendo da concentração, ainda podem ser considerados tóxicos, prejudicando o funcionamento normal do organismo humano. Estes elementos também estão presentes na maioria das plantas e extratos medicinais analisados neste estudo.

$\mathrm{Na}$ literatura encontram-se vários relatos de quantificação de metais pesados em plantas medicinais e amostras de alimentos (Rajurkar e Damane, 1998; AbouArab et al., 1999; Lopes et al., 2002; Macari et al., 2002; Bordajandi et al., 2004; Caldas e Machado, 2004). O monitoramento de metais tóxicos é muito importante em países em desenvolvimento onde estas plantas são usadas como alimentos ou com fins medicinais, como no Brasil, que possui uma elevada diversidade de plantas usadas para fins farmacológicos (Caldas e Machado, 2004). 
Nas plantas onde o arsênio (As) pode ser quantificado, a concentração média encontrada foi de $250 \mathrm{ng} \mathrm{g}^{-1}$, variando entre $51,5 \mathrm{ng} \mathrm{g}^{-1}$ e $530 \mathrm{ng} \mathrm{g}^{-1}$. O limite máximo de contaminantes inorgânicos estabelecidos para As em chás, erva mate e outros vegetais para infusão pela RDC no 42 (ANVISA, 2002) é de $0,6 \mu \mathrm{g} \mathrm{g}^{-1}$. O extrato com maior concentração deste elemento foi o de Zingirber officinale (gengibre) que apresentou uma concentração de $0,2 \mu \mathrm{g} \mathrm{g}^{-1}$. A ingestão média de As, considerando-se os alimentos e bebidas em geral, é de 30 a $60 \mu \mathrm{g}$ diários (Dietary Reference Intakes for Arsenic, 2001). Considerando-se o valor obtido para o extrato de gengibre determinado neste trabalho, se consumido como recomendado um individuo estaria ingerindo uma quantidade de 0,8 $\mu \mathrm{g}$ de As ao dia, observa-se que o consumo deste chá implica em uma ingestão bem abaixo da quantidade ingerida na dieta normal.

A concentração média de cádmio (Cd) para as plantas foi de $0,14 \mu \mathrm{g} \mathrm{g}^{-1}$ e nos extratos, de $0,017 \mu \mathrm{g} \mathrm{g}^{-1}$. Solanum paniculatum (jurubeba) foi a espécie que apresentou a maior concentração para os extratos para este elemento com valor de $0,04 \mu \mathrm{g} \mathrm{g}^{-1}$. A RDC acima citada também determina um limite máximo para cádmio de $0,4 \mu \mathrm{g} \mathrm{g}^{-1}$ presentes nas folhas para preparo das infusões. $O$ limite de ingestão diário tolerável para Cd é de $0,8 \mu \mathrm{g} / \mathrm{kg}$ de peso corpóreo o que resulta em $58,3 \mu \mathrm{g}$ por dia para uma pessoa de $70 \mathrm{~kg}$. A ingestão do chá de Solanum paniculatum, de acordo com a recomendação da ANVISA, acarreta um consumo de $0,16 \mu \mathrm{g}$ por dia de $\mathrm{Cd}$ por dia, valor que não representa perigo, pois esta bem abaixo do limite máximo permite.

O chumbo $(\mathrm{Pb})$ pode causar distúrbios neurológicos, gastrointestinais e renais. A amostra de Aesculus hippocastanum (castanha-da-índia) apresentou a mais elevada concentração deste elemento $\left(38,2 \mu \mathrm{g} \mathrm{g}^{-1}\right)$ nas plantas e Sambucus nigra (sabugueiro) no extrato $\left(0,58 \mu \mathrm{g} \mathrm{g}^{-1}\right)$. O limite máximo tolerável semanal para $\mathrm{Pb}$ é de $25 \mu \mathrm{g} / \mathrm{kg}$ peso corpóreo (Azevedo e Chasin, 2003). Um individuo com $70 \mathrm{Kg}$ pode, portanto, ingerir semanalmente um máximo de $12250 \mu \mathrm{g}$ de $\mathrm{Pb}$. Ao consumir este chá como indicado pela ANVISA, três vezes ao dia, em uma semana ele estará ingerindo 5,22 $\mu \mathrm{g}$ por dia de $\mathrm{Pb}$, quantidade menor que limite estipulado. 
O níquel ( $\mathrm{Ni}$ ) está envolvido em processos metabólicos que regulam a produção de energia e o bom funcionamento do corpo humano. O maior problema deste elemento é ser um composto tóxico acumulativo, podendo ocasionar dermatites e má formação de fetos. A concentração de Ni nas amostras analisadas neste trabalho variou entre $0,43 \mu \mathrm{g} \mathrm{g}^{-1}$, na amostra de Solanum paniculatum (jurubeba), e $27 \mu \mathrm{g} \mathrm{g}^{-1}$, na amostra de Aesculus hippocastanum (castanha-da-índia), para as plantas e de $0,02 \mu \mathrm{g} \mathrm{g}^{-1}$, para a amostra de Cynara scolymus (alcachofra), a $0,50 \mu \mathrm{g} \mathrm{g}^{-1}$, na de Malva sylvestris (malva), para os extratos. Nos extratos, estes valores encontrados não ultrapassam a recomendação diária para ingestão deste metal mesmo para crianças lactentes, que é de 5 a $15 \mu \mathrm{g} \mathrm{g}^{-1}$ por dia presentes no leite (Barceloux, 1999). O consumo do chá de malva acarreta em uma ingestão de 4 $\mu \mathrm{g} / \mathrm{dia}$, abaixo do consumo estimado numa dieta normal para homens adultos que é de cerca de $150 \mu \mathrm{g} / \mathrm{dia}$ (Gjorgieva et al.,2012).

A concentração dos elementos bário $(\mathrm{Ba})$ e tório $(\mathrm{Th})$ pode ser determinada em 22 das espécies medicinais e seus extratos analisados com média de $59 \mu \mathrm{g} \mathrm{g}^{-1} \mathrm{e}$ $0,21 \mu \mathrm{g} \mathrm{g} \mathrm{g}^{-1}$ para as plantas e $5,36 \mu \mathrm{g} \mathrm{g}^{-1}$ e $0,10 \mu \mathrm{g} \mathrm{g} \mathrm{g}^{-1}$ para os extratos, respectivamente.

O elemento antimônio ( $\mathrm{Sb}$ ) foi determinado em pouco mais da metade das espécies analisadas, das quinze amostras nas quais foi possível mensurar sua concentração, a maior foi encontrada na espécie Mentha pulegium (poejo), igual a $0,052 \mu \mathrm{g} \mathrm{g}^{-1}$ na planta e no extrato de Solanum paniculatum (jurubeba) cujo valor foi de $0,035 \mu \mathrm{g} \mathrm{g}^{-1}$. O valor médio para as demais plantas foi de $0,024 \mu \mathrm{g} \mathrm{g}^{-1}$ e para os extratos foi de $0,026 \mu \mathrm{g} \mathrm{g}^{-1}$. O limite de ingestão diária tolerável (IDT) de antimônio é de $6 \mu \mathrm{g} / \mathrm{kg}$ de peso corporal (Committee On Toxicity Of Chemicals In Food, 2006). Um individuo com $60 \mathrm{~kg}$ de peso corpóreo pode ingerir $360 \mu \mathrm{g}$ por dia de Sb. Ao ingerir o chá de jurubeba esta pessoa esta ingerindo $0,14 \mu \mathrm{g}$.

O urânio $(U)$ foi determinado em oito espécies de plantas e apenas em três extratos. A concentração média de urânio nas plantas foi de $0,4 \mu \mathrm{g} \mathrm{g}^{-1}$ e nos extratos foi de $0,015 \mu \mathrm{g} \mathrm{g}^{-1}$. A maior concentração mensurada na planta foi de $0,87 \mu \mathrm{g} \mathrm{g}^{-1}$ na 
espécie Cinnamomum verum (canela) e no extrato foi na amostra de Psidium guajava (goiabeira) com valor de $0,023 \mu \mathrm{g} \mathrm{g}^{-1}$. O IDT estabelecido para o urânio e de $0,6 \mu \mathrm{g} / \mathrm{kg}$ do peso corpóreo/dia (Committee On Toxicity Of Chemicals In Food, 2006). Um individuo com $70 \mathrm{~kg}$, por ingerir por dia $42 \mu \mathrm{g}$ de $U$ por dia. A indicação de uso para o estrato de goiabeira é de 10 vezes ao dia, resultando em uma ingestão diária de $0,46 \mu \mathrm{g}$, não representando risco de intoxicação por excesso deste elemento.

Por ser um elemento com alta pressão de vapor em temperaturas relativamente baixa o elemento $\mathrm{Hg}$ não pode ser quantificado em nenhum dos extratos de plantas medicinais, devido à perda rápida deste elemento no processo de produção do extrato, uma vez que o $\mathrm{Hg}$ é volátil em temperaturas superiores a $60^{\circ} \mathrm{C}$. Para as plantas a maior concentração deste metal foi encontrada na espécie Eucalyptus globulus (eucalipto), $434 \mu \mathrm{g}-\mathrm{g}^{1}$.

\subsubsection{Considerações sobre os elementos $\mathrm{Br}$, $\mathrm{Hf}, \mathrm{Rb}, \mathrm{Sc}, \mathrm{Ta}, \mathrm{Ti}$ e $\mathrm{Zr}$}

Este grupo de elementos inclui aqueles que são detectados em alguma quantidade no organismo, porém sem nenhuma função metabólica específica.

O bromo $(\mathrm{Br})$, pode ser considerado um elemento químico de essencialidade duvidosa. Entretanto, Vobecky et al. (1996), descrevem que o elemento pode interferir no transporte de iodo para a glândula tireoide, podendo inibir a sua função. A concentração média de $\mathrm{Br}$ nas plantas foi de $28 \mu \mathrm{g} \mathrm{g}^{-1}$ sendo que a concentração mínima foi de $0,72 \mu \mathrm{g} \mathrm{g}^{-1}$ na amostra de Illicium verum (anis estrelado) e a máxima foi de $115,3 \mu \mathrm{g} \mathrm{g}^{-1}$ em Aesculus hippocastanum (castanha-da-índia). A concentração média para os extratos foi de $0,91 \mu \mathrm{g} \mathrm{g}^{-1}$ sendo que a concentração mínima foi de $0,13 \mu \mathrm{g} \mathrm{g}^{-1}$ em Cynara scolymus (alcachofra) e a máxima de $4,88 \mu \mathrm{g} \mathrm{g}^{-1}$ em Malva sylvestris (malva). O IDT é de $1 \mathrm{mg} / \mathrm{kg}$ de peso corpóreo/dia (Committee on toxicity of chemicals in food, 1997). Um individuo com $70 \mathrm{~kg}$ pode ingerir $70 \mathrm{mg} / \mathrm{dia}$. O consumo do chá de malva representa, portanto, uma ingestão de 0,039 mg ao dia. Valor que pode ser considerado muito baixo quando comparado ao permitido. 
A concentração de rubídio (Rb) variou de $3 \mu \mathrm{g} \mathrm{g}^{-1}$ a $176 \mu \mathrm{g} \mathrm{g}^{-1}$ entre as plantas e de $2 \mu \mathrm{g} \mathrm{g}^{-1}$ a $135 \mu \mathrm{g} \mathrm{g}^{-1}$ para os extratos.

A concentração média de escândio (Sc) foi de $0,24 \mu \mathrm{g} \mathrm{g}^{-1}$ para as plantas e $0,006 \mu \mathrm{g} \mathrm{g}^{-1}$ para os extratos. A maior concentração deste elemento foi encontrada na espécie Mentha pulegium (poejo) com valor de $0,4 \mu \mathrm{g} \mathrm{g}^{-1}$ e para o extrato foi na amostra de Phyllanthus niruri (quebra-pedra) com valor de $0,02 \mu \mathrm{g} \mathrm{g}^{-1}$.

O elemento háfnio $(\mathrm{Hf})$ foi determinado nas amostras de plantas medicinais analisadas com concentração média de $0,35 \mu \mathrm{g} \mathrm{g}{ }^{-1}$. A maior concentração deste elemento nas plantas foi na espécie Mentha pulegium (poejo) com valor de 2,34 $\mu \mathrm{g}$ $\mathrm{g}^{-1}$. A concentração média deste elemento para os extratos foi de $0,002 \mu \mathrm{g} \mathrm{g}^{-1}$ e a maior concentração foi observada na espécie Rosmarinus officinalis (alecrim) com valor de $0,003 \mu \mathrm{g} \mathrm{g}^{-1}$.

O elemento zircônio $(\mathrm{Zr})$, devido a sua baixa toxicidade, não oferece ameaça biológica para a saúde humana. A concentração média de zircônio para as plantas foi de $32 \mu \mathrm{g} \mathrm{g}{ }^{-1}$ e nos extratos, foi de $4,0 \mu \mathrm{g} \mathrm{g}^{-1}$.

Não há indícios de que o titânio ( $\mathrm{Ti}$ ) seja tóxico ao ser humano assim, por ser biocompatível, ele e suas ligas são usados em próteses diversas. A concentração média deste elemento foi de $190 \mathrm{\mu g} \mathrm{g}^{-1}$ para as plantas sendo que a maior foi encontrada na espécie Mentha pulegium (poejo) com valor de $644 \mathrm{\mu g} \mathrm{g}^{-1}$ e a menor, na espécie Bidens pilosa (picão preto) com valor de $0,7 \mu \mathrm{g} \mathrm{g}^{-1}$.

O elemento tântalo $(\mathrm{Ta})$ pode se determinado em apenas cinco amostras de plantas medicinais com concentração média de $0,005 \mu \mathrm{g} \mathrm{g}^{-1}$ e em apenas dois extratos concentração com média de $0,002 \mu \mathrm{g} \mathrm{g}{ }^{-1}$. 


\subsection{Fator de transferência dos elementos das plantas para os extratos}

A transferência dos elementos presentes nas plantas medicinais para 0 organismo depende não apenas de sua concentração na droga vegetal, mas principalmente, de quanto deste elemento pode ser transferido para o seu extrato (chá). Desta forma, foram calculados os fatores de transferência, da planta para o extrato, de cada elemento. O calculo para determinação do fator de transferência (FT) é expresso em porcentagem (\%), sendo definido como a razão da concentração do elemento presente no extrato pela concentração do elemento presente na planta, de acordo com a equação 3.6 .

FT\%= (concentração do elemento no extrato/ concentração do elemento na planta) $\times 100$

(Equação 3.6)

$\mathrm{Na}$ Figura 5.1 são apresentados os fatores de transferência em valores absolutos para os elementos $\mathrm{Fe}$ e $\mathrm{Ca}$ e verifica-se que, para a maioria das plantas, estes elementos são transferidos para os extratos em quantidades inferiores a $50 \%$.

Para as plantas Melissa officinalis (melissa) e Psidium guajava (goiabeira) que apresentaram as maiores concentração de $\mathrm{Ca}$ na amostra seca, os fatores de transferência foram de $15 \%$ e $0,5 \%$, respectivamente. O extrato que apresentou a maior concentração $(0,40 \%)$ deste elemento foi o de Cynara scolymus (alcachofra) e o seu fator de transferência foi da ordem de $26 \%$. O maior FT foi verificado para a amostra de Cymbopongo citratus (capim santo), 44\%, sendo que para esta espécie as concentrações na planta seca e no extrato foram de $0,52 \%$ e de $0,23 \%$, respectivamente. 


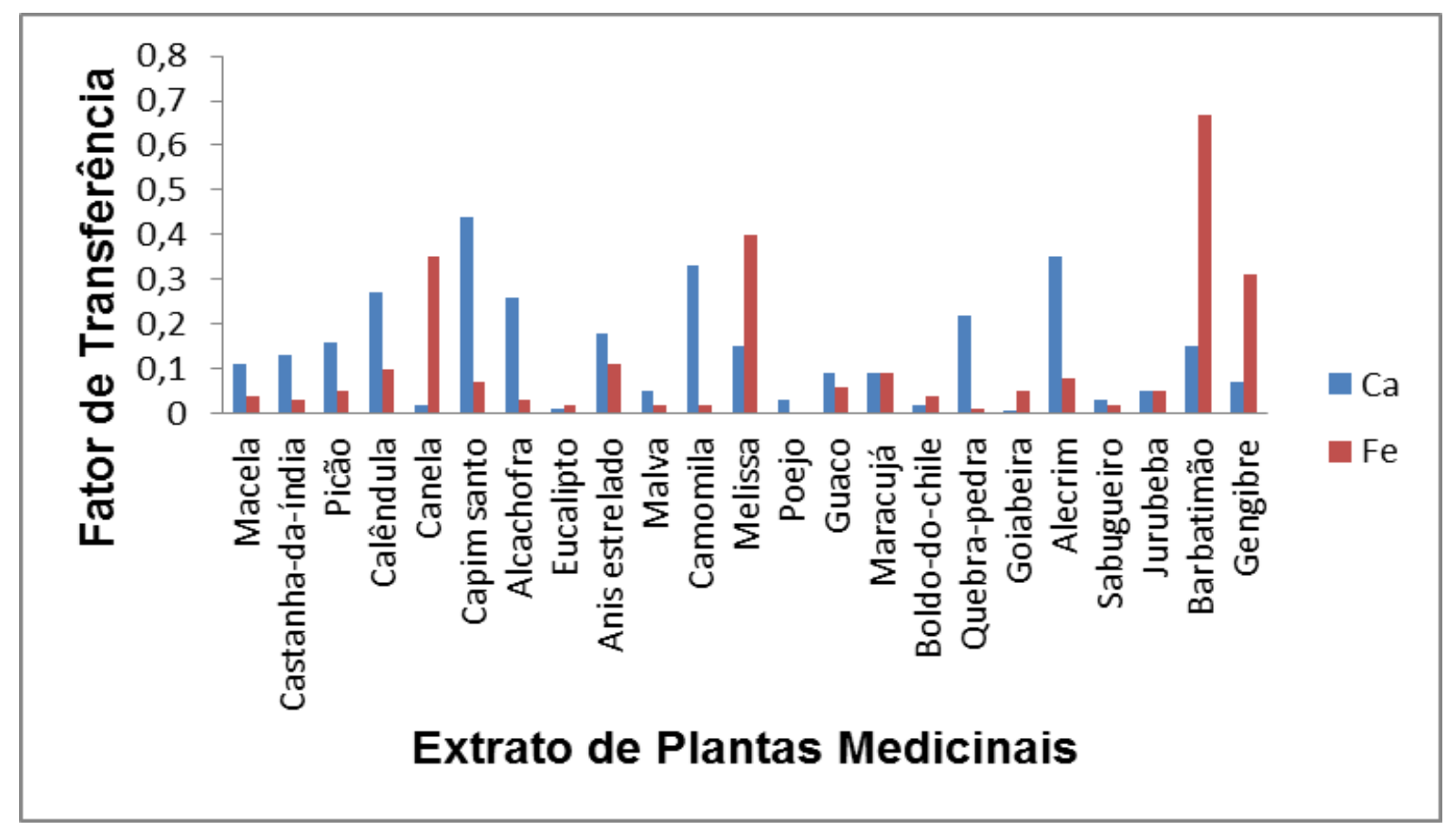

FIGURA 5.1: Fator de transferência para os elementos Ca e Fe.

Para o $\mathrm{Fe}$ a espécie que apresentou o maior fator de transferência foi a Stryphnodendron adstringens (barbatimão) com FT de 67\%, sendo que a concentração deste elemento para esta amostra foi uma das menores observadas entre as plantas. Por outro lado, espécies com alta concentração de $\mathrm{Fe}$ como Mentha pulegium (poejo), que apresentou a maior concentração tanto na planta quanto no extrato, Phyllanthus niruri (quebra-pedra) e Malva sylvestris (malva) apresentaram baixos fatores de transferência, da ordem de $0,6,1 \%$ e $2 \%$, respectivamente.

Na Figura 5.2 são mostrados os fatores de transferência em valores absolutos para os elementos Cu e Zn. Verifica-se que o FT para o Cu é geralmente inferior a 30\% e apenas a espécie Cynara scolymus (alcachofra) apresentou valor superior a este. O Zn apresentou FT abaixo de $50 \%$ para todas as amostras, exceto para Mentha pulegium (poejo) e Zingirber officinale (gengibre). 


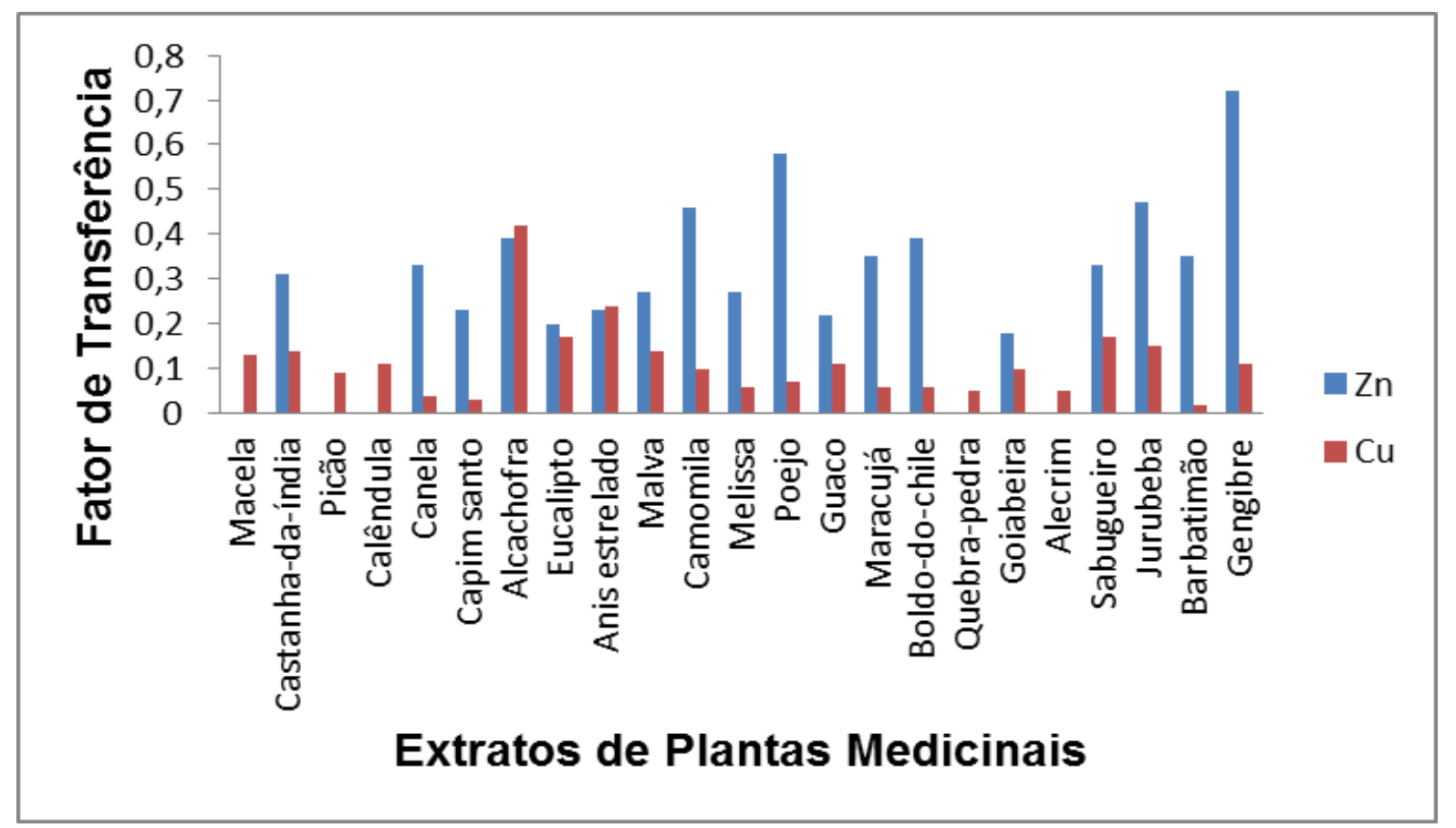

FIGURA 5.2: Fator de transferência para os elementos Cu e Zn.

O maior FT observado para $\mathrm{Zn}$ foi na amostra de Zingirber officinale (gengibre) com valor de $72 \%$, sendo que a concentração deste elemento foi de 23,1 $\mu \mathrm{g} \mathrm{g}^{-1}$ na planta e de 16,6 $\mu \mathrm{g} \mathrm{g}^{-1}$ no extrato. A amostra de Malva sylvestris (malva) foi a que apresentou a maior concentração tanto na planta quanto no extrato, porém seu fator de transferência foi da ordem de $27 \%$.

O maior FT para o $\mathrm{Cu}$ foi observado na amostra de Cynara scolymus (alcachofra) sendo que aproximadamente $42 \%$ deste elemento foi transferido da planta para o extrato. Esta espécie também foi a que apresentou a concentração mais elevada deste elemento no extrato, $2,34 \mu \mathrm{g} \mathrm{g}^{-1}$, enquanto que as maiores concentrações nas plantas foram obtidas nas amostras de Solanus paniculatum (juurubeba) e Melissa officinalis (melissa), ambas com concentração igual a 14,7 $\mu \mathrm{g}$ $\mathrm{g}^{-1}$. Seus fatores de transferência, no entanto, foram da ordem de $6 \%$ e $15 \%$, respectivamente. 
Na Figura 5.3 são apresentados os fatores de transferência em valores absolutos para os elementos $\mathrm{Co}, \mathrm{Cr}$ e Se. Pode-se verificar que para o $\mathrm{Cr}$ e $\mathrm{Co}$ os valores de FT são geralmente inferiores a $30 \%$, sendo que apenas as amostras de Cinnamomum verum (canela) e Passiflora alata (maracujá) apresentam valores superiores a este para o Co enquanto que os maiores FT para o $\mathrm{Cr}$ foram observados para as amostras de Passiflora alata (maracujá) e Psidium guajava (goiabeira). A amostra de Mentha pulegium (poejo) foi a que apresentou a maior concentração de Co tanto na planta quanto no extrato, porém seu FT foi de apenas $9 \%$. Com relação ao $\mathrm{Cr}$, a maior concentração foi observada na amostra de Aesculus hippocastanum (castanha-da-índia), que apresentou FT de apenas $2 \%$. Entre os extratos as maiores concentrações deste elemento foram observadas nas amostras de Cynara scolymus (alcachofra) e Solanum paniculatum (jurubeba). No caso destas plantas seus FT foram da ordem de 9 e $7 \%$, respectivamente.

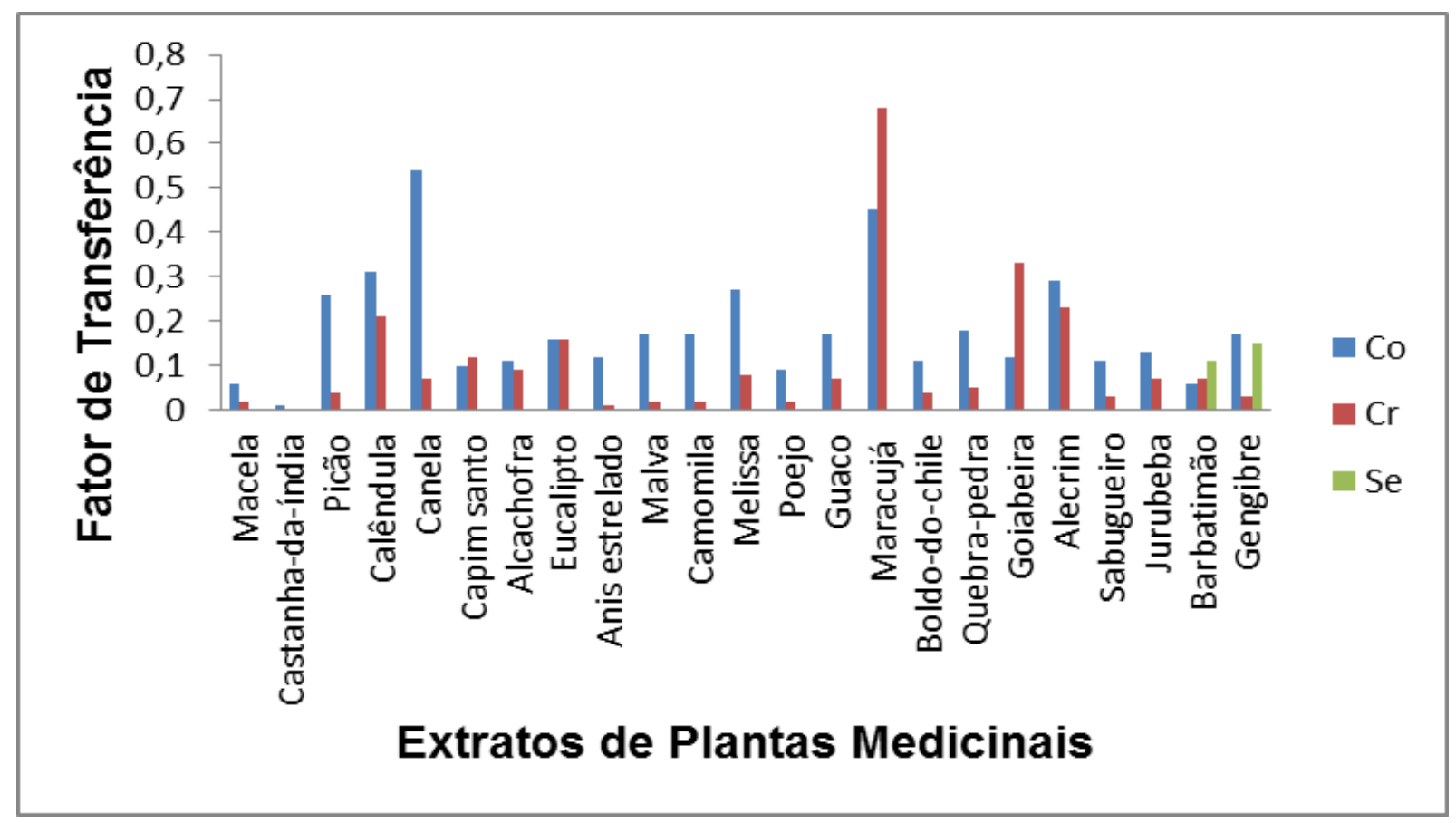

FIGURA 5.3: Fator de transferência para os elementos $\mathrm{Co}$, $\mathrm{Cr}$ e Se. 
O FT para o Se só pode ser calculado para duas das plantas analisadas. Os resultados podem indicar que este elemento possui baixa capacidade de ser transferido para os extratos, possivelmente devido à baixa solubilidade ou a sua perda por volatilização, durante o preparo do extrato.

$\mathrm{Na}$ Figura 5.4 são mostrados os fatores de transferência em valores absolutos para $\mathrm{As}, \mathrm{Cd}$ e $\mathrm{Pb}$. Para o As o maior FT foi observado na espécie Zingirber officinales (gengibre) sendo que $38 \%$ deste elemento foi transferido da planta para o extrato.

Para $\circ \mathrm{Pb}$, valores de fator de transferência maiores que $30 \%$ foram observados apenas para as amostras de Calendula officinalis (calêndula), Illicium verum (anis estrelado), Mikania glomerata (guaco) e Stryphnodendron adstringens (barbatimão), sendo que esta última foi a que apresentou o maior FT para este elemento, $73 \%$, e também a maior concentração no extrato. A maior concentração para este elemento na planta foi observada na amostra de Aesculus hippocastanum (castanha-da-índia). No entanto, o FT para esta espécie foi de apenas $1 \%$.

Os maiores fatores de transferência para o Cd são verificados nas amostras de Mentha pulegium (poejo) e Matricaria recutita (camomila), apresentando FT de 48 e $49 \%$, respectivamente. A maior concentração de Cd entre as amostras de plantas foi observada para a espécie Phyllanthus niruri (quebra-pedra) enquanto que entre nos extratos, a espécie Solanum paniculatum (jurubeba) foi a que apresentou a maior concentração. $\mathrm{Na}$ amostra de quebra pedra o FT foi de apenas $4 \%$ e na jurubeba não foi determinado.

As espécies Aesculus hippocastanum (castanha-da-índia) e Passiflora alata (maracujá) apresentaram um FT menor que $1 \%$ para $\circ \mathrm{Ni}$, sendo que, nestas plantas, foram observadas as maiores concentrações para este elemento enquanto que a amostra de Malva sylvestris (malva) apresentou a maior concentração entre os extratos. O maior FT encontrado, no entanto, foi para a espécie Solanum paniculatum (jurubeba) com FT de $23 \%$. 


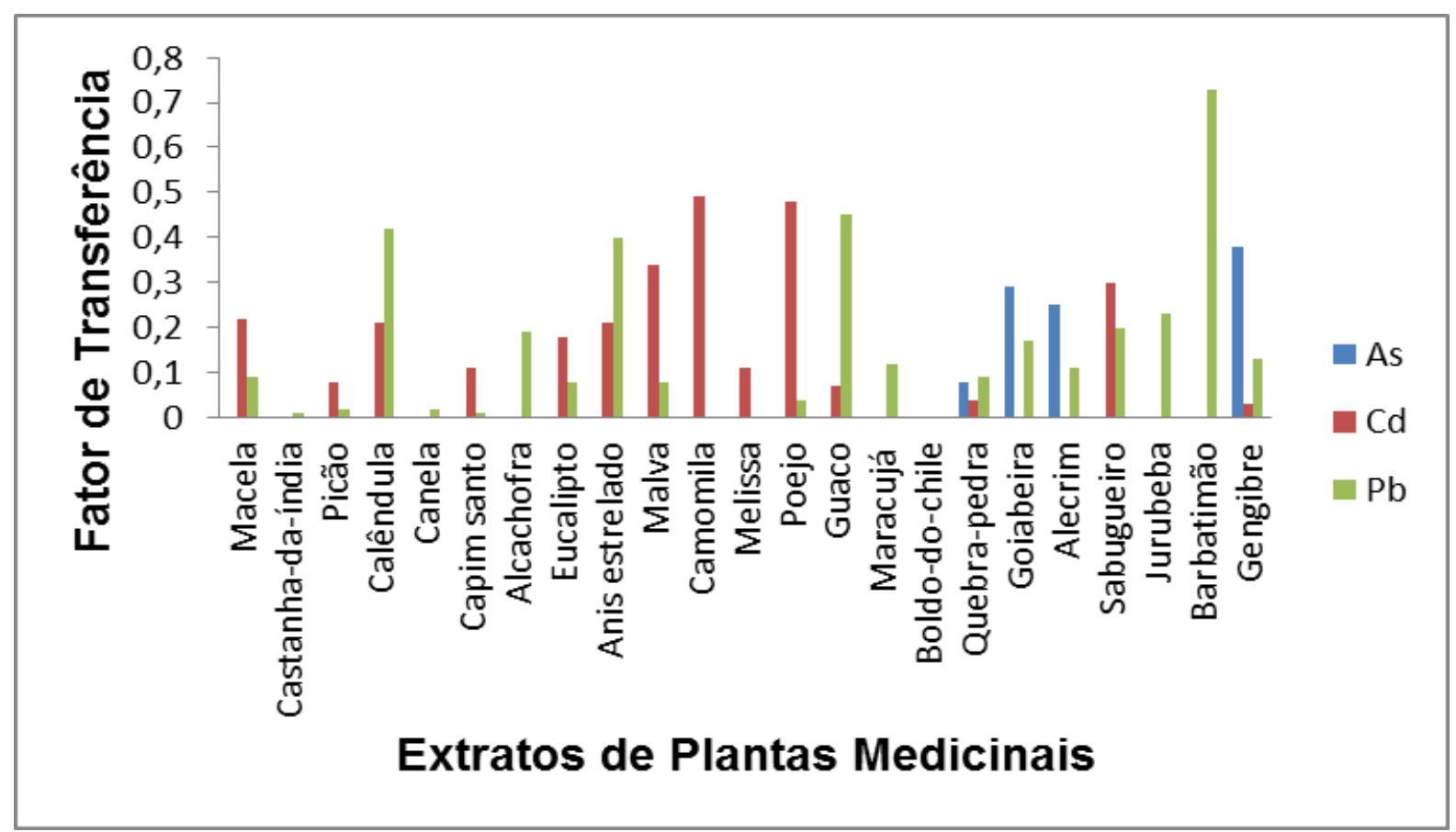

FIGURA 5.4: Fator de transferência para os elementos As, Cd e Pb.

Na Figura 5.5 são mostrados os fatores de transferência em valores absolutos para os elementos $\mathrm{Ba}$, Th e $\mathrm{Ni}$.

O maior FT para o $\mathrm{Ba}(43 \%)$ foi determinado para a espécie Matricaria recutita (camomila). Para a maioria das plantas, no entanto, este valor foi inferior a 20\%. A amostra de Malva sylvestris (malva) foi a que apresentou a maior concentração na planta, porém seu FT foi de apenas 7\%. Para a amostra de Passiflora alata (maracujá), que foi a que apresentou a maior concentração entre os extratos, o FT foi da ordem de $16 \%$.

Os maiores fatores de transferência para o Th foram verificados nas amostras de Stryphnodendrm adstrigens (barbatimão) e Zingirber officinales (gengibre), ambas com FT de 29\%. As demais amostras apresentaram FT inferiores a $20 \%$ na maioria delas. A maior concentração deste elemento foi determinada na amostra de Mentha pulegium (poejo) que apresentou FT de aproximadamente 1\%. 


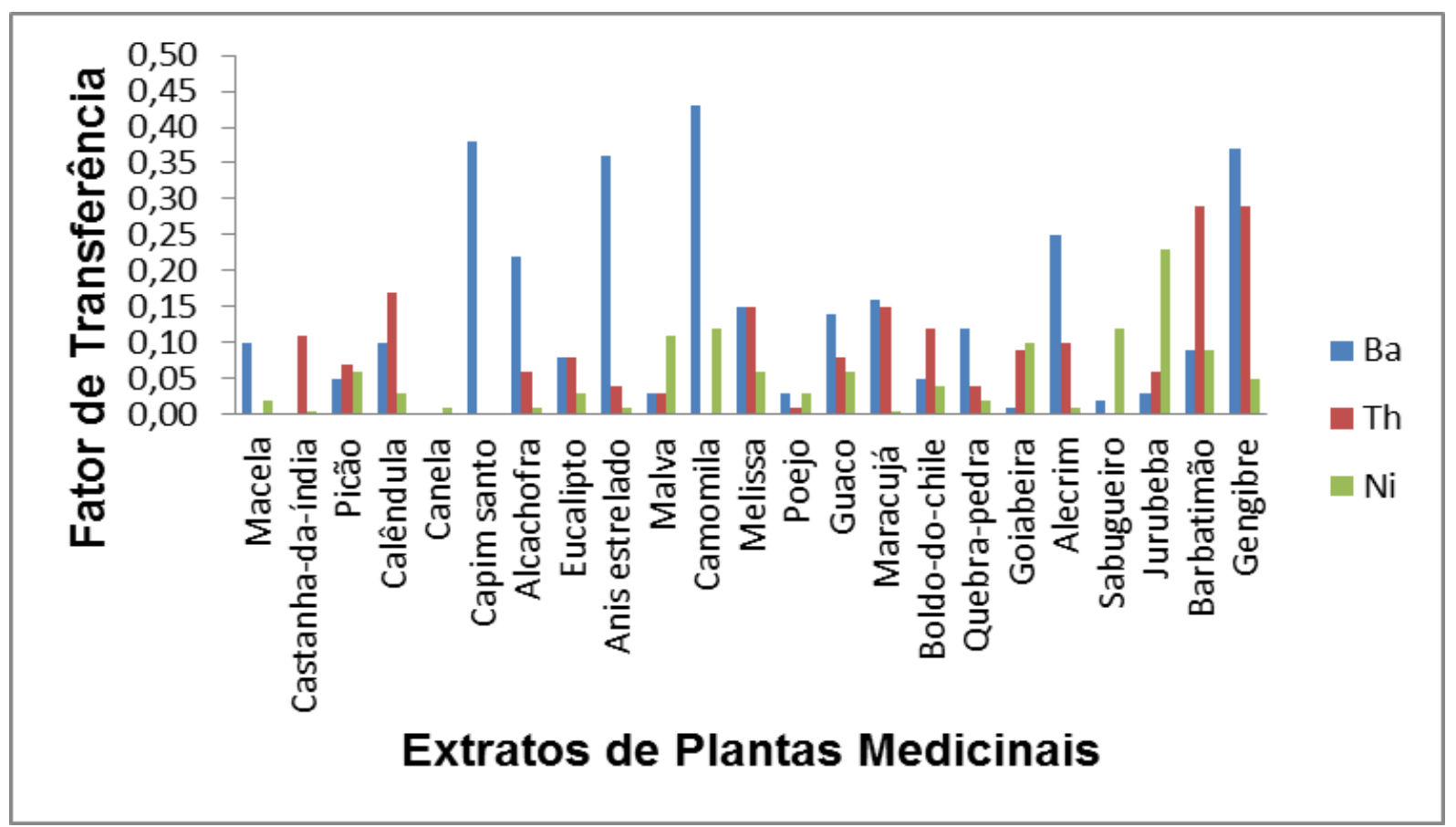

FIGURA 5.5: Fator de transferência para os elementos $\mathrm{Ba}$, Ni e Th.

Na Figura 5.6 estão apresentados os fatores de transferência em valores absolutos para os elementos $\mathrm{Br}$, Rb e Sc. O Br apresentou o maior FT na espécie Illicium verum (anis estrelado) com valor de 63\%. Em praticamente todas as outras amostras este valor foi inferior a 10\%. A maior concentração de $\mathrm{Br}$ entre as plantas foi observada na amostra de Aesculus hippocastanum (castanha-da-índia), porém, o FT para esta amostra não pode ser calculado uma vez que a concentração deste elemento não foi determinada no extrato. Resultados semelhantes podem ser observados para o Sc, que também apresentou FT inferiores a 10\% na maioria das amostras sendo que o maior valor foi observado para a amostra de Cinnamomum verum (canela). A planta com maior concentração deste elemento foi a Mentha pulegium (poejo), enquanto que entre os extratos, o maior valor de concentração foi determinado na amostra de Phyllanthus niruri (quebra-pedra), que apresentaram fatores de transferência de 1 e $9 \%$, respectivamente. Estes resultados indicam que os elementos $\mathrm{Br}$ e Sc são muito pouco transferidos das plantas para os seus respectivos extratos. 
O fator de transferência para $\circ \mathrm{Rb}$ foi maior que $60 \%$ na maioria das amostras. Ao contrário do observado para os elementos $\mathrm{Br}$ e Sc, verifica-se que a maior parte do $\mathrm{Rb}$ presente nas plantas é transferida para os extratos.

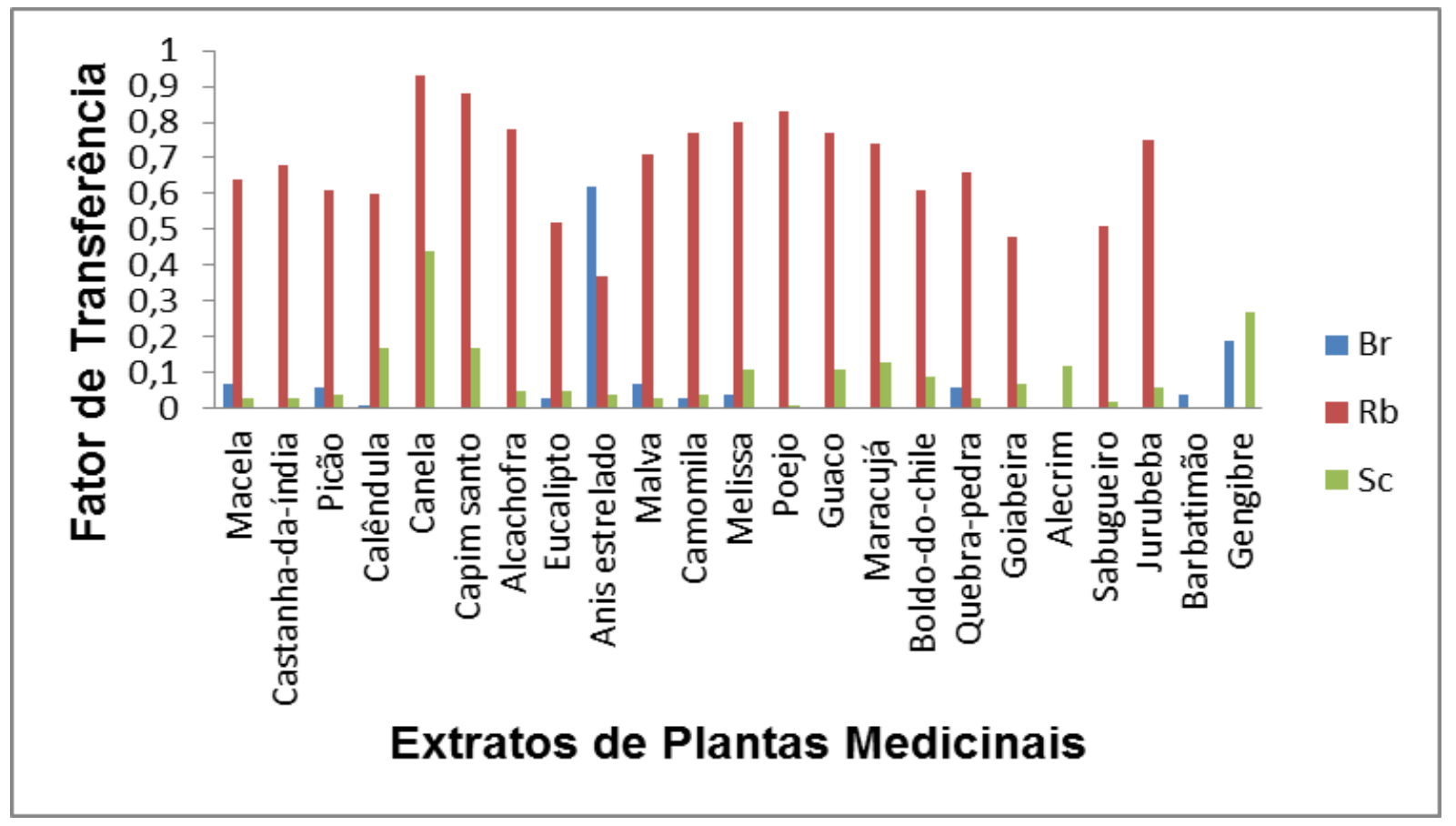

FIGURA 5.6: Fator de transferência para os elementos $\mathrm{Br}$, Rb e Sc.

$\mathrm{Na}$ Figura 5.7 estão apresentados os fatores de transferência em valores absolutos para $\mathrm{Cs}, \mathrm{Hf}, \mathrm{Sb}$, e $\mathrm{Zr}$.

Nas amostras de Melissa officinalis (melissa) e Zingirber officinale (gengibre) pode-se verificar que praticamente todo o $\mathrm{Sb}$ foi transferido da planta para o extrato. As amostras de Mikania glomerata (guaco) e Mentha pulegium (poejo) apresentaram FT da ordem de $60 \%$ e as demais plantas apresentam este valor geralmente menor que $30 \%$. A maior concentração de Sb nas plantas ocorreu na amostra de Mentha pulegium (poejo) e a maior concentração observada nos extratos foi verificada na amostra de Cymbopogon citratus (capim santo), no entanto o FT para esta última não pode ser calculado, pois o valor deste elemento, nesta planta ficou abaixo do limite de detecção. 
O maior fator de transferência observado para Cs foi determinado na amostra de Stryphnodendron adstringens (barbatimão), 76\%, com concentração de 0,02 $\mu \mathrm{g}$ $\mathrm{g}^{-1}$ para a suas cascas e de $0,016 \mu \mathrm{g} \mathrm{g}^{-1}$ em seu extrato. A maior concentração para este elemento foi observada na amostra de Illicium verum (anis estrelado), cujo fator de transferência foi de $21 \%$.

O háfnio é outro elemento que, embora tenha tido seus fatores de transferência determinado em um número pequeno de amostras, pode-se afirmar que apresenta uma baixa capacidade de ser transferido das plantas para os extratos. Seus FT variaram de 0,1 a $4,7 \%$ nas amostras nas quais este valor foi determinado.

$\mathrm{O} \mathrm{Zr}$ foi transferido significativamente das plantas para os extratos apenas nas amostras de Aesculus hippocastanum (castanha-da-índia) e Mikania glomerata (guaco), nas demais amostras este valor foi de aproximadamente $5 \%$.

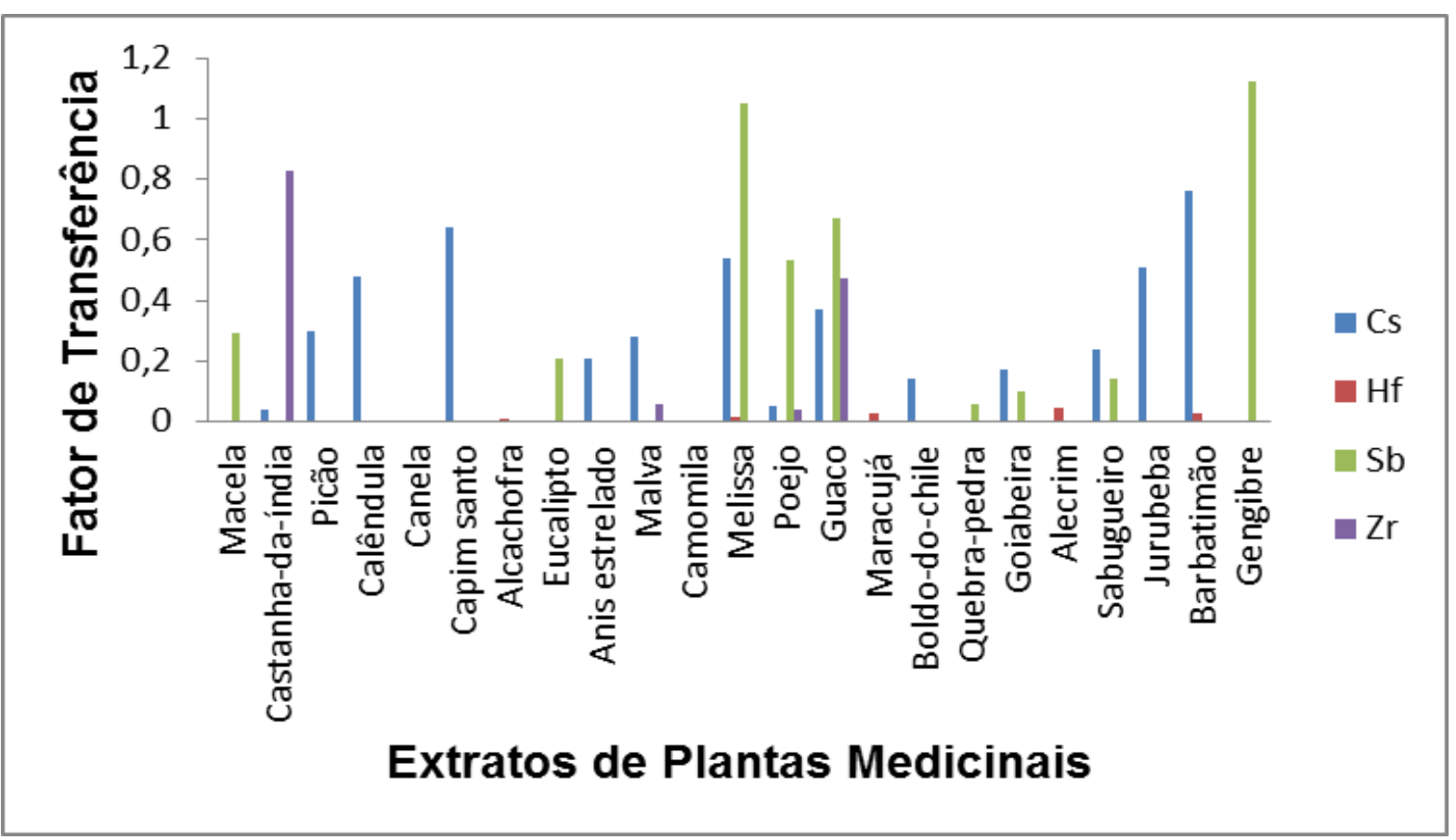

FIGURA 5.7: Fator de transferência para os elementos Cs, Hf, Sb e Zr. 
Na Figura 5.8 são mostrados os fatores de transferência em valores absolutos para os elementos $\mathrm{K}$ e $\mathrm{Na}$. Embora o FT não tenha sido calculado para todas as plantas para estes elementos, verifica-se que eles apresentam uma tendência de serem facilmente transferidos das plantas para os extratos.

Pode-se observar que para a maioria das plantas o fator de transferência foi superior a $50 \%$. Apenas as espécies Cinnamomum verum (canela) e Bidens pilosa (picão) para $\mathrm{K}$ e Aesculus hippocastanum (castanha-da-índia) para $\mathrm{Na}$ ficaram abaixo deste valor.

Os dois mais elevados fatores de transferência para $\mathrm{K}$ foram determinados nas espécies Illicium verum (anis estrelado) com valor de $79 \%$ e Malva sylvestris (malva) com $\mathrm{FT}$ de $70 \%$. A maior concentração para o $\mathrm{K}(4 \%)$ foi encontrada na amostra de Bidens pilosa (picão) e seu FT foi da ordem de 43\%. Esta espécie foi também a que apresentou a maior concentração deste elemento no extrato com valor de $1,7 \%$

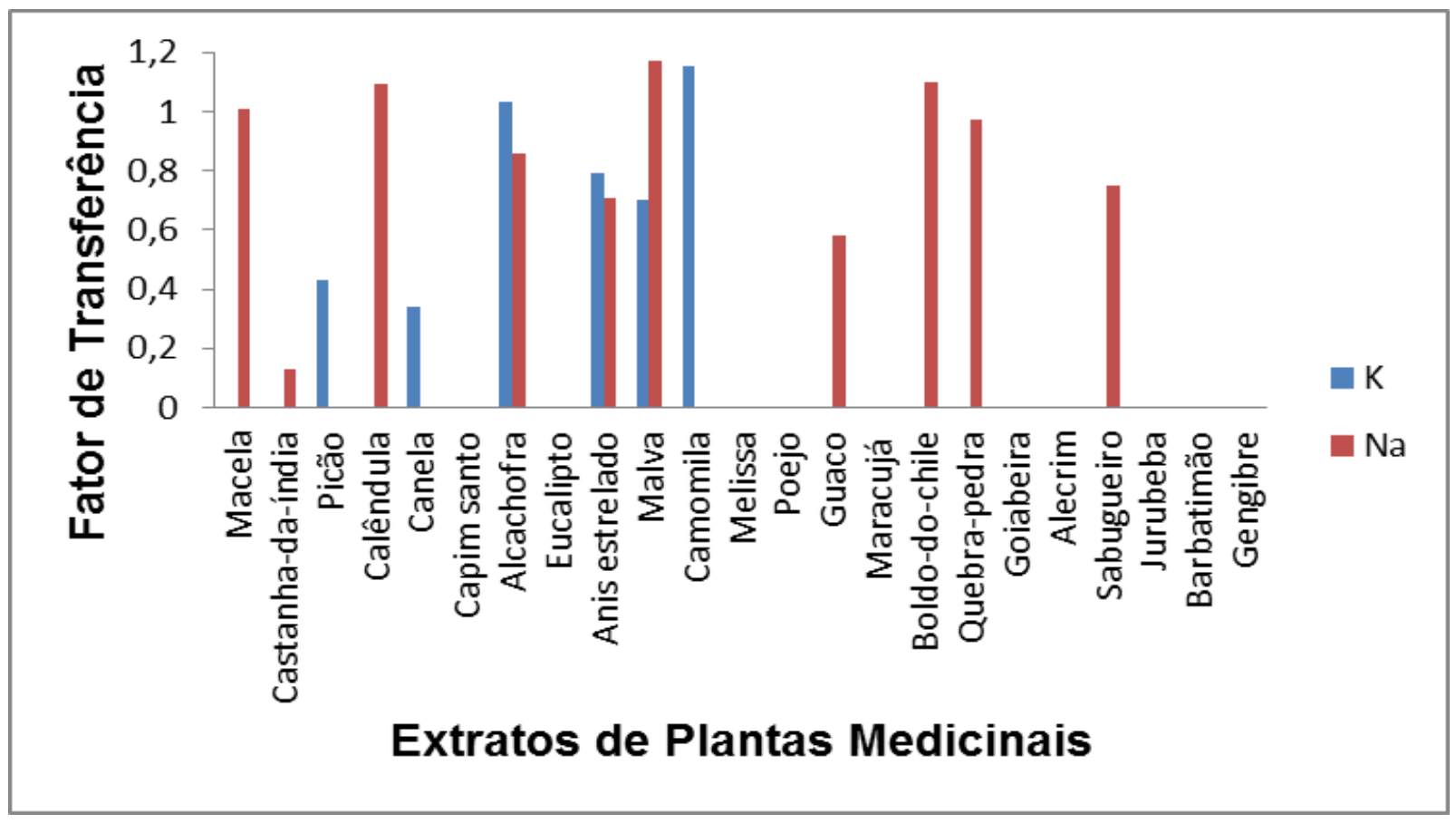

FIGURA 5.8: Fator de transferência para os elementos $\mathrm{K}$ e $\mathrm{Na}$. 
Para o elemento $\mathrm{Na}$ o maior FT foi obtido na amostra de Achyroclines saturoides (macela) com valor de $99 \%$ sendo que nesta planta a concentração foi de $270 \mu \mathrm{g} \mathrm{g}^{-1}$, enquanto que a maior concentração foi verificada na amostra de Cynara scolymus (alcachofra) que apresentou FT da ordem de $86 \%$.

Pode-se concluir por estes resultados que altas concentrações elementares nas plantas medicinais não implicam em altas concentrações nos extratos. A concentração no extrato depende do fator de transferência que por sua vez depende da solubilidade e volatilidade do elemento nas condições de preparo do extrato.

\subsection{Coeficiente de correlação e Análise de agrupamento}

Para os elementos determinados pelas técnicas analíticas utilizadas neste trabalho INAA, CV AAS e ICP OES foram calculados o coeficiente de correlação para as amostras de plantas medicinais e de seus extratos.

O coeficiente de correlação de Pearson é uma medida estatística da variância compartilhada entre duas variáveis, o número obtido a partir da equação da reta indicará como as variáveis variam conjuntamente, considerando-se que uma variável não determina o valor da outra. O coeficiente de correlação (r) é usado para medir a força da associação entre as variáveis. Quando o coeficiente de correlação é igual a 1,0 ou -1,0, indica uma correlação perfeita, positiva ou negativa, respectivamente. Normalmente, os coeficientes de correlação de $\pm 0,8$ a $\pm 1,0$ indicam uma correlação forte, enquanto que os valores de $\pm 0,5$ a \pm 0,8 indicam uma correlação moderada e valores inferiores a $\pm 0,5$ indicam uma correlação fraca. A maioria dos pacotes estatísticos, no entanto, considera um valor de "r" como uma correlação significativa baseado no número de medidas (n) a um dado nível de singificância.

Os coeficientes de correlação de Pearson para os elementos analisados nas amostras de plantas medicinais, e seus exctratos, selecionadas para este estudo são mostrados nas Tabelas 5.3 e 5.4, respectivamente. Os coeficientes de 
correlação apresentados foram obtidos por meio do programa Statistica para um nível de significância $p<0,05$.

Os resultados das analises para as plantas demonstram que normalmente os elementos Co, Fe, Hf, Sc, Th, Ti e V apresentam boa correlação entre si. Entre os elementos considerados tóxicos, apenas apresentam correlação significativa $\circ \mathrm{Pb}$ com o $\mathrm{Cr}$, Sb e Ni. Os pares de elementos As/Cr, Ca/U, Cs/V. Mg/Zn, Ti/V também demonstraram boas correlações, observou-se também uma perfeita correlação entre o par de elemento $\mathrm{Fe} / \mathrm{Sc}$. Os elementos $\mathrm{Cd}$ e $\mathrm{Hg}$ embora não apresentem correlações significativas, mostram uma tendência de correlação negativa com a maioria dos demais elementos. Os elementos $\mathrm{Cl}$, $\mathrm{Cu}$ e Se não apresentaram correlação significativa com nenhum outro elemento.

Os resutlados obtidos para a análise de correlação para os extratos mostram correlaçãoes semelhantes às obtidas para as plantas. Os elementos Co, Fe, Th, Sc e $\mathrm{Zn}$ apresentaram boa correlação entre si, assim como, os elementos $\mathrm{Ca}, \mathrm{Cr}, \mathrm{Na}, \mathrm{K}$ e Cd. Nos extratos, os pares que apresentam boas correlações entre si são formados pelos elementos $\mathrm{Cs} / \mathrm{Rb}, \mathrm{Sb} / \mathrm{Th}, \mathrm{K} / \mathrm{Na}$. O Cd apresentou boa correlação com o $\mathrm{Zn}$. Os demais elementos considerados tóxicos como $\mathrm{As}$, $\mathrm{Ba}$ e $\mathrm{Pb}$ não se correlacionaram com nenhum outro elemento, assim como $\mathrm{Cu}, \mathrm{Hf}$ e Se. Correlações significativas negativas são observadas apenas para o par de elementos Fe/U.

Para melhor compreensão dos resultados obtidos na análise de coeficiente de correlação dos elementos, optou-se pela visualização por meio da análise de agrupamento ou cluster analysis, que tem como objetivo dividir um conjunto de observações (elementos, indivíduos, tratamentos, genótipos, etc.) em grupos homogêneos ou compactos, segundo algum critério conveniente de similaridade. Assim, os elementos pertencentes a um mesmo grupo serão homogêneos (similares) entre si, com respeito a certas características medidas, enquanto que os pertencentes a grupos diferentes deverão ser heterogêneos entre si em relação às mesmas caracteristicas . Para este estudo utilizou-se o método de Ward, também chamado de "Mínima Variância". 
TABELA 5.3: Coeficiente de correlação de Pearson obtido para as concentrações dos elementos determinados nas amostras de plantas.

\begin{tabular}{|c|c|c|c|c|c|c|c|c|c|c|c|c|c|c|c|c|c|c|c|c|c|c|c|c|c|c|c|c|}
\hline & As & $\mathrm{Ba}$ & $\mathrm{Br}$ & $\mathrm{Ca}$ & Co & $\mathrm{Cl}$ & $\mathrm{Cr}$ & Cs & $\mathrm{Fe}$ & $\mathrm{Hf}$ & $\mathrm{K}$ & $\mathrm{Mg}$ & $\mathrm{Mn}$ & $\mathrm{Na}$ & $\mathbf{R b}$ & $\mathrm{Sb}$ & $\mathrm{Sc}$ & $\mathrm{Se}$ & Th & $\mathrm{Ti}$ & $\mathrm{U}$ & $\mathrm{v}$ & $\mathrm{Zn}$ & $\mathrm{Hg}$ & $\mathrm{Cd}$ & $\mathrm{Cu}$ & $\mathrm{Ni}$ & $\mathrm{Pb}$ \\
\hline As & 1,00 & & & & & & & & & & & & & & & & & & & & & & & & & & & \\
\hline $\mathrm{Ba}$ & $-0,82$ & 1,00 & & & & & & & & & & & & & & & & & & & & & & & & & & \\
\hline $\mathrm{Br}$ & $-0,14$ & 0,36 & 1,00 & & & & & & & & & & & & & & & & & & & & & & & & & \\
\hline $\mathrm{Ca}$ & $-0,58$ & 0,37 & $-0,15$ & 1,00 & & & & & & & & & & & & & & & & & & & & & & & & \\
\hline Co & 0,76 & 0,26 & 0,25 & 0,02 & 1,00 & & & & & & & & & & & & & & & & & & & & & & & \\
\hline Cl & $-0,01$ & $-0,05$ & $-0,25$ & $-0,01$ & $-0,15$ & 1,00 & & & & & & & & & & & & & & & & & & & & & & \\
\hline $\mathrm{Cr}$ & 0,96 & 0,22 & 0,73 & $-0,24$ & 0,34 & $-0,07$ & 1,00 & & & & & & & & & & & & & & & & & & & & & \\
\hline Cs & $-0,60$ & $-0,16$ & $-0,15$ & $-0,09$ & 0,11 & 0,15 & $-0,08$ & 1,00 & & & & & & & & & & & & & & & & & & & & \\
\hline $\mathrm{Fe}$ & 0,13 & 0,29 & 0,18 & 0,08 & 0,99 & 0,02 & 0,25 & 0,13 & 1,00 & & & & & & & & & & & & & & & & & & & \\
\hline $\mathrm{Hf}$ & 0,08 & 0,59 & 0,52 & $-0,01$ & 0,76 & $-0,16$ & 0,39 & 0,07 & 0,75 & 1,00 & & & & & & & & & & & & & & & & & & \\
\hline K & 0,70 & 0,14 & 0,12 & 0,05 & 0,00 & $-0,32$ & $-0,09$ & $-0,05$ & 0,03 & 0,02 & 1,00 & & & & & & & & & & & & & & & & & \\
\hline Mg & $-0,06$ & 0,60 & $-0,02$ & 0,38 & 0,00 & $-0,05$ & $-0,16$ & $-0,27$ & 0,07 & 0,31 & 0,44 & 1,00 & & & & & & & & & & & & & & & & \\
\hline Mn & 0,76 & $-0,11$ & $-0,09$ & 0,26 & 0,03 & $-0,21$ & $-0,10$ & 0,40 & 0,04 & $-0,01$ & $-0,34$ & $-0,28$ & 1,00 & & & & & & & & & & & & & & & \\
\hline $\mathrm{Na}$ & $-0,02$ & $-0,15$ & $-0,06$ & 0,29 & 0,06 & $-0,29$ & $-0,02$ & 0,23 & 0,07 & $-0,02$ & 0,51 & 0,10 & 0,31 & 1,00 & & & & & & & & & & & & & & \\
\hline Rb & $-0,66$ & $-0,04$ & $-0,11$ & 0,14 & $-0,11$ & $-0,18$ & $-0,16$ & 0,46 & $-0,11$ & $-0,13$ & 0,16 & 0,01 & 0,44 & 0,45 & 1,00 & & & & & & & & & & & & & \\
\hline $\mathrm{Sb}$ & $-0,42$ & 0,12 & 0,16 & 0,14 & 0,59 & $-0,04$ & 0,46 & 0,28 & 0,61 & 0,43 & $-0,19$ & $-0,06$ & 0,16 & 0,01 & $-0,24$ & 1,00 & & & & & & & & & & & & \\
\hline Sc & 0,13 & 0,29 & 0,11 & 0,10 & 0,97 & 0,10 & 0,16 & 0,14 & 1,00 & 0,73 & 0,02 & 0,08 & 0,06 & 0,06 & $-0,10$ & 0,61 & 1,00 & & & & & & & & & & & \\
\hline Se & 0,96 & $-0,33$ & 0,00 & $-0,37$ & 0,47 & $-0,44$ & 0,52 & $-0,59$ & $-0,02$ & $-0,17$ & 0,21 & 0,03 & $-0,02$ & $-0,12$ & 0,35 & $-0,04$ & $-0,21$ & 1,00 & & & & & & & & & & \\
\hline Th & 0,06 & 0,52 & 0,28 & 0,15 & 0,85 & $-0,12$ & 0,18 & 0,12 & 0,88 & 0,91 & 0,09 & 0,32 & 0,09 & 0,03 & $-0,13$ & 0,53 & 0,87 & $-0,21$ & 1,00 & & & & & & & & & \\
\hline $\mathrm{Ti}$ & & $-0,14$ & $-0,13$ & 0,03 & 0,78 & 0,49 & $-0,09$ & 0,74 & 0,85 & 0,63 & $-0,18$ & $-0,01$ & 0,70 & $-0,05$ & $-0,43$ & 0,70 & 0,86 & 0,22 & 0,74 & 1,00 & & & & & & & & \\
\hline U & & $-0,27$ & 0,34 & 0,75 & $-0,21$ & 0,27 & $-0,34$ & 0,07 & $-0,18$ & $-0,31$ & 0,29 & $-0,26$ & 0,03 & 0,30 & $-0,09$ & 0,63 & $-0,19$ & $-0,67$ & $-0,18$ & $-0,28$ & 1,00 & & & & & & & \\
\hline v & & 0,10 & 0,00 & 0,07 & 0,56 & 0,28 & 0,05 & 0,69 & 0,64 & 0,54 & 0,04 & 0,19 & 0,19 & 0,45 & $-0,41$ & 0,39 & 0,65 & $-0,10$ & 0,60 & 0,90 & 0,27 & 1,00 & & & & & & \\
\hline $\mathrm{Zn}$ & $-0,47$ & 0,56 & $-0,05$ & 0,32 & 0,26 & $-0,02$ & $-0,09$ & $-0,19$ & 0,32 & 0,49 & 0,22 & 0,81 & $-0,10$ & 0,04 & 0,13 & 0,01 & 0,33 & 0,10 & 0,53 & 0,39 & $-0,39$ & 0,52 & 1,00 & & & & & \\
\hline $\mathrm{Hg}$ & $-0,60$ & 0,12 & $-0,11$ & 0,14 & $-0,17$ & $-0,12$ & $-0,26$ & 0,08 & $-0,16$ & $-0,10$ & $-0,34$ & $-0,33$ & 0,39 & $-0,28$ & $-0,11$ & 0,32 & $-0,13$ & $-0,22$ & $-0,11$ & 0,25 & 0,21 & $-0,13$ & $-0,25$ & 1,00 & & & & \\
\hline $\mathrm{Cd}$ & & $-0,12$ & $-0,20$ & $-0,04$ & $-0,14$ & 0,15 & $-0,39$ & $-0,34$ & $-0,08$ & $-0,23$ & $-0,02$ & $-0,13$ & 0,11 & 0,06 & $-0,05$ & $-0,44$ & $-0,07$ & 0,04 & $-0,20$ & 0,14 & 0,15 & 0,61 & $-0,03$ & $-0,25$ & 1,00 & & & \\
\hline $\mathrm{Cu}$ & $-0,82$ & 0,42 & 0,02 & 0,06 & 0,10 & 0,09 & 0,01 & 0,03 & 0,08 & 0,20 & $-0,22$ & 0,19 & $-0,09$ & $-0,10$ & 0,18 & 0,09 & 0,07 & 0,08 & 0,05 & 0,03 & $-0,38$ & $-0,16$ & 0,28 & 0,06 & $-0,27$ & 1,00 & & \\
\hline $\mathrm{Ni}$ & $-0,34$ & 0,34 & 0,48 & $-0,13$ & 0,24 & 0,16 & 0,77 & 0,23 & 0,18 & 0,20 & $-0,18$ & $-0,21$ & $-0,02$ & $-0,13$ & $-0,04$ & 0,16 & 0,11 & $-0,40$ & 0,07 & $-0,22$ & $-0,27$ & $-0,09$ & $-0,14$ & $-0,17$ & $-0,46$ & $-0,01$ & 1,00 & \\
\hline $\mathrm{Pb}$ & $-0,16$ & 0,00 & 0,76 & $-0,24$ & 0,14 & 0,00 & 0,88 & $-0,19$ & 0,05 & 0,11 & $-0,17$ & $-0,29$ & $-0,13$ & $-0,18$ & $-0,19$ & 0,71 & $-0,03$ & 0,15 & $-0,07$ & $-0,26$ & 0,40 & $-0,19$ & $-0,26$ & $-0,23$ & $-0,13$ & $-0,02$ & 0,78 & 1,00 \\
\hline
\end{tabular}


TABELA 5.4: Coeficiente de correlação de Pearson obtido para as concentrações dos elementos determinados nas amostras de extrato.

\begin{tabular}{|c|c|c|c|c|c|c|c|c|c|c|c|c|c|c|c|c|c|c|c|c|c|c|c|}
\hline & As & $\mathrm{Ba}$ & $\mathrm{Br}$ & $\mathrm{Ca}$ & Co & $\mathrm{Cr}$ & Cs & $\mathrm{Fe}$ & $\mathrm{Hf}$ & $\mathrm{K}$ & $\mathrm{Na}$ & $\mathbf{R b}$ & $\mathrm{Sb}$ & $\mathrm{Sc}$ & $\mathrm{Se}$ & Th & $\mathbf{U}$ & $\mathrm{Zn}$ & $\mathrm{Zr}$ & $\mathrm{Cd}$ & $\mathrm{Cu}$ & $\mathrm{Ni}$ & $\mathrm{Pb}$ \\
\hline As & 1,00 & & & & & & & & & & & & & & & & & & & & & & \\
\hline $\mathrm{Ba}$ & $-0,21$ & 1,00 & & & & & & & & & & & & & & & & & & & & & \\
\hline $\mathrm{Br}$ & $-0,08$ & 0,06 & 1,00 & & & & & & & & & & & & & & & & & & & & \\
\hline $\mathrm{Ca}$ & $-0,04$ & 0,37 & $-0,15$ & 1,00 & & & & & & & & & & & & & & & & & & & \\
\hline Co & 0,41 & $-0,09$ & 0,64 & $-0,09$ & 1,00 & & & & & & & & & & & & & & & & & & \\
\hline $\mathrm{Cr}$ & 0,00 & 0,35 & $-0,02$ & 0,45 & 0,18 & 1,00 & & & & & & & & & & & & & & & & & \\
\hline Cs & 0,70 & $-0,22$ & $-0,13$ & 0,07 & $-0,14$ & 0,06 & 1,00 & & & & & & & & & & & & & & & & \\
\hline $\mathrm{Fe}$ & 0,49 & $-0,08$ & 0,01 & $-0,21$ & 0,77 & 0,20 & $-0,16$ & 1,00 & & & & & & & & & & & & & & & \\
\hline $\mathrm{Hf}$ & & $-0,48$ & 0,09 & $-0,19$ & $-0,05$ & $-0,20$ & $-0,38$ & 0,43 & 1,00 & & & & & & & & & & & & & & \\
\hline K & 0,62 & 0,08 & $-0,09$ & 0,70 & 0,05 & 0,92 & $-0,17$ & 0,41 & & 1,00 & & & & & & & & & & & & & \\
\hline $\mathrm{Na}$ & $-0,43$ & 0,00 & $-0,26$ & 0,46 & 0,14 & 0,50 & $-0,04$ & 0,16 & $-0,08$ & 0,90 & 1,00 & & & & & & & & & & & & \\
\hline $\mathbf{R b}$ & $-0,12$ & 0,10 & 0,15 & 0,21 & $-0,05$ & 0,16 & 0,49 & $-0,22$ & $-0,21$ & 0,44 & 0,30 & 1,00 & & & & & & & & & & & \\
\hline $\mathrm{Sb}$ & 0,29 & 0,08 & $-0,18$ & 0,27 & $-0,03$ & 0,36 & 0,27 & $-0,07$ & $-0,77$ & 0,50 & $-0,07$ & 0,13 & 1,00 & & & & & & & & & & \\
\hline Sc & $-0,09$ & 0,00 & 0,28 & 0,02 & 0,85 & 0,16 & $-0,25$ & 0,65 & 0,61 & $-0,14$ & 0,11 & $-0,17$ & $-0,08$ & 1,00 & & & & & & & & & \\
\hline $\mathrm{Se}$ & & $-0,67$ & 0,76 & $-0,21$ & 0,92 & $-0,03$ & & $-0,08$ & & & & $-0,16$ & & 0,87 & 1,00 & & & & & & & & \\
\hline Th & $-0,16$ & $-0,08$ & 0,75 & $-0,12$ & 0,53 & 0,43 & $-0,15$ & 0,51 & 0,74 & 0,15 & 0,05 & $-0,15$ & 0,62 & 0,59 & $-0,95$ & 1,00 & & & & & & & \\
\hline $\mathbf{U}$ & 0,19 & $-0,30$ & & $-0,05$ & 0,21 & 0,23 & $-0,11$ & $-1,00$ & & & & $-0,11$ & & $-0,09$ & & $-0,35$ & 1,00 & & & & & & \\
\hline $\mathrm{Zn}$ & 0,55 & 0,01 & 0,68 & 0,05 & 0,74 & 0,25 & $-0,29$ & 0,59 & 0,46 & 0,37 & 0,08 & $-0,07$ & $-0,17$ & 0,75 & & 0,62 & 0,28 & 1,00 & & & & & \\
\hline $\mathrm{Zr}$ & $-0,24$ & $-0,23$ & 0,29 & $-0,32$ & $-0,01$ & 0,01 & $-0,29$ & 0,44 & $-0,26$ & 0,89 & $-0,25$ & $-0,25$ & 0,03 & $-0,18$ & & $-0,18$ & & $-0,14$ & 1,00 & & & & \\
\hline $\mathrm{Cd}$ & $-0,33$ & $-0,12$ & 0,19 & $-0,17$ & 0,47 & 0,44 & $-0,12$ & 0,38 & $-0,23$ & 0,46 & 0,14 & 0,05 & $-0,19$ & 0,40 & $-0,03$ & 0,43 & 0,66 & 0,48 & 0,15 & 1,00 & & & \\
\hline $\mathrm{Cu}$ & $-0,17$ & $-0,10$ & 0,10 & $-0,01$ & $-0,09$ & 0,23 & 0,25 & $-0,13$ & $-0,66$ & 0,50 & 0,32 & 0,08 & $-0,21$ & $-0,19$ & 0,24 & 0,06 & 0,96 & $-0,11$ & $-0,01$ & 0,17 & 1,00 & & \\
\hline $\mathbf{N i}$ & $-0,14$ & $-0,05$ & 0,84 & $-0,24$ & 0,32 & $-0,08$ & $-0,02$ & 0,08 & $-0,57$ & $-0,27$ & $-0,20$ & 0,04 & 0,16 & 0,28 & $-0,17$ & 0,61 & 0,28 & 0,31 & $-0,09$ & $-0,04$ & 0,24 & 1,00 & \\
\hline $\mathrm{Pb}$ & $-0,24$ & $-0,40$ & $-0,15$ & $-0,36$ & $-0,19$ & $-0,06$ & 0,04 & 0,16 & 0,70 & 0,22 & 0,02 & $-0,12$ & $-0,19$ & $-0,20$ & $-0,84$ & 0,19 & $-0,62$ & $-0,02$ & 0,10 & 0,05 & 0,32 & $-0,08$ & 1,00 \\
\hline
\end{tabular}


Esse método consiste em um procedimento hierárquico no qual a medida de similaridade usada para juntar os agrupamentos é calculada como a soma de quadrados entre os dois agrupamentos feitos sobre todas as variáveis.

Esse método tende a resultar em agrupamentos de tamanhos aproximadamente iguais devido a sua minimização de variação interna. Em cada estágio, combinam-se os dois agrupamentos que apresentarem menor aumento na soma global de quadrados dentro dos agrupamentos (Hair et al., 2005).

O resultado da análise de agrupamento para os elementos determinados nas amostras das plantas está demonstrado na Figura 5.9, na qual pode ser observada a formação de cinco grupos principais de similares.

\section{Dendrograma Para os 30 Elementos Determinados nas Plantas Medicinais \\ Mé todo de Ward \\ Distância Euclidiana}

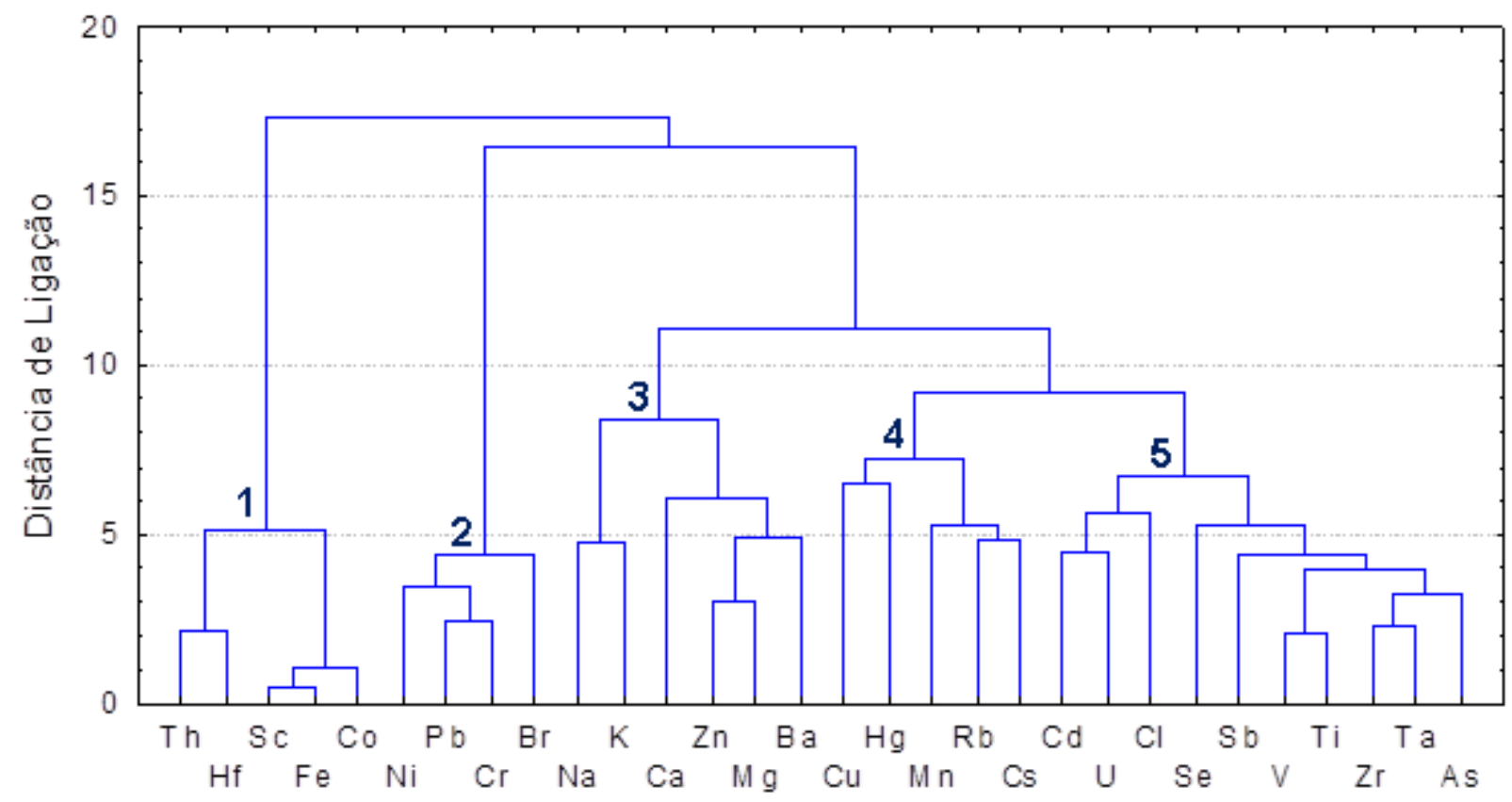

FIGURA 5.9: Dendrograma para os elementos determinados nas plantas medicinais.

Observou-se que os grupos formados estão de acordo com o observado na análise de coeficiente de correlação o que confirma a similaridade do comportamento destes grupos de elementos em relação à variação de suas 
concentrações observadas nas plantas. O grupo 1 contém os elementos essências Co e Fe e os elementos $\mathrm{Hf}$, Sc e Th, uma possível justificativa para estes elementos estarem relacionado ao $\mathrm{Fe}$ e Co pode ser pela semelhança na capacidade de absorção destes pelas plantas. No grupo 2 estão os elementos de transição $\mathrm{Cr}$ e $\mathrm{Ni}$, o metal tóxico $\mathrm{Pb}$ e o halogênio $\mathrm{Br}$, a formação deste grupo provavelmente está relacionada à capacidade de absorção destes elementos por diferentes tecidos das plantas como raiz, folhas, flores e etc. $\mathrm{O}$ grupo 3 é formado pelos metais alcalinos $\mathrm{K}$ e $\mathrm{Na}$ que apresentam alta solubilidade, os alcalinos terrosos $\mathrm{Ca}$ e $\mathrm{Mg}$ em associação ao $\mathrm{Zn}$. O grupo 4 é formado pelos elementos considerados tóxicos $\mathrm{Cs}, \mathrm{Hg}$ e $\mathrm{Rb}$ e os elementos essenciais $\mathrm{Cu}$ e $\mathrm{Mn}$. O grupo 5 formado por elementos determinados em relativamente poucas amostras de plantas como o $\mathrm{Cl}, \mathrm{Se}, \mathrm{V}, \mathrm{Ta}, \mathrm{Ti}, \mathrm{Zr}$ e os tóxicos As, $\mathrm{Cd}$, Sb e U em associação ao $\mathrm{Cl}$. Na Figura 5.10 é mostrado o dendrograma em função das plantas medicinais analisadas.

Dendrograma das 24 Espécies de Plantas Medicinais

Método de Ward

Distância Euclidiana

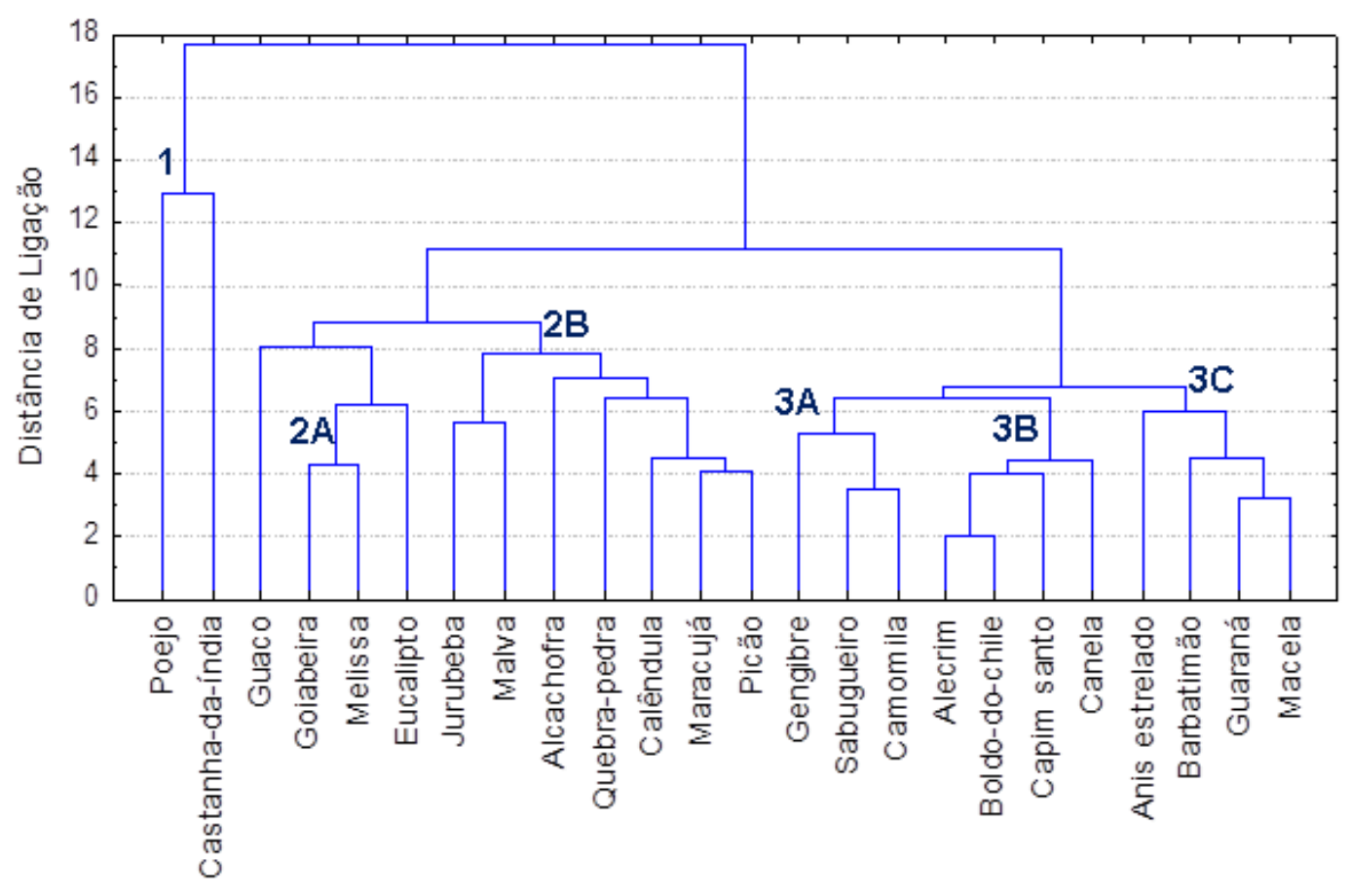

FIGURA 5.10: Dendrograma para as plantas medicinais. 
O grupo 1 foi constituído pelas espécies castanha-da-índia e poejo e é caracterizado pela alta concentração para a maioria dos elementos determinados. $A$ parte recomendada para uso destas espécies são sementes com cascas e partes aéreas, respectivamente, o que indica que tais partes são enriquecidas na maioria dos elementos químicos determinado neste estudo.

O grupo 2 é subdividido em dois subgrupos. No subgrupo $2 \mathrm{~A}$, que contém as espécies guaco, goiabeira, melissa e eucalipto, é predominante o uso das folhas como parte indicada, exceto para a melissa cuja indicação de uso são as sumidades floridas. Neste subgrupo a maioria dos elementos encontra-se em baixas concentrações, como por exemplo, os elementos essenciais Co, Cr, Fe, K, Se, V e $\mathrm{Ni}$, outros elementos como $\mathrm{Ba}, \mathrm{Br}, \mathrm{Hf}$, Sc, Th e $\mathrm{Zr}$ e os elementos tóxicos $\mathrm{As}$ e $\mathrm{Pb}$. Os elementos $\mathrm{Ba}, \mathrm{Mg}, \mathrm{Na}, \mathrm{Cs}$ e $\mathrm{Sb}$ encontram-se em níveis intermediários de concentrações e altas concentrações predominam apenas para os elementos $\mathrm{Ca}, \mathrm{Cl}$, $\mathrm{Mn}, \mathrm{Zn}$ e os tóxicos $\mathrm{Hg}$, Cd e Cu. No Subgrupo 2B encontram-se as espécies jurubeba, malva, alcachofra, quebra-pedra, calêndula, maracujá e picão. As partes da planta recomendadas para uso neste subgrupo são folhas, flores, partes aéreas e planta inteira. Este subgrupo é caracterizado pelas altas concentrações de elementos essenciais como $\mathrm{Ca}, \mathrm{Cl}, \mathrm{K}, \mathrm{Mg}, \mathrm{Na}, \mathrm{Se}, \mathrm{V}, \mathrm{Zn}$, Ba e Ta e os tóxicos As e $\mathrm{Cd}$; concentrações intermediárias dos elementos $\mathrm{Br}$, Co, $\mathrm{Cu}, \mathrm{Hf}, \mathrm{Ni}, \mathrm{Rb}, \mathrm{Sb}, \mathrm{Th}, \mathrm{Ti}, \mathrm{U}$ e $\mathrm{Zr}$ e baixas concentrações dos elementos $\mathrm{Cr}$, Fe, Mn, Sc, Cs, Hg e Pb.

O grupo 3, de maneira geral, contém as plantas que apresentaram as mais baixas concentrações e pode ser subdivido em três grupos. O subgrupo 3A, que contém as espécies gengibre, sabugueiro e camomila, tem como partes recomendadas para uso flores e rizomas. Apenas os elementos $\mathrm{K}, \mathrm{Mg}, \mathrm{Rb}, \mathrm{Sc}, \mathrm{Zn}$ e As apresentaram concentrações relativamente mais altas. Os elementos $\mathrm{Cu}, \mathrm{Hg} \mathrm{e}$ $\mathrm{Sb}$ apresentaram concentrações intermediárias. No subgrupo 3B encontram-se as espécies alecrim, boldo-do-chile, capim santo e canela sendo que para elas as partes indicadas para uso são, na maioria, as folhas. Neste grupo, encontram-se em níveis altos de concentrações os elementos $\mathrm{K}$, Sc e U, em níveis intermediário os elementos $\mathrm{As}, \mathrm{Br}, \mathrm{Ca}, \mathrm{Mg}, \mathrm{Mn}$ e $\mathrm{Cd}$ e os demais aparecem em baixas 
concentrações. No grupo $3 \mathrm{C}$, que é formado pelas as espécies anis estrelado, barbatimão, guaraná e macela, cascas, sementes, sumidades floridas e frutos são as partes recomendados para uso. Neste grupo as baixas concentrações para os elementos químicos também são predominante. Apenas os elementos $\mathrm{Br}, \mathrm{Cl}$ e $\mathrm{K}$ apresentaram concentrações em níveis intermediários e os elementos $\mathrm{Cu}$ e Cs, concentrações mais altas.

Na Figura 5.11 é mostrado o dendrograma obtido em função dos elementos, para os extratos. Observa-se a formação de 2 grupos. O grupo 1 pode ser subdividido em: grupo $1 \mathrm{~A}$ que contém, além dos elementos essenciais Co, Fe e Zn, os elementos $\mathrm{Sc}$ e $\mathrm{Cd}$ e o grupo $1 \mathrm{~B}$, que contém os elementos $\mathrm{Ni}$, Th e $\mathrm{Br}$. O grupo 2 pode ser subdividido em: $2 \mathrm{~A}$, formado pelos metais alcalinos $\mathrm{Na}$ e $\mathrm{K}$, altamente solúveis, alcalinos terrosos $\mathrm{Ca}$ e $\mathrm{Ba}$ e pelo $\mathrm{Cr}$; o grupo $2 \mathrm{~B}$, composto pelos elementos considerados tóxicos $\mathrm{Sb}$ e $\mathrm{Cs}$ e o elemento $\mathrm{Rb}$; no grupo $\mathrm{2C}$ pode-se observar o comportamento individualizado dos elementos $\mathrm{Pb}$ e $\mathrm{Cu}$; e o grupo 2D que é formado pelos elementos determinados em um numero relativamente pequeno entre as espécies de plantas analisadas, $\mathrm{Zr}, \mathrm{Hf}, \mathrm{Ta}$, Se, As e U.

Dendrograma para os 24 Eementos Determinad os nos Extratos de Plantas Medicinais

Método de Ward

Distância Euclidiana

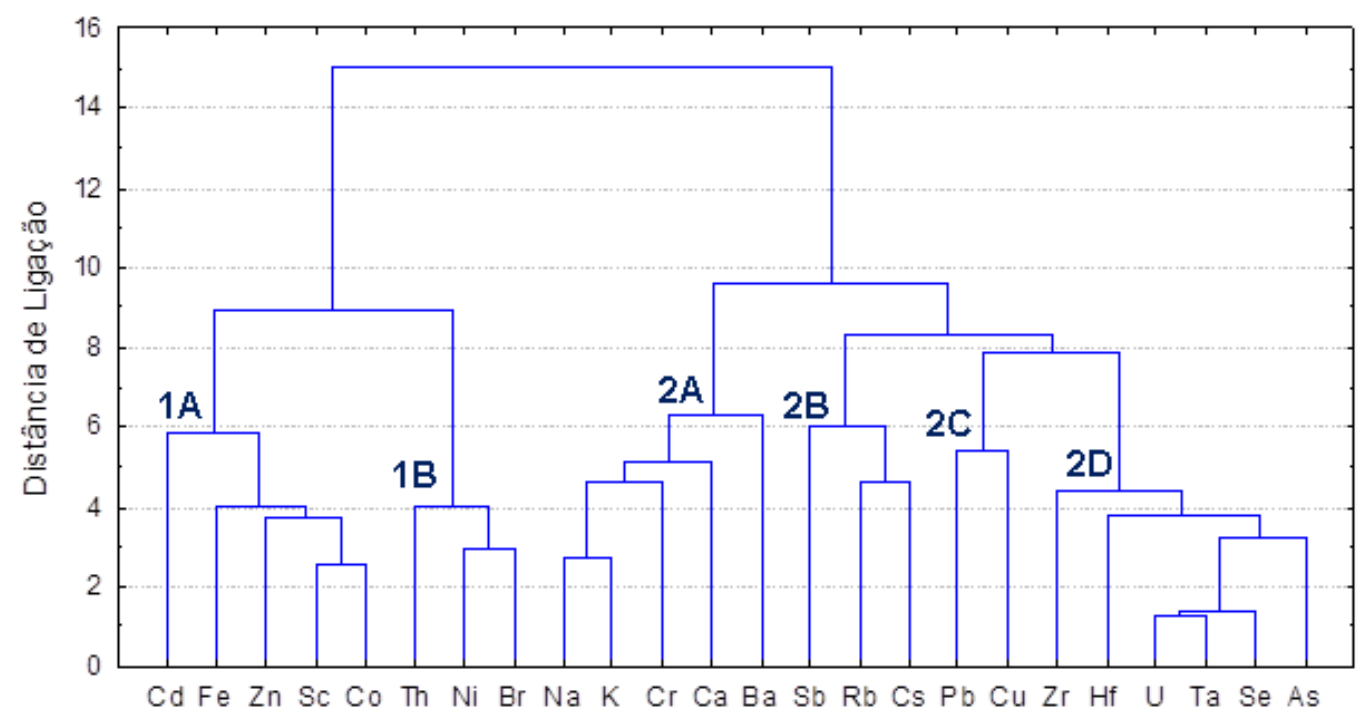

FIGURA 5.11: Dendrograma para os elementos determinados nos extratos de plantas medicinais. 
$\mathrm{Na}$ Figura 5.12 é demonstrado o dendrograma em função das plantas utilizadas para obtenção dos extratos. O grupo 1 é caracterizado por concentrações relativamente altas de todos os elementos exceto para $\mathrm{Hf}$ e Se. Este grupo possui altas concentrações dos elementos essenciais $\mathrm{Co}, \mathrm{Cu}, \mathrm{Fe}, \mathrm{K}, \mathrm{Zn}$ e $\mathrm{Cr}$, dos elementos $\mathrm{Br}$, $\mathrm{Rb}$ e $\mathrm{Zr}$ e dos considerados tóxicos $\mathrm{Ni}$ e $\mathrm{Cd}$.

O grupo 2 é composto principalmente por plantas cujos extratos são enriquecidos em elementos como $\mathrm{Ca}, \mathrm{Cr}, \mathrm{K}, \mathrm{Na}, \mathrm{Se}, \mathrm{Zn}, \mathrm{Ba}, \mathrm{Hf}, \mathrm{Rb}$ e em elementos considerados tóxicos como $\mathrm{As}, \mathrm{Cu}, \mathrm{Sb}$ e $\mathrm{Pb}$. Os elementos $\mathrm{Co}, \mathrm{Fe}, \mathrm{Sc}$, os tóxicos $\mathrm{Cd}$, Cs e Ni apresentaram concentração intermediária e $\mathrm{Br}$, Th e $\mathrm{Zr}$ apresentaram baixas concentrações.

\section{Dendrograma para os 23 Extratos de Pantas Medicinais Analisados \\ Método de Ward \\ Distância Euclidiana}

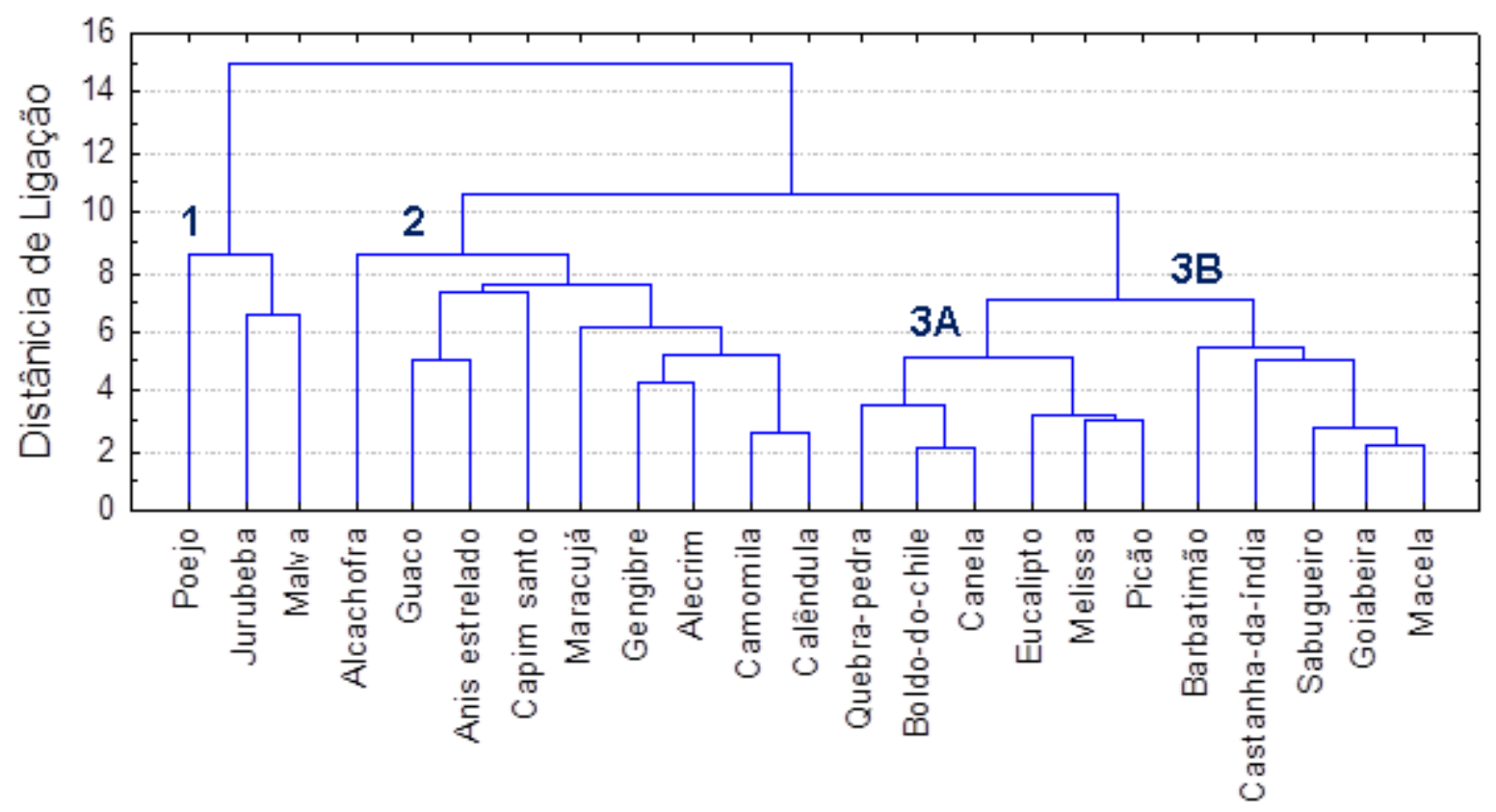

FIGURA 5.12: Dendrograma contendo os 23 extratos de plantas medicinais.

No grupo 3 foram observadas as mais baixas concentrações para todos os elementos nos extratos das espécies analisadas. Este grupo pode ser subdividido nos subgrupos $3 \mathrm{~A}$, formado pelas espécies que possuem concentrações 
intermediárias para os elementos $\mathrm{Br}, \mathrm{Ca}, \mathrm{Cs}, \mathrm{Hf}, \mathrm{Rb}, \mathrm{Th}, \mathrm{Cd}, \mathrm{Cu}$ e baixas concentrações para os elementos $\mathrm{Pb}$ e $\mathrm{As}, \mathrm{Br}$, Co, $\mathrm{Cr}$, Fe, K, Na, Sb, $\mathrm{Zn}$ e $\mathrm{Zr}$, apenas os elementos $\mathrm{Ni}$ e Sc possuem elevada concentração nas plantas pertencentes a este subgrupo; e 3B, no qual a maioria dos elementos se encontra em concentração baixa em praticamente todos os extratos analisados. Com exceção de $\mathrm{Cr}, \mathrm{Fe}, \mathrm{Hf}, \mathrm{Ta}$, Th, $\mathrm{Cd}$ e Cu que encontram-se em concentrações intermediárias e dos elementos $\mathrm{U}, \mathrm{Zr}$, $\mathrm{Ni}$ e $\mathrm{Pb}$ que apresentaram concentrações relativamente mais altas.

Com relação às análises estatísticas realizadas para os extratos, verifica-se que, assim como para as plantas, os resultados obtidos pela análise de agrupamento são concordantes com os obtidos na análise dos coeficientes de correlação. Da mesma forma pode-se verificar a confirmação da similaridade no comportamento destes grupos de elementos em relação à variação de suas concentrações observadas nos extratos.

Os resultados obtidos para a análise de agrupamento poderão futuramente subsidiar estudos que relacionem as concentrações elementares, tanto das plantas quanto dos extratos, com sua indicação terapêutica ou ainda para serem utilizadas para fins nutricionais. 


\section{CONCLUSÃO}

Foram selecionadas 24 espécies de plantas medicinais e seus extratos para determinação de teor de umidade, teor de impurezas, cinzas totais, cinzas insolúveis em ácido e das concentrações dos elementos $\mathrm{As}, \mathrm{Ba}, \mathrm{Br}, \mathrm{Ca}, \mathrm{Cl}, \mathrm{Cs}, \mathrm{Co}, \mathrm{Cr}, \mathrm{Fe}, \mathrm{Hf}$, $\mathrm{K}, \mathrm{Mg}, \mathrm{Mn}, \mathrm{Na}, \mathrm{Rb}, \mathrm{Sb}, \mathrm{Sc}$, Se, Ta, Th, Ti, U, V, Zn e Zr pela técnica de Análise por Ativação Neutrônica Instrumental (INAA), $\mathrm{Cu}, \mathrm{Ni}, \mathrm{Pb}$ e $\mathrm{Cd}$ por Espectrometria de Emissão Atômica com Plasma Indutivamente Acoplado (ICP-OES) e $\mathrm{Hg}$ por Espectrometria de Absorção Atômica com Geração de Vapor Frio (CV AAS).

As técnicas utilizadas neste estudo apresentaram sensibilidade adequada para a determinação das concentrações para a maior parte dos elementos presentes nas amostras de plantas e nos seus extratos.

Em relação à análise de impurezas, observou-se que os teores mais elevados são encontrados quando a parte indicada para o consumo são as folhas. Para as análises de teor de umidade, cinzas totais e cinzas insolúveis em ácido a maioria das amostras apresentou resultados que atendem aos requisitos da Farmacopeia Brasileira.

As comparações dos resultados obtidos neste estudo com valores encontrados em literatura, de maneira geral, demonstraram uma boa concordância entre as concentrações elementares das plantas analisadas neste estudo e aquelas encontradas nos referidos artigos, embora tenha sido possível verificar o enriquecimento de alguns elementos como $\mathrm{Co}, \mathrm{Cr}$, Fe, Ni, $\mathrm{Ti}$ e $\mathrm{Zn}$ ou deficiência de outros $\mathrm{Cu}, \mathrm{K}, \mathrm{Na}, \mathrm{Mn}$ e $\mathrm{Pb}$. Entre as espécies analisadas, as plantas que apresentaram maior concentração dos elementos determinados foram Aesculus hippocastanum (castanha-da-índia) e Mentha pulegium (poejo). Em relação aos extratos, as maiores concentrações para os elementos determinados foram encontradas nos chás de Mentha pulegium (poejo), Malva sylvestris (malva) e Solanum paniculatum (jurubeba). 
Quanto aos elementos $\mathrm{As}, \mathrm{Ba}, \mathrm{Rb}, \mathrm{Sb}, \mathrm{Th}, \mathrm{U}, \mathrm{Hg}, \mathrm{Cd}$ e $\mathrm{Pb}$, considerados tóxicos não foram encontrados em concentrações que possam representar algum tipo de dano ao organismo devido ao consumo de chá. Por outro lado, elementos que desempenham papel importante no metabolismo como $\mathrm{Ca}$, Fe, Se, Zn, $\mathrm{Na}$ e K foram encontrados, nas espécies analisadas, em quantidades que possivelmente podem auxiliar na ação terapêutica de plantas como Cynara scolymus (alcachofra), Eucaliptos globulus (eucalipto), Mentha pulegium (poejo), Passiflora alata (maracujá), Paullinia cupana (guaraná), Psidium guajava (goiabeira) e Zingiber officinale (gengibre).

Verificou-se que as concentrações dos elementos nos extratos e nas plantas não são necessariamente proporcionais, devido às diferentes porcentagens de extração observadas para as diferentes espécies estudadas. Portanto, estudos de ação terapêutica ou relacionados à dieta alimentar devem levar em consideração as concentrações obtidas nos extratos e não somente na planta como se observa na maioria dos trabalhos publicados sobre este assunto.

Os elementos $\mathrm{Co}, \mathrm{Cr}, \mathrm{Fe}, \mathrm{Na}, \mathrm{Pb}, \mathrm{Sc}$, Th, e $\mathrm{V}$ foram o que apresentaram maior diferença entre suas concentrações mínimas e máximas e os elementos As, $\mathrm{Ca}, \mathrm{Cu}, \mathrm{Sb}, \mathrm{Se}, \mathrm{U}$ e $\mathrm{Zn}$, a menor variação entre as suas concentrações.

Os resultados apresentados pelas análises estatísticas de coeficiente de correlação e análises de agrupamento demonstraram boa concordância possibilitando confirmar a similaridade no comportamento de determinados elementos químicos em relação à variação de suas concentrações observadas nas plantas e em seus extratos.

A análise de agrupamento (cluster analysis) indicou que as espécies Aesculus hippocastanum (castanha-da-índia) e Mentha pulegium (poejo) são enriquecidas em praticamente todos os elementos determinados, as espécies Mikania glomerata (guaco), Psidium guajava (goiabeira), Melissa officinalis (melissa) e Eucalyptus globulus (eucalipto) são enriquecidas nos elementos $\mathrm{Ca}, \mathrm{Cl}, \mathrm{Mn}, \mathrm{Zn}, \mathrm{Hg}, \mathrm{Cd}$ e $\mathrm{Cu}$ e as espécies Solanum paniculatum (jurubeba), Malva sylvestris (malva), Cynara 
scolymus (alcachofra), Phyllanthus niruri (quebra-pedra), Calendula officinalis (calêndula), Passiflora alata (maracujá) e Bidens pilosa (picão) são enriquecidas nos elementos $\mathrm{Ca}, \mathrm{Cl}, \mathrm{K}, \mathrm{Mg}, \mathrm{Na}$, Se, V, Zn, Ba, Ta, As e Cd.

Entre os extratos verificou-se que os de Mentha pulegium (poejo), Solanum paniculatum (jurubeba) e Malva sylvestris (malva) são os mais enriquecidos em relação aos elementos determinados, Cynara scolymus (alcachofra), Mikania glomerata (guaco), Illicium verum (anis estrelado), Cymbopogon citratus (capim santo), Passiflora alata (maracujá), Zingirber officinale (gengibre), Rosmarinus officinales (alecrim), Matricaria recutita (camomila) e Calendula officinalis (calêndula) são enriquecidas nos elementos $\mathrm{Ca}, \mathrm{Cr}, \mathrm{K}, \mathrm{Na}$, Se, Zn, Ba, Hf, Rb, As, Cu, Sb e Pb. Estes resultados podem ser úteis para futuros estudos sobre a ação terapêutica que possam exercer os elementos aqui determinados.

Este estudo demonstrou que as plantas medicinais podem disponibilizar elementos químicos para organismo humano, por meio do consumo dos chás preparados a partir das plantas medicinais. É preciso ainda que ocorram futuros estudos que determinem se a presença destes elementos pode contribuir para a melhoria da ação terapêutica de cada espécie. Entretanto os elementos presentes nas plantas medicinais como $\mathrm{Ca}, \mathrm{Fe}$ e $\mathrm{Zn}$ entre outros, podem auxiliar na suplementação em casos de carência, uma vez introduzidos na dieta alimentar. 


\section{REFERÊNCIAS BIBLIOGRÁFICAS}

Abdul-Wahab, O. E.; Adnan M. M.; Mohammad N. O. Evaluation of Pb, Cu, Zn, Cd, $\mathrm{Ni}$ and Fe levels in Rosmarinus officinalis labaiatae (Rosemary) medicinal plant and soils in selected zones in Jordan, 2007. Environ Monit Assess 140: 61- 68, 2008.

Abou-Arab A. A. K.; Kawther M. S.; El Tantawy M. E.; Badeaa R. I.; Khayria N. Quantity stimation of some contaminants in commonly used medicinal plants in the Egyptian market. Food Chem. 67: 357-363, 1999.

Adeodado, S.; Oliveira, L.; Oliveira, V. Uma farmácia no fundo do quintal. Revista Globo Ciências, 64(6): 44-49, 1996.

Ajasa, M. O.; Bello, M. O.; Ibrahimb, A. O.; Ogunwandeal, A.; Olaworeb, N. O. Heavy trace metals and macronutrients status in herbal plants of Nigeria. Food Chem. 85: 67-71, 2004.

Alexandre, R. F.; Bagatini, F.; Simões, C. M. O. Interações entre fármacos e medicamentos fitoterápicos à base de ginkgo ou ginseng. Rev. Bras. Farm. 18 (1): 117-126, 2008.

Almeida, E. R. Plantas Medicinais Brasileiras: conhecimentos Populares e Científicos. São Paulo, SP, Brasil: Hemus, p. 341, 1993.

Almeida, M. M. B.; Lopes, M. F. G.; Nogueira C. M. D.; Magalhães, C. E. C.; Morais, N. M. T. Determinação de Nutrientes Minerais em Plantas Medicinais, Ciência e Tecnologia dos Alimentos. Campinas, 22 (1): 94-97, São Paulo, 2002.

Aničić, M.; Spasić, T.; Tomašević, M.; Rajšić, S.; Tasić, M. 2011. Trace elements accumulation and temporal trends in leaves of urban deciduous trees (Aesculus hippocastanum and Tilia spp.). Ecological Indicators. 11: 824-830, 2011.

Alvim, N. A. T.; Ferreira, M. A.; Cabral. I. E.; Almeida Filho, A. J. O uso de plantas medicinais como recurso terapêutico das influências da formação profissional às implicações éticas e legais de sua aplicabilidade como extensão da prática de cuidar realizada pela enfermeira. Revista Latino Americana de Enfermagem. 14: 3, 2006. Ansel, H. C.; Popovich, N. G.; Allen Júnior, L. V. Farmacotécnica: formas farmacêuticas e sistemas de liberação de fármacos. $6^{a}$ ed., p. 568. São Paulo: Premier 2000.

ANVISA. Resolução de Diretoria Colegiada $\mathrm{n}^{\circ} .42$ de 29 de agosto de 2002. Dispõe sobre o Regulamento Técnico MERCOSUL sobre Limites Máximos de Contaminantes Inorgânicos em Alimentos. Diário Oficial da União, 2002.

ANVISA. Resolução RDC no 48, de16 de março de 2004. Dispõe sobre o registro de medicamentos fitoterápicos. D.O.U.- Diário Oficial da União; Poder Executivo de18 de março de 2004. 
Azevedo, J.; Maduro, R.; Goulart, J. Programa de análise de produtos-Relatório sobre análise em chás. Instituto Nacional de Metrologia, Normalização e Qualidade Industrial-INMETRO. Rio de Janeiro, 2009. Disponível em: < http://www.inmetro.gov.br>. Acesso em 13/11/12.

Azevedo, F. A., Chasin, A. A. M., Metais: Gerenciamento da toxicidade, ed. Atheneu, São Paulo, Brasil (2003).

Badke, M. R. Conhecimento popular sobre o uso de plantas medicinais e o cuidado de enfermagem. 2008. Dissertação (Mestrado) - Universidade Federal de Santa Maria, Santa Maria, RS.

Balbach, A. A flora nacional na medicina natural. $1^{\underline{a}}$ ed., p. 915, Itaquaquecetuba, SP: Vida Plena, 1996.

Barceloux G. D. Manganese, nickel. Clin Toxicol. 37: 239-258 e 293-307, 1999.

Batalha, M. A.; Cianciaruso, M. V.; e Motta-Junior, J. C. Consequences of simulated loss of open Cerrado areas to bird functional diversity. Natureza \& Conservação. 8: $34-40,2010$.

Beaty, R. D.; Keber, J. D. Concepts, Instrumentations and Techiniques in Atomic Absorption Spectrophotometry: Perkin Elmer, USA, 1993.

Biazzi, E. O maravilhoso poder das plantas. Tatui, SP.: Casa Publicadora Brasileira, 2004.

Bordajandi, L. R.; Gómez, G.; Abad, E.; Rivera, J.; Fernández-Baston, M. M.; Blasco, J.; González, J. Survey of persistent organochlorine contaminants (PcBs, PCDD/FS and $\mathrm{PAHS}$ ), heavy metals ( $\mathrm{Cu}, \mathrm{Cd}, \mathrm{Zn}, \mathrm{Pb}$ and $\mathrm{Hg}$ ), and arsenic in food samples from Huelva (Spain): levels and health implications. J Agric Food Chem .52: 992-1001, 2004.

Boss, C. B.; Fredeen, K. J. Concepts, Instrumentation and Techniques in Inductively Coupled Plama Optical Emission Spectrometry, $2^{a}$ ed. Perkin Elmer Corporation, USA, 1997.

Brasil. Ministério da Saúde. CIPLAN no 8/88, de 8 de março de 1988. Regulamenta a implantação da prática de fitoterapia nos serviços de saúde. Diário Oficial da República Federativa do Brasil. Brasília, DF, seção 4, p. 126, 1988.

Brasil. Conselho Nacional de Saúde. Resolução no 338 de maio de 2004. Aprova a Política Nacional de Assistência Farmacêutica. Diário Oficial da República Federativa do Brasil. Brasília, DF, 20 maio de 2004.

Bostelmann, E. Avaliação da concentração de metais em amostras de sedimento do Reservatório Billings, Braço Rio Grande, São Paulo, Brasil. 2006. Dissertação (Mestrado) - Instituto de Pesquisas Energéticas Nucleares, São Paulo. 
DOU - Diário Oficial da União, 10/03/2010, Resolução-RDC № 10, de 9 de março de 2010. p. 53.

Brandão, M. G. L.; Freire, N.; Soares, C. D. V. Vigilância de fitoterápicos em Minas Gerais: Verificação da qualidade de diferentes amostras comerciais de camomila. Caderno de Saúde Pública. 14 (3): 613-616, 1998.

Brandão, M. Árvores nativas e exóticas do Estado de Minas Gerais. Belo Horizonte: EPAMIG, p. 528, 2002.

Cala, V.; Cases, M. A.; Walter, I. Biomass production and heavy metal content of Rosmarinus officinalis grown on organic waste-amended soil. Journal of Arid Environments. 62: 401-412, 2005.

Caldas E. D.; Machado L. L. Cadmiun, mercury and lead in medicinal herbs in Brazil. Food Chem Toxicol. 42: 599-603, 2004.

Calixto, J. B. Efficacy, safety, quality control, marketing and regulatory guidelines for herbal medicines. Brazilian Journal of Medical and Biological Research. 33: 179189, 2000.

Camargo JR., K. R. O campo das plantas medicinais do Brasil: lições de uma história. Hist. Cienc. Saúde-Manguinhos. 13 (1), Rio de Janeiro, Jan-Mar. 2006.

Cañigueral, S.; Dellacassa, E. e Bandoni, A. L. Plantas Medicinales y Fitoterapia: indicadores de dependencia 0 factores de desarrollo. Acta Farmacéutica Bonaerense. 22 (3): 265-278, 2003.

Cantarelli, M. A; Pelerano, R. G; Del Vitto, L. A; Marchevsky, E. J; Camina, J. M. Characterisation of two South American food and medicinal plants by chemometric methods based on their multielemental composition. Phytochem. Anal. 21: 550555, 2010.

Carreira, L. O cuidar ribeirinho: os saberes e práticas de saúde das famílias da ilha Mutum-PR (Dissertação de Enfermagem). Rio de Janeiro- RJ: EEAN/UFRJ, p. 134, 2002.

Coelho, S. R. Levantamento de plantas medicinais em comunidades de Rio Novo do Sul, Iconha, Itapemirim e Cachoeiro de Itapemirim. In: ENCONTRO SOBRE PLANTAS MEDICINAIS. 1: 13-27, 1989.

Committee on toxicity of chemicals in food, consumer products and the environment cot statement on the 2006 uk total diet study of metals and other elements. Disponível em : http://cot.food.gov.uk/pdfs/cotstatementtds200808.pdf. acesso em: 12/2013.

Committee on toxicity of chemicals in food, consumer products and the environment statement on the 1997 total diet study - fluorine, bromine, and iodine. Disponível em: http://multimedia.food.gov.uk/multimedia/pdfs/halogens.pdf. Acesso em 12/2013.

Conselho Nacional de Saúde. Resolução no 338, de 06 de maio de 2004. Diário Oficial da República Federativa do Brasil. Brasília, DF, 20 de maio de 2004. 
Cunha, A. P. Aspectos históricos sobre plantas medicinais, seus constituintes activos e fitoterapia 2008. Disponível em: http://www.antoniopcunha.com.sapo.pt/, acesso em 23/04/2013.

Chen, C. Y.; Pan, L. K. Trace elements of Taiwanese dioscorea spp. using instrumental neutron activation analysis. Food Chemistry, 72: 255-260, 2001.

Czelusniak, K. E.; Brocco, A.; Pereira, D. F.; Freitas, G. B. L. Farmacobotânica, fitoquímica e farmacologia do Guaco: revisão considerando Mikania glomerata Sprengel e Mikania laevigata Schulyz Bip. ex Baker.Universidade Estadual do Centro-Oeste, Campus Cedeteg, Departamento de Farmácia. Botucatu São PauloSP, 2012.

Correia, P. R. M.; Nomura, C. S.; Oliveira, P. V. Espectrometria de Absorção Atômica multielementar: Desafios e perspectivas. Revista Analytica, no. 5, junho/julho, p. 52$59,2003$.

Divienne, K. F.; Raddi, M. S. G.; Pozeti, G. L. Das plantas medicinais aos fitofármacos. Revista Brasileira de Plantas Medicinais. Botucatu, 6 (3): 11-14. São Paulo, 2004.

Diaconu, D.; Diaconu, R; Navrotescu, T. Estimation of heavy metals in medicinal plants and their infusions, Universitatii "Ovidius" Constanta - Seria Chimie. 23 (1): 115-120, 2012.

Dietary Reference Intakes for Vitamin A, Vitamin K, Arsenic, Boron, Chromium, Copper, lodine, Iron, Manganese, Molybdenum, Nickel, Silicon, Vanadium, and Zinc, 2001. Disponível em: http://www.iom.edu/Reports/2001/Dietary-Reference-Intakesfor-Vitamin-A-Vitamin-K-Arsenic-Boron-Chromium-Copper-lodine-Iron-ManganeseMolybdenum-Nickel-Silicon-Vanadium-and-Zinc.aspx Acesso: em 02/2014.

Dietary Reference Intakes for Water, Potassium, Sodium, Chloride, and Sulfate, 2005. Disponível em: http://www.nap.edu/openbook.php?record id=10925\&page=270. Acesso em $02 / 2014$.

Dim, L. A.; Funtua, I. I.; Oyewale, A. O.; Grass, F.; Umar, I. M.; Gwozdz, R.; Gwarzo, U. S. Determination of some elements in Ageratum conyziodes, a tropical medicinal plant, using instrumental neutron activation analysis. Journal of Radioanalytical and Nuclear Chemistry. 261 (1): 225.228, 2004.

DOU - Diário Oficial da União, 10/03/2010, Resolução-RDC № 10, de 9 de março de 2010, p. 53.

Ducat, G; Torres, Y. R; Santa, H. S. D; Caetano, I. K; Kleinubing, S. A; Stock, D; Tussolini, L; Justo, T. H; Quináia, S. P. Correlation among metallic ions, phenolic compounds and antimicrobial action in medicinal plants estracts. Journal of Food Quality 34: 306-314, 2011. 
Ernest, E.; Rand, J. I.; Stevinson, C. Complementary therapies for depression - An overview. Archives of General Psychiatry 55: 1026-1032, 1998.

Ernest, E.; Thompson. C. J. Heavy Metals in tradicional Chinese medicines: a systematic review. Clin. Pharmacol. Ther. 70: 497-504, 2001.

Farias, M. R. Avaliação da qualidade de matérias-primas vegetais. p. 197-220, 2001. In: C. M. O. Simões (ed.). Farmacognosia: da planta ao medicamento. Florianópolis, Universidade Federal de Santa Catarina.

Farias M. R. Avaliação da qualidade de matérias-primas vegetais, 2003. In: Simões, C. M. O.; Schenkel, E. P., Gosmann, G.; Mello J. C. P.; Mentz, L. A., Petrovick, P. R. (org.) Farmacognosia: da planta ao medicamento. 5a ed. Porto Alegre: UFRGS, Florianópolis: UFSC.

Faquim, V. Nutrição mineral de plantas. Curso de pós-graduação "lato sensu" (especialização) à distância solos e meio ambiente. Universidade Federal de Lavras - UFLA, 2005.

Farmacopéia Brasileira. 2ª edição. São Paulo: Indústria Gráfica Siqueira, p. 1265, 1959.

Farmacopeia Brasileira. Volume 1, 4⿳亠丷a edição. Atheneu Editora, São Paulo, p. $392,1988$.

Farmacopeia Brasileira. Volume 1, 5a edição. Agência Nacional de Vigilância Sanitária, Brasília. p. 545, 2010.

Favier A. Les oligoéléments en nutrition humaine. In: CAPPUIS, P. (Ed) Les oligoéléments en medicine et biologic. Paris: Editions médicales Internacionales, $\mathrm{p}$. 41-74, 1991.

FEBRAFARMA 2007. Brasil. Fitoterápico atrai investimentos. Disponível em: <http://www.febrafarma.org.br/materias > (acessado em maio de 2013).

Ferreira, M. O. M.; Sato, I. M.; Salvador, V. L. R. Validação da Metodologia analítica na determinação de componentes inorgânicos em plantas medicinais Valeriana officinalis, Ginkgo folium e Echunodorus macrophyllus. Anais do congresso METROLOGIA- 2003 - Metrologia para a Vida, Sociedade Brasileira de Metrologia (SBM), Recife, Pernambuco - Brasil, 2003.

Foglio, M. A.; Queiroga, C. L.; Sousa, I. M. O.; Rodrigues, R. A. F. Plantas medicinais como fonte de recursos terapêuticos: um modelo multidisciplinar. MultiCiência: Construindo a história dos produtos naturais. 2006. Disponível em: <http://www.multiciencia.unicamp.br/artigos_07/a-047.pdf> (acessado em março de 2013).

Franco, F. Tabela de Composição de Alimentos. 9ª ed. Atheneu. São Paulo, 1998. 
Golden M. H. Proposed recommended nutrient densities for moderately malnourished children (supplement). Food and Nutrition Bulletin. 30 (3): 43, 2009.

Gonçalves, R. D. M. R.; Francisconi, L. S.; Silva, P. S. C. Inorganic constituents in herbal medicine by neutron activation analysis. In: Internacional Nuclear Atlantic Conference - INAC 2011, Belo Horizonte. Anais da International Nuclear Atlantic Coference - INAC 2011 (CD-ROON) Rates, S. M. K. Plants as source of drougs. Toxicon, 39: 603-613, 2001.

Gowrishankar, R.; Kumar, M.; Menon, V.; Divi, S. M.; Saravanan, M.; Magudapathy, P.; Panigrahi, B. K.; Nair, K. G. M.; Venkataramaniah, K. Trace element studies on Tinospora cordifolia (Menispermaceae), Ocimum sanctum (Lamiaceae), Moringa oleifera (Moringaceae), and Phyllanthus niruri (Euphorbiaceae) Using PIXE. Biol. Trace Elem. Res. 133:357-363, 2010.

Gjorgieva, D.; Kadifkova-Panovska, T.; Baceva, K.; Stafilov, T. Contento of toxic and essential metals in medicinal herbs growing in polluted and unpolluted areas of Macedonia. Arh Hig Rada Toksikol. 61: 297-303, 2010.

Glascock, M. D. - An Overview of Neutron Activation Analysis, 2003 - Disponível em: http://www.missouri.edulglascok\naa_over.htm, acesso em junho de 2013. In Amorim, P. A. Avaliação da concentração de metais e outros elementos de interesse em amostras de sedimentos dos estuários de Santos São Vicente e Cananéia, Estado de São Paulo, Brasil. 2012. Dissertação (Doutorado) Instituto de Pesquisas Energéticas e Nucleares, SP.

Gurib-Fakim, A. Medicinal plants: traditions of yesterday and drugs of tomorrow. Molecular Aspects of Medicine 27: 1-93, 2006.

Hair, J. F. Análise multivariada de dados. Trad. Adonai S. Sant'Anna e Anselmo C. Neto. 5 ed. Porto Alegre: Bookman, 2005.

Hiçsönmez, Ü.; Ereeş, F. S.; Özdemir, C.; Özdemir, A.; Çam, S. Determination of major and minor elements in the Malva sylvestris L. from turkey using ICP-OES techniques. Biol. Trace Elem. Res. 128:248-257, 2009.

IAEA - INTERNATIONAL ATOMIC ENERGY AGENCY. Use of research reactors for neutron activation analysis. 2001. (IAEA- TECDOC 1215).

INMETRO - Instituto Nacional de Metrologia, Normalização e Qualidade Industrial. Orientações sobre Validação de Métodos de Ensaios Químicos, DOQ-CGCRE008, 2003.

Karada, C; Kara D. Chemometric approach to evaluate trace metal concentrations in some spices and herbs. Food Chemistry. 130: 196-202, 2012.

Karak, T.; Bhagat, R. M. Traces elements in tea leaves, made tea and tea infusion: A review. Food Research International v 43: 2234-2252, 2010. 
Kobers, V. C.; Santos, C. R. R.. Plantas medicinais. Francisco Beltrão: editora Grafti, p.13, 2007.

Lameira, O. A.; Pinto, J. E. B. P. Plantas medicinais: do cultivo, manipulação e uso à recomendação popular. Embrapa Amazônia Oriental. Belém, PA, 2008.

Langmead, L.; Rampton, D. S. Herbal treatment in gastrointestinal and liver diseasebenefites and dangers. Aliment Pharmacol. Ther. 15 (9): 1239-1252, 2001.

Lopes, M. F. G.; Vasconcenlos, N. M. S.; Almeida, M. M. B.; Nogueira, C. M. D.; Morais, N. M. T.; Sá, M. J. H. C. Caracterização Analítica de Plantas Medicinais. Rev. Bras. Farm. 79 (3-4): 88-89, Fortaleza/CE, 1998.

Lou, C; Liu, C; Wang, Y; Liu, X; Li, F; Zhang, G; Li, X. Heavy metal contamination in soils and vegetables near an e-waste processing site, south China. Journal of Hazardous Materials 186: 481-490, 2011.

Lopes, M. F. G.; Almeida, M. M. B.; Nogueira, C. M. D.; Morais, N. M. T.; Magalhães C. E. C. Estudo mineral de plantas medicinais. Rev. Bras. Farm. 12:115-116, 2002.

Macari, P. A.T.; Sousa, R. R.; Crespo, M. L. L.; Martins, P. A.; Vieira, J. D. D.; Velosa, A. C.; Fávero, O.; Gomes, E. P. C. Comparação entre os metais presentes em Crotonfl oribundus Spreng. e Baccharis dracunculifolia DC. Rev. Bras. Farm. 12: 76-77, 2002.

Machado, T.B. In vitro activity of Brazilian medicinal plants, naturally occurring naphthoquinones and their analogues, against methicillin-resistant Staphilococcus aureus. International Journal of Antimicrobial Agents 21 (3): 279-284, 2003.

Maiga, A.; Diallo, D.; Bye, R.; Paulsen, B. S. Determination of some toxic and essential metal ions in medicinal and edible plants from Mali. J Agric Food Chem 53: 2321, 2005.

Mamani, M. C. V.; Aleixo, L. M.; Abreu, M. F.; Rath, S. Studies on chemical composition and utilization of the wild edible vegetable athalakkai (Momordica tuberosa). Journal of Pharmaceutical and Biomedical Analysis. 37: 709-713, 2005.

Manning, T. J.; Grow, W. R. Inductively Coupled Plasma-Atomic Emission Spectrometry. 2 (1). Springer-V Erla G, New York, 1997.

Martins, E.R.; Santos, R.H.S. Plantas medicinais: uma alternativa terapêutica de baixo custo. Viçosa: UFV, Imprensa Universitária, p. 26, 1995.

Martins, E. R.; Castro, D. M. de; Castellani, D. C.; Dias, J.E. Plantas medicinais. Viçosa, MG.: Editora UFV: Universidade Federal de Viçosa, 2000.

Matos, F.J.A. Plantas medicinais: guia de seleção e emprego de plantas usadas em fitoterapia no nordeste do Brasil. 2.ed. p. 344. Fortaleza: Editora UFC, 2000. 
Meena, A. K.; Bansal, P. Kumar, S.; Rao, M. M.; Garg, V. K. Estimation of heavy metals in commonly used medicinal plants: a market basket survey. Environ Monit Assess, 170: 657-660, 2010

Melo, J. G.; Nascimento, V. T.; Amorim, E. L. C.; Lima, C. S. A.\& Albuquerque, U. P. Avaliação da qualidade de amostras comerciais de boldo (Peumus boldus Molina), pata-de-vaca (Bauhinia spp.) e ginco (Ginkgo biloba L.). Rev. Bras. Farm. 14, 2 a ed, p. 111-120, 2004.

Menezes, R. F. História de medicamentos, reações adversas e vigilância sanitária à farmacovigilância: $O$ pioneirismo do centro de vigilância sanitária do Estado de São Paulo, SP, 2005.

Ministério da Saúde. PORTARIA № 971, DE 03 DE MAIO DE 2006. Política Nacional de Práticas Integrativas e Complementares (PNPIC) no Sistema Único de Saúde.

Ministério da Saúde, Série A. Normas e Manuais Técnicos: Práticas integrativas e complementares: plantas medicinais e fitoterapia na atenção básica. Brasília, 2012.

Ministério da Saúde, Série B. Textos Básicos de Saúde: A Fitoterapia no SUS e o Programa de Pesquisas de Plantas Medicinais da Central de Medicamentos. Brasília, (2006).

Mishra, C.; Sharma, S.; Kakkar, P. A Study to Evaluate Heavy Metals and Organochlorine Pesticide Residue in Zingiber officinale Rosc. Collected from Different Ecological Zones of India. Bull Environ Contam Toxicol 79: 95-98, 2007.

Moreira, E. G. Preparo e caracterização de um material de referência de mexilhão perna perna (Linnaeus, 1975). 2010. Tese (Doutorado) - Instituto de Pesquisas Energéticas e Nucleares, São Paulo.

Mors, W. Plantas medicinais. Ciência Hoje, Rio de Janeiro 1 (3): 51-54, 1982.

Naidu, G. R. K., Denschlag, H. O., Mauerhofer, E., Porte, N., Balaji T. Determination of macro, micro nutrient and trace element concentrations in Indian medicinal and vegetable leaves using instrumental neutron activation analysis. Appl. Radiat. Isot. 50: 947 - 953, 1999.

Naithani, V.; Kakkar, P. Effect of ecological variation on heavy metal content of some medicinal plants used as herbal tea ingredients in India. Bull. Environ. Contam. Toxicol 76: 285-292, 2006.

Oliveira, E. R.; Menini Neto, L. Levantamento etnobotânico de plantas medicinais utilizadas pelos moradores do povoado de Manejo, Lima Duarte - MG. Revista Brasileira de Plantas Medicinais 14 (2): 311-320, 2012. 
Organização Mundial da Saúde (OMS). Cuidados primários de saúde. Brasília, 1979, p. 64, Alma-Ata, 1978.

Petenatti, M. E.; Petenatti, E. M.; Del Vitto, L. A.; Tevês, M. R.; Caffini, N. O.; Marchevsky, E. J.; Pellerano, R. G. Evaluation of macro and microminerals in crude drugs and infusions of five herbs widely used as sedatives. Brazilian Journal of Pharmacognosy 21 (6): 1144-1149, 2011.

Peris, M.; Micó, C.; Recatalá, L.; Sánchez, R.; Sánchez, J. Heavy metal contents in horticultural crops of a representative area of the European Mediterranean region. Science of the Total Environment 378: 42-48, 2007.

PNPIC, Política Nacional de Práticas Integrativas e Complementares, $1^{\underline{a}}$ edição. Ministério da Saúde, Brasília DF, 2006.

Prassad, S.; Adusumilli, M. D.; Byrne, L.; Kalpaj, P.; Farrelly, P. A. Acalculus Eosinophilic Cholecystitis from herbal medicine: a review of adverse effects of herbal medicine in surgical patients. Surgery, 131: 352-356, 2002.

Queiroz, M.S. O itinerário rumo às medicinas integrativas: uma análise em representações sociais de profissionais da saúde. Caderno de Saúde Pública, 16:363-75, 2000.

Queralt, I.; Ovejero, M.; Carvalho, M. L.; Marques, A. F.; Llabre's, J. M. Quantitative determination of essential and trace element content of medicinal plants and their infusions by XRF and ICP techniques. X-Ray Spectrom 34: 213-217, 2005.

Rajurkar, N. S.; Damane, M. M. Mineral content of medicinal plants used in the treatment of diseases resulting from urinary tract disorders. Appl Radiat Isot 49: 773-776, 1998.

Razic, S; Dogo, S; Slavkovic, L. Investigation on bioavailability of some essential and toxic elements in medicinal herbs. J. Nat. Med. 62: 340-344, 2008.

RENISUS, Relação Nacional de Plantas Medicinais de Interesse ao SUS, Ministério da Saúde, Brasília D.F, 2009. Disponível em: <http:// portal.saude.gov.br/ portal/saude $>$. Acesso em 22/09/2013.

Saiki, M.; Vasconcellos, M. B. A.; Sertie, J. A. A. Determination of inorganic components in Brazilian medicinal plants by neutron activation analysis. Biol. Trace Elem. Res. 26 (7): 743-750, 1990.

Schwanz, M.; Ferreira, J. J.; Fröehlich, P; Zuanazzi, J. A. S.;Henriques, A. T. Análise de metais pesados em amostras de Peumus boldus Mol. (Monimiaceae). Rev. Bras. Farm., 2007. UFRS, Porto Alegre-RS, Brasil.

Secretaria Municipal de Saúde. Relatório comparativo da produção nas oficinas do programa Farmácia Viva as SERIV entre os anos de 1998 a 2001. Fortaleza, 2002. 
Shu, Y.Z. Recent natural products based drug development: A pharmaceutical industry perspective. J. Nat. Prod. 61: 1053-1071, 1998.

Silva, M. V.; Ritter, M. R. Plantas medicinais e toxicas da reserva biológica do Lami, Porto Alegre, Rio Grande do Sul, Brasil. Iheringia, Sér. Bot., 57 (1): 61-67, 2002.

Silveira, I. M. M. O conhecimento popular sobre o papel curador das plantas e a sua educação na escola. 2005, 51f. Monografia (Especialização em Gestão Educacional) - Universidade Federal de Santa Maria, Santa Maria, RS.

Simões, C. O.; Shenkel, E. P.; Gosmão, G.; Mello J. C. P.; Mentz, L. A.; Petrovick, P. R. Farmacognosia da Planta ao Medicamento. 5aㅡ. Ed. Porto Alegre/Florianópolis: Editora UFRGS/ Editora UESC, 1999.

Simioato, C. P.; Rosa, S. C; Wosny, A. M. Horto Didático de Plantas Medicinais do Hu. Universidade Federal de santa Catarina. Centro de Ciências da Saúde, 2011. Disponivel em http://www.hortomedicinaldohu.ufsc.br/planta. Acesso em 04/12/2013.

Singh, V.; Garg, A. N. Availability of essential trace elements in ayurvedic indian medicinal herbs using instrumental neutron activation analysis. Appl. Radiat. Isot. 48 (1): 97-101, 1997.

Skoog, D. A.; Holler, F. J.; Nieman, T. A. Princeples of Instrumental Analysis. Fifth edition. Saunders College Publishing, EUA. 0-03-002078-6, 1998.

Skoog, D. A.; Holler, F. J.; Nieman, T. A. Principles of Instrumental Analysis. Fifth edition. Saunders college Publishing, EUA. 0-03-002078-6, 1998. In: Guimarães, G. M. Avaliação da concentração de metais e elementos traço em amostras de sedimento do Reservatório Guarapiranga, São Paulo-SP, Brasil. 2011. Dissertação (Mestrado) - Instituto de Pesquisas Energéticas e Nucleares, SP.

Sonaglio, D.; González, O. G.; Petrovick, P. R.; Bassani, V. L. Desenvolvimento tecnológico e produção de fitoterápicos. In: Simões, C. M. O.; Schenkel, E. P.; Gosmann, G.; Mello, J. C. P.; Mentz, L. A.; Petrovick, P. R. Farmacognosia: da

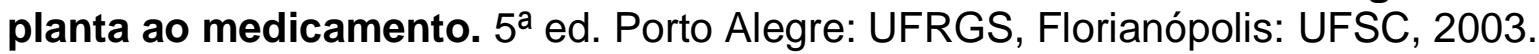

Stefanello, R. Efeito da luz, temperatura e estresse hídrico no potencial fisiológico de sementes de anis, funcho e endro. Santa Maria, RS, 2005. Dissertação (Mestrado). Universidade Federal de Santa Maria (UFSM), RS.

Strobl, W.R. The role of natural products in a modern drug discovery program. Drug Disc. Today 5: 29-41, 2000.

Sun, Y.; Zhou, Q.; Wang. X. R.; Wong M. H. Cadmium tolerance and accumulation characteristics of Bidens pilosa $L$. as a potencial cdhyperaccmulator Hazard. Mater. 161 (2-3): 808-814, 2009. 
Sussa, F. V.; Silva, P. S. C.; Damatto, S. R.; Fávaro, D. I. T.; Mazzilli, B. P. Radioactive and stable element's concentration in medicinal plants from Brazil. Journal of Radioanalytical and Nuclear Chemistry 281: 165-170, 2009.

U.S.EPA - United States Environmental Protection Agency, Method SW-846 3051A: Microwave assisted acid digestion of sediments, sludges, soils, and oils, Revision 1, U.S.: U.S.EPA., Feb, 2007.

Vasconcelos, N. M. S.; Almeida, M. M. B.; Lopes, M. F. G.; Nogueira, C. M. D.; Morais, N. M. T. Plantas Medicinais: Um estudo analítico. Anais Assoc. Bras. Quím. 49 (3): 115-118, 2000.

Vaz, S. M. Análise de extratos de plantas medicinais pelo método de ativação com nêutron. 1995. Dissertação (Mestrado) - Instituto de Pesquisas Energéticas e Nucleares, SP.

Vieira, R. A. Validação científica de plantas medicinais como fator catalisador no desenvolvimento da indústria farmacêutica nacional. Revista Saúde e Ambiente 2 (1/2): 57- 64, 2001.

Veiga Junior, V. F.; Pinto, A. C.; Maciel, M. A. M.. Plantas medicinais: cura segura? Química Nova 28 (3): 519-528, 2005.

Vobecky, M.; Babicky, A.; Lener, J. Effect of increased bromide intake on iodine excretion in rats. Biological Trace Element Research 55: 215-19, 1996.

World Health Organization (WHO). Resoluções WHA 31.33, WHA 40.33 e WHA 42.43, 1976-1978, 1987-1988 e 1989-1990.

World Health Organization (WHO), Quality control methods for medicinal plant materials, Geneva, (1998).

World Health Organization (WHO), Monographs on Selected Medicinal Plants, vol. 1, WHO, Geneva. (1999).

World Health Organization (WHO), A Call for Action by World Health Ministers, WHO, Geneva. (2001).

World Health Organization (WHO), Summary and conclusions of the seventythird meeting of the Joint FAO/WHO Expert Committee on Food Additives, Geneva, 8-17 June 2010. Rome, Food and Agriculture Organization of the United Nations; Geneva, World Health Organization. (2010).

World Health Organization (WHO), Guidelines for Drinking-Water Quality, 2011 disponível em http://whqlibdoc.who.int/publications/2011/9789241548151 eng.pdf acesso em 08/01/2014. 
Wu, Y; Fang, G; Lin, S. Season variations for metallic elements compositions study in plant Bidenens pilosa L. var. radiate Sch. in central Taiwan. Environ Monit Assess. 168: 255-267, 2010.

Yamashita, C. I.; Saiki, M.; Vasconcellos, M. B. A.; Sertie,' J. A. A. Characterization of trace elements in Casearia medicinal plant by neutron activation analysis. Applied Radiation and Isotopes 63. Published by Elsevier Ltda (2005).

Yamamoto, C. H.; Pinto, T. J. A.; Meuren, V. M.; Carvalho, A. M.; Rezende, P. Controle de qualidade microbiológica de produtos farmacêuticos, cosméticos e fitoterápicos produzidos na Zona da Mata. Anais do $2^{\circ}$ Congresso de Extensão Universitária. Belo Horizonte, 2004.

Yunes, R. A.; Pedrosa, R. C.; Cechinel, F. V. Fármacos e fitoterápicos: a necessidade do desenvolvimento da indústria de fitoterápicos e fitofármacos no Brasil. Química Nova 24 (1): 147-152, 2001.

Zuccolotto, T.; Apel, M.; Rates, S. M. K. Avaliação da qualidade de produtos fitoterápicos comercializados em Porto Alegre- RS. Revista do Instituto Adolfo Lutz, 58 (2): 25-31, 1999.

Zuin, V. G.; Yariwake, J. H.; Bicchi, C. Avaliação da qualidade de drogas vegetais a base de Passiflora spp. Comercializadas no Brasil: presença de resíduos de pesticidas. Revista Brasileira de Plantas Medicinais 6 (2): 60-66, 2004. 